\title{
Journal of Ahoriginal Health
}

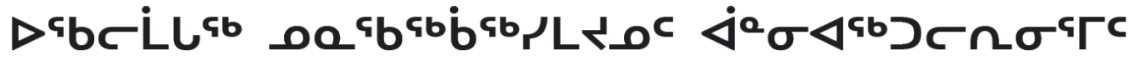

Summer 2015, Vol. 9, Issue 2

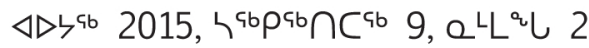

Journal of Aboriginal Health

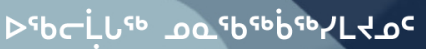

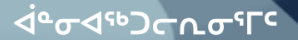

\section{Special Issue on Inuit Health and Well-being}

\section{Editorial}

1

3

Endings and Beginnings for Aboriginal Health

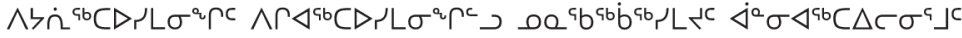

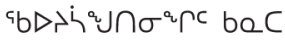

C. Furgal, D. Kinnon

\section{Articles}

6

Exploring Elders' and Seniors' Perceptions of How Climate Change is Impacting Health and Well-being in Rigolet, Nunatsiavut

J. Ostapchuk, S. Harper, A. Cunsolo Willox, V. L. Edge, Rigolet Inuit Community Government

25

31

38
Our Living Ecosystem: What are the Interconnections among the Elements Surrounding Us? A Classroom-based Activity in Nunavik Community Story

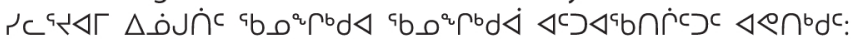

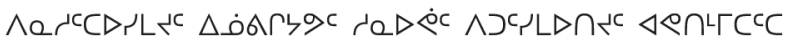

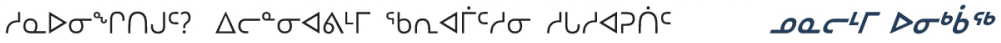

M. Lemire, M. Riva, M. Ruiz-Castell

Culturally Appropriate Care-A Multicultural Task: Assessing the Needs of Inuit Youth in the Care of Child Welfare Services

S. L. Fraser, C. Rousseau, R. Kasudluak, P. Burmester, M. J. Arauz

Foodland Security: Access to Inuit Country Food in an Urban Setting As told by Barry Pottle through contemporary Inuit Art Photography

Community Story

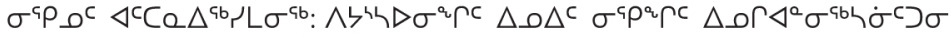

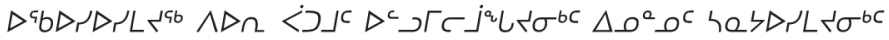
$\Delta \vec{\top} \subset \Delta \Omega \sigma^{q b}$

oec $\tau^{L} \Delta \sigma^{b} \dot{b} \leq b$

B. Pottle

Socioeconomic and Psychosocial Adversity in Inuit Mothers from Nunavik during the First Postpartum Year

S. Fortin, S. W. Jacobson, J. Gagnon, N. Forget-Dubois, G. Dionne, J. L. Jacobson, G. Muckle

Co-op Healthy Foods Corner and Meal Packages: A Partnership among Community Members, a Grocery Store, and Community Radio in Pangnirtung, Nunavut

Community Story

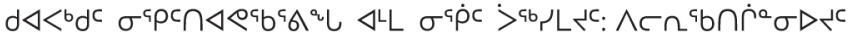

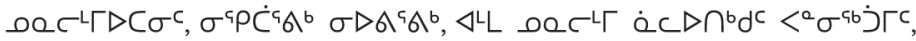
ค० $>c$

oec $\Delta \nabla \sigma^{b} \dot{b} s b$

C. Racicot-Matta, M. Wilcke, O. Nashalik, G. Egeland

Medevac and Beyond: The Impact of Medical Travel on Nunavut Residents C. McKenzie 


\section{Journal of Ahoriginal Health

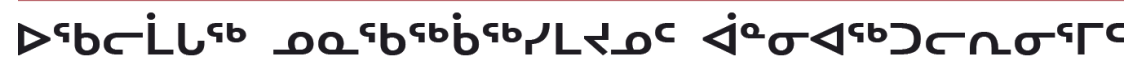

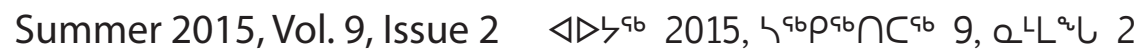

The Journal of Aboriginal Health has been an official peer-reviewed publication of the National Aboriginal Health Organization (NAHO) since 2004. With the closing of NAHO in June 2012, the publication of Vol. 9, Issue 2 is made possible through collaboration between Inuit Tuttarvingat of NAHO and the Nasivvik Centre for Inuit Health and Changing Environments. Future issues of the Journal will be published by the Aboriginal Health Research Network Secretariat (AHRNetS) under its new name International Journal of Indigenous Health.

\section{Copyright}

The Journal of Aboriginal Health is covered by the Canadian Copyright Act and international agreements (all rights reserved). Although NAHO and the Nasivvik Centre have collaborated in the production of this issue, the copyright for Vol. 9, Issue 2 is held by the Aboriginal Health Research Network Secretariat (AHRNetS). Written permission is required from AHRNetS to reprint, reproduce, modify or redistribute any information or articles, in whole or in part, published in the Journal of Aboriginal Health for any purpose other than personal photocopying.

\section{Disclaimer}

The Journal of Aboriginal Health is intended for education and informational purposes only. The articles and contents herein represent the views of the authors and do not necessarily reflect the views of NAHO and the Nasivvik Centre. NAHO and the Nasivvik Centre do not assume responsibility or liability for damages arising from any error or omission, or from the use of any information or advice contained in this publication.

\section{Subscription}

The Journal of Aboriginal Health, now entitled the International Journal of Indigenous Health, is an open access online journal available at http://uvic.ca/ijih. You may register on the website to receive notifications of future issues.

\section{Submissions}

Vol. 9, Issue 2 is the last issue of the Journal of Aboriginal Health published by the National Aboriginal Health Organization. Information on submissions to the International Journal of Indigenous Health is available on its website.

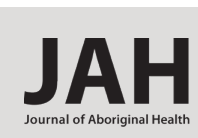

PUBLISHER

Nasivvik Centre for Inuit Health and Changing Environments

EDITORS

Chris Furgal Co-director, Nasivvik Centre for Inuit Health and Changing Environments

Dianne Kinnon, Former Director, Inuit Tuttarvingat of the National Aboriginal Health Organization (NAHO)

ASSISTANT EDITOR

Shirin Nuesslein,

Administrative Coordinator, Nasivvik Centre for Inuit Health and Changing Environments

\section{EDITORIAL ADVISORY BOARD} Chris Furgal,

Co-director, Nasivvik Centre for Inuit Health and Changing Environments

Dianne Kinnon,

Former Director, Inuit Tuttarvingat of NAHO

Cathleen Knotsch,

Former Senior Research Officer, Inuit Tuttarvingat of NAHO

Mary Bergin,

Former Community Liaison Officer, Inuit Tuttarvingat of NAHO

\section{COPY EDITOR}

Leslie Ordal

\section{DESIGN \& LAYOUT}

James MacDougall

TRANSLATORS

Innirvik Support Services Inc.

Jeela Palluq-Cloutier

Kevin Kablutsiak

Looee Okalik

Sarah Aloupa

\section{CONTRIBUTORS}

J. Ostapchuk, S. Harper, A. Cunsolo Willox, V. L. Edge, Rigolet Inuit Community Government, M. Lemire, M. Riva,

M. Ruiz-Castell, S. L. Fraser, C. Rousseau, R. Kasudluak, P. Burmester, M. J. Arauz,

B. Pottle, S. Fortin, S. W. Jacobson, J. Gagnon,

N. Forget-Dubois, G. Dionne, J. L. Jacobson,

G. Muckle, C. Racicot-Matta, M. Wilcke,

O. Nashalik, G. Egeland, C. McKenzie

\section{EDITORIAL OFFICE}

Nasivvik Centre for Inuit Health and Changing Environments, Indigenous Studies Department, Trent University 1600 West Bank Drive

Peterborough, Ontario K9J 7B8

Telephone: 705-748-1011 ext 7242 Fax: 705-748-1416

Email: nasivvik@gmail.com

Website: www.nasivvik.ca

ISSN 1710-0712

RETURN UNDELIVERABLE ITEMS TO NASIVVIK CENTRE, INDIGENOUS STUDIES DEPARTMENT, TRENT UNIVERSITY, 1600 WEST BANK DRIVE, PETERBOROUGH, ONTARIO, K9J 7B8 


\title{
Endings and Beginnings for Aboriginal Health Research in Canada
}

\author{
By: Chris Furgal and Dianne Kinnon
}

$\mathrm{I}$ $\mathrm{t}$ is surprising that in a G8 country such as Canada, the average life expectancy of individuals of certain heritage is significantly less than that of Canadians overall. This is unfortunately the case for Aboriginal peoples, who have a life expectancy more than 10 years less than the country's average. The answer to the question "Why?" is in some cases quite straight forward, and in others quite complex. What cannot be argued is the need to understand this reality in order to better serve, support, and improve Aboriginal health today and in the future.

"Guided by the original consultation reports about the role of a national Aboriginal health institute, the National Aboriginal Health Organization (NAHO) became aware that there was a void in the availability and accessibility of health information and outcomes of Aboriginal health research. To remedy this, the National Aboriginal Health Organization's (NAHO) Board of Directors and staff decided to produce a research journal focusing on Aboriginal health." (www.naho.ca)

Launched in 2004, NAHO's Journal of Aboriginal Health (JAH) has promoted and disseminated peer-reviewed articles pertaining to Aboriginal health from leading health scholars, academics, and Aboriginal community members. In addition to offering in-depth analyses on emerging issues in the field, the journal has included original research, editorials, and reading suggestions on selected themes. JAH was also dedicated to open access by publishing online through the NAHO website, being a front-runner in the online access movement in the academic publishing community.

To date, JAH has published 9 volumes and 13 issues on topics that raise awareness of and provide critical insights in the field of Aboriginal health. For nearly 10 years, JAH has represented a leading source of research findings and critical dialogue on the reality of Aboriginal heath in Canada, serving researchers, decisionmakers, and communities. In a publishing and electronic information landscape that is expanding rapidly with new journals focused on specific aspects of health and well-being, JAH has continued to represent one of the few venues for an Aboriginal-specific focus to health, healing, and well-being.

Sadly, 2012 marked NAHO's twelfth and final year of operations, when its funding was cut in the 2012 Canadian federal budget. NAHO's offices closed on June 29, 2012 and with it, JAH was forced to close down its operations as well. As a result, this issue represents the final issue of the Journal of Aboriginal Health to be produced under the JAH banner and NAHO's direction. With significant threats to the role and place of Aboriginal health research in today's funding landscape (Webster, 2012; http://kahwatsire.com) and significant pressures on access to basic resources and services supporting Aboriginal health in many regions of the country (e.g., food security in the North), there is an even more pressing need to disseminate evidence-based findings on Aboriginal health and well-being.

While this issue marks the passing of an important actor in the Aboriginal health research communication field, we are very pleased to announce that it is not the end of the journal. With a strong belief in the need for such an outlet, the Secretariat of the Network Environments for Aboriginal Health Research (NEAHR) in Canada has taken on the role of continuing and growing the mandate of the journal (Loppie and Marsden, 2014). Moving forward, the Journal of Aboriginal Health will be published by the Secretariat - based at the University of Victoria - under the title International Journal of Indigenous Health (http://journals.uvic.ca/ index.php/ijih). Volume 10 (currently available) and future issues will continue to disseminate high quality research findings and community perspectives to fuel critical dialogue on these important topics in Canada and around the world.

This final issue of JAH also represents the only issue specific to Inuit health. While other volumes and issues have included Inuit-focused content, this publication is dedicated to research, community stories, and perspectives specific to Inuit. It is produced in collaboration with the Nasivvik Centre for Inuit Health and Changing Environments based at Laval and Trent Universities.

Created in 2002 with a grant from the Canadian Institutes of Health Research - Institute for Aboriginal Peoples Health (CIHRIAPH) under the NEAHR program, the Nasivvik Centre is one of nine NEAHR Centres across the country. It is the only Centre in this program focused exclusively on capacity building and training for research in Inuit communities. Directed through partnerships with the regional Inuit governments, land claim organizations, and national organizations-including at the time Inuit Tuttarvingat, the Inuit Centre at NAHO - the Nasivvik Centre focuses on supporting researcher community relationships, student training and capacity building, and Inuit-specific research and communication on issues related to environment-health relationships in the North.

However, funding for the NEAHR program has come to an end and the Centres across the country are now striving to maintain a presence on the landscape of Aboriginal health research and training. Following 10 years of initial investment in capacity building in this area, great strides have been made in Aboriginal engagement in and direction of health research, as well as our collective understanding and appreciation for Aboriginal health issues. If one thing has come out of the rich and valuable volume of research exploring this topic in the country over the last 15 years, it has been an appreciation for the complexity and diversity 
of experiences and realities faced by different Aboriginal groups and individuals. The need for Aboriginal cultural and place-based understanding and action on health has been made clear and it is for this reason that a special issue featuring articles on Inuit health issues is so valuable.

This issue spans diverse topics from elder and seniors' perspectives on climate change and implications for Inuit health (see article by Ostapchuk et al.) to the impacts of medical travel on Inuit residents in Nunavut (see article by McKenzie). It stays true to the mandate and vision of JAH in presenting evidencebased, peer-reviewed research findings (see articles by Fortin et al. and Fraser et al.), but also community perspectives and stories on health realities and initiatives (see articles by Racicot-Matta et al. and Lemire et al.). Finally, it provides a venue for innovative forms of communication on Inuit health perspectives (see Pottle's photography-based story on food security). The final issue of JAH is quintessentially representative of what JAH strived for: providing a forum for diverse, unique, multidisciplinary, and Aboriginalspecific contributions to dialogue and learning about Aboriginal health.

Finally, as this issue would not have been possible without the cooperation of the Nasivvik Centre, it is only appropriate that we pay tribute to the co-director who died this past year. Dr. Éric Dewailly, a medical doctor and researcher based at Laval University, was the co-creator of the Nasivvik Centre in 2002 and a strong advocate for community engagement, training, and direction in Inuit health research for many years. He was lost tragically in a rockslide while on vacation with his family last summer on the island of La Réunion in the Indian Ocean. Dr. Dewailly was a pioneer and international leader in the field of environmental epidemiology and made significant contributions to our understandings of Inuit health, and of the environment as a critical and dynamic determinant of Inuit health status. He will be greatly missed by his colleagues, friends, and students past and present. It is fitting that many of the articles presented in this final issue of JAH are the products of research and training activities funded and supported by the Nasivvik Centre. Dr. Dewailly's passion for understanding and improving Inuit health lives on in his former students and trainees, some of whom are authors of the works included here.

We sincerely hope you find this final issue of the Journal of Aboriginal Health to be an interesting and useful contribution to our collective understanding of Inuit health and well-being. Finally, we encourage you to continue your pursuit of knowledge about these and other Aboriginal health topics through future issues of the International Journal of Indigenous Health (http://journals.uvic.ca/ index.php/ijih).

Chris Furgal

Co-director, Nasivvik Centre, Trent University

Dianne Kinnon

Former Director, Inuit Tuttarvingat, NAHO

\section{REFERENCES}

Loppie, C., \& Marsden, N. (2014). Welcome to the International Journal of Indigenous Health (IJIH) [Editorial]. International Journal of Indigenous Health, 10(1).

Webster, P. C. (2012). Aboriginal health programming under siege, critics charge [News]. Canadian Medical Association Journal, 184(14). 


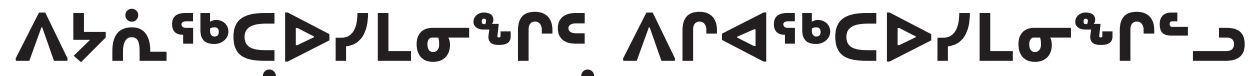

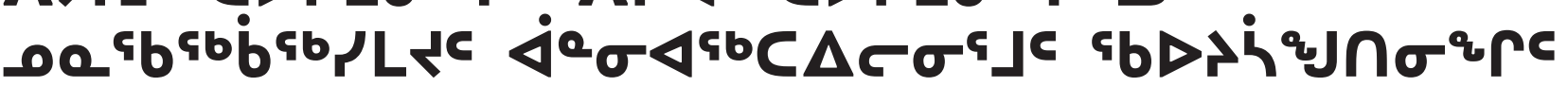 bec}

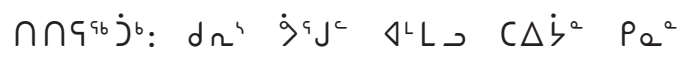

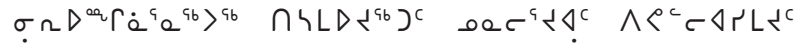
¿a beC, $\Delta$ ف $\Delta c^{8} \Gamma^{c} \triangleleft^{c} \cap \sigma^{9 b} h D^{L} L C$ be $C \Gamma D C D \mathbb{L}^{c} \quad h \sigma \Delta \sigma$. $C^{2} L^{\circ} a$

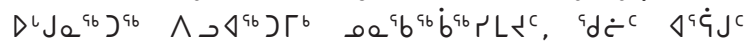

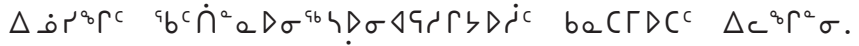

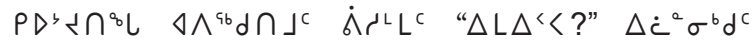

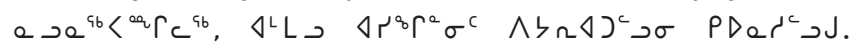

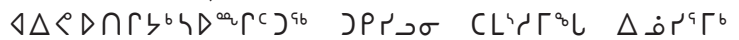
$\left.\wedge r^{c} \cap^{a b} C D^{c} \cap \Delta b^{a} \sigma^{a} d^{c} \nu^{c}, \quad \Delta b d^{a b}\right)^{a b} C D^{c} \cap \Delta b^{a} \sigma^{c} d^{c} \nu^{c}$,

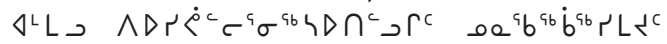

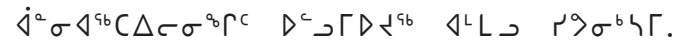

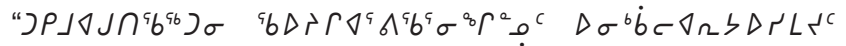

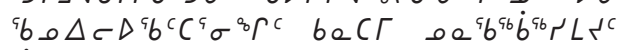

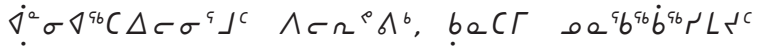

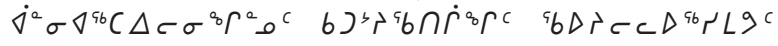

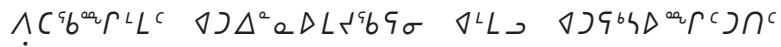

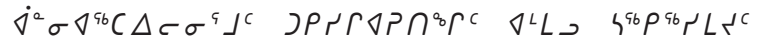

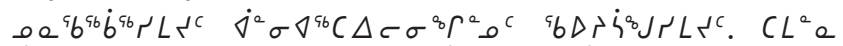

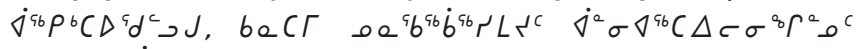

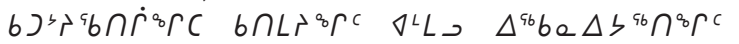

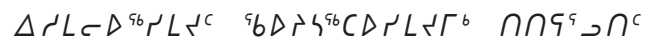

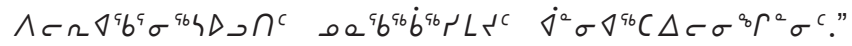
(www.naho.ca)

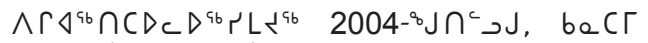

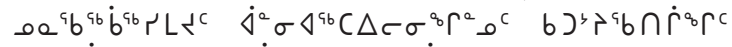

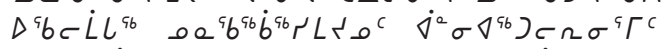

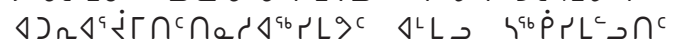
$\left.{ }^{a} b D+4^{9 b} \cap \sigma^{c}{ }^{a} b D+L^{9 b} C D r L L^{c} \cap \cap^{a b} b \sigma^{c} D^{a} b D r^{9} b^{9 b}\right)^{c}$ مa $a^{a} b^{a b} \dot{b}^{a b} r L l^{c} \quad j^{a} \sigma \Delta^{a b} C \Delta c \sigma^{b} \Gamma^{a} \sigma^{c} \quad C \Delta^{b} d a^{a a} L^{c}$

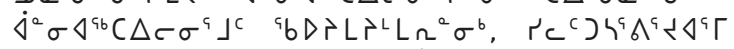

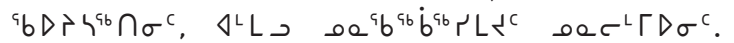

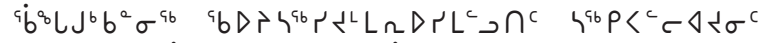

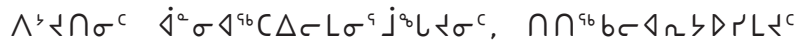

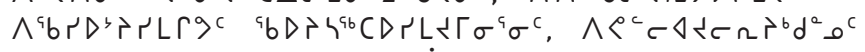

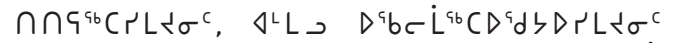

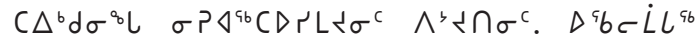

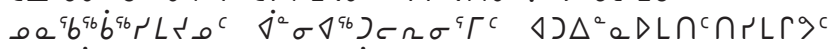

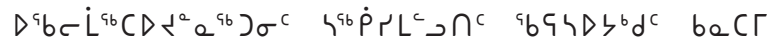

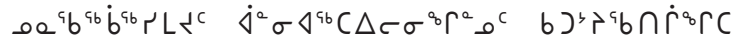

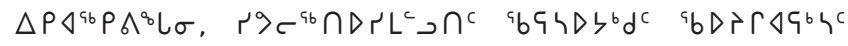

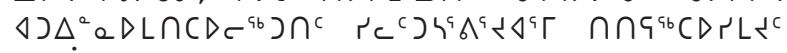
$4^{96} \mathrm{Pi}^{9 b} \cap\left(D^{9} b^{c} C^{9 b}\right) \cap^{c}$.

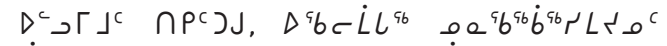

$\left.\left.\dot{\nabla}^{c} \sigma \nabla^{a b}\right) \subset \Omega \sigma^{a} \Gamma^{c} \Lambda^{c}\right\lrcorner \Gamma^{c} L^{a b} \dot{P}\left\lceil L c^{a b}\right)^{c}$

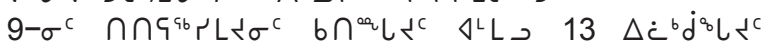

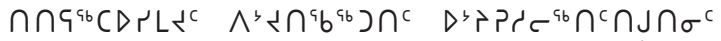

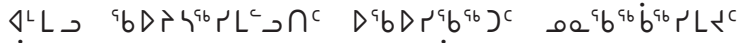

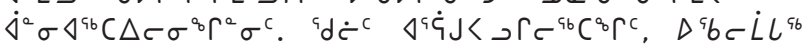

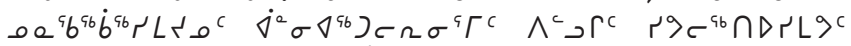

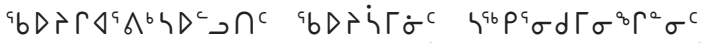

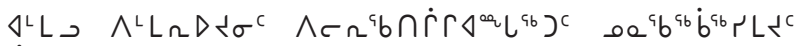

$\dot{\triangleleft}^{a} \sigma \Delta^{a b} C \Delta c \sigma^{a} \Gamma^{a} \sigma^{c}$ be $C \Gamma,{ }^{q} b D+L^{a b} \cap \sigma^{c}, \Delta r L \subset D^{a b} \cap \sigma^{c}$,

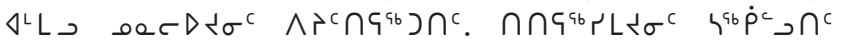

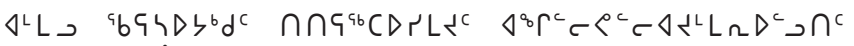

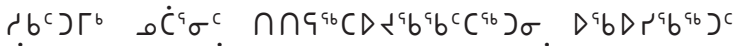

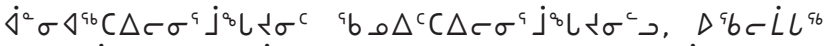

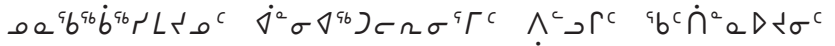

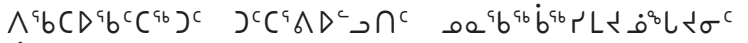

$\dot{\triangleleft}^{a} \sigma \Delta^{a b} C \Delta c \sigma^{b} \Gamma^{a} \rho^{c}, L \Gamma L^{c} \sigma^{b} \Gamma^{a} \rho^{c}, \Delta^{L} L$

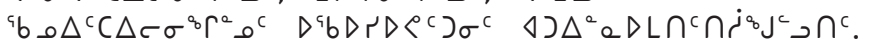

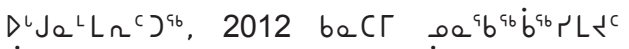

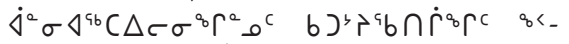

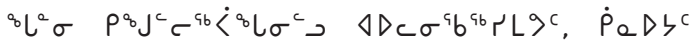

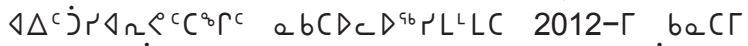

$L<L^{b} d^{c} \dot{P}_{a} D \zeta^{a b} J P \bigcap^{b} \zeta^{8} \Gamma^{a} \sigma^{c}$. beC厂 $0 a^{a} b^{a b} b^{a b} r L L^{c}$

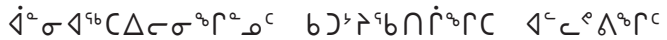

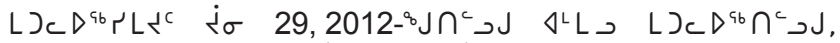

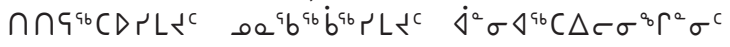

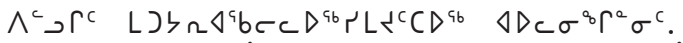

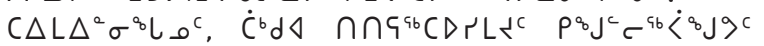

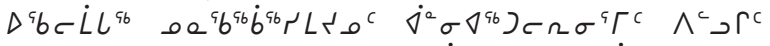

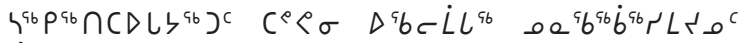

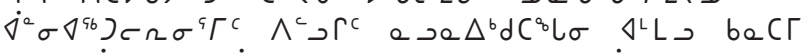

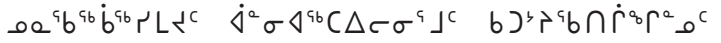

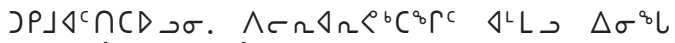

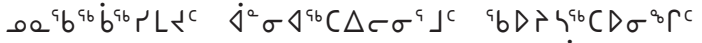

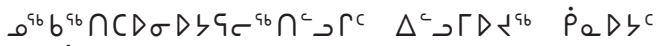

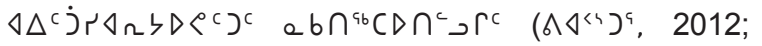

http://kahwatsire.com) $\triangleleft^{L} L$

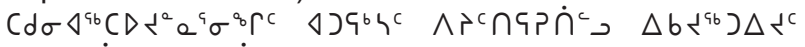

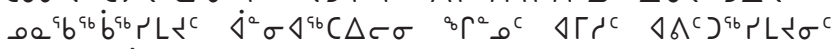

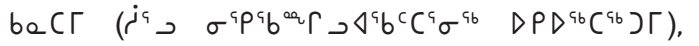

$\left.\checkmark)^{a b}\left(D^{a} b^{c} C \Omega \Delta^{a} b^{L} L n^{c}\right)^{c} \quad \triangleleft\right)^{a b}\left(D^{a} b^{c} C^{c} \sigma d \Gamma \sigma^{a} \sigma^{c}\right.$

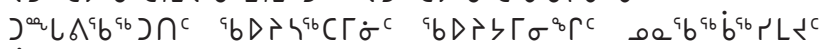

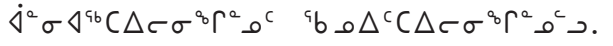




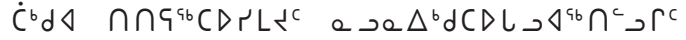

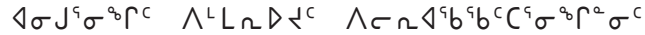

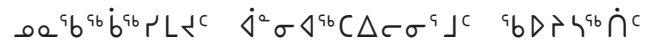

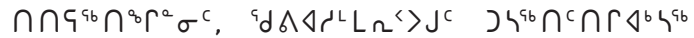

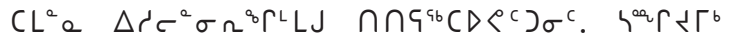

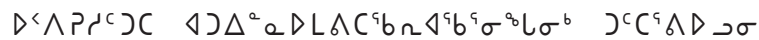

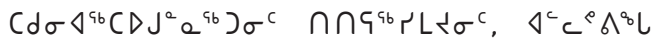

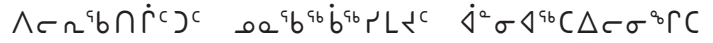

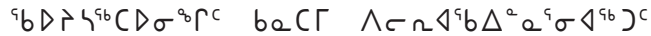

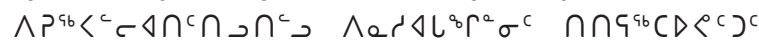

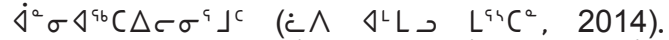

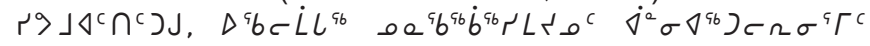

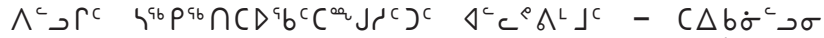

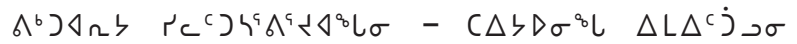

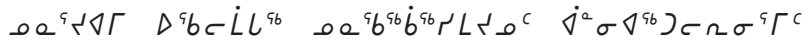

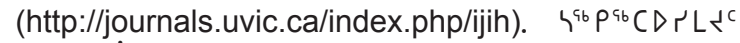

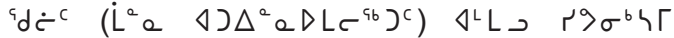

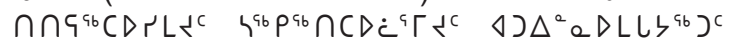

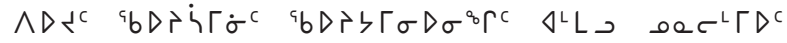

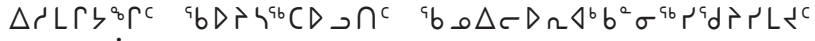

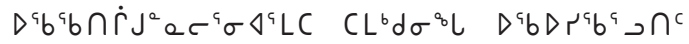

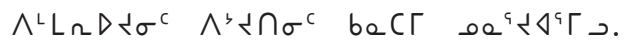

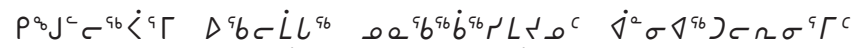

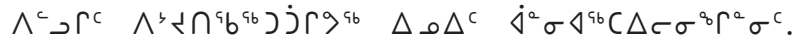

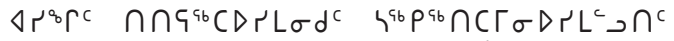

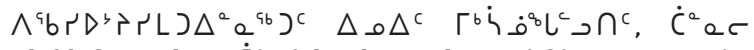

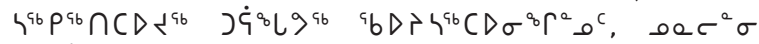

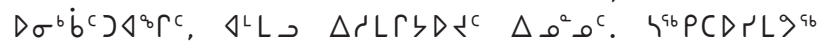

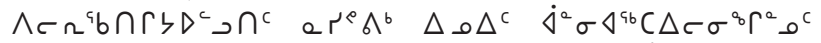

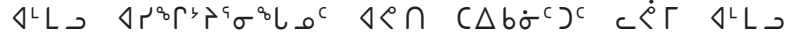

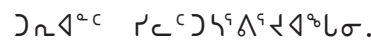

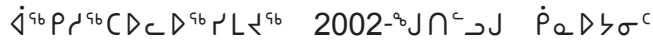

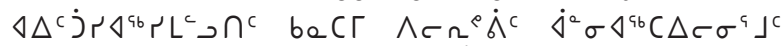

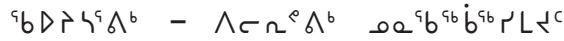

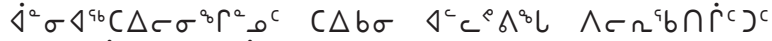

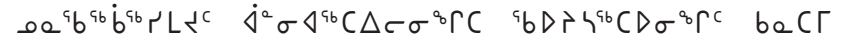

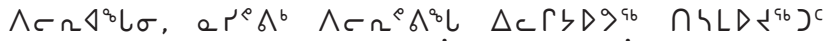

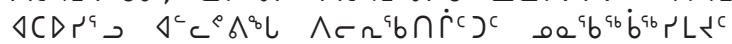

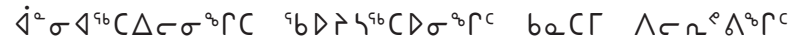

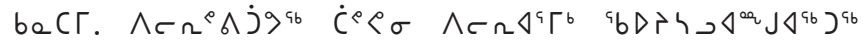

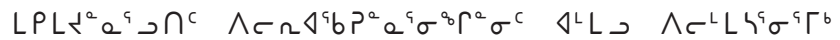

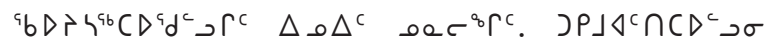

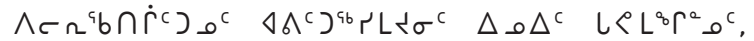

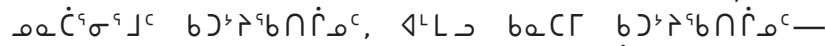

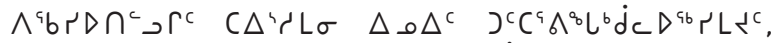

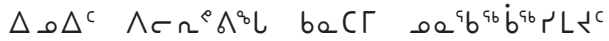

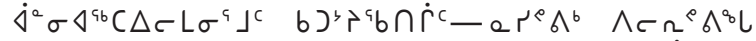

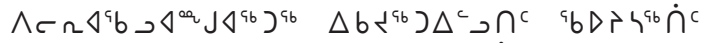

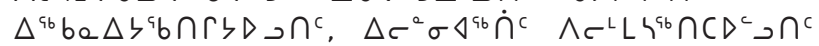

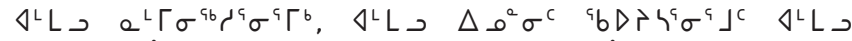

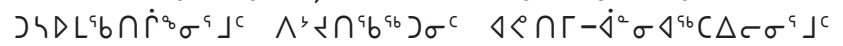
$\left.D P D^{96} C^{96}\right) \Gamma$.

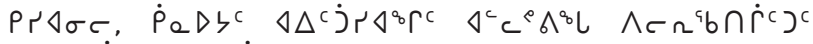

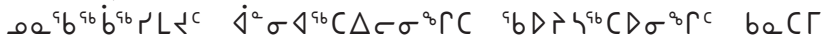

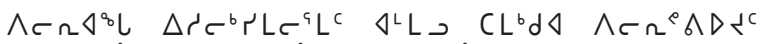
be C厂 $\dot{L}^{a} a a^{c} b^{c b} \dot{b}^{c b} r L L^{c} \sigma^{c} j^{a} \sigma \Delta^{9 b} C \Delta r \sigma^{c} J^{c}$

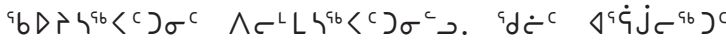

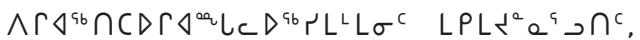

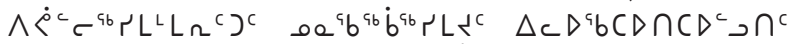

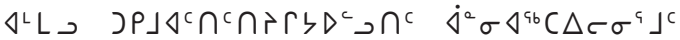

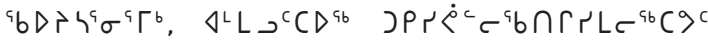

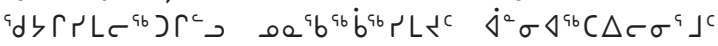

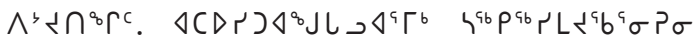

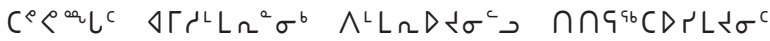

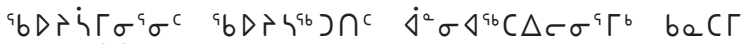

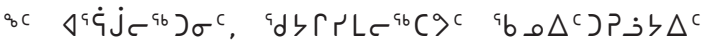

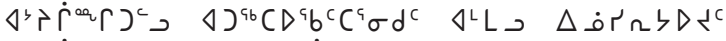

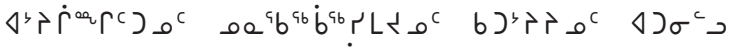

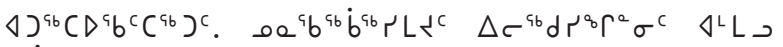

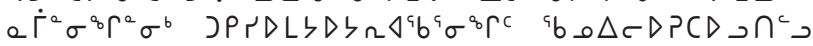

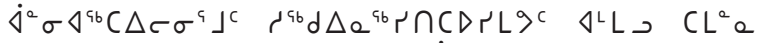

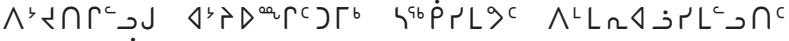

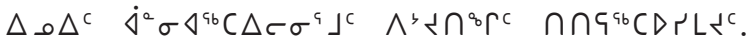

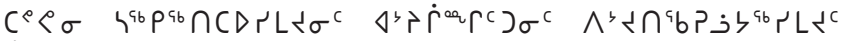

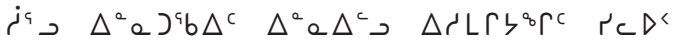

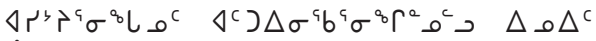

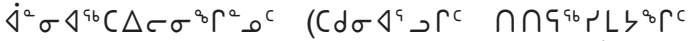

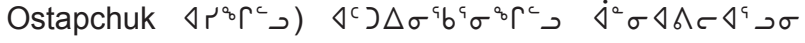

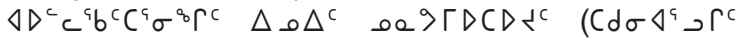

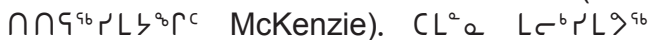

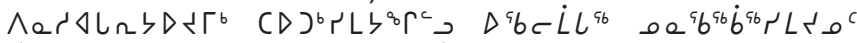

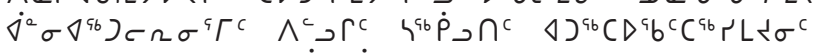

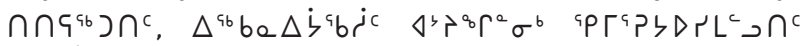

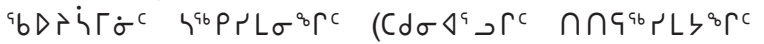

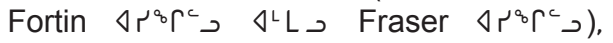

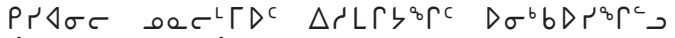

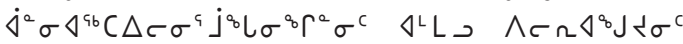

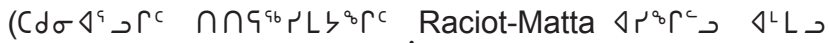

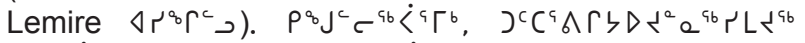

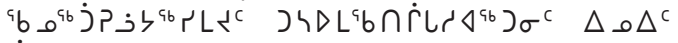

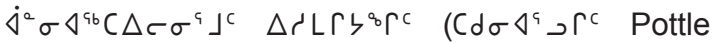

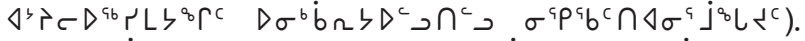

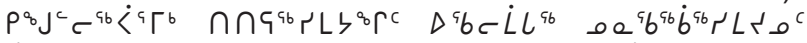

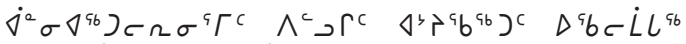

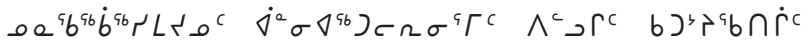

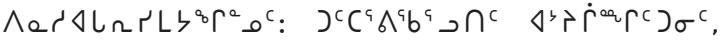

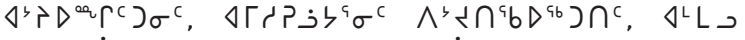
ـ د

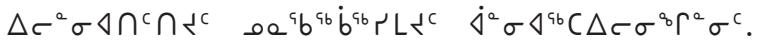

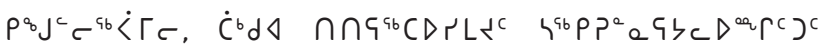

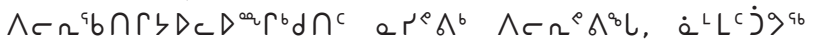

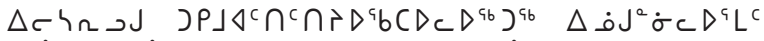

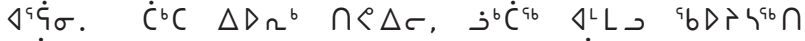

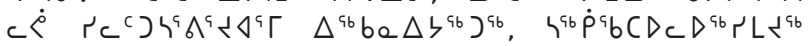




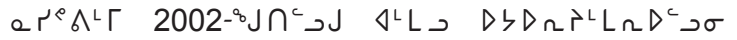

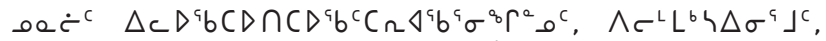

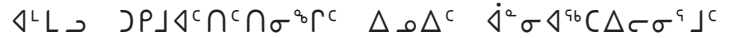

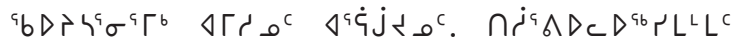

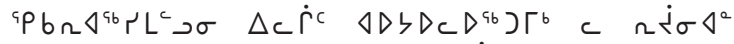

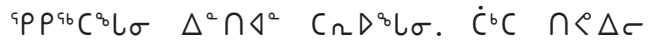

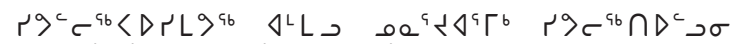

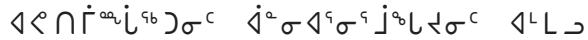

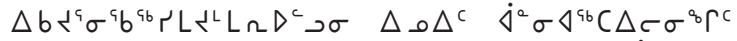

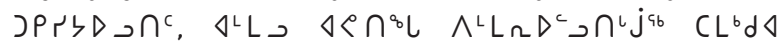

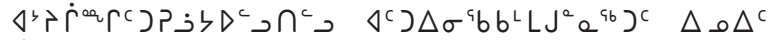

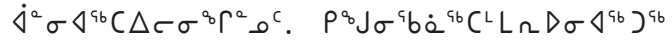

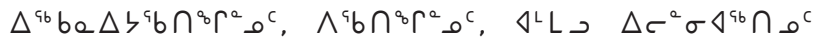
$\nabla \Delta^{c} \cap \Delta b \quad \Delta^{a b} b a \Delta b^{a} b \cap \Gamma^{a} b^{c} C c D^{a b} r L b^{a} \Gamma^{a} \sigma^{c}$,

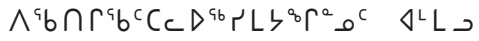

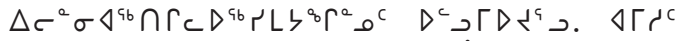

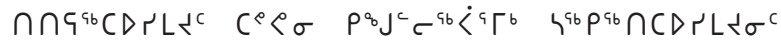

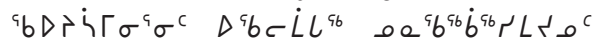
$\left.\left.\dot{\nabla}^{a} \sigma \nabla^{a b}\right) \subset \Omega \sigma^{c} \Gamma^{c} \quad \Lambda^{c}\right\lrcorner \Gamma^{c} b J^{b} \Gamma^{a} b \cap \dot{\Gamma}^{b} \Gamma^{a} \sigma^{c}$

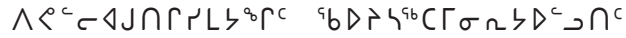

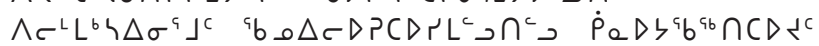

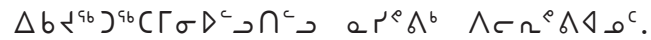

$\dot{C}^{b} C \cap<\Delta c^{<}$JPr $\dot{<}^{c} \dot{C}^{a} a P L^{a} b^{c} C \subset D^{a} \sigma^{b} L$

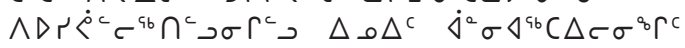

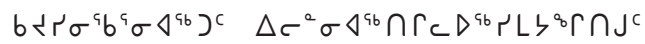

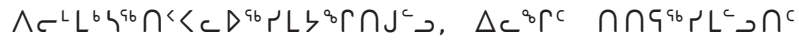
Ce< $<L^{a b} \rho^{a b} \cap C D r L \sigma^{c}$.

$\dot{C}^{b} d \triangleleft \quad p^{a b} J^{c} c^{a b} \dot{<} \Gamma \quad \cap \cap q^{a b} C D r L L^{c c}{ }^{a} b D r i<\dot{\sigma}^{c}$

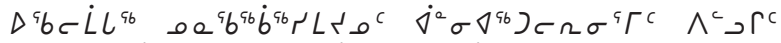

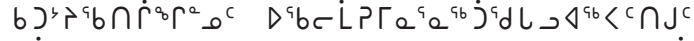

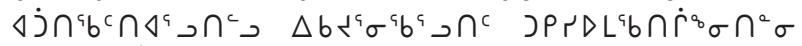

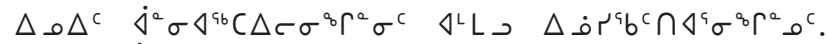

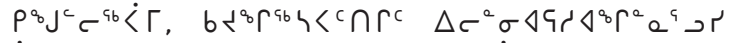

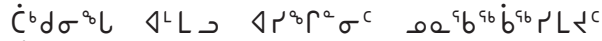

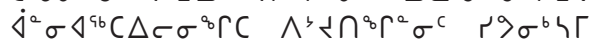

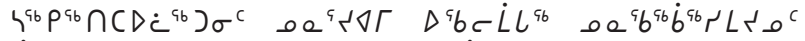

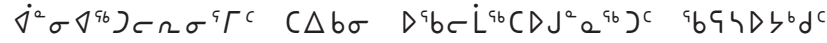
$\Delta<\sigma \quad$ (http://journals.uvic.ca/index.php/ijih).

$d \Omega^{4} \quad \dot{\zeta}^{4} J^{c}$

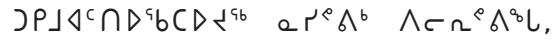

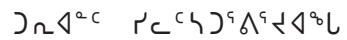

$C \triangle \dot{i}^{\circ} \quad P_{e}{ }^{a}$

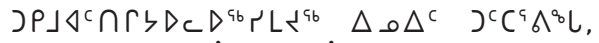

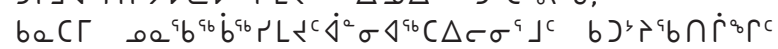

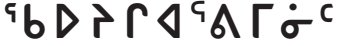

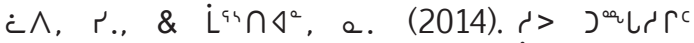

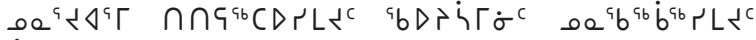

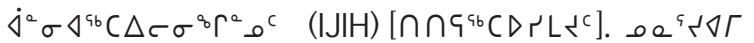

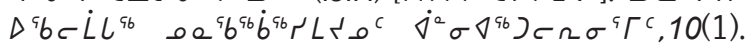

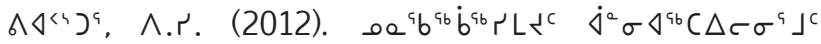

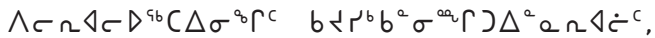

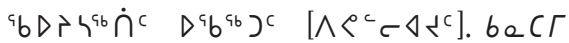

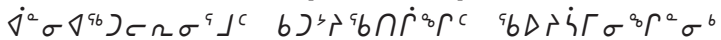
กกร. ${ }^{96} \sim \sigma^{8}{ }^{8} \Gamma^{C}, 184(14)$. 


\title{
Exploring Elders' and Seniors' Perceptions of How Climate Change is Impacting Health and Well-being in Rigolet, Nunatsiavut
}

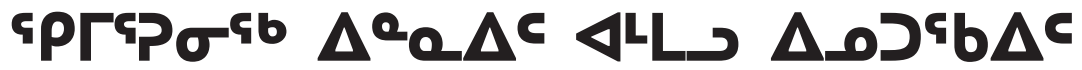

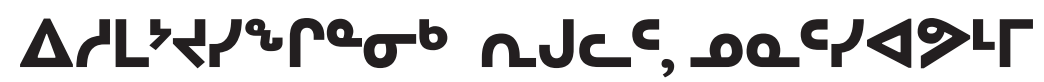

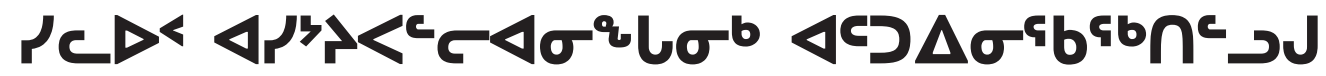

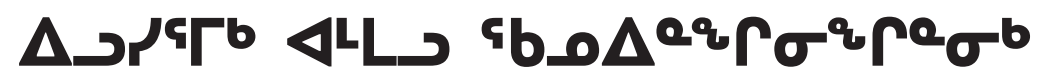

Joshua Ostapchuk, BSc, MPH Candidate, Columbia University, New York, New York, USA

Sherilee Harper, MSc, PhD, Assistant Professor, University of Guelph, Guelph, Ontario, Canada

Ashlee Cunsolo Willox, PhD, Canada Research Chair in Determinants of Healthy Communities and Assistant Professor in Community Health, Cape Breton University, Sydney, Nova Scotia,

Canada

Victoria L. Edge, MSc, PhD, Adjunct Professor, University of Guelph, Guelph, Ontario, Canada

Rigolet Inuit Community Government, Rigolet, Nunatsiavut, Labrador, Canada

\section{ABSTRACT}

Climate changes are rapidly intensifying and can lead to adverse global health impacts. Indigenous populations are especially vulnerable to climate change because of their dependence on the environment for cultural activities and subsistence. The voices of Inuit Elders and seniors encompass deep wisdom and history; as such, the goal of this research was to examine the perceived impacts of climate and environmental changes on physical, mental, and emotional health, as observed by Elders and seniors in the Inuit community of Rigolet, Nunatsiavut, Labrador, Canada. A mixed-methods approach was used to gather data capturing these local observations, as well as perceived impacts on community health. A community survey was administered in November $2009(n=75)$ and in-depth interviews were conducted with Elders and seniors from January to October $2010(n=22)$. Survey results indicated that Elders and seniors observing changes in weather patterns, water systems, and wildlife were more likely to perceive climate change impacts on health $(p<0.05)$. Emergent themes from the interviews included: recurring observations of climate change, including changes in temperature, ice, snow, and seasonal timing; impacts on physical health, including reduced 
physical activity levels and poorer nutrition; impacts on mental and emotional health, including feelings of isolation and depression; and an identified need for community-wide adaptation. This research emphasized the importance of understanding Elder-specific perspectives of climate-health relationships in the Canadian North to develop sustainable, culturally relevant adaptation strategies to mitigate health impacts related to climate change.

\section{KEYWORDS}

Elders, Inuit, Indigenous, Nunatsiavut, climate change, environmental change, mixed-methods research, well-being, health, adaptation

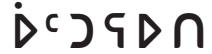

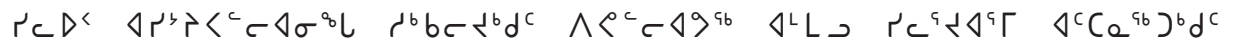

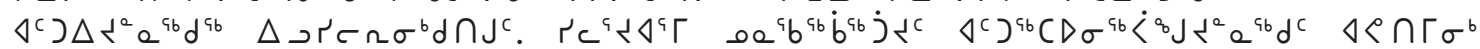

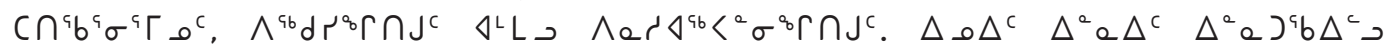

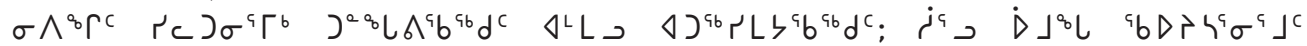

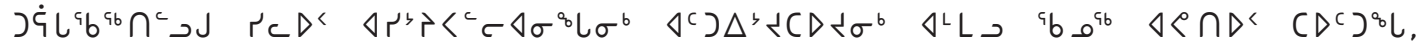

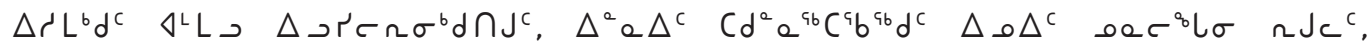

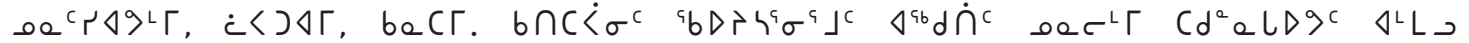

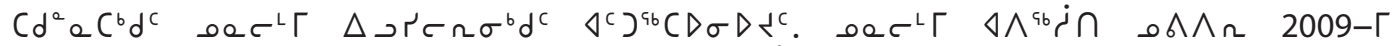

حـ

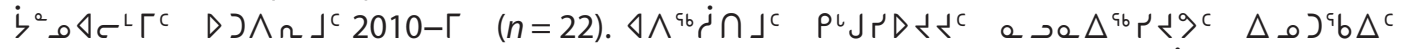

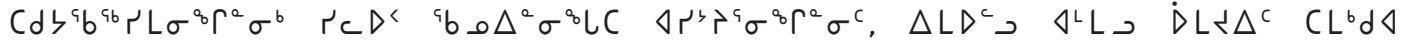

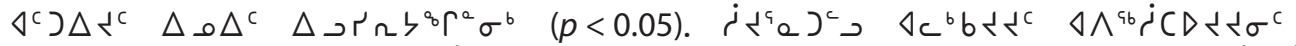

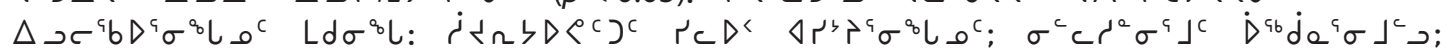

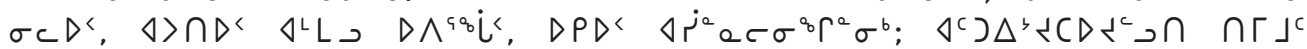

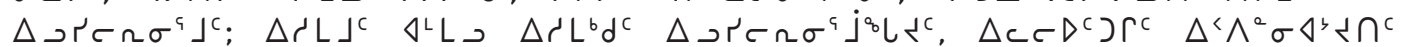

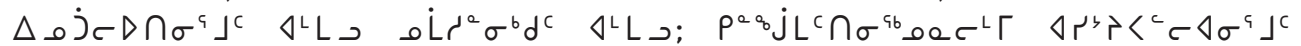

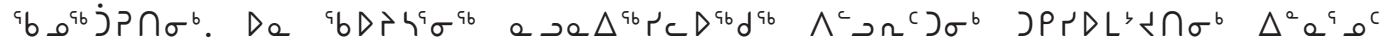

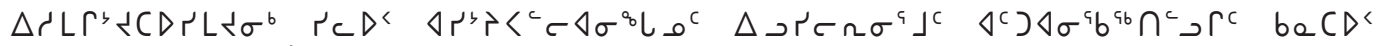

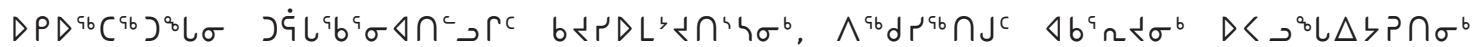

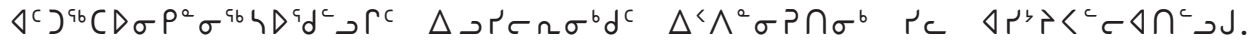

\section{$D^{a} b D r^{a b} C^{c}$}

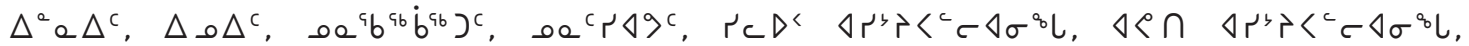

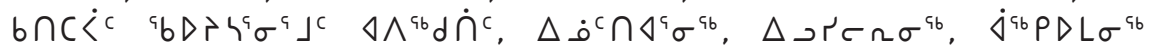

\section{INTRODUCTION}

I t has been said that health impacts of climate change will represent the "greatest public health challenge humanity has 1 faced" (Myers \& Patz, 2009, p. 223). Human-induced global climate change is now acknowledged as reality within the scientific community (Christensen et al., 2007; Füssel, 2009). Projected increases in regional temperatures—combined with changes in the intensity, duration, and frequency of precipitation and severe storms-are expected to have substantial impacts on physical, mental, and emotional health outcomes, resulting from increased exposure to infectious disease, water and food insecurity, population displacement, conflicts over natural resources, and degradation of landscapes and ecosystems (Christensen et al., 2007; Costello et al., 2009; Fritze, Blashki, Burke, \& Wiseman, 2008; Frumkin, Hess, Luber, Malilay, \& McGeehin, 2008; Swim et al., 2011). Given 
the increasing rate at which these climatic and environmental changes are occurring, it becomes more important to examine and understand various ways in which climate change affects health. This will help ensure successful implementation of sustainable health adaptation strategies (Ford, 2009; Ford et al., 2010a).

Climate change is expected to have a substantial impact on those who rely on natural ecosystems for subsistence, such as many Indigenous populations. Also at increased risk are the elderly (due to reduced mobility and immune function), children, women, and those living in climate-sensitive areas such as polar and coastal regions worldwide (Costello et al., 2009; Health Canada, 2002; McMichael, Friel, Nyong, \& Corvalan, 2008; Schneider et al., 2007). Across the Canadian North, several environmental and climate changes already have been observed by Indigenous peoples as well as documented empirically. These include higher ambient temperatures; increased frequency and intensity of storms; and unpredictable changes in rainfall, snow, and ice formation patterns (Christensen et al., 2007; Cunsolo Willox et al., 2012,2013a,b; Ford et al., 2008; Fox, 2002; Furgal, Martin, \& Gosselin, 2002; Füssel, 2009; Healey et al., 2011; Pearce et al., 2009). Indigenous populations living in these regions, such as Canadian Inuit, are particularly vulnerable to effects of climate change due to their dependence on the surrounding land, water, and ice for livelihood, cultural activities, and subsistence (Ford, Pearce, Duerden, Furgal, \& Smit, 2010b; Ford, Smit, \& Wandel, 2006; Ford et al., 2007; Ford et al., 2008; Furgal \& Seguin, 2006). In addition, the impacts of colonization-economic, social, and political marginalization; a history of residential schools; and forced relocation of communities from historical homelands-contribute to underlying social inequities and disparities in health outcomes in many Indigenous populations (Gracey \& King, 2009; Richmond, 2009; Richmond \& Ross, 2008, 2009). Climate change negatively impacts or exacerbates several of these social determinants of health, leading to poorer social and health outcomes (Costello et al., 2009; Health Canada, 2002; McMichael et al., 2008).

For many Inuit, the concept of "good health" does not simply imply a disease-free state; rather, it signifies the achievement of a physical, emotional, mental, and spiritual balance (Borré, 1994; Cunningham, Reading, \& Eades, 2003; Inuit Tuttarvingat, 2010; King, Smith, \& Gracey, 2009). Climate change and variability increasingly challenge this balance of health and well-being. For example, Inuit in Nunatsiavut have reported various impacts on health, such as dietary changes, reduced access to safe drinking water, and increased stress that are attributed to a changing climate (Cunsolo Willox et al., 2013a,b, 2012; Furgal et al., 2002; Furgal \& Seguin, 2006; Harper et al., 2011). Research, however, has consistently called for more information about how climate change affects vulnerable subgroups within populations, such as the elderly, and those with limited equipment and financial resources (Furgal et al., 2002; Furgal \& Seguin, 2006; Health Canada, 2002).

In Nunatsiavut and across the Canadian North, the concept of healthy and successful aging emphasizes and values the transmission of accumulated knowledge and wisdom, in addition to physical factors (Aporta \& MacDonald, 2011; Collings, 2000,
2001; Lewis, 2011). Inuit Elder and senior observations of climate and environmental change, and perceived impacts on health within Inuit communities, are based on a substantial amount of wisdom, insight, and history. Furthermore, the elderly are a subgroup who are more vulnerable to climate change because of their often reduced mobility, increased prevalence of chronic illnesses, weakened immune systems, and higher poverty rates (Costello et al., 2009; Health Canada, 2002; Schneider et al., 2007). These risk factors increase susceptibility to infectious diseases and negative effects of extreme environmental conditions (e.g., weather events, heat waves, smog, water contamination, etc.), which are projected to be exacerbated by climate change (Costello et al., 2009; Health Canada, 2002; Schneider et al., 2007).

While anyone over the age of 50 can be considered a senior, the designation of "Elder" is only given to those individuals recognized as having an abundance of knowledge and wisdom, and are considered leaders in their communities (Bell, 2003). In particular, Elders are highly valued in their communities as knowledge-keepers and wisdom-holders, and hold an esteemed place in the culture. While previous research has involved Inuit Elders and seniors in documenting community-wide observations of climate change in relation to Inuit community health, these studies have not specifically investigated how climate change affects, or has the potential to affect, the health of older Inuit.

The goal of this research was to examine the impacts of climate change on physical, mental, and emotional health, as observed by Elders and seniors in the Inuit community of Rigolet, Nunatsiavut, Canada. The objectives of this case study were to identify recent climate changes and resulting environmental disturbances observed by Elders and seniors in Rigolet; to examine their perceptions about physical, mental, and emotional health impacts related to observed climate and environmental changes; and to identify potential sustainable, culturally relevant adaptation strategies for a preferred and optimistic future. While this research explores perspectives and insights through the voices of Elders and seniors in one Inuit community, the improved understanding of how climate change affects community health could be extended to other Indigenous populations experiencing rapid climate and environmental change.

\section{Community profile}

Nunatsiavut ("Our Beautiful Land”) is one of Canada's four Inuit regions (Figure 1); ratified in 2005 as an Inuit Land Claim Settlement Area, it is self-governed by the Nunatsiavut Government. The community of Rigolet, Nunatsiavut $\left(54^{\circ} \mathrm{N}\right.$, $58^{\circ} \mathrm{W}$ ) has a population of 300 people, with approximately equal numbers of men and women, of whom $95 \%$ identify as Aboriginal. Approximately $25 \%$ of the total population of Rigolet are over the age of 50; however, Rigolet remains a growing community with over $40 \%$ of the population under the age of 25 (Statistics Canada, 2013). The languages spoken in Nunatsiavut include English and the Rigolet dialect of Inuttitut; however, Inuttitut is listed as a UNESCO endangered language and is spoken by only three people 
in the community (UNESCO, 2010). Rigolet is remote, accessible only by seasonal ferry and year-round commercial airline service. Transportation within and around the community is primarily by snowmobile in the winter and by boat and ATV in the summer. The community relies heavily on hunting, trapping, and gathering practices for food - which may include caribou, partridge, seal, rabbit, duck, fish, and berries—as well as furs and firewood for warmth. The community also relies on resources from the surrounding land for various cultural activities, such as grass weaving, carving, and sewing.

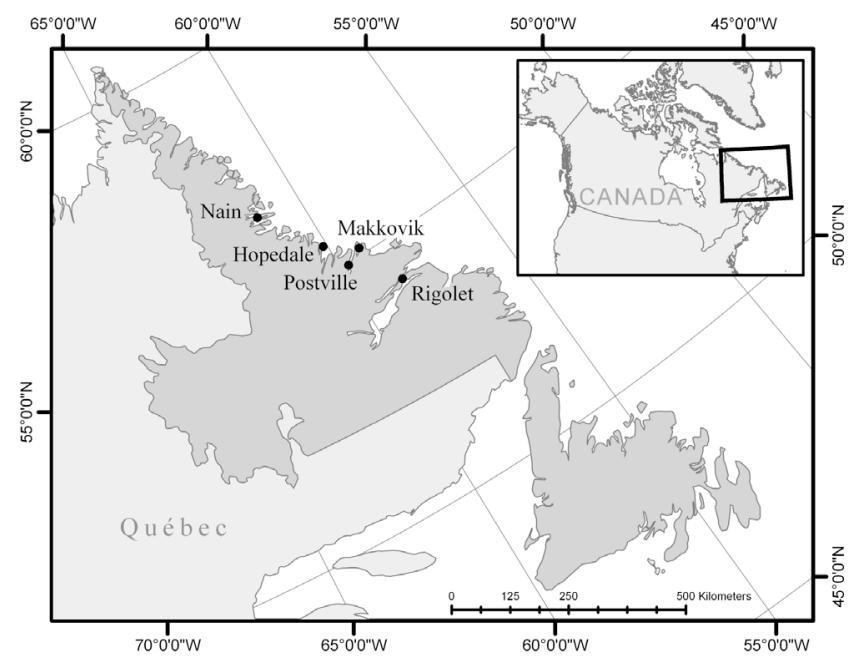

Figure 1. A map of communities in Nunatsiavut, Canada.

\section{METHODS}

\section{Project background}

This research was part of a larger, multi-year research project entitled Changing Climate, Changing Health, Changing Stories (Harper, Edge, Cunsolo Willox, \& Rigolet Inuit Community Government, 2012). In an effort to explore climate-health relationships within a culturally relevant framework, the project was conducted by a multidisciplinary team of researchers, health practitioners, and community digital storytelling facilitators, in partnership with the Rigolet Inuit Community Government. Local community members were engaged in all aspects of the research process, including project design, data collection, analysis, and dissemination (Pearce et al., 2009; Stephens, Porter, Nettleton, \& Willis, 2006). To respect and acknowledge the authority, experience, wisdom, and historical knowledge seniors and Elders possess, Elder and senior observations and perceptions were critical in all stages of the research. This research emerged from a larger data set collected through the Changing Climate, Changing Health, Changing Stories project, and although the questions were not specifically designed for Elders or seniors, it became clear to the research team that the voices, experiences, and observations of Elders and seniors were rich and contained a number of important differences when compared to the responses of other age groups. As a result, our team undertook a specific in-depth analysis of the responses from Elders and seniors to highlight these important and valuable voices.

This study followed ethical guidelines for research with Indigenous communities (Canadian Institutes of Health Research, 2007; Grenier, 1998; Inuit Tapiriit Kanatami \& Nunavut Research Institute, 2007). It received approval from the University of Guelph Research Ethics Board, the Health Canada Research Ethics Board, and the Nunatsiavut Government Research Advisory Committee.

\section{Conceptual framework}

We used a case study design because it involved in-depth, placebased research that focused on a particular population (Yin, 1994), which is particularly effective in characterizing vulnerability determinants and identifying opportunities to enhance adaptive capacity (Ford et al., 2010a). We used a convergent, parallel, mixed-methods approach, which involved collecting quantitative survey data and qualitative in-depth interview data at the same time (Figure 2), analyzing the data separately, and then merging the results to explore convergence, divergence, contradictions, and relationships between the two data sets (Creswell, 2009; Creswell \& Clark, 2007; Stake, 2005). The combination of results from the two types of data analysis provided a more complete understanding of the health impacts of climate change in Rigolet. The quantitative data provided an understanding of the issue at the population level, while the qualitative data gave a more detailed and in-depth understanding of the issue. For the purposes of this study, and following Nunatsiavut age classifications, we considered Elders and seniors to be Rigolet residents over the age of 50 years.

\section{Quantitative data collection and analyses}

In November 2009, as part of the larger Changing Climate, Changing Health, Changing Stories project, we conducted a community survey in Rigolet to capture data on local knowledge of climate change, observations of various climate and environmental changes, and perceived health impacts of climate change. The questionnaire was open to those 12 years and over, and included 26 closed-ended and 11 open-ended questions (questionnaire available upon request), which took approximately 15 minutes to complete. The questionnaire had been formally pre-tested for content, context, and clarity by academics, health professionals, and community members in October 2009. Trained community research assistants went door-to-door over a two-week period in November 2009 to verbally administer the confidential questionnaire.

We compared the gender demographics of the survey sample with those of the 2006 Canadian census of the Rigolet population (Statistics Canada, 2007). We examined frequency counts and distribution of the questionnaire data, and coded and 
tabulated the various responses from the open-ended questions. Using the Fisher's exact test and a significance level of $p<0.05$, we tested the null hypothesis of no overall association between the following independent and dependant variables: gender and weather observations for Elders and seniors; weather observations and perceived climate change impacts on lifestyle for Elders and seniors; and weather observations and perceived climate change impacts on health for Elders and seniors. We managed and analyzed all data with Microsoft Excel (2010 edition) and Intercooled Stata (version 10).

\section{Qualitative data collection and analyses}

Qualitative data were collected from January to October 2010 through in-depth, semi-structured interviews (Kvale \& Brinkmann, 2009). The interviews were designed to gather data on the depth and breadth of local observations of climate and environmental change, and perceived health impacts of climate change. Interviews were open-ended and conducted conversationally to allow for new ideas and themes to emerge (Kvale, 1996). Interviews took approximately 60 to 90 minutes to complete. The interview guide (available upon request) had

To examine the impacts of climatic and environmental change on physical, mental, and emotional health, as observed by Inuit Elders and seniors in the northern community of Rigolet, Nunatsiavut, Labrador, Canada.

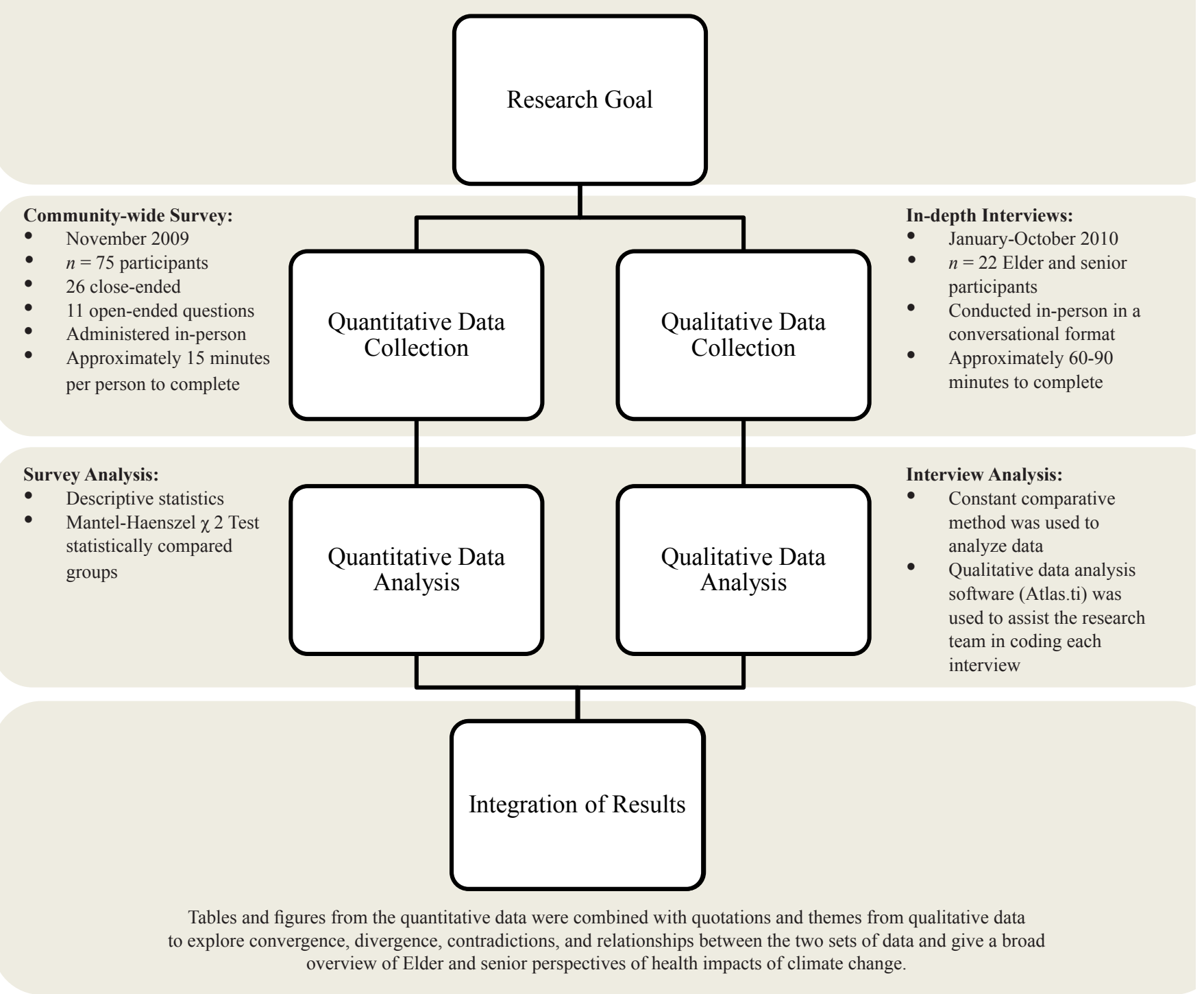

Figure 2. A model outlining the mixed-methods approach used to conduct this study in 2009-2010 in Rigolet, Nunatsiavut, Canada. 
been pre-tested in October 2009 for content, context, and clarity by community members, academics, and health professionals. We recruited participants from the community using posters, mailbox flyers, radio announcements, door-to-door visits, and word-of-mouth communication. Interviews were held until a point of qualitative data saturation was evidently reached (Miles \& Huberman, 1994). Though participants had the option of being interviewed in Inuttitut, all participants preferred English, which was their first language. All interviews were audio-recorded with permission, transcribed professionally, and reviewed by the research team for errors.

We used a constant comparative method for analysis, involving six iterative steps (Bourgeault, Dingwall, \& de Vries, 2010). First, a multidisciplinary team reviewed and analyzed each transcript while listening to the accompanying audio recording. Second, the team wrote reflective memos that profiled each interview and compared the similarities and disparities within and among interviews. Third, the team discussed each interview transcript and used key words to generate a list of codes, which described common and contrasting themes (Miles \& Huberman, 1994). Fourth, the transcripts were then coded, line by line, by labelling the text. Fifth, the team expanded the list of codes and then collapsed them into emerging recurring themes that best fit the data. Finally, the team checked the list of codes for accuracy, reliability, and authenticity. Atlas.ti (version 6), a qualitative data analysis software tool, was used to assist in data organization through the use of electronic transcript coding, and for the retrieval of relevant quotations relating to themes that emerged from the research team's content analysis (Friese, 2012; Konopásek, 2008; Richards \& Richards, 1994).

\section{RESULTS}

\section{Quantitative results}

Of 100 people invited, 75 people participated, giving a response rate of $75 \%$. Twenty-eight of those surveyed were over 50 years of age (37\% of respondents). Using the 2006 census as a guide, we determined that the gender proportion was representative of the Rigolet community (Figure 3).

Nearly all Elder and senior participants had heard of the term "climate change" or "global warming" (96\%; Figure 4). Elder and senior survey respondents indicated that climate change was an important issue in the community, with $71 \%$ indicating it was "very important" or "important" (Figure 5).

We analyzed gender differences among Elders and seniors to explore the possible influences of gender roles on climate-health observations and perceptions. Male Elders and seniors more often reported changes in weather, temperature, rain, snow, and ice, as well as climate change impacts on health, as compared to females (Figure 6). Conversely, female Elders and seniors reported changes in water systems and wildlife, as well as impacts of climate change on lifestyles, more often than men. However, these differences were not significantly different $(p>0.05$; see Table 1$)$.

Many Elder and senior participants felt that climate change was having an impact on their lifestyle (57\%) and health (64\%; Figure 4). Elders and seniors reporting climate change impacts on health significantly differed in whether or not participants observed changes in weather patterns, water systems, and wildlife $(p<0.05$; Table 1$)$. There were no statistically significant relationships between Elder and senior observations on weather and perceived climate change impacts on lifestyle (Table 1 ). Since nearly all Elders and seniors reported changes in temperature, snow, and ice, there was not enough variation to test these variables.

\section{Qualitative results}

A total of 22 in-depth interviews with Elders and seniors over the age of 50 years were completed in the community, which represents one-third of the Elder and senior population in Rigolet.

\section{Climate change observations}

All Elder and senior interview participants discussed changes in climate, as well as climate variability over their lifetimes, including changes in temperature, ice, snow, rain, and seasonal timing. Many participants observed that the average annual temperature had increased over the years, yielding much milder winters. Furthermore, participants noted greater variability in temperature from year to year. Many participants observed that ice freezing patterns, normally dependent on predictable seasonal temperatures, have changed. They observed that ice was no longer forming as quickly, was melting sooner, and was of poorer quality (Table 2).

All Elder and senior interview participants reported changes in precipitation. Snowfall was said to have decreased, resulting in reduced depth and condition of snow accumulation. Participants reported that snow conditions had decreased because accumulated snow would melt at an increased rate after falling, an observation also attributed to the increase in average annual temperature. Also noted was an increase in rainfall throughout the year, including when seasonal precipitation was anticipated to fall as snow. Most participants explained that the combination of these observed climate changes resulted in altered seasonal timing, including winters being shorter in duration, with ice formation occurring later in the year and ice break-up occurring sooner. Elders and seniors noted that ice formation historically took place in November, but had recently occurred in January; ice break-up historically occurred in June, but had recently happened in April. A male Elder explained:

There is a lot of change. And you know, years ago, like in the 50 's and 60's, and probably even into the 70's, you could pretty much tell when [the ice] was going to... break-up in the spring. .. and freeze-up in the fall. You could almost judge [the timing], but it seems like you can't do that anymore. 


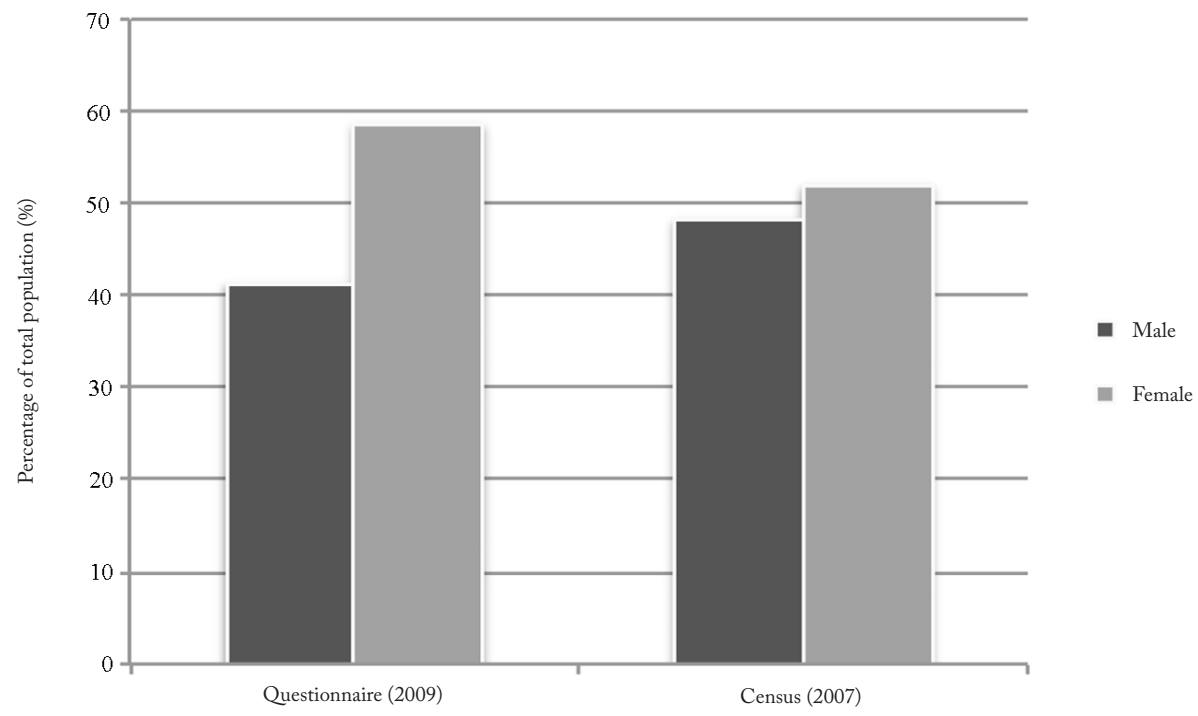

Figure 3. Gender demographics of survey respondents $(n=75)$ in Rigolet, Nunatsiavut, Canada (2009) compared to the 2007 Canadian census (Statistics Canada, 2007), as a proportion of the total population.

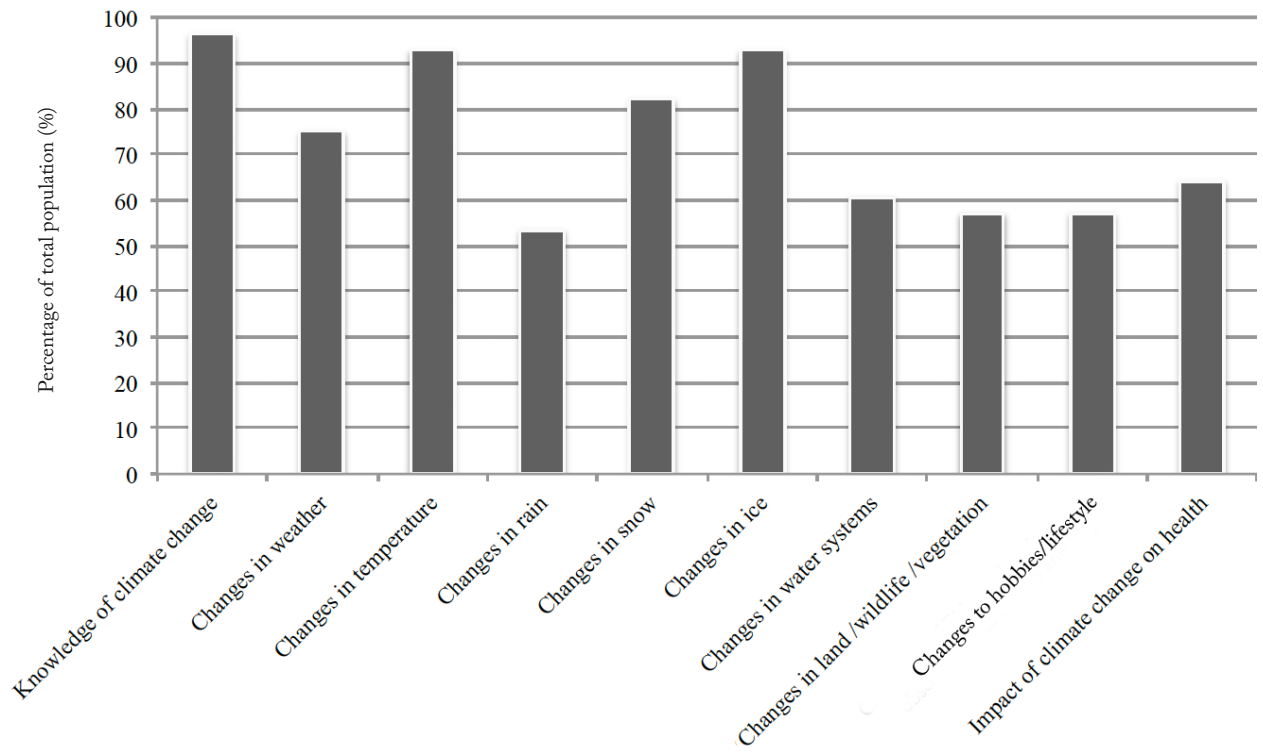

Figure 4. The proportion of elder and senior respondents observing changes in weather and the environment, and resulting impacts on health and lifestyle in Rigolet, Nunatsiavut, Canada (2009). Displayed as a percentage of the total survey population over the age of $50(n=28)$. 


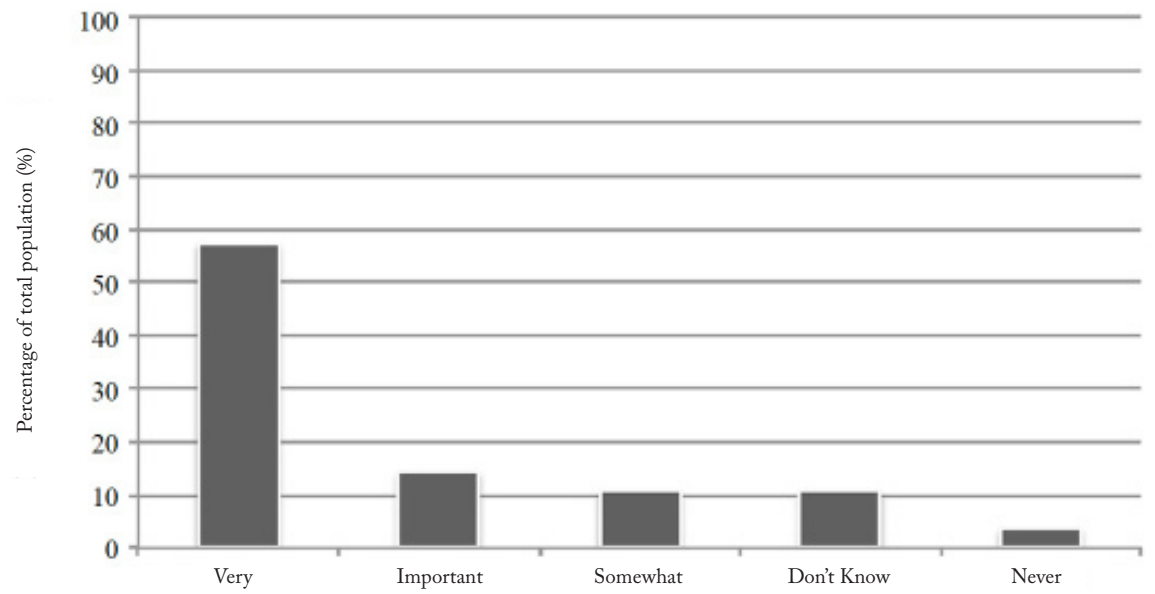

Figure 5. The frequency of elder and senior survey responses about their perceptions of climate change importance to Rigolet residents (2009). Displayed as a percentage of the total survey population over the age of 50 .

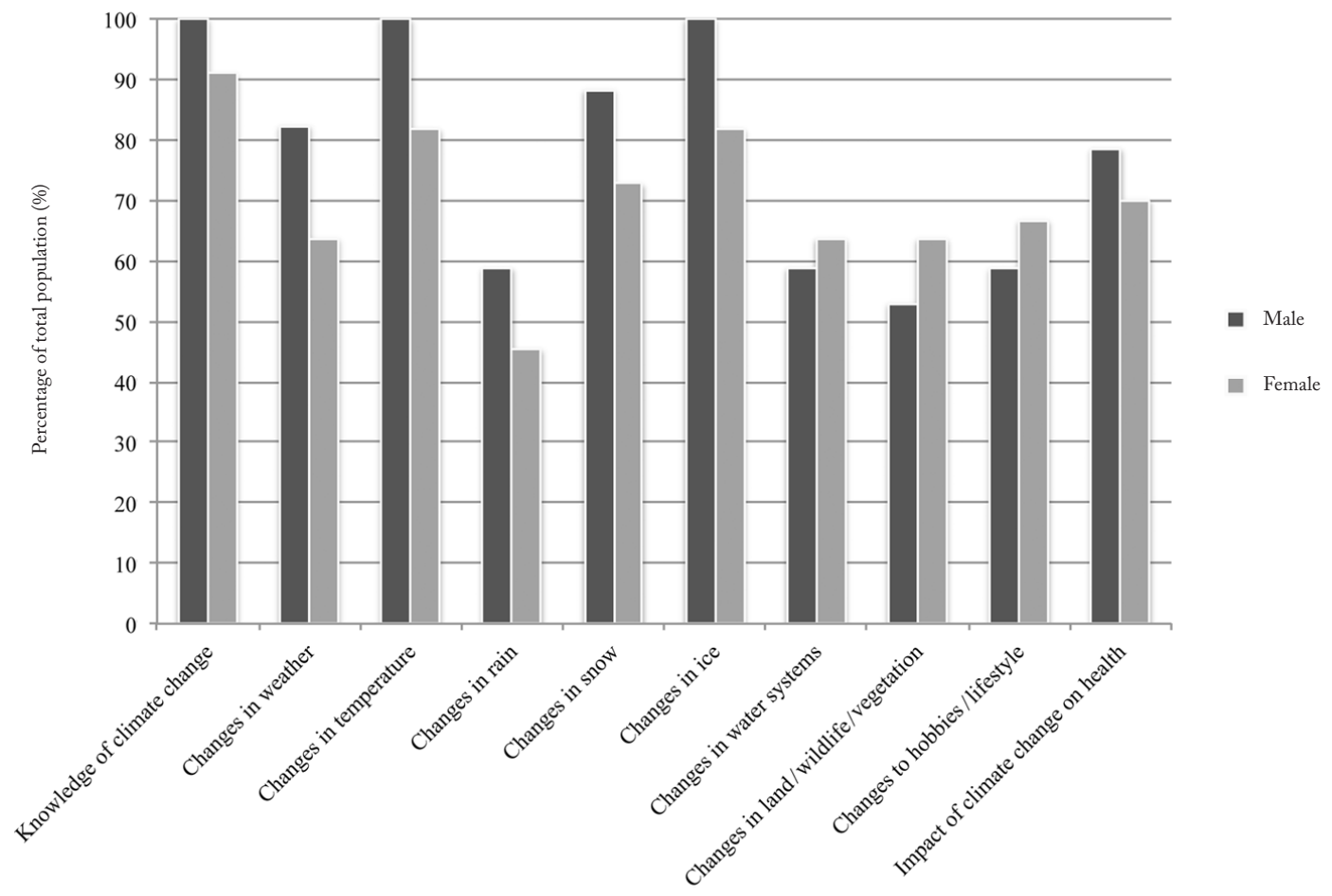

Figure 6. The proportion of community respondents observing changes in weather and the environment, and resulting impacts on health and lifestyle in Rigolet, Nunatsiavut, Canada (2009). Displayed as a percentage of the total elder and senior survey participants $(n=28)$ and stratified by gender. 
Table 1. The results of a series of Fisher's exact tests investigating statistical differences in environmental change observations between gender (male and female), perceived climate change impacts on lifestyle, and perceived climate change impacts on health for Elders and seniors in Rigolet, Nunatsiavut, Canada.

\begin{tabular}{lll}
\hline Variable & $n$ & $p$ \\
Elders' environmental change observations and perceived impacts by gender & & \\
\hline Observed changes in weather patterns & 28 & 0.38 \\
Observed changes in rain & 28 & 0.70 \\
Observed changes in water systems & 28 & 1.00 \\
Observed changes in snow & 28 & 0.36 \\
Climate change in land/wildlife/vegetation & 28 & 0.71 \\
Climate change impacted health & 24 & 0.67 \\
Climate change impacted lifestyle & 26 & 1.00 \\
\hline
\end{tabular}

Elders' environmental change observations by reported climate change impact on lifestyle

\begin{tabular}{lcc}
\hline Observed changes in weather & 26 & 0.64 \\
Observed changes in rain & 26 & 1.00 \\
Observed changes in water & 26 & 0.11 \\
Observed changes in land/wildlife/vegetation & 26 & 0.23 \\
Observed changes in snow & 26 & 0.63 \\
\hline
\end{tabular}

Elders' environmental change observations by reported climate change impact on health

\begin{tabular}{lrr}
\hline Observed changes in weather & 24 & 0.035 \\
Observed changes in water & 24 & 0.003 \\
Observed changes in land/wildlife/vegetation & 24 & 0.007
\end{tabular}

While some participants attributed these seasonal changes to annual climate variability, many reported that these changes were part of a long-term trend in regional climate change. Participants perceived that these changes had had an impact on their lifestyle, including a substantial reduction in ice travel, which also resulted in decreased cabin accessibility and difficulty hunting. Referring to these impacts, one male Elder and hunter stated, "The weather has changed, and it has changed for the worse" (Table 2).

\section{Physical health, activity, and nutrition}

Changes in ice formation patterns, perceived to have resulted from climate change, were reported to impact livelihoods in a variety of ways. Elder and senior interviewees explained their heavy reliance on the formation of good ice for travel during the winter months. One male Elder and hunter expressed concern regarding these changes and said, "We won't be able to get anywhere in the winter without ice." Another participant said, "The ice is our highway."
Participants also reported challenges in hunting, accessing their cabins, and performing certain land-based cultural activities, such as ice fishing, trapping, and collecting firewood, due to the inability to travel over ice. Participants believed that these challenges resulted in a decrease in outdoor activities, which they believed contributed to an overall decrease in physical activity levels, and increase in sedentary lifestyles. Many interviewees also reported concern regarding climate-related changes in the physical activity levels of the younger generation (Table 2).

Participants also reported various challenges to obtaining adequate hunted food, including a decreased ability to hunt because of a lack of reliable ice for travelling, as well as changes in animal migration patterns and the introduction and disappearance of species. Participants perceived that these changes were collectively contributing to a nutritional shift in the diet of many community members (Table 2).

Among the participants, the most prominent observation of nutritional change was the shift from wild meat to store-bought 
Table 2. A comparison of the quantitative and qualitative evidence from Rigolet Elders and seniors for each of the research findings from this case study: climate change observations and resultant impacts on lifestyle and health.

\begin{tabular}{|c|c|c|c|}
\hline Theme & Quantitative evidence & Qualitative evidence: Salient quotations & Codes \\
\hline \multirow[t]{5}{*}{$\begin{array}{l}\text { Climate change } \\
\text { observations }\end{array}$} & $\begin{array}{l}\text { Changes in weather: } \\
\text { - Observed changes } \\
\text { in weather: } 75 \% \text { of } \\
\text { Elder participants }\end{array}$ & $\begin{array}{l}\text { "This year when I saw the difference between }-3 \text { and } \\
0 \text { or }+1 \text { [degrees Celsius], that is all the difference of } \\
\text { ice forming or not. That was a huge difference, those } 3 \\
\text { degrees... What came down was rain instead of snow } \\
\text { because of those } 2,3 \text { degrees." } \\
\text { "Our snow is supposed to last until June - or at least } \\
\text { part of June, even early July. But this past spring here in } \\
\text { Rigolet, I found the snow was almost gone by April." } \\
\text { "There is a lot of change. And you know, years ago, like } \\
\text { in the } 50 \text { 's and } 60 \text { 's, and probably even into the 70's, you } \\
\text { could pretty much tell when [the ice] was going to be a } \\
\text { break-up in the spring [...] and freeze-up in the fall. You } \\
\text { could almost judge [the timing], but it seems like you } \\
\text { can't do that anymore." } \\
\text { "The weather has changed, and it has changed for the } \\
\text { worse." }\end{array}$ & $\begin{array}{ll}\text { - } & \text { Ice } \\
\text { - } & \text { Snow } \\
\text { - } & \text { Temperature } \\
\text { - } & \text { Seasonal timing } \\
\text { - } & \text { Wind and/or } \\
& \text { storms }\end{array}$ \\
\hline & $\begin{array}{l}\text { Changes in temperature: } \\
\text { - Observed changes in } \\
\text { temperature: } 93 \% \text { of } \\
\text { Elder participants }\end{array}$ & $\begin{array}{l}\text { "This winter is mild, really mild. I've [never] ever seen } \\
\text { it like this in my life. This is the first time I ever saw a } \\
\text { Christmas with no ice." }\end{array}$ & $\begin{array}{ll}- & \text { Ice } \\
\text { - } & \text { Snow } \\
\text { - } & \text { Rain } \\
\text { - } & \text { Temperature } \\
\text { Seasonal timing }\end{array}$ \\
\hline & $\begin{array}{l}\text { Changes in } \\
\text { precipitation: } \\
\text { - Observed changes in } \\
\text { rain: } 54 \% \text { of Elder } \\
\text { participants } \\
\text { - Observed changes in } \\
\text { snow: } 82 \% \text { of Elder } \\
\text { participants }\end{array}$ & $\begin{array}{l}\text {-We don't get so much snow and the snow don't seem to } \\
\text { last like it used to. It goes away a lot faster." } \\
\text { "[There has been] more rain this winter and mild weather } \\
\text { than anybody can remember." }\end{array}$ & $\begin{array}{ll}\text { - } & \text { Ice } \\
\text { - } & \text { Snow } \\
\text { - } & \text { Rain } \\
\text { - } & \text { Semperature } \\
\text { - Wind and/or } & \text { Wiming } \\
& \text { storms }\end{array}$ \\
\hline & $\begin{array}{l}\text { Changes in ice: } \\
\text { - Observed changes } \\
\text { in ice: } 93 \% \text { of Elder } \\
\text { participants }\end{array}$ & $\begin{array}{l}\text { - "The ice] has changed a lot, because it used to be really } \\
\text { thick and it would last, but now it's not so thick, and } \\
\text { early in the spring, the ice goes out, so we don't have so } \\
\text { much ice or snow." } \\
\text { "When I was a young fellow, there used to be a lot of } \\
\text { snow and ice. I can remember my grandfather [having to } \\
\text { cut] a fish hole with a 12-foot stick." }\end{array}$ & $\begin{array}{ll}\text { - } & \text { Ice } \\
\text { - } & \text { Rain } \\
\text { - } & \text { Semperature } \\
& \text { Seasonal timing }\end{array}$ \\
\hline & $\begin{array}{l}\text { Other changes: } \\
\text { - } \quad \text { Observed changes in } \\
\text { water systems: } 60 \% \\
\text { of Elder participants } \\
\text { - Observed changes in } \\
\text { land, wildlife, and/or } \\
\text { vegetation: } 57 \% \text { of } \\
\text { Elder participants }\end{array}$ & $\begin{array}{l}\text { "We have migrating animals, birds... maybe they too did } \\
\text { notice there was something changing in our land and } \\
\text { they didn't come back." }\end{array}$ & $\begin{array}{ll}\text { - } & \text { Berries } \\
\text { - } & \text { Hegetation } \\
\text { Hunting/fishing/ } \\
\text { trapping } \\
\text { Animal } \\
\text { migration }\end{array}$ \\
\hline
\end{tabular}


Table 2. A comparison of the quantitative and qualitative evidence from Rigolet Elders and seniors for each of the research findings from this case study: climate change observations and resultant impacts on lifestyle and health.

\begin{tabular}{|c|c|c|c|}
\hline Theme & Quantitative evidence & Qualitative evidence: Salient quotations & Codes \\
\hline $\begin{array}{l}\text { Climate change } \\
\text { impacts }\end{array}$ & $\begin{array}{l}\text { Impacts on lifestyle: } \\
\text { - } \quad \text { Perceived climate } \\
\text { change impacts } \\
\text { on hobbies and } \\
\text { lifestyle: } 57 \% \text { of } \\
\text { Elder participants } \\
\text { No statistically } \\
\text { significant } \\
\text { relationships } \\
\text { between weather } \\
\text { observations and } \\
\text { perceived impacts } \\
\text { on hobbies and } \\
\text { lifestyle } \\
(p>0.05)\end{array}$ & $\begin{array}{l}\text { - It affects everyone because you can't travel like you could } \\
\text { before. It affects you in that way. You don't know if the ice } \\
\text { is going to be safe anymore." }\end{array}$ & $\begin{array}{ll}\text { - } & \text { Hunting/fishing/ } \\
\text { trapping } \\
\text { - } \quad \text { Survival skills } \\
\text { Travel }\end{array}$ \\
\hline & $\begin{array}{l}\text { Impacts on health: } \\
\text { Perceived climate } \\
\text { change impact } \\
\text { on health: } 64 \% \text { of } \\
\text { Elder participants } \\
\text { Observing changes } \\
\text { in weather patterns } \\
\text { significantly } \\
\text { increased the } \\
\text { odds of Elders } \\
\text { and seniors } \\
\text { perceiving climate } \\
\text { change impacts } \\
\text { on health by } 10 \\
\text { times compared } \\
\text { to Elders and } \\
\text { seniors reporting no } \\
\text { changes in weather } \\
\text { patterns (controlling } \\
\text { for gender; } p<0.05 \text { ) } \\
\text { Observing changes } \\
\text { in water systems } \\
\text { significantly } \\
\text { increased the } \\
\text { chance of Elders } \\
\text { and seniors } \\
\text { perceiving climate } \\
\text { change impacts } \\
\text { on health by } 33 \\
\text { times compared } \\
\text { to Elders and } \\
\text { seniors reporting } \\
\text { no changes in water } \\
\text { systems (controlling } \\
\text { for gender; } p<0.05 \text { ) }\end{array}$ & $\begin{array}{l}\text { Physical activity: } \\
\text { "Even the physical exercise of being able to go and chop } \\
\text { your wood in the winter, Ski-Dooing here and there, and } \\
\text { doing your ice fishing. Those things would be physical- } \\
\text { walking on your snowshoes or whatever, but they also } \\
\text { would be good for your outlook on life, because it's so } \\
\text { calm, it's so relaxing, it's so quiet." } \\
\text { "For one thing, they tend to eat more food from the land } \\
\text { when they're out there, and they probably walk more. } \\
\text { And you know, you're engaged more with like hunting } \\
\text { and stuff like that." } \\
\text { "You don't see [youth] out and around; you do not see } \\
\text { them taking part in activities. You do not see them, } \\
\text { the young people these days, with a pair of snowshoes } \\
\text { on. You do not see them going sliding, or just running } \\
\text { around and stuff like that." } \\
\text { Nutrition: } \\
\text { "Wild meat is healthier, and other people would tell me } \\
\text { that wild meat is healthier too. That's what I grew up on, } \\
\text { wild meat." } \\
\text { "I think [the changes] affect everyone to a certain degree, } \\
\text { you know... It makes [the wildlife] different... and we've } \\
\text { always used wildlife for food." } \\
\text { "We have to rely on store food if we can't get a caribou. } \\
\text { We eat a lot of caribou and wild meat, [like] partridges. If } \\
\text { we can't get that, we rely on store food." }\end{array}$ & $\begin{array}{ll} & \\
\text { - } & \text { Hunting/fishing/ } \\
\text { trapping } \\
\text { - } \quad \text { Survival skills } \\
\text { - } \quad \text { Sedentary } \\
\text { lifestyle } \\
\text { - } \quad \text { Travel } \\
\text { Animal } \\
\text { migration } \\
\text { Diabetes/high } \\
\text { blood pressure } \\
\text { - } \quad \text { Fiet } \\
\text { Food sharing } \\
\text { Wild meat vs. } \\
\text { store-bought food }\end{array}$ \\
\hline
\end{tabular}


Table 2. A comparison of the quantitative and qualitative evidence from Rigolet Elders and seniors for each of the research findings from this case study: climate change observations and resultant impacts on lifestyle and health.

\begin{tabular}{|c|c|c|c|}
\hline Theme & Quantitative evidence & Qualitative evidence: Salient quotations & Codes \\
\hline $\begin{array}{l}\text { Climate change } \\
\text { impacts } \\
\text { (continued) }\end{array}$ & $\begin{array}{l}\text { Impacts on health } \\
\text { (continued): } \\
\text { - } \text { Observing } \\
\text { changes in wildlife } \\
\text { significantly } \\
\text { increased the } \\
\text { chance of Elders } \\
\text { and seniors } \\
\text { perceiving climate } \\
\text { change impacts } \\
\text { on health by } 31 \\
\text { times compared } \\
\text { to Elders and } \\
\text { seniors reporting no } \\
\text { changes in wildlife } \\
\text { (controlling for } \\
\text { gender; } p<0.05 \text { ) } \\
\text { No statistically } \\
\text { significant } \\
\text { relationships } \\
\text { between gender } \\
\text { and climate change } \\
\text { observations } \\
\text { No statistically } \\
\text { significant } \\
\text { relationships } \\
\text { between gender and } \\
\text { perceived climate } \\
\text { change impacts }\end{array}$ & $\begin{array}{l}\text { Nutrition (continued): } \\
\text { - I believe that the rate of diabetes has jumped really high. } \\
\text { When I came here } 30 \text { years ago. . I do not think there } \\
\text { were any diabetics in town at the time-now there [are] } \\
\text { lots. A lot of diabetics, a lot of people on high blood } \\
\text { pressure medication." } \\
\text { "I find it hard, because like if I want to go caribou } \\
\text { hunting or something, I can't get there. You know, there's } \\
\text { not enough snow on the land." } \\
\text { Mental and emotional health and well-being: } \\
\text { "You'll probably see more people being stressed.... If you } \\
\text { can't go out and everyone is kind of just stuck here, after a } \\
\text { while I think it's going to kind of get to people." } \\
\text { "People get bored and people turn to drinking and } \\
\text { drugging and social problems and stuff like that." } \\
\text { "I mean people, day after day after day look out the } \\
\text { window and it's this old, depressing fog and rain and } \\
\text { wind. I mean it's got to play on people's minds." } \\
\text { "Your cultural identity [is partly] what you eat and stuff } \\
\text { like that. I mean, when you stop eating the land foods } \\
\text { and stuff like that, I mean, part of identifying with being } \\
\text { Inuit is eating what I call 'Inuit food,'so that is certainly } \\
\text { something that's going to be impacted." } \\
\text { "It becomes a part of you [begins to cry]. Those beautiful } \\
\text { days in October, I just loved to go and collect my grass." } \\
\text { "I can't see nothing good coming out of the climate } \\
\text { change." }\end{array}$ & $\begin{array}{ll}\text { - } & \text { Alcohol/drug use } \\
\text { - } & \text { Cabin } \\
\text { Connection with } & \text { the land } \\
\text { - } & \text { Depression/ } \\
\text { frustration/ } \\
\text { boredom } \\
\text { Knowledge } \\
\text { transfer } \\
\text { - Land-based } \\
\text { cultural activities } \\
\text { Loss of Inuit } \\
\text { culture and } \\
\text { language } \\
\text { Travel } \\
\text { - Worry } \\
\text { Younger } \\
\text { generation }\end{array}$ \\
\hline $\begin{array}{l}\text { Climate-health } \\
\text { adaptation: }\end{array}$ & $\begin{array}{l}\text { Familiarity with } \\
\text { the term "climate } \\
\text { change" or "global } \\
\text { warming": } 96 \% \text { of } \\
\text { Elder participants } \\
\text { - Hear people discuss } \\
\text { climate change } \\
\text { "often" or "always" } \\
\text { in Rigolet: } 40 \% \text { of } \\
\text { Elder participants } \\
\text { Believe climate } \\
\text { change is an } \\
\text { "important" or "very } \\
\text { important" topic } \\
\text { in Rigolet: } 71 \% \text { of } \\
\text { Elder participants }\end{array}$ & $\begin{array}{l}\text { - If it keeps getting warmer, I guess we're just going to } \\
\text { have to adapt to the climate, because we have no plans of } \\
\text { leaving." } \\
\text { "[There are] a lot of people that have to be prepared. I } \\
\text { think now, they know that the snow is not going to stay } \\
\text { very long, so I find a lot of people now, [in] January, a lot } \\
\text { of people are [collecting wood] every chance they get." } \\
\text { "We are not used to [not being able to go to our cabin], } \\
\text { but we can keep ourselves busy with like I said, we both } \\
\text { work full-time, and I got sheds and we do crafts and stuff } \\
\text { like that, so we are always busy." } \\
\text { "Nothing you can do about the weather though... you } \\
\text { just have to adapt I guess." }\end{array}$ & $\begin{array}{ll}\text { - } & \text { Adapt } \\
\text { - } & \text { Alternative } \\
\text { activities } \\
\text { - } & \text { Climate change } \\
\text { - } & \text { awareness } \\
\text { - } & \text { consulder } \\
\text { - } & \text { Research } \\
\text { - } & \text { Travel } \\
\text { Worry }\end{array}$ \\
\hline
\end{tabular}


food, which some participants attributed to environmental and climate change. Participants explained that the traditional Inuit diet revolves around the consumption of wild meat, as it provides an abundant source of vitamins and essential nutrients. In contrast, participants reported that the selection of store-bought foods is often limited and that many products contain high levels of preservatives and few essential nutrients. Another participant stated, "Without a doubt you are eating processed meat and salt and additives and everything else."

All participants reported that a diet largely based on storebought foods was affecting physical health. One female participant, a mother and grandmother, linked a substantial increase in diabetes within the community to a rise in the consumption of store-bought foods, which she perceived to have resulted indirectly from climate change (Table 2). These changes in diet and physical activity levels were reported by almost all interview participants, who linked them to a variety of observed climate and environmental changes in the Nunatsiavut region (Table 2).

\section{Mental and emotional health and well-being}

All participants emphasized their deep and intimate connection with the land. A male Elder and hunter described this connection:

You have to know what the land does to a person, like it, it just gives you that sense of freedom, identity. It, you know it's the best therapy that anybody could have in the world.

Given this powerful connection, participants reported that the on-going climate and environmental changes were particularly difficult to observe and experience, and affected mental and emotional health. While describing this connection with the land, one of the participants expressed his concern about changes observed in the younger generation by saying, "I think my generation is the last generation that got a true connection with the land."

Many participants spoke about a sense of isolation during times when the ice surrounding Rigolet was not suitable for travel. A male Elder described this isolation:

I mean people, day after day after day look out the window and it's this old, depressing fog and rain and wind. I mean it's got to play on people's minds.

Some participants perceived a sense of depression throughout the community during times of decreased cabin accessibility. Furthermore, several participants believed that some community members had turned to alcohol and drug use as a coping mechanism for decreased cabin accessibility, and decreased traditional land-based activities caused by reduced ice travel.

While female participants focused on how climate changes would impact the well-being of their families, male participants more often focused on the well-being of the overall community of Rigolet. Many participants also reported that men were no longer able to hunt as easily because of the reduced ice travel, and women were no longer able to regularly participate in their land-based cultural activities, such as grass weaving.
Lastly, it should be noted that participants reported no positive impacts of climate change in Rigolet, even when asked directly. For example, a male Elder and hunter said, "I can't see nothing good coming out of the climate change" (Table 2).

\section{Climate-health adaptation}

Numerous participants noted a sense of worry about adaptation. They expressed concern about the escalating rate at which climate and environmental changes were being observed, as well as the community's ability to adapt, and how the changes would alter their traditional Inuit lifestyle. Worry about the appropriate measures and timing for culturally relevant adaptation strategies was widespread among interview participants. This sense of concern was described by one male Elder:

I think a lot of people are starting to worry about. . what's going to happen in a few years down the road.

Participants said they must be able to travel over ice to maintain their traditional Inuit lifestyle. Since participants reported that the ice surrounding Rigolet has been becoming increasingly unreliable, alternative methods of transportation have become the focus of most of the local adaptation initiatives. A male Elder and hunter explained, "We won't be able to get anywhere in the winter without ice." As such, several participants suggested boats as an alternative method of transportation in the milder winter months.

The implementation of current adaptation strategies was also reported to have begun within the community of Rigolet. Several participants mentioned alternative activities as an adaptive method for constructively occupying themselves while unable to access their cabins. The implementation of these activities was explained by a male Elder:

We are not used to [not being able to go to our cabin], but we can keep ourselves busy with like I said, we both work fulltime, and I got sheds and we do crafts and stuff like that, so we are always busy.

Participants identified that the goal of these adaptation strategies and alternative activities was to ultimately reduce the physical, mental, and emotional health impacts of climate change and variability within the community. As one participant said, there is "nothing you can do about the weather. . you just have to adapt, I guess" (Table 2).

\section{DISCUSSION}

The results from this research project indicate that there is a strong awareness among Elders and seniors about the health impacts of climate change in Rigolet. Observations of climate and environmental changes reported by Elder and senior interview participants included increased average annual temperatures; increased rain; decreased snowfall; decreased ice quality, thickness, 
and extent; and unpredictable seasonal timing. The findings from this subgroup support previously published Inuit observations and empirical research both within the region of Nunatsiavut, as well as across the Canadian North (Christensen et al., 2007; Cunsolo Willox et al., 2012, 2013a,b; Ford et al., 2008; Fox, 2002; Furgal et al., 2002; Furgal \& Seguin, 2006; Füssel, 2009; Healey et al., 2011; Nickels, Furgal, Buell, \& Moquin, 2005; Pearce et al., 2009).

Many Elders and seniors in Rigolet reported that climate change had affected their ability to access the surrounding land for hunting and gathering, altered animal migration patterns, and increased reliance on food bought from the store. Elders and seniors perceived that these changes decreased physical activity and led to poorer nutrition in the community. Indeed, other research indicates that accessing the land for hunting and gathering provides physical activity, and that eating wild food is part of a nutritious diet (Nancarrow \& Chan, 2010; Kuhnlein, Soueida, \& Receveur, 1996; Kuhnlein, Chan, Leggee, \& Barthet, 2002). Unfortunately, high levels of diabetes, malnutrition, and obesity have been documented across the Arctic (Egeland, Johnson-Down, Cao, Sheikh, \& Weiler, 2011; Huet, Rosol, \& Egeland, 2012; Sheikh, Egeland, Johnson-Down, \& Kuhnlein, 2011). Research suggests that these poor health outcomes could be exacerbated by current and future climate change, particularly among the elderly, unless appropriate adaptation strategies are developed and successfully implemented. Therefore, future research across the Canadian North is required to better understand how climate change affects health, and to develop programs to manage these climate-related health outcomes in vulnerable subgroups of Inuit populations, such as Elders and seniors. This type of climate-related health research and programming will be essential to enable Elders and seniors to remain physically healthy and active, and maintain a nutritious and subsistence-based diet in the face of climate change.

All Elder and senior interview participants also reported climate change was having an impact on personal and communitywide mental and emotional health and well-being. This included a perceived sense of depression throughout the community because of decreased access to the land resulting from hazardous ice conditions, accompanied by a sense of isolation in not being able to travel. These Elder and senior perspectives support communitywide observations previously reported in the literature (Berry, Bowen, \& Kjellstrom, 2010; Cunsolo Willox et al., 2012, 2013a,b, 2014; Fritze et al., 2008; Saniotis \& Irvine, 2010). Furthermore, this research identified Elder-specific concerns and worries about how climate change might affect future health challenges for Inuit youth, including a loss of Inuit language and culture. Similarly, other research from Rigolet has shown that youth are concerned about the well-being of Elders in the face of climate change (Petrasek MacDonald, Harper, Cunsolo Willox, Edge, \& Rigolet Inuit Community Government, 2012). This common concern between the generations might present an opportunity to actively unite Elders and youth in the development and implementation of health-related climate change adaptation strategies.

Past research has called for rapid implementation of sustainable, culturally relevant adaptation strategies in the Canadian
North (Berrang-Ford, Ford, \& Paterson, 2011; Ford, 2009; Ford et al., 2010b). Accessing and including the extensive historical knowledge possessed by Inuit Elders and seniors could support the development of adaption strategies to lessen the health impacts of climate change in the Canadian North. Furthermore, the involvement of Inuit Elders and seniors-who are often wellrespected and have a substantial amount of authority, experience, and history within their communities - in implementing these strategies could also support community-wide, long-term participation. This research also highlights the need for actions and programs that specifically target Inuit Elders and seniors. These could include programs that unite youth and Elders, nurture the emotional and spiritual connections Elders maintain with the land, promote physical activity among Elders, and enable Elders to access wild food sources. Obtaining funding for climate change adaptation strategies suitable for vulnerable communities across Canada remains challenging (Ford, Smith, \& Berrang-Ford, 2011), and we encourage long-term climate-health adaptation strategies from all levels of government. Such strategies will lessen the potentially harmful and far-reaching health impacts of climate change.

As noted previously, our research is limited by the fact that the findings are based on a subgroup of data from a case study where the sample population was relatively small, and where the length of time for the study was relatively short. Bias may be present in the qualitative analysis since a subset of the interview data was used from the Changing Climate, Changing Health, Changing Stories project (which was not specifically designed for Elders and seniors). However, given the limited Inuit Elder-centric perspectives in the climate and health literature, the importance of this work is that it not only supports greater recognition of these wise and valuable voices - whose availability is rapidly diminishing — but it also serves as an introduction to understanding Elder and senior perspectives on climate-health relationships. In order to better extrapolate the results and Elder-specific adaptation-related insights across the Canadian North, similar studies should be conducted in more Inuit communities.

\section{CONCLUSION}

Inuit are an essential part of the fabric of Canadian society and deserve the attention of the political and scientific community, particularly because they are especially vulnerable to climate change due to their dependence on the surrounding environment for cultural activities and subsistence. Nunatsiavut Elders and seniors are their community's history; they have a strong connection with the land, and powerful insights into how it is changing. Results from this research suggest that the physical, mental, and emotional health of Inuit Elders and seniors has been affected by climate change. Therefore, further research and funding from all levels of government is important for a better understanding of climate-health relationships among the Inuit, and other vulnerable Indigenous populations. The results from this case study represent 
an organized collection of observations that the community can use to better understand the various health impacts of climate change. They also can use these observations to develop culturally relevant and sustainable adaptation strategies for health and well-being in Rigolet and across the Canadian North. The inclusion of these community voices and perspectives ensures that the results from this research project can influence climate-related public policy at the municipal, provincial, and federal levels of government, providing new hope for the future of the Canadian North.

\section{ACKNOWLEDGEMENTS}

The authors would like to thank the Changing Climate, Changing Health, Changing Stories project, along with Charlotte Wolfrey, Sarah Blake, Dan Michelin, and the Council (Rigolet Inuit Community Government), Marilyn Baikie and Inez Shiwak (of My Word: Storytelling and Digital Media Lab) and Tanya Pottle, Dina Wolfrey, Ashley Shiwak, Joelene Pardy, Candice Elson, and Carlene Palliser (former team members at My Word), Joanna MacDonald, Liane Langstaff, Andra Zommers, Kathryn Marsilio, Kassandra Hamilton, and Libby Dean (student research team). We thank the community of Rigolet for sharing their knowledge, observations, and perceptions. Finally, thank you to the Climate Change and Health Adaptation for Northern First Nations and Inuit Communities program through Health Canada's First Nations and Inuit Health Branch, the Nasivvik Centre for Inuit Health and Changing Environments, the Nunatsiavut Department of Health and Social Development, the Canadian Institutes for Health Research (through the Vanier Canada Graduate Scholarship to Sherilee Harper), and the Social Sciences and Humanities Research Council (through the J-Armand Bombardier Canada Graduate Scholarship to Ashlee Cunsolo Willox) (funders). 


\section{REFERENCES}

Aporta, C., \& MacDonald, J. (2011). An elder on sea ice: An interview with Aipilik Inuksuk of Igloolik, Nunavut. Canadian Geographer, 55(1), 32-35.

Bell, M. (2003). What we have learned from our Elders: A discussion paper toward the development of the Nunavut economic strategy. Retrieved from Inukshuk Management Consultants website: http://www.inukshukmanagement.ca/What\%20we\%20 have\%20learned\%20from\%20our\%20Elders--final2.pdf

Berrang-Ford, L., Ford, J. D., \& Paterson, J. A. (2011). Are we adapting to climate change? Global Environmental Change, 21(1), 25-33.

Berry, H. L., Bowen, K., \& Kjellstrom, T. (2010). Climate change and mental health: A causal pathways framework. International Journal of Public Health, 55(2), 123-32.

Borré, K. (1994). The healing power of the seal: The meaning of Inuit health practice and belief. Arctic Anthropology, 31(1), 1-15.

Braaf, R. R. (1999). Improving impact assessment methods: Climate change and the health of indigenous Australians. Global Environmental Change, 9(2), 95-104.

Bourgeault, I. L., Dingwall, R., \& de Vries, R. (2010). The Sage bandbook of qualitative methods in health research. Thousand Oaks, CA: Sage Publications.

Canadian Institutes of Health Research. (2007). CIHR guidelines for health research involving Aboriginal people. Retrieved from: http://www.cihr-irsc.gc.ca/e/29134.html

Christensen, J. H., Hewitson, B., Busuioc, A., Chen, A., Gao, X., Held, I., ... Whetton, P. (2007). Chapter 11: Regional Climate Projections. In S. Solomon, D. Qin, M. Manning, Z. Chen, M. Marquis, K. B. Averyt, ... H. L. Miller (Eds.), Climate change 2007: The physical science basis (Fourth assessment report of the Intergovernmental Panel on Climate Change). Cambridge, UK: Cambridge University Press.

Collings, P. (2000). Aging and life course development in an Inuit community. Arctic Anthropology, 37(2), 111-125.

Collings, P. (2001). "If you got everything, it's good enough": Perspectives on successful aging in a Canadian Inuit community. Journal of Cross-Cultural Gerontology, 16(2), $127-155$.
Costello, A., Abbas, M., Allen, A., Ball, S., Bell, S., Bellamy, R., ... Patterson, C. (2009). Managing the health effects of climate change. Lancet, 373, 1693-1733.

Creswell, J. W. (2009). Research design: Qualitative, quantitative, and mixed methods approaches. Thousand Oaks, CA: Sage Publications.

Creswell, J. W., \& Plano Clark, V. L. (2007). Designing and conducting mixed methods research. Thousand Oaks, CA: Sage Publications.

Cunningham, C., Reading, J., \& Eades, S. (2003). Health research and Indigenous health. British Medical Journal, 327, 445-447.

Cunsolo Willox, A., Stephenson, E., Allen, J., Bourque, F., Drossos, A., Elgarøy, S., . . Wexler, L. (2014). Examining relationships between climate change and mental health in the Circumpolar North? Regional Environmental Change. doi 10.1007/s10113014-0630-z

Cunsolo Willox, A., Harper, S. L, Ford, J., Landman, K., Houle, K., Blake, S., \& Wolfrey, C. (2013a). Climate change and mental health: An exploratory case study from Rigolet, Nunatsiavut, Canada. Climatic Change, 121(2), 255-270.

Cunsolo Willox, A., Harper, S. L., Edge, V. L., Landman, K., Houle, K., Ford, J. D., \& the Rigolet Inuit Community Government. (2013b). The land enriches the soul: On climatic and environmental change, affect, and emotional health and well-being in Rigolet, Nunatsiavut, Canada. Emotion, Space, and Society, 6, 14-24.

Cunsolo Willox, A., Harper, S. L., Ford, J. D., Landman, K., Houle, K., Edge, V. L., \& the Rigolet Inuit Community Government. (2012). "From this place and of this place": Climate change, sense of place, and health in Nunatsiavut, Canada. Social Science E Medicine, 75(3), 538-547.

Egeland, G. M., Johnson-Down, L., Cao, Z. R., Sheikh, N., \& Weiler, H. (2011). Food insecurity and nutrition transition combine to affect nutrient intakes in Canadian Arctic communities: International Polar Year Inuit Health Survey, 2007-2008. Journal of Nutrition, 141(9), 1746-1753.

Few, R. (2007). Health and climatic hazards: Framing social research on vulnerability, response, and adaptation. Global Environmental Change, 17(2), 281-295.

Ford, J. D. (2009). Dangerous climate change and the importance of adaptation for the Arctic's Inuit population. Environmental Research Letters, 4(2), 024006. 
Ford, J. D., Berrang-Ford, L., King, M., \& Furgal, C. (2010). Vulnerability of Aboriginal health systems in Canada to climate change. Global Environmental Change, 20, 668-680.

Ford, J. D., \& Furgal, C. (2009). Foreword to the special issue: Climate change impacts, adaptation, and vulnerability in the Arctic. Polar Research, 28, 1-9.

Ford, J. D., Keskitalo, E. C. H., Smith, T., Pearce, T., Berrang-Ford, L., Duerden, F., \& Smit, B. (2010a). Case study and analogue methodologies in climate change vulnerability research. Wiley Interdisciplinary Reviews: Climate Change, 1(3), 374-392.

Ford, J. D., Pearce, T., Duerden, F., Furgal, C., \& Smit, B. (2010b). Climate change policy responses for Canada's Inuit population: The importance of and opportunities for adaptation. Global Environmental Change, 20,177-191.

Ford, J., Pearce, T., Smit, B., Wandel, J., Allurut, M., Shappa, K., . . . Qrunnut, K. (2007). Reducing vulnerability to climate change in the Arctic: The case of Nunavut, Canada.Arctic, 60(2), 150-166.

Ford, J. D., Smit, B., \& Wandel, J. (2006). Vulnerability to climate change in the Arctic: A case study from Arctic Bay, Canada. Global Environmental Change, 16, 145-160.

Ford, J. D., Smit, B., Wandel, J., Allurut, M., Shappa, K., Ittusarjuat, H., \& Qrunnut, K. (2008). Climate change in the Arctic: Current and future vulnerability in two Inuit communities in Canada. Geographical Journal, 174, 45-62.

Ford, J. D., Smith, T. R., \& Berrang-Ford, L. (2011). Canadian federal support for climate change and health research compared with the risks posed. American Journal of Public Health, 101(5), 814-821.

Fox, S. (2002). "These are things that are really happening”: Inuit perspectives on the evidence and impacts of climate change in Nunavut. In I. Krupnik \& D. Jolly (Eds.), The earth is faster now: Indigenous observations of Arctic environmental change (pp. 12-53). Fairbanks, AK: Arctic Research Consortium of the United States.

Friese, S. (2012). Qualitative data analysis with ATLAS.ti. London, UK: Sage Publications.

Fritze, J. G., Blashki, G. A., Burke, S., \& Wiseman, J. (2008). Hope, despair and transformation: Climate change and the promotion of mental health and wellbeing. International Journal of Mental Health Systems, 2, 13.
Frumkin, H., Hess, J., Luber, G., Malilay, J., \& McGeehin, M. (2008). Climate change: The public health response. American Journal of Public Health, 98(3), 435-445.

Furgal, C., Martin, D., \& Gosselin, P. (2002). Climate change and health in Nunavik and Labrador: Lessons from Inuit knowledge. In I. Krupnik \& D. Jolly (Eds.), The earth is faster now: Indigenous observations of Arctic environmental change (pp. 266-300). Fairbanks, AK: Arctic Research Consortium of the United States.

Furgal, C. M., \& Seguin, J. (2006). Climate change, health, and vulnerability in Canadian northern Aboriginal communities. Environmental Health Perspectives, 114(12), 1964-1970.

Füssel, H.-M. (2009). An updated assessment of the risks from climate change based on research published since the IPCC Fourth Assessment Report. Climatic Change, 97, 469-482.

Grenier, L. (1998). Working with indigenous knowledge: A guide for researchers. Ottawa, ON: International Development Research Centre.

Gracey, M., \& King, M. (2009). Indigenous health part 1: Determinants and disease patterns. Lancet, 374, 65-75.

Harper, S. L., Edge, V. L., Cunsolo Willox, A., \& Rigolet Inuit Community Government. (2012). "Changing climate, changing health, changing stories” profile: Using an EcoHealth approach to explore impacts of climate change on Inuit health. EcoHealth, 9, 89-101.

Harper, S. L., Edge, V. L., Schuster-Wallace, C. J., Berke, O., \& McEwen, S. A. (2011). Weather, water quality, and infectious gastrointestinal illness in two Inuit communities in Nunatsiavut, Canada: Potential implications for climate change. EcoHealth, 8, 93-108.

Healey, G. K., Magner, K. M., Ritter, R., Kamookak, R., Aningmiuq, A., Issaluk, B., . . Moffit, P. (2011). Community perspectives on the impact of climate change on health in Nunavut, Canada. Arctic, 64, 89-97.

Health Canada. (2002). Climate change and health E' well-being: A policy primer for Canada's North. Ottawa, ON: Author.

Huet, C., Rosol, R., \& Egeland, G. M. (2012). The prevalence of food insecurity is high and the diet quality poor in Inuit communities. Journal of Nutrition, 142(3), 541-547.

Inuit Tuttarvingat. (2010). Inuit Tuttarvingat of the National Aboriginal Health Organization strategic plan 2010-15. Ottawa, ON: National Aboriginal Health Organization. 
King, M., Smith, A., \& Gracey, M. (2009). Indigenous health part 2: The underlying causes of the health gap. Lancet, 374, 76-85.

Konopásek, Z. (2008). Making thinking visible with Atlas.ti: Computer assisted qualitative analysis as textual practices. Forum: Qualitative Social Research, 9(2), Art. 12.

Kuhnlein, H. V., Soueida, R., \& Receveur, O. (1996). Dietary nutrient profiles of Canadian Baffin Island Inuit differ by food source, season, and age. Journal of the American Dietetic Association, 96, 155-162.

Kuhnlein, H., Chan, H., Leggee, D., \& Barthet, V. (2002). Macronutrient, mineral, and fatty acid composition of Canadian Arctic traditional food. Journal of Food Composition and Analysis, 15, 545-566.

Kvale, S. (1996). InterViews: An introduction to qualitative research interviewing. Thousand Oaks, CA: Sage Publications.

Kvale, S., \& Brinkmann, S. (2009). InterViews: Learning the craft of qualitative research interviewing. Thousand Oaks, CA: Sage Publications.

Lewis, J. P. (2011). Successful aging through the eyes of Alaska Native Elders. What it means to be an Elder in Bristol Bay, AK. Gerontologist, 51(4), 1-8.

McMichael, A. J., Friel, S., Nyong, A., \& Corvalan, C. (2008). Global environmental change and health: Impacts, inequalities, and the health sector. British Medical Journal, 336, 191-194.

Miles, M. B., \& Huberman, A. M. (1994). Qualitative data analysis. Thousand Oaks, CA: Sage Publications.

Myers, S. S., \& Patz, J. A. (2009). Emerging threats to human health from global environmental change. Annual Review of Environment and Resources, 34, 223-252.

Nancarrow, T. L., \& Chan, H. M. (2010). Observations of environmental changes and potential dietary impacts in two communities in Nunavut, Canada. Rural and Remote Health, 10(2), 1370.

Nickels, S., Furgal, C., Buell, M., \& Moquin, H. (2005). Unikkaaqatigiit-Putting the human face on climate change: Perspectives from Inuit in Canada. Ottawa, ON: Inuit Tapiriit Kanatami, Nasivvik Centre for Inuit Health and Changing Environments, \& the Ajunnginiq Centre at the National Aboriginal Health Organization.
Parkinson, A. J., \& Butler, J. C. (2005). Potential impacts of climate change on infectious diseases in the Arctic. International Journal of Circumpolar Health, 64(5), 478-486.

Pearce, T. D., Ford, J. D., Laidler, G. J., Smit, B., Duerden, F., Allarut, M., ... Wandel, J. (2009). Community collaboration and climate change research in the Canadian Arctic. Polar Research, 28, 10-27.

Petrasek MacDonald, J., Harper, S. L., Cunsolo Willox, A., Edge, V. L., \& Rigolet Inuit Community Government. (2012). A necessary voice: Climate change and lived experiences of youth in Rigolet, Nunatsiavut, Canada. Global Environmental Change, 23(1), 360-371.

Richards, T., \& Richards, L. (1994). Using computers in qualitative analysis. In N. K. Denzin \& Y. S. Lincoln (Eds.), Handbook of qualitative research. Thousand Oaks, CA: Sage Publications.

Richmond, C. A. M. (2009). The social determinants of Inuit health: A focus on social support in the Canadian Arctic. International Journal of Circumpolar Health, 68(5), 471-487.

Richmond, C. A. M., \& Ross, N. A. (2008). Social support, material circumstance and health behaviour: Influences on health in First Nations and Inuit communities of Canada. Social Science E' Medicine, 67(9), 1423-1433.

Richmond, C. A. M., \& Ross, N. A. (2009). The determinants of First Nation and Inuit health: A critical population health approach, Health E' Place, 15, 403-411.

Saniotis, A., \& Irvine, R. (2010). Climate change and the possible health effects on older Australians. Australian Journal of Primary Health, 16, 217-220.

Schneider, S. H., Semenov, S., Patwardhan, A., Burton, I., Magadza, C. H. D., Oppenheimer, M., .. Yamin, F. (2007). Chapter 19: Assessing key vulnerabilities and the risk from climate change. In M. L. Parry, O. F. Canziani, J. P. Palutikof, P. J. van der Linden, \& C. E. Hanson (Eds.), Climate change 2007: Impacts, adaptation and vulnerability. Contribution of Working Group II to the Fourth Assessment Report of the Intergovernmental Panel on Climate Change (pp. 779-810). Cambridge, UK: Cambridge University Press.

Sheikh, N., Egeland, G. M., Johnson-Down, L., \& Kuhnlein, H. V. (2011). Changing dietary patterns and body mass index over time in Canadian Inuit communities. International Journal of Circumpolar Health, 70(5), 511-519. 
Stake, R. E. (2005). Qualitative case studies. In N. K. Denzin \& Y.

S. Lincoln (Eds.), Handbook of qualitative research (3rd edition).

Thousand Oaks, CA: Sage Publications.

Statistics Canada. (2007). Community profiles. Retrieved from: http://www12.statcan.ca/english/census06/data/profiles/ community/Index.cfm?Lang=E

Stephens, C., Porter, J., Nettleton, C., \& Willis, R. (2006).

Disappearing, displaced, and undervalued: A call to action for Indigenous health worldwide. Lancet, 367, 2019-2028.

Swim, J., Stern, P., Doherty, T., Clayton, S., Reser, J., Weber, E., ... Howard, G. S. (2011). Psychology's contributions to understanding and addressing global climate change. American Psychologist, 66(4), 241-250.

UNESCO. (2010). UNESCO atlas of the world's languages in danger. Retrieved from: http://www.unesco.org/new/en/culture/ themes/endangered-languages/atlas-of-languages-in-danger/

Yin, R. K. (1994). Case study research: Design and methods. Thousand Oaks, CA: Sage Publications. 


\section{Our Living Ecosystem: What are the} Interconnections among the Elements Surrounding Us? A Classroom-based Activity in Nunavik

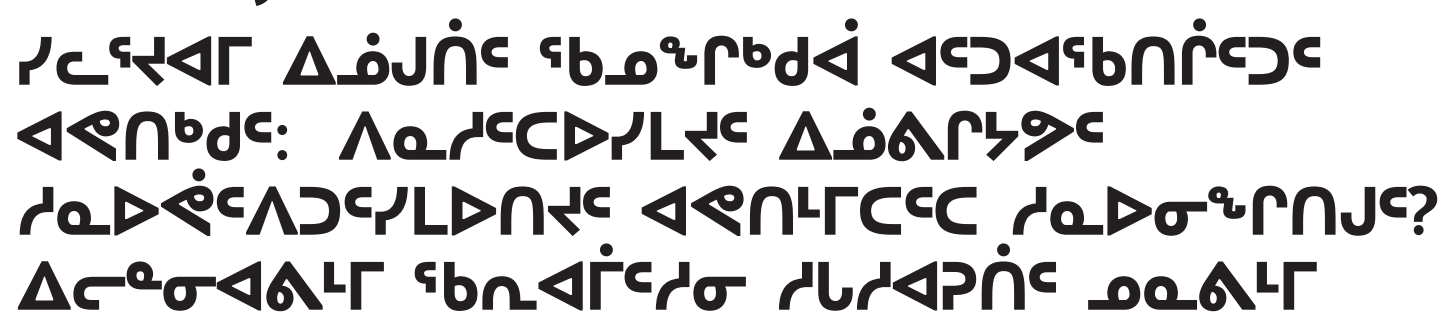

Mélanie Lemire, PhD, CIHR-Banting postdoctoral fellow, Dépt Médecine sociale et préventive, Université Laval, Axe Santé des populations et pratiques optimales en santé, Centre de recherche du CHU de Québec, Québec, Québec, Canada

Mylène Riva, PhD, Assistant Professor, Dépt Médecine sociale et préventive, Université Laval, Axe Santé des populations et pratiques optimales en santé, Centre de recherche du CHU de Québec, Québec, Québec, Canada

Maria Ruiz-Castell, PhD, Santé-Cap postdoctoral fellow, Dépt Médecine sociale et préventive, Université Laval, Axe Santé des populations et pratiques optimales en santé, Centre de recherche du CHU de Québec, Québec, Québec, Canada

\section{INTRODUCTION}

$\mathrm{N}$ atural environment (water, soil, air, etc.) and built environment (houses, schools, roads, etc.) are part of a larger global ecosystem; all elements are tightly interconnected and affect each other. People, plants, animals and other living beings are also integral components of the ecosystem. An ecosystem includes not only elements that we see, but also intangible ones such as culture, spiritual beliefs, music, arts, and the economy. Emphasizing the dynamic links among these elements and how they relate to each other is central to understanding the intimate interdependence between an ecosystem and the health of all its living beings.

Drawing from this premise, we developed an environmental education activity that was conducted in high schools in two villages in Nunavik (Northern Quebec) during February and March 2012. In this report, we share our methods and rationale to promote the adaptation and modification of this activity in other schools.

\section{THE COMMUNITY STORY}

This environmental education activity is a result of our collective research efforts to promote ecosystem approaches to health, also known as Ecohealth, a research method that embraces complexity, transdisciplinarity, social justice, gender equity, multi-stakeholder participation, and sustainability (Webb et al., 2010). We saw this activity as a way to merge our respective research interests, i.e., environmental contaminants and country foods' health benefits and risks, as well as the social determinants of Inuit health, with a focus on housing, health, and well-being.

This activity was conceived during an initial visit to Nunavik for research purposes on the above mentioned topics in October 2011. At a community event, we had the opportunity to meet and talk to high school teachers. We discussed the possibility of presenting our research to the students, and eventually offering educational activities to encourage high school students (grades 9 
to 11) to learn more about the natural and built environments of their communities. Often, teachers in the North are required to teach all subjects and some of them mentioned having a limited science background (e.g., in geography or natural sciences). They were enthusiastic about the possibility of external input to help include local environmental issues in their teaching program. They strongly favored hands-on and outdoor interactive activities to engage students in learning and sharing their knowledge and concerns about their environment. Between October 2011 and February 2012, we developed the content and learning objectives of the activity in a joint effort with the high school science teachers. The school directors and school board then gave approval for the activities to take place in the two schools. Additional support was provided by Let's Talk Science (www.letstalkscience.org), a Canadian charitable organization that funds and delivers hands$\mathrm{on} / \mathrm{minds}$-on educational activities to promote interest in science among children and youth.

We developed this activity independently of our respective research projects, as a means of collectively acknowledging the involvement of communities in our research, building innovative research-based relationships, and establishing ties with new stakeholders. We also wanted to share our results and increase our awareness of young Inuit perceptions of their ecosystem in order to better involve them in our own research and intervention projects.

\section{DESCRIPTION OF THE ACTIVITY}

The overall goal of the environmental education activity was to stimulate students' interest in both natural and social sciences. We used hands-on exercises to explore the links among the different elements of the surrounding ecosystem. We also included health issues related to environmental contaminants, diet, food security, physical activity, smoking, diabetes, etc.

The learning objectives of the activity were to:

1. Explore notions of natural and built environments, the interconnections between them, and how they form a global system (an ecosystem) that includes all living beings and intangible elements such as culture, spiritual beliefs, music, arts, and the economy.

2. Explore how their community ecosystem relates to their health and well-being and to the health of other living beings in the community ecosystem.

3. Allow the students to share and express their knowledge and concerns about their ecosystem through interactive games, discussions, photography, and mapping.

The activity was composed of two classroom-based activities and one outdoor activity. They were held on the same day but ideally should be done over two consecutive days.

\section{Activity 1: Notions about natural and built environments - the circle of interconnections}

Location: Classroom

Duration: 20 minutes

Materials: Yarn; pictures representing elements of the surrounding natural and built environments, local country and market foods, Inuit arts and culture, and youth day-to-day life ${ }^{i}$. Each picture was slipped into a transparent folder that could be worn around the neck using a length of yarn.

- $\quad$ Sitting on the floor in a circle, we first introduced ourselves (where we are from and who we are), and then students and teachers did the same.

\section{Circle 1:}

- We presented notions of natural and built ecosystems using different pictures displayed on the floor (water, air, soil, school, housing, transportation, etc.).

- Everyone was given a different picture (to wear around their neck) representing tangible elements of the surrounding natural and built ecosystems.

- $\quad$ Students were asked to identify and discuss links among the different pictures/elements by throwing the yarn ball from one person to another in such a way to create links - like a spider web-between the different pictures (a circle of interconnections). Questions to promote discussion with the students during the activity included:

- Where do you fish the Arctic char? (The student with the Arctic char picture throws the yarn ball to the person with the ice picture.)

- How do you go seal hunting? (The student with the seal picture throws the yarn ball to the student with the picture of the Ski-Doo.)

- Where can you find children in the community? (The student with the picture of children throws the yarn ball to the person with the school picture.)

- How do the vegetables get into the village? (The student with the vegetable picture throws the yarn ball to the student with the Air Inuit plane picture.)

- Where does the soft drink can go after you drink it? (The student with the can picture throws the yarn ball to the person with the photo of the dump site.)

- A discussion then took place on the dynamic web of yarn that was created during the activity and how each element was interconnected. Some examples of discussion questions were:

- Do you realize how many things are interconnected? 
- If you pull the pieces of yarn in your hand towards you, do you realize how it will affect the others?

- What do you think could happen if one piece of yarn is broken? What do you think could happen if the climate changes?

- What are the recycling possibilities in your community? (Why, how, etc.)

\section{Circle 2:}

- Ideas of more intangible aspects of an ecosystem were then presented using pictures representing culture, social media, arts, and music.

- We redistributed some pictures from Circle 1 while adding new pictures to represent social and cultural elements.

- Students recreated a circle of interconnections by throwing the yarn ball from one person to another, considering the new pictures/elements.

- A discussion then took place on how all the different elements in the circle are integral parts of an ecosystem and how they influence the health of living beings in the circle.

\section{Activity 2: Photo voice-pictures of the village ecosystem}

Location: In the village and surrounding locations (the duration and areas to be visited were determined with the help of the teachers)

Duration: One or two classroom lessons

Material: Digital cameras, photographic paper, and photo printer

- Facilitators invited students to form groups, with each group accompanied by a researcher or teacher.

- $\quad$ Each group was given a camera and assigned different sectors of the village. Their instructions were to take pictures of the ecosystem of this sector and return to class after 30 minutes to one hour.

- Students then had an introduction to the third activity: mapping. They were asked if they could find additional pictures or objects related to their ecosystem at home and were encouraged to bring them for the map during the next activity.

- The research team printed the pictures taken by the students before the next activity began.

\section{Activity 3: Mapping the village ecosystem}

Location: Classroom

Duration: One lesson

Material: A very large piece of paper, printed pictures taken in the previous activity, pictures used in the first activity, scissors, pens, pipe cleaners, markers, glue, and students' objects from home (according to the suggestion given at the end of Activity 2).

- Researchers drew a map of the village on the paper before the activity began.

- In the classroom, students were asked to look at the printed pictures and to decide together how they want to recreate the village ecosystem.

- $\quad$ Students glued the selected pictures and other objects (e.g., an igloo made with pipe cleaners) on the map (see Figure 1).

- Discussions took place about how the community ecosystem influences health and well-being. Discussion questions included:

- How important is the community freezer for health? Country food is very good for the body, but do you think it is also good for the mind? Why?

- What do you know about the possibility of finding environmental contaminants in some country foods?

- How important is it to go on the land (the larger ecosystem in which the village ecosystem is embedded)?

- How can the smoke that comes from the dump [trash is burned periodically in the villages] affect your health? Who can be more affected in the village? What about the animals? The berries?

- What happens if there are not enough places to stay in the village? Can living in an old, broken down house affect the health of your family?

- Who is the best singer in town? The most famous carver? What do you find in his/her craft that relates to you? How does it makes you feel?

Following the three activities, we gave the pictures, cameras, and printer to the teachers so they would have the materials for similar activities in the future. Teachers received more information about Let's Talk Science and were given the contact details of the program supervisor for future interactive web-based activities. They also were given a list of useful websites with innovative material for teaching science to high school students. These websites emphasize Ecosystem approaches to health and teaching methods; cover issues such as environmental contaminants; and feature photo, voice, and interactive activities that were designed for other projects. ${ }^{\text {ii }}$ 


\section{THE CONDUCT OF THE EDUCATIONAL ACTIVITY:TAKING STOCK}

Overall, the first and second activities worked very well. The students were enthusiastic and happy to participate in the circle of interconnections. They even created unexpected links. Some young hunters were very proud of their knowledge of their ecosystem and how to get country foods. The students were also dedicated and very creative photographers. Ideally, the third activity (see Figure 1) should have taken place the following day in order to have time to print the pictures between the two activities, and make sure students focused solely on the activities. Unfortunately, due to logistical and time constraints, we had to do the third activity right after the second. It was challenging to motivate students to participate during the mapping exercise. One solution could have been to print a Google Maps or Google Earth image of the community on a large piece of paper (instead of hand drawing the map), although in some communities satellite images are of low resolution or outdated. Sometimes, high quality maps are available from local or provincial government institutions. A more precise map would have helped capture the students' attention by giving them a more accurate representation of their community. It also would have required less preparation. The map could have been divided into different sectors, one for each group of the second activity. Each group could have taken pictures in their respective sector of the community, designed their own map in smaller teams, and merged all maps into a single, larger one at the end of the activity. Discussions about the overall ecosystem of the village could then have focused on how the different sectors of the community (smaller ecosystems) relate to each other. Although discussions on the links among the different elements of the community's ecosystem flowed easily, it was more difficult to elicit students' ideas about how these might influence their health and daily life, as well as the health of other elements of the ecosystem. Other approaches to better facilitate group discussions or stimulate students' critical thinking should be explored. An entire virtual map posted with the student pictures is also a possibility.

As academic researchers, we are not always able to stay in communities for long periods of time. It was therefore important to organize the activity well before our visit, but also to be flexible, patient, and prepared to quickly adapt to the day-to-day reality of students, schools, and communities. For example, the outdoor temperature-frequently dropping to $-30^{\circ} \mathrm{C}$ during this time of year-was important to consider for the second activity.

The pictures for the first activity were selected to represent both past and present Inuit culture and lifestyle. Everyone sat in a circle on the floor, which is a familiar way of sharing in the Inuit culture. In the school in the first village, high school students (grade 9 to 11) were very enthusiastic, and quickly and spontaneously wove together the links among the different elements of the ecosystem. By contrast, high school students in the second school needed prompting to become engaged in the activity. These differences may be due to several sociocultural factors, such as the importance of the transmission of Inuit culture and traditional way of living to the youth (both in the schools and from the Elders), the dietary transition towards southern foods, and the social cohesion in the village. As part of the widespread effort to promote Inuit culture in Nunavik high schools, it would be interesting to hold this activity in collaboration with Inuit Elders to discuss traditional knowledge and intergenerational issues as they relate to living ecosystems and health.

We first designed this activity to promote exchange and knowledge sharing between researchers and high school students in two Nunavik villages. However, based on our experience, this activity could possibly be adapted for younger students or integrated into a science class curriculum or science fair. Regardless, this exercise proved to be a rich and enlightening researchercommunity experience. We strongly encourage masters' or doctoral students to integrate similar activities into their time spent as researchers in First Nations, Inuit and Métis communities. This will help them develop innovative ways of interacting with community members and translating scientific concepts into concrete examples that youth can understand, learn from, and potentially use in their own education. 

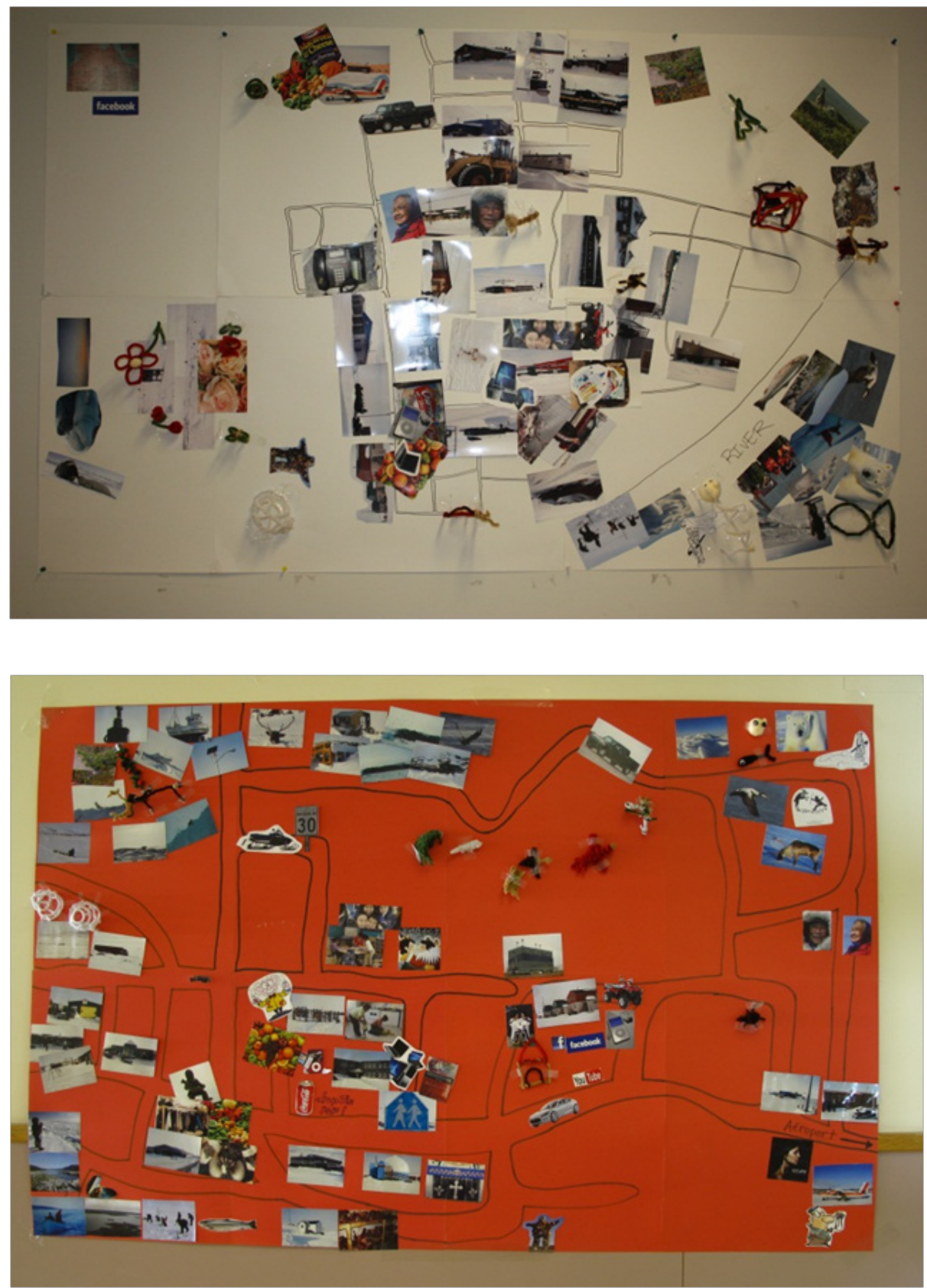

Figure 1. Examples of maps made by the students in Activity 3: Mapping the village ecosystem.

These maps were made by the students in the two villages where the activity took place. The maps show the villages-delimited by roads—with images (also used in Activity 1) and pictures (taken by the students during Activity 2) representing the surrounding natural environment (rivers, sea, land, etc.), built environment (local institutions, community facilities, place of worship, etc.), and living beings found in or near the communities. Craft supplies were used to create 3-D objects: igloos, houses, caribou, flowers in the cemetery, trees, and fish. Interestingly, there are no trees in the first map since the village is located above the tree line. 


\section{ACKNOWLEDGEMENTS}

We are grateful to all the students for their active involvement, and we also thank the teachers, school directors, and Let's Talk Science for their support and participation in the design of the activities. Additional environmental education activities may be realized in other villages over the coming months.

\section{APPENDIX}

Checklist of material:

- Yarn (three balls)

- Pictures or images representing items of the surrounding natural and built environments, dietary habits, Inuit arts and culture, and youth day-to-day life (according to the number of students)

- Transparent folders (according to the number of students)

- Digital cameras (according to number of groups)

- Photographic paper

- Photo printer and ink

- $\quad$ Large piece of paper, large map, or printed Google Map of the community

- Scissors

- Pens and markers

- $\quad$ Pipe cleaners

- Glue and tape

\section{REFERENCES}

Webb, J. C., Mergler, D., Parkes, M. W., Saint Charles, J., Spiegel, J., Waltner Toews, D., . . Woollard, R. F. (2010). Tools for thoughtful action: The role of ecosystem approaches to health in enhancing public health. Canadian Journal of Public Health, 101, 439-441.

\section{ENDNOTES}

i Pictures (available on request) were selected according to the number of students and the possibilities of interconnections. When possible, we used photographs of the villages where the activities were held. Subjects included: the natural environment (atmosphere, ice, river, tundra, caribou, seal, beluga, Arctic char, goose, ptarmigan, mussels, polar bear, children, Elders, dogs); built environment (house, school, health care centre, igloo, Ski-Doo, 4-wheeler, boat, pick-up truck, Air Inuit plane, dump [specifically, the metal section in the dump nicknamed Canadian Tire because people go there for metal parts and furniture]); dietary habits (berries, community freezer, soft drinks, plastic bottles, fruits, vegetables); and culture, arts, and other social elements (hunting, fishing, computer, iPods, Facebook icon, Elisapie Isaac CD, Lady Gaga CD, throat singers, carving, Inuksuk).

ii More information on ecosystem approaches to health, including an online teaching manual can be found at www.copeh-canada.org. Other relevant websites include the Niqiit online course on environmental contaminants in the Arctic (www.inuitknowledge.ca) and the following:

- www.ecokids.ca/pub/kids_home.cfm

- http://magma.nationalgeographic.com/ ngexplorer/0403/quickflicks

- http://forest.mtu.edu/kidscorner/ecosystems/ definition.html

- www.kidsgeo.com/index.php

- www.carc.org/index.php?option=com_content\&vie $\mathrm{w}=$ article $\& i d=109 \&$ Itemid $=171$ 


\section{रc

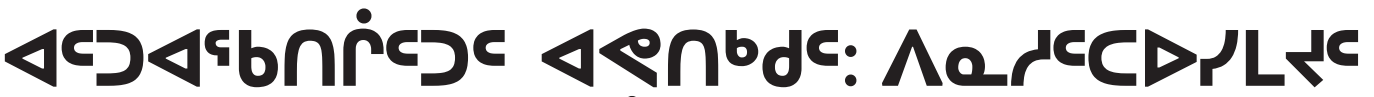

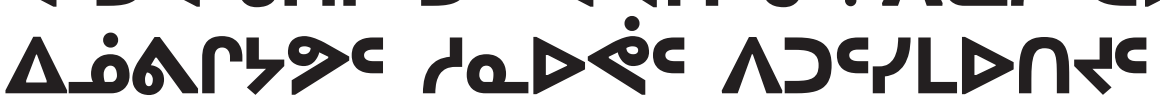

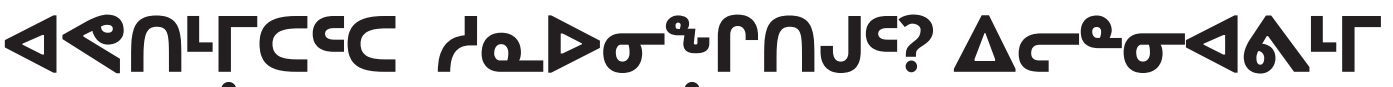

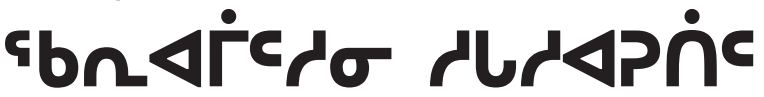 \\ Our Living Ecosystem: What are the Interconnections among the Elements Surrounding Us? A Classroom- based Activity in Nunavik}

$\Gamma c \sigma \quad \subset \Gamma D^{\natural}$, Mélanie Lemire, PhD, CIHR-Banting postdoctoral fellow, Dépt Médecine sociale et préventive, Université Laval, Axe Santé des populations et pratiques optimales en santé, Centre de recherche du CHU de Québec, Québec, Québec, Canada

$L c^{\circ} \Omega<$, Mylène Riva, PhD, Assistant Professor, Dépt Médecine sociale et préventive, Université Laval, Axe Santé des populations et pratiques optimales en santé, Centre de recherche du CHU de Québec, Québec, Québec, Canada

\lrcorner$_{\Omega} \triangleleft \quad 9-b r \cap \triangleleft^{c}$, Maria Ruiz-Castell, PhD, Santé-Cap postdoctoral fellow, Dépt Médecine sociale et préventive, Université Laval, Axe Santé des populations et pratiques optimales en santé, Centre de recherche du CHU de Québec, Québec, Québec, Canada

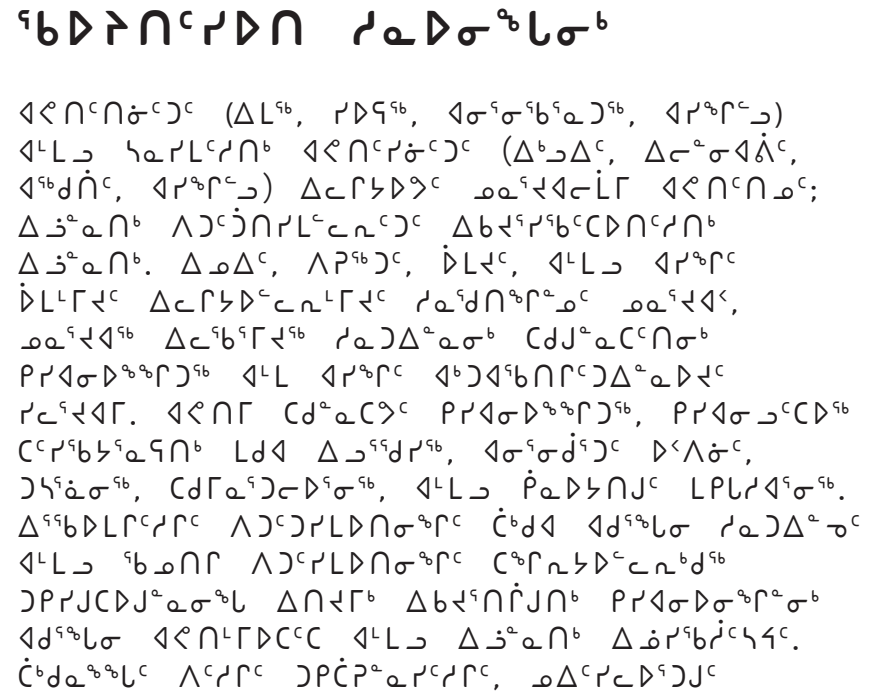

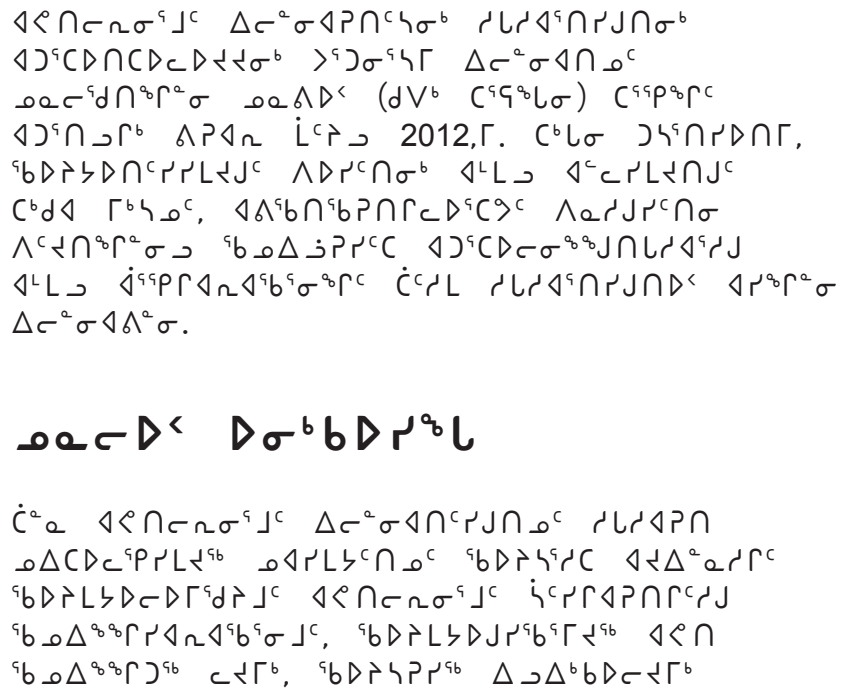




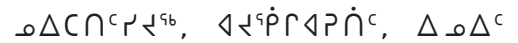

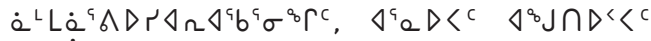

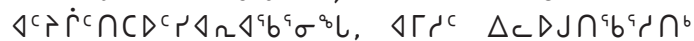

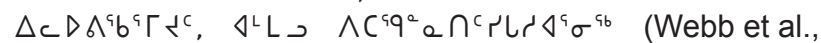

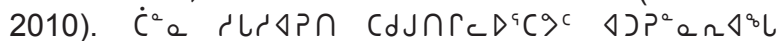

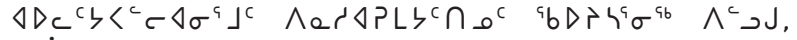
Dد

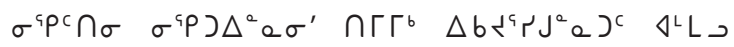

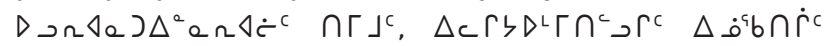

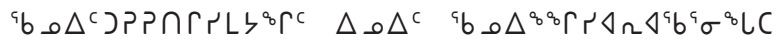
กГГ⿰丿⿱丄𠃍,

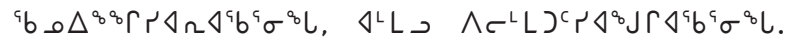

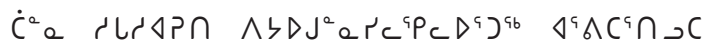

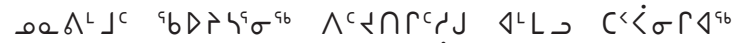

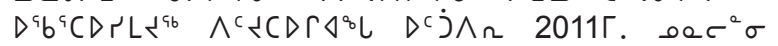

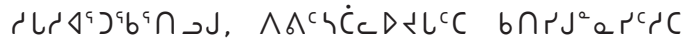

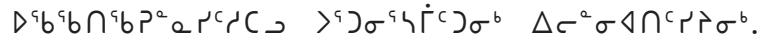

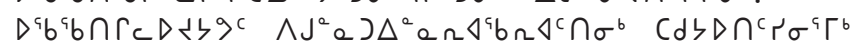

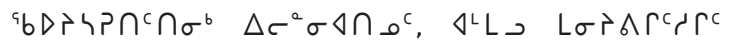

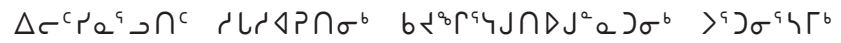
$\left.\Delta c^{a} \sigma \Delta \cap \sigma^{b} \quad\left(>^{a} J \sigma c^{a} \sigma^{b} \quad 9 \Gamma^{c} \quad 11\right\lrcorner^{c}\right) \Delta c^{c} r c \Delta \Gamma^{a} d^{c} \Gamma^{c}$

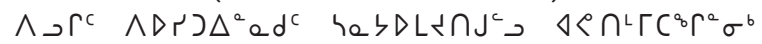

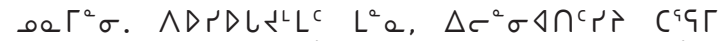

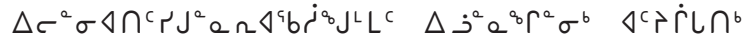

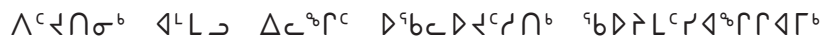

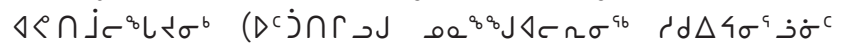

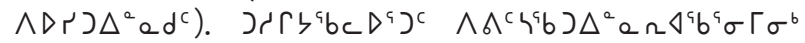

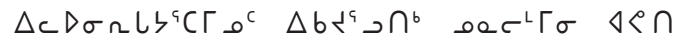

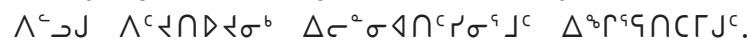

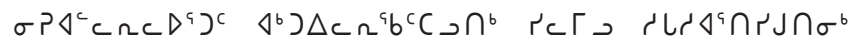

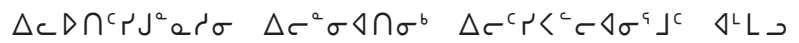

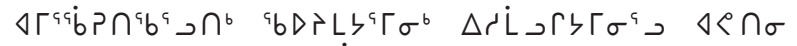

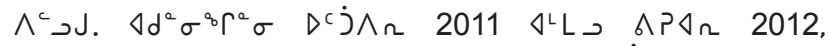

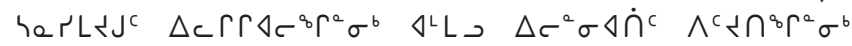

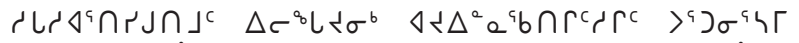

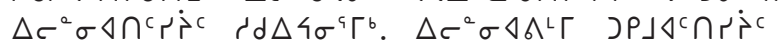

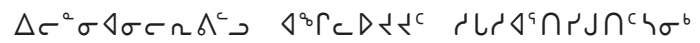

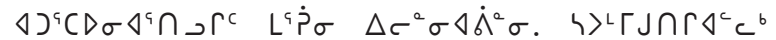

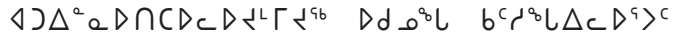

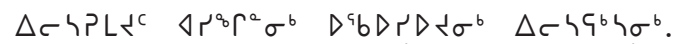

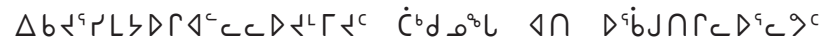
¿d $\Delta 4 \sigma^{\text {qb }}$ Let's Talk Science (www.letstalkscience.org),

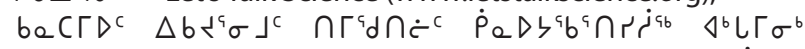

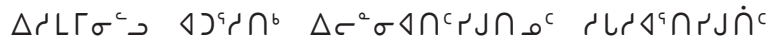

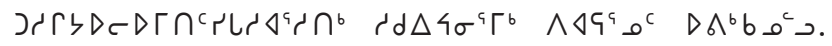

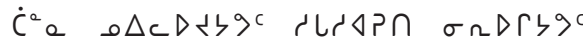

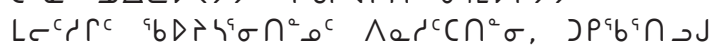

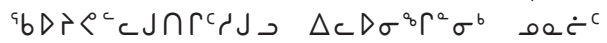

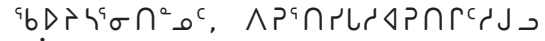

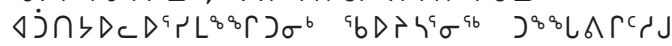

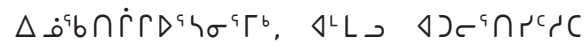

$\Lambda x_{c} r L D \cap^{a} b \cap_{a}^{a} b^{a} \sigma \Gamma^{b} \quad \Delta c D J \cap \dot{C} \cap D_{a} J \sigma^{b}$.

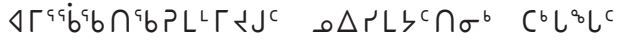

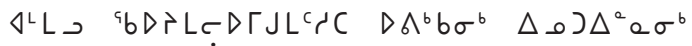

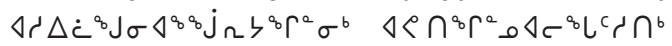

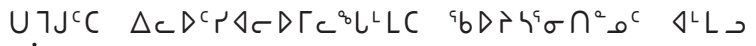

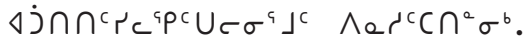

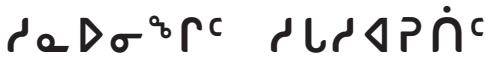

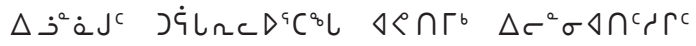

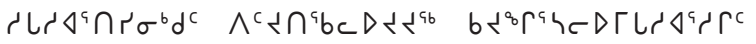

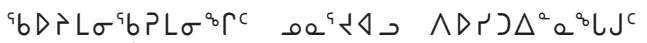

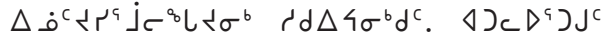

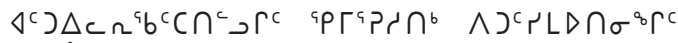

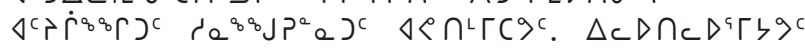

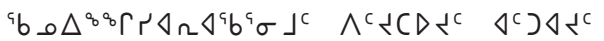

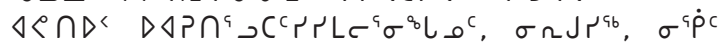

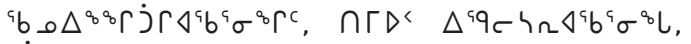

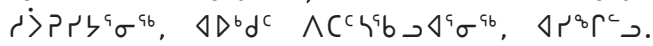

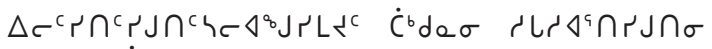
$A T$ T)

1.

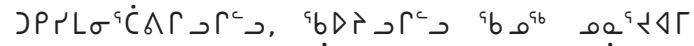

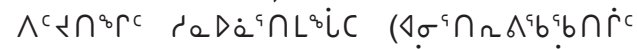

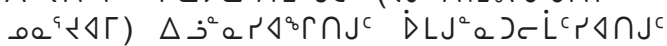

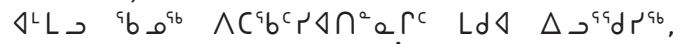

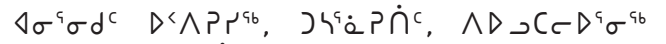

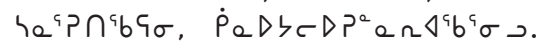

2.

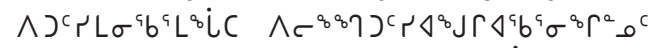

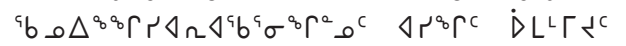

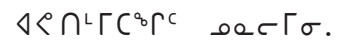

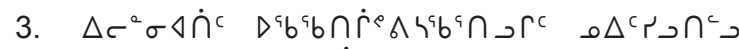

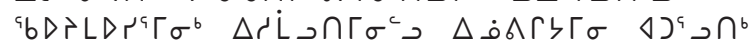

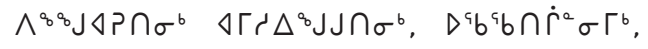

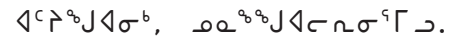

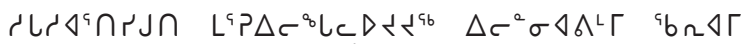

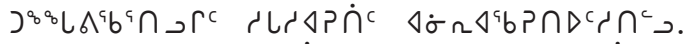

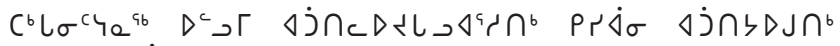

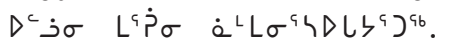




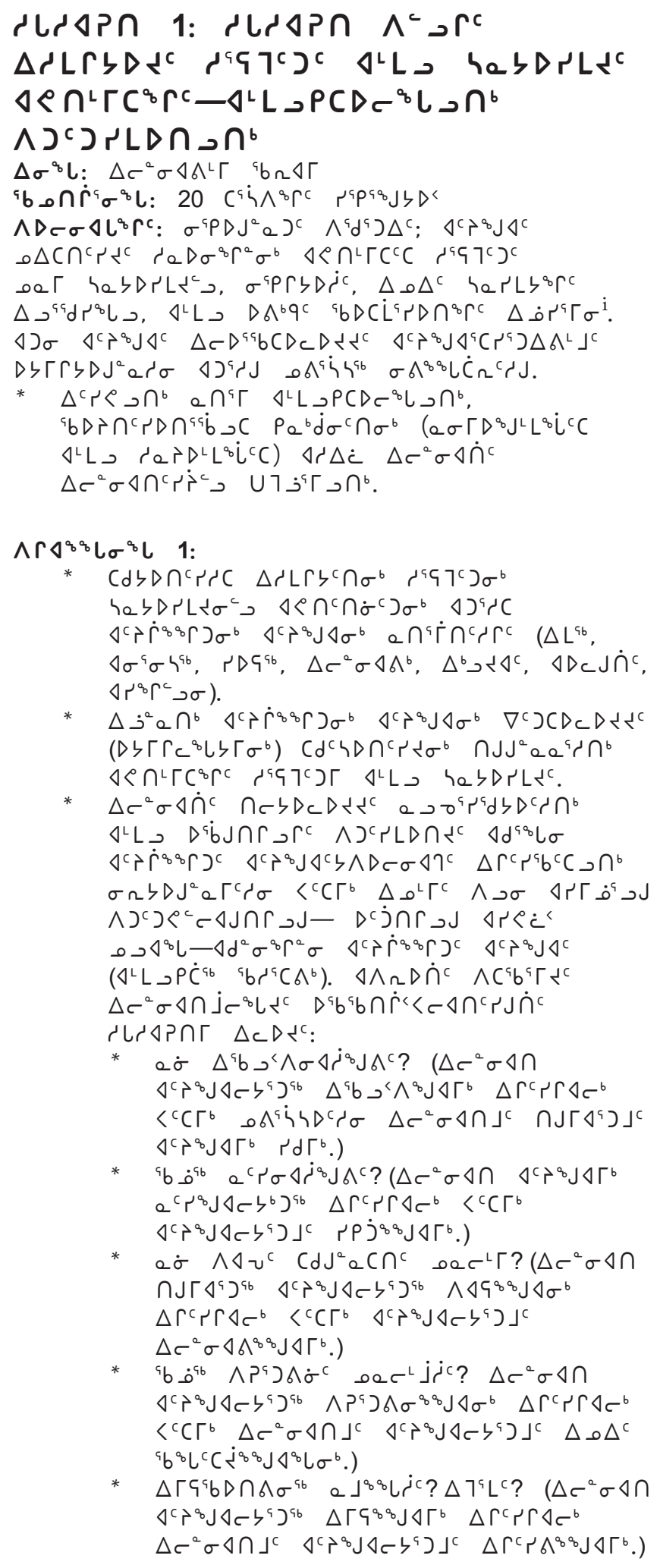

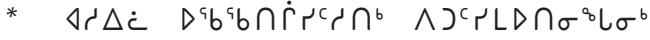

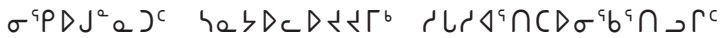

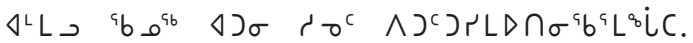

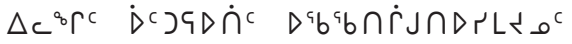

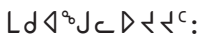

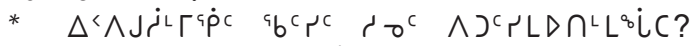

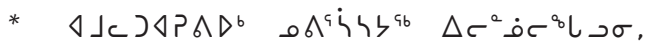
Cd $\dot{\Delta}^{c}$ bo

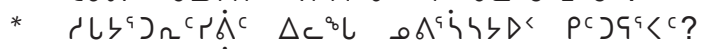

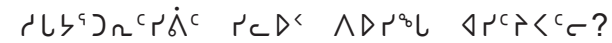

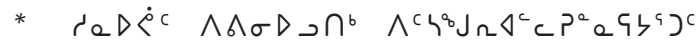

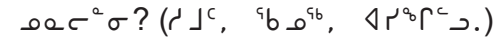

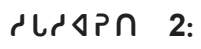

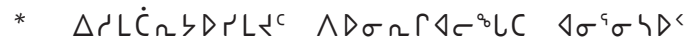

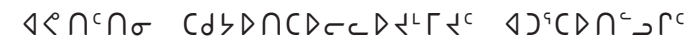

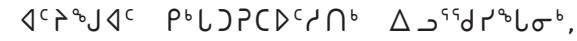
उ५दc

כ

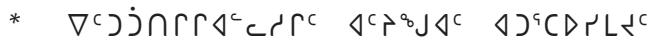

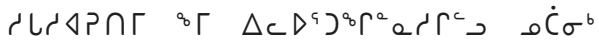

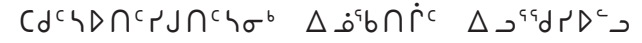
¿aD $\sigma^{\mathrm{b}} \Gamma^{a} \sigma^{b}$.

* $\left.\quad \Delta c^{a} \sigma \Delta \dot{\Pi}^{c} \Delta^{c} \Delta^{c} r \Gamma \Delta^{c} c\right)^{c} \Delta^{L} L$

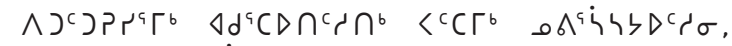

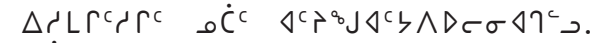

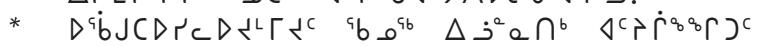
$\wedge D \subset \sigma \Delta]^{C} \quad \triangleleft^{L} L \perp P C D \subset^{8} L \sigma^{4} \Gamma \quad \triangle C \Gamma L D^{C} C \Omega^{L} L C$

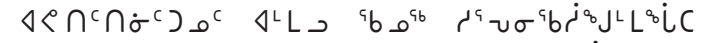

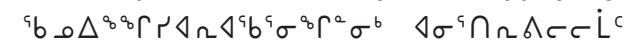
$\triangleleft^{L} L \_P C D \subset^{\circ} L \Lambda^{L} \Gamma$.

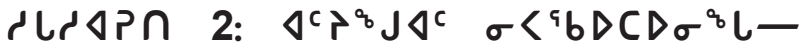 $\triangle_{c} r^{a} J \Delta_{c}^{c}$ oac}

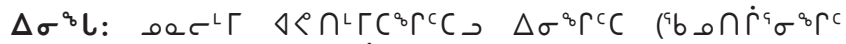

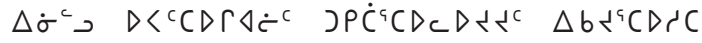
$\left.\triangle c^{a} \sigma \Delta \cap c 4 r^{c} \rho_{c}\right)$

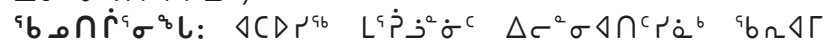

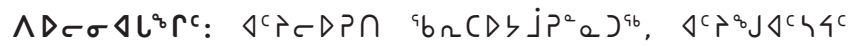

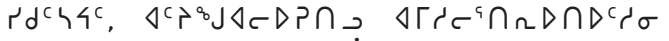

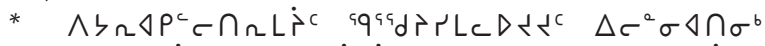

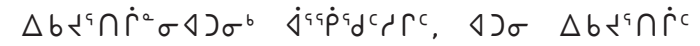

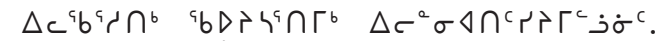

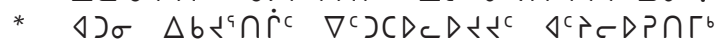

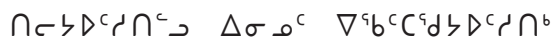

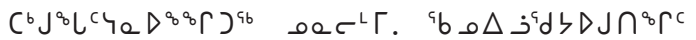

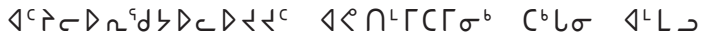

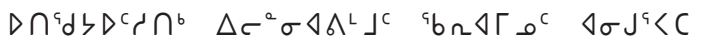

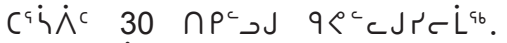

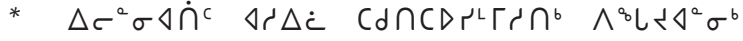

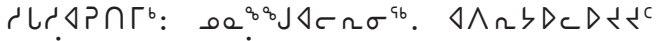

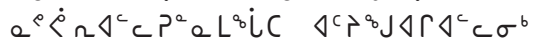




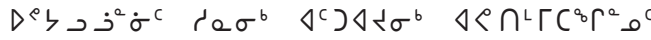

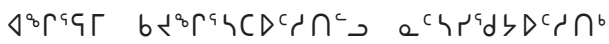
مـ a $\triangle c^{\circ} \iota<\sigma^{b}$

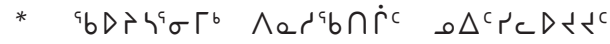

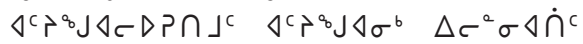

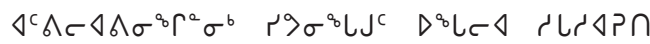
$\wedge \Gamma \triangleleft^{a} C D^{b} \Gamma^{a} \sigma^{i} L \sigma$.

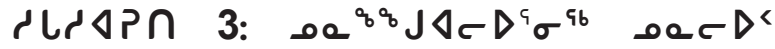 $\triangle<\cap \Gamma D C^{a} \Gamma^{a} \sigma^{b}$}

$\Delta \sigma^{a} \mathrm{~L}: \Delta c^{a} \sigma \Delta \Delta^{L} \Gamma$ ib $\Omega \Delta \Gamma$

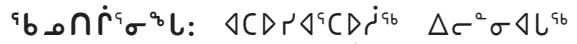

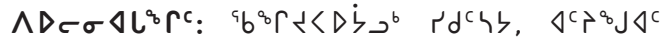

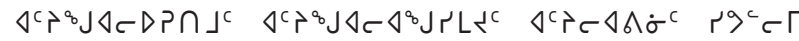

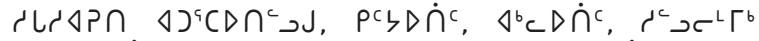

h $د^{L} L \zeta J \cap \dot{U} U, \triangleleft^{b} c D \cap \Delta \Delta^{c} \Delta^{c} \Delta L \dot{c}^{c}, \sigma \wedge \cap P \dot{\Pi}^{c}, \Delta^{L} L$

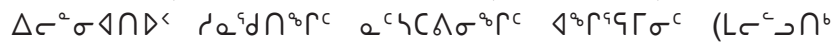

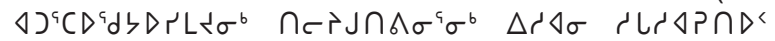
$2 \dot{\Gamma}(\dot{j})$.

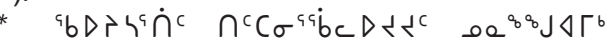

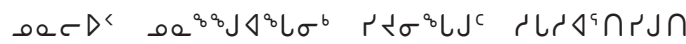
$\wedge \Gamma \triangleleft^{4} C D_{C} D^{\mathrm{a}} \mathrm{MeJ}_{\mathrm{a}} \mathrm{J}$.

* $\Delta c^{\alpha} \sigma \Delta \Delta^{L} \Gamma \quad{ }^{q} b \Omega \Delta \Gamma, \Delta c^{a} \sigma \Delta \dot{\Pi}^{c}$

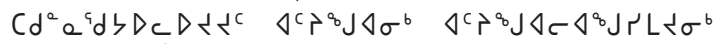

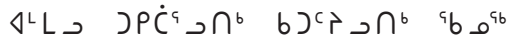
$\triangle \sigma^{c} \supset J L^{L} L^{b} \dot{L}^{a} \Gamma^{b}$ sac $D^{<} \quad \triangle<\cap \Gamma D C^{b} \Gamma^{a} \sigma^{b}$.

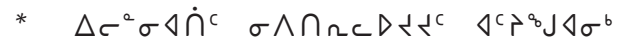

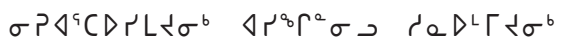

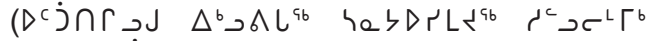
ــ $\left.\Delta c \vec{r}^{8} J \Delta^{a b} 1\right)$

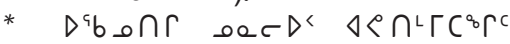

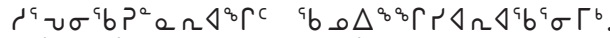

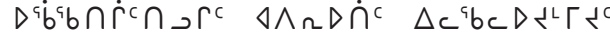
$\Delta d \sigma^{\circ} \mathrm{L}$ :

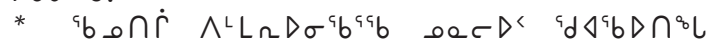

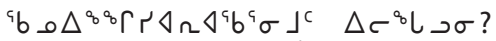

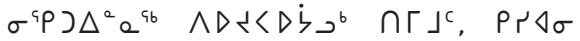

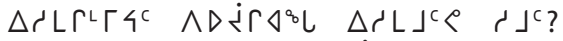

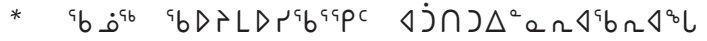

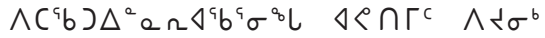
$\left.\triangle \triangle P \cap^{a}\right\lrcorner \sigma^{b} \Delta c^{b} \Gamma^{a} \sigma \quad \sigma^{a} P J \Delta^{a} a \sigma$ ?

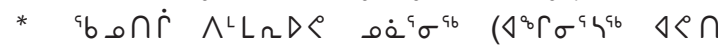
ـa

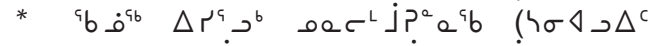

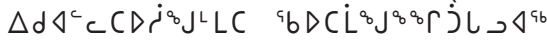

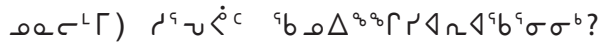

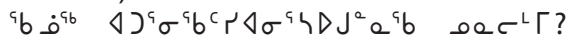

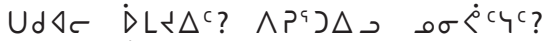

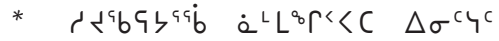

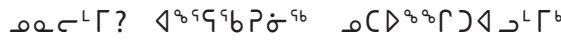

$\left.\Delta^{b} \rightarrow\right)^{a} b \sim^{L} \Gamma^{b} \quad r^{a} d^{c} \cap \sigma^{a} \Gamma^{b} \quad 4^{a} \uparrow C D L^{a q} b$

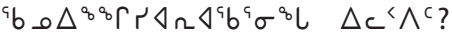

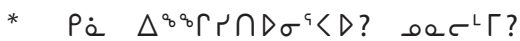

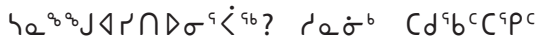

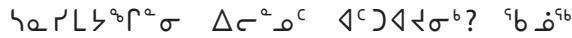
$\Delta c^{a} \sigma^{b} \quad \Delta^{<} \wedge \sigma \Delta^{a} \cap r^{c}$ ?

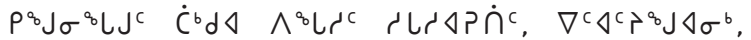

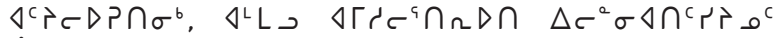

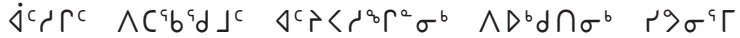

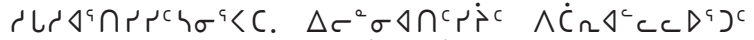

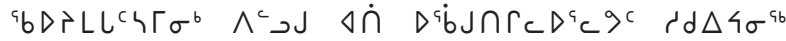

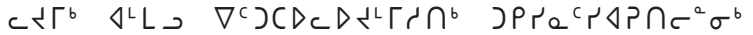

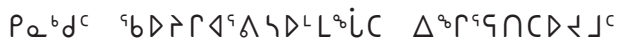

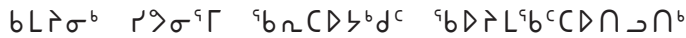
a

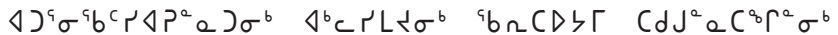

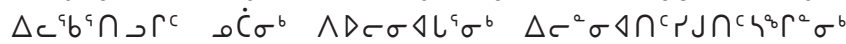
$d d \Delta 4 \sigma^{a} \Gamma^{b}>^{a} J \sigma^{a} 4 \dot{\Gamma}^{c} J \sigma^{b} \Delta \sigma^{a} \sigma \Delta \cap \sigma^{b}$. $\dot{C}^{b} d \triangleleft \quad{ }^{a} b \Omega C D \zeta \Gamma$

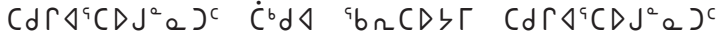

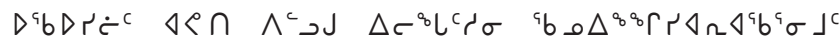

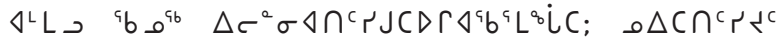

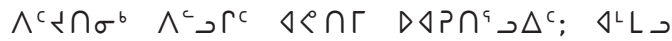

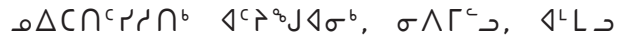

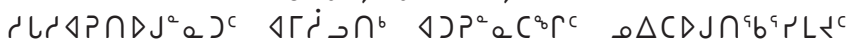
$\triangle r^{\circ} \Gamma^{a} \sigma^{b} \Lambda_{a} \lambda^{c} C D \Gamma \downarrow \sigma^{b}$.

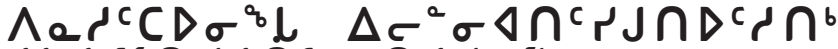

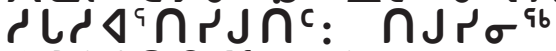 $\wedge D^{b} d \cap \Gamma \Delta^{c} c \sigma^{b}$}

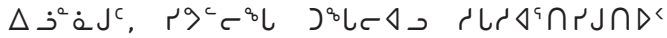

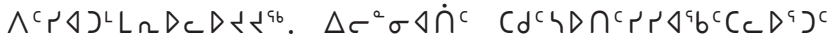

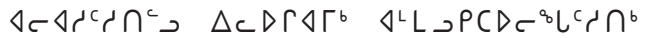

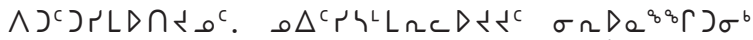

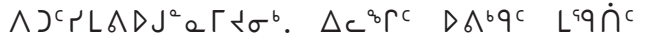

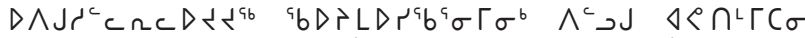

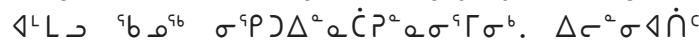

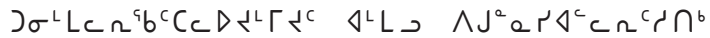

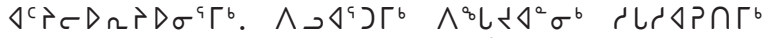
(Cd J J

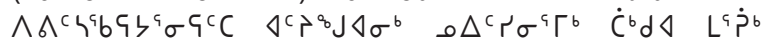

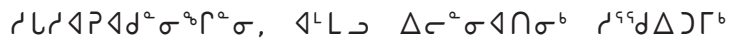

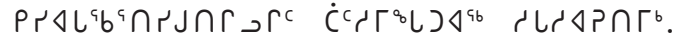

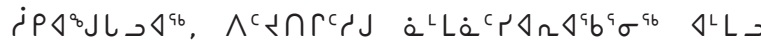

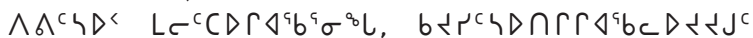

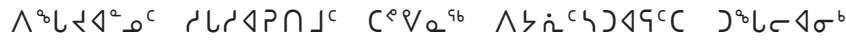

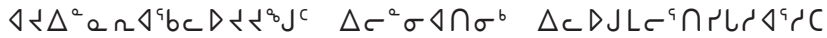

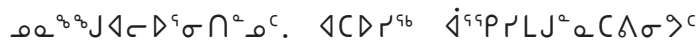
مـ حـ C

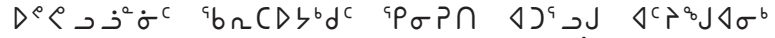
מa

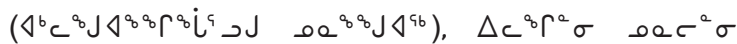




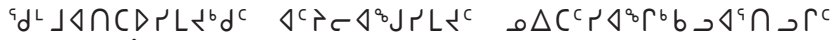
مCDib

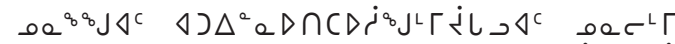
b $<L^{b} d \sigma \dot{j}^{a} \dot{\sigma}^{c} \Lambda^{c} \downarrow \lambda \Lambda^{a} \sigma$. $0 a^{8 b} J \Delta^{a b} \quad \dot{C}^{a} a, j \sigma^{a}\langle D<c$

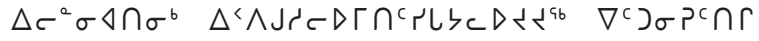

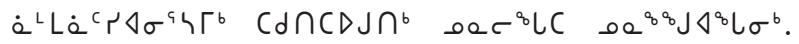

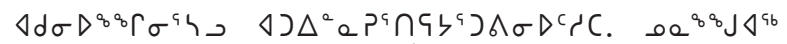

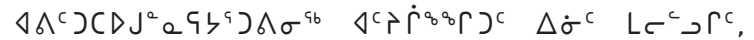

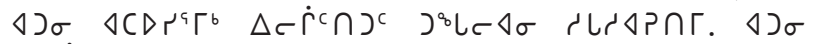

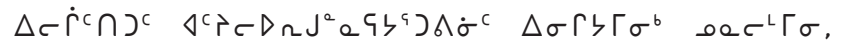

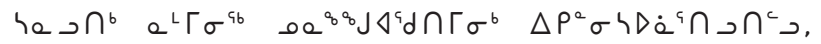

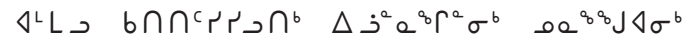

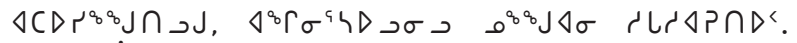

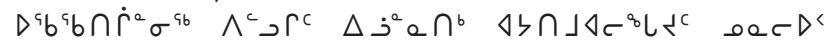

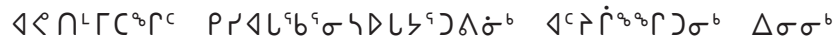

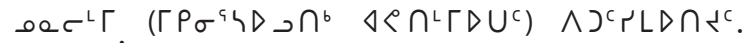

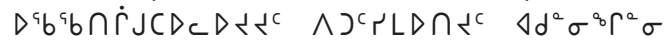

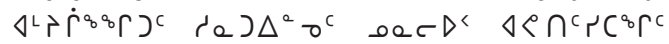

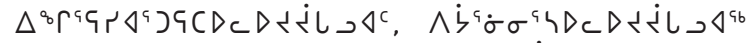

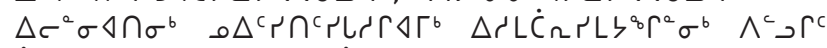

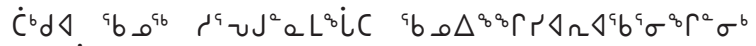

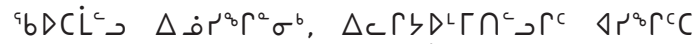

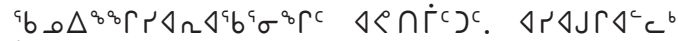

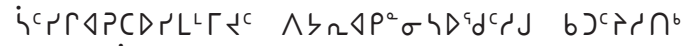

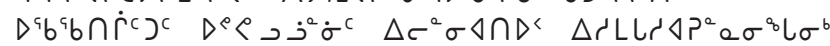

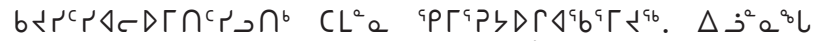

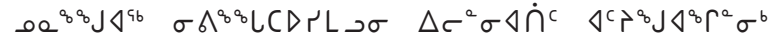

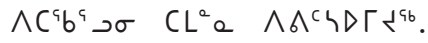

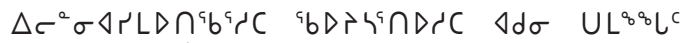

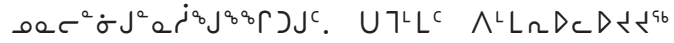
$\triangle \supset \triangle^{a} a b_{a} \cap C \Delta \Gamma^{b}$ ا

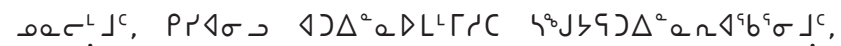

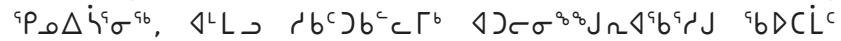

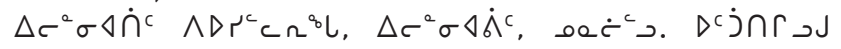

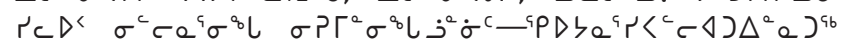

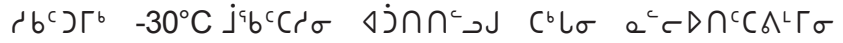

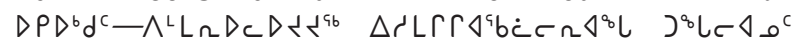
‘し $\triangleleft P \cap J^{c}$.

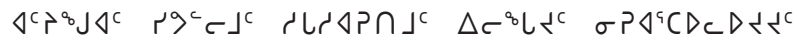

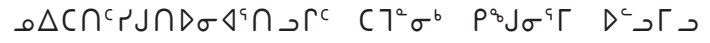

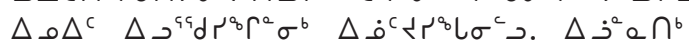

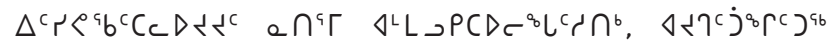

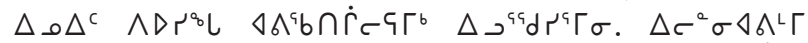

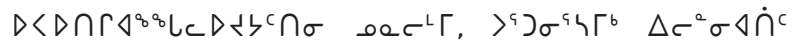

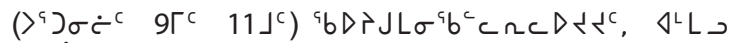

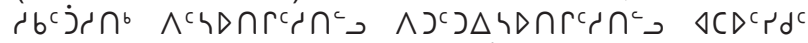

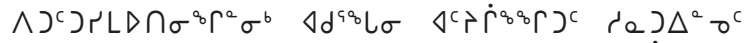

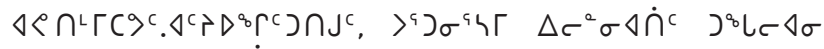

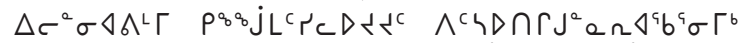

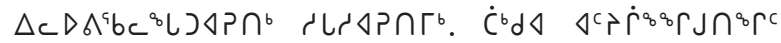

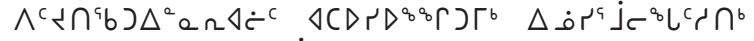

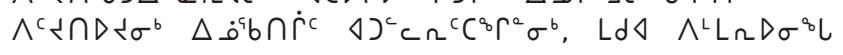

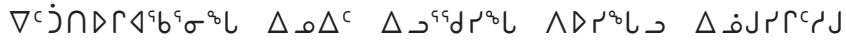

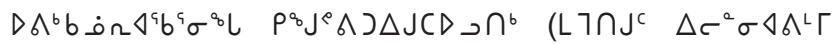

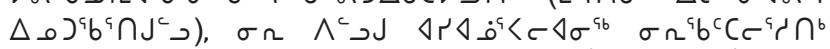

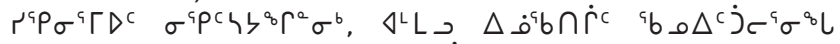

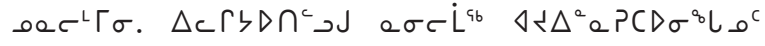

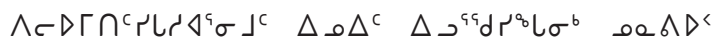

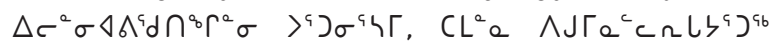

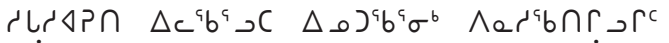

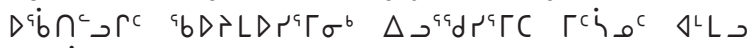

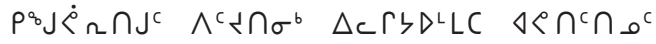
أ $b$ ـ مـ مـ

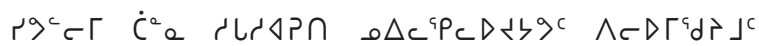
$C D^{4} r^{3} b^{c} C D \cap \sigma^{a} \Gamma^{b}{ }^{a} b D \Gamma L D r^{4} \Gamma^{b} \quad \Delta d^{a b} L_{\sigma}{ }^{a} b D+L^{4} \dot{\Pi}^{c}$

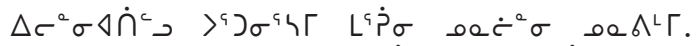
१ـ

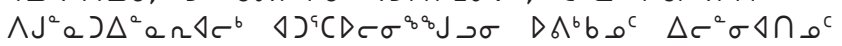
$\triangle J c^{a} \cap C D \sim \sigma \dot{\partial}^{a} \dot{\sigma}^{c} \quad d d \Delta 4 \sigma^{a} \Gamma^{b} \quad \Delta c^{a} \sigma \Delta \cap^{c} r \Delta^{L} \Gamma$

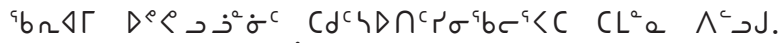

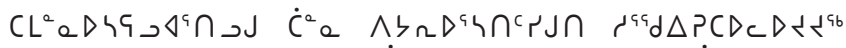

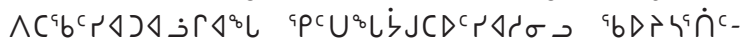
مo

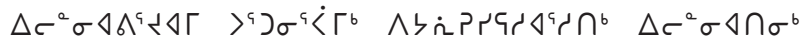

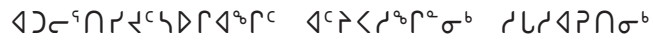

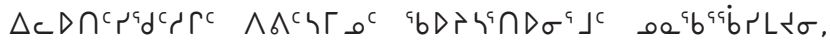

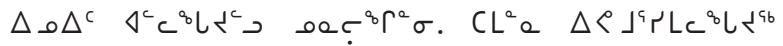

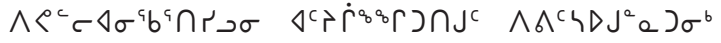

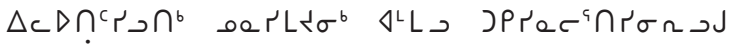

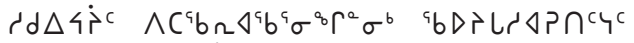

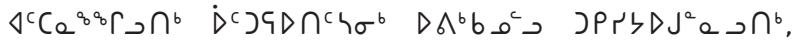

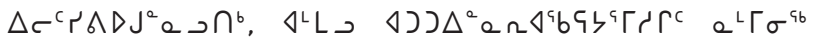
$\Delta c^{a} \sigma \Delta C \Gamma \rho^{c}$. 

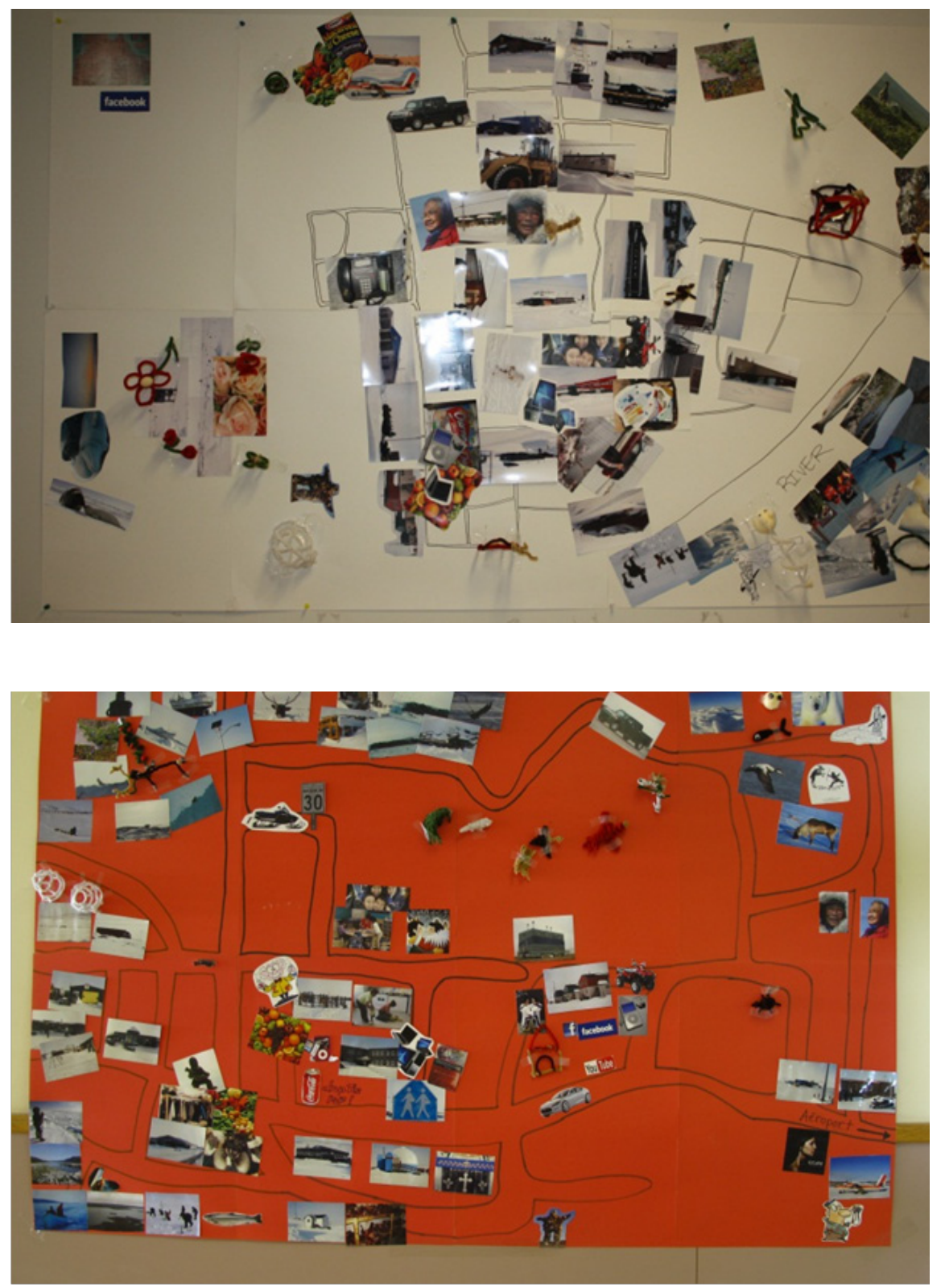

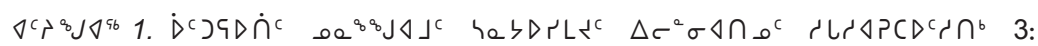

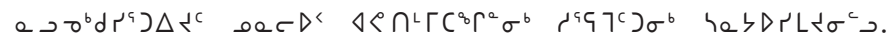

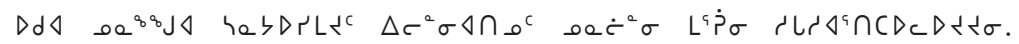

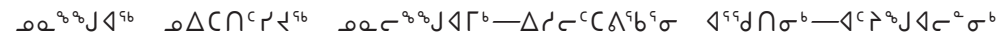

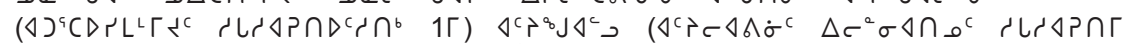

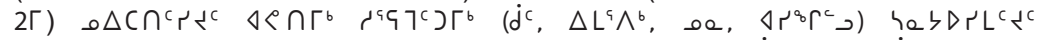

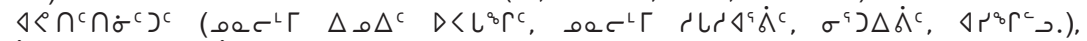

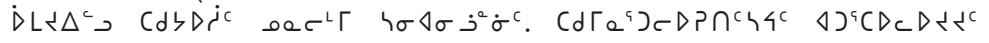

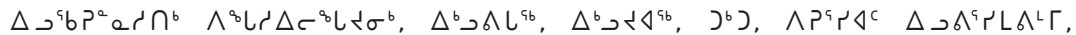

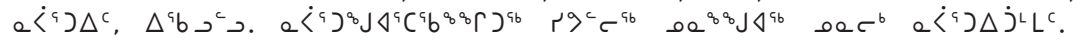




\section{${ }^{q} b D+P^{c} c J \cap^{q} b^{q} \dot{\sigma}^{c}$}

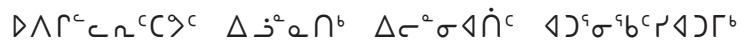

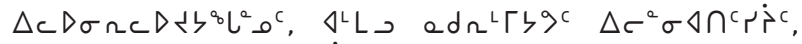

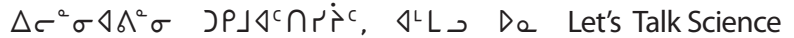

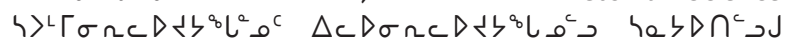

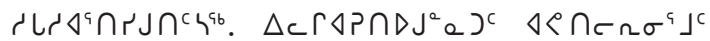

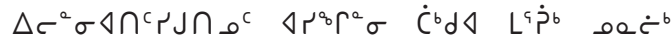

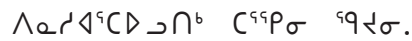

\section{$\Delta \subset \Gamma \triangleleft P \cap$}

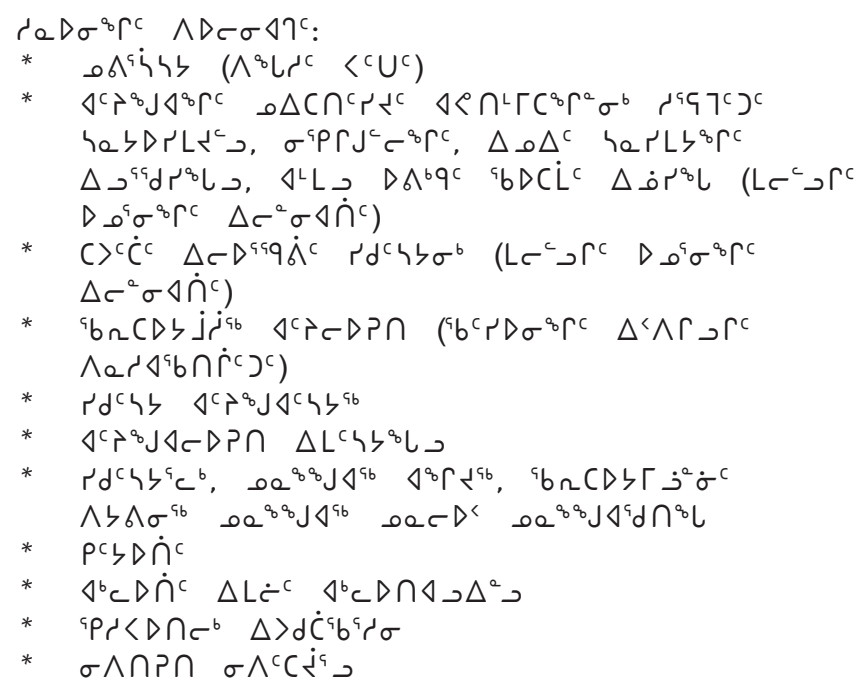

\section{${ }^{q} b D+r \Delta^{q} \triangle D J a J^{c}$}

Webb, J. C., Mergler, D., Parkes, M. W., Saint Charles, J., Spiegel, J., Waltner Toews, D., ... Woollard, R. F. (2010). Tools for thoughtful action: The role of ecosystem approaches to health in enhancing public health. Canadian Journal of Public Health, 101, 439-441.

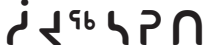

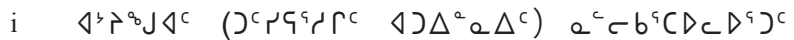

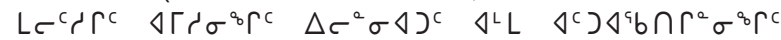
$\left.\left.\Delta c^{a} \sigma \Delta C^{8} \Gamma C . \quad \Delta \Delta^{4} a^{b} \Gamma\right) \Delta^{a} L^{c}, \Delta J^{a} b^{c} C c D^{a}\right) J^{c}$

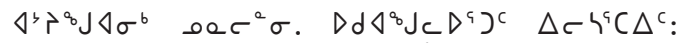
$\Delta<\cap^{b}(\Delta<\cap) \Delta^{a} a^{a b}, \quad r d, d^{c}$, o e, $\left.x^{c}\right) \Delta^{c}, e^{c} r^{c}$,

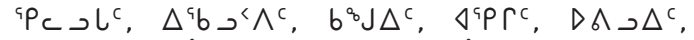

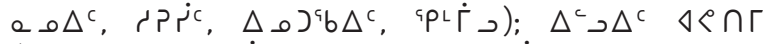

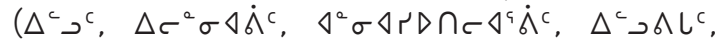

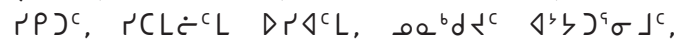

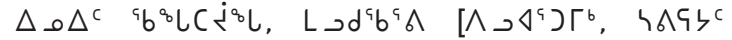

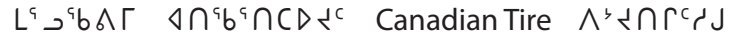

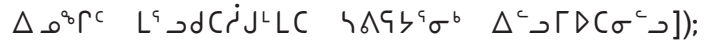
$\sigma \cap J r^{b} \Gamma^{c}\left(\left\langle D^{c} b \Delta^{c},{ }^{c} d \Delta^{b} d \Delta^{c}, \Delta \Gamma L^{c} \cap \cap^{c} \cap\right)^{c}\right.$,

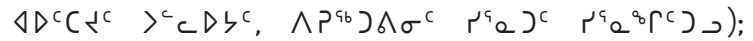

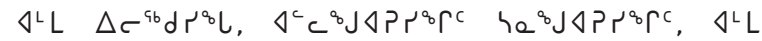

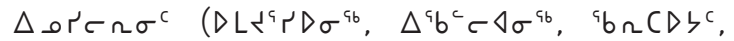
iPods, Facebook, $\Delta \subset\left\langle\wedge \Delta \Delta \zeta D^{<} \sigma \Lambda^{\mathrm{b}} \mathrm{L}, c \Delta \cap\right.$ $b b D^{<}$, Lady Gaga $\sigma \Lambda^{\circ} b, b C^{b} \zeta \cap^{c}$, he $D L \Delta^{c}$, $\left.\Delta 0^{\mathrm{b}} \mathrm{r}^{\mathrm{b}}\right)$.

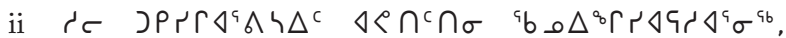

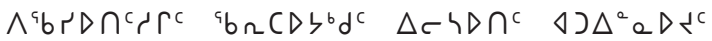

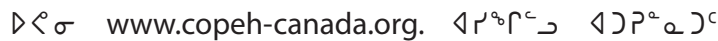
${ }^{a} b \Omega C D \zeta^{b} d^{c} \lambda^{c} \supset \sigma \dot{\Lambda}^{c}$, Niqiit online $\triangleleft \Delta^{a} a D \Delta^{c}$ $\triangle<\cap^{c} \cap \sigma \quad \triangleleft P \triangle^{c} \quad D P D^{a}() \Gamma \quad D<\sigma$ (www.inuitknowledge.ca) $\triangleleft^{L} L \quad \triangleright d \triangleleft \quad \dot{\zeta}^{L} \dot{\cap}^{c}$ :

- $\quad$ www.ecokids.ca/pub/kids_home.cfm

- http://magma.nationalgeographic.com/ ngexplorer/0403/quickflicks

- http://forest.mtu.edu/kidscorner/ecosystems/ definition.html

- www.kidsgeo.com/index.php

- $\quad$ www.carc.org/index.php?option=com_content\& view $=$ article\&id $=109 \&$ Itemid $=171$ 


\title{
Culturally Appropriate Care-
}

\section{A Multicultural Task: Assessing the Needs of Inuit Youth in the Care of Child Welfare Services}

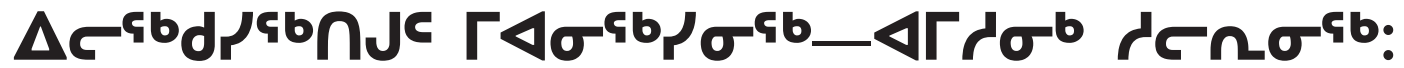 दिГकР

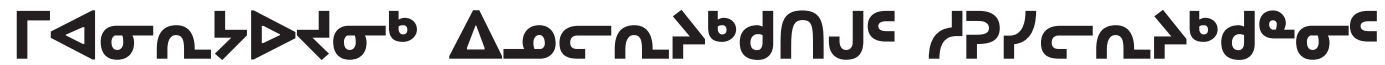

Sarah L. Fraser, OPQ, PhD, Associate Professor, École de Psychoéducation, University of Montréal, Montréal, Québec, Canada

Cécile Rousseau, MD, Professor, Department of Psychiatry, McGill University, Montreal, Quebec; and Scientific Director, CSSS-CAU de la Montagne, Montréal, Québec, Canada

Rebecca Kasudluak, Cultural Consultant, Montréal, Québec, Canada

Pamela Burmester, MBA, PsyD, University of Sherbrooke, Sherbrooke, Québec, Canada

Maria José Arauz, MPH, University of Montréal, Montréal, Québec; and Research Professional, Transcultural Research and Intervention Team, CSSS de la Montagne, Montréal, Québec, Canada

\begin{abstract}
Over $30 \%$ of children in Nunavik have been reported to child welfare services by professionals, community workers, and/or community members due to possible need of protection, according to a recent report that identified important gaps in the system of care for Inuit youth in Nunavik (Sirois \& Montminy, 2010). The objective of this qualitative study was to assess the perspectives of various actors regarding the needs of Inuit youth living in a residential facility in Montreal. Our methods included non-participant observation; semi-structured interviews with youth, residential staff, therapists, and a culture broker; and video production with youth. Adopting a systemic approach, we discuss how the various perspectives converge and diverge and the place that is given to culture in the discourses. We conclude that developing culturally appropriate care for Inuit youth in the care of child welfare is a multicultural task, as it involves multiple groups of individuals influenced by their professional and personal cultures. We suggest the merging of perspectives as a potential for creating innovative practices that are culturally sensitive.
\end{abstract}




\section{KEYWORDS}

Inuit well-being, youth, child welfare, cultural competence, needs assessment

\section{DCכ९Dก}

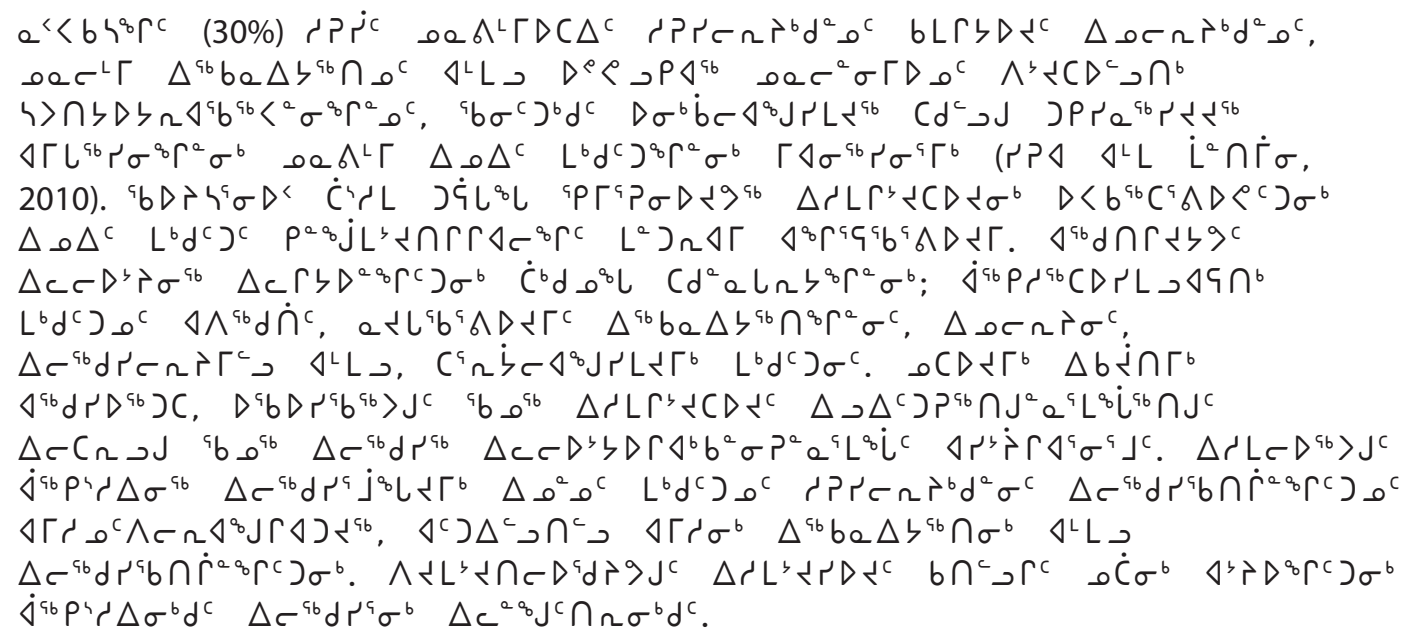

\section{$D^{9} b D r^{9 b} C^{c}$}

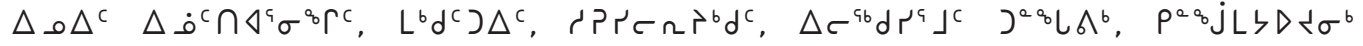
${ }^{\mathrm{p}} \mathrm{\rho} \Gamma^{\mathrm{q}} \mathrm{P} \sigma^{\mathrm{q} b}$

\section{INTRODUCTION}

$\mathrm{O}$ ver $30 \%$ of children in Nunavik have been reported to child welfare agencies. Professionals, community workers, and/or community members have identified these children as needing assessment to determine whether their safety or development is being compromised (Sirois \& Montminy, 2010). The number of reports kept for evaluation by the Nunavik child welfare system doubled between 2006 and 2010 (Sirois \& Montminy, 2010). Because of housing shortages and lack of specialized resources, the Nunavik Regional Board of Health and Social Services requested funds from the Quebec Ministry of Health and Social Services to open a residential program in Montreal for Inuit youth 12-18 years of age. The goal was to develop a culturally and clinically adapted program that would eventually be reintegrated within Nunavik.

Out-of-community placement is common among Aboriginal youth across Canada, including Inuit youth from northern Canada. Out-of-home placements have been criticized for being a colonialist approach with potential long-term and devastating consequences on communities and cultures (Blackstock \& Trocmé, 2005; Carriere \& Richardson, 2009; Cross, Earle, Echo-Hawk Solie, \& Manness, 2000; Lafrance \& Bastien, 2007; Libesman, 2004). Some have compared the current welfare system to the residential school system of the 20th century, an experience that has left marks on generations of Aboriginal families-including Inuit families - partly by breaking the intergenerational transmission of parenting skills and culture (Bennett \& Blackstock, 2002). The question therefore becomes how to develop services that are both culturally safe and clinically appropriate for high-risk Inuit youth in order to maximize individual and collective well-being in a setting where non-Inuit individuals and organizations can offer both the infrastructure and human resources required for such programs. Former Auditor General Sheila Fraser highlights the lack of culturally adapted services for Aboriginal youth in Canada (Office of the Auditor General of Canada, 2011). A priority recommendation is to determine the needs of First Nations, Métis, and Inuit youth and define culturally appropriate care. 
This study aimed to assess the needs of Inuit youth living in an out-of-community residential facility, by adopting a systemic and cultural perspective in both the data collection and analysis. The needs analysis focused on the similarities and differences in the perceptions of various actors-educators, therapists, cultural broker (an Inuit educator), and youth-as well as on the place given to culture in their discussions. The project is meant to guide stakeholders directly or indirectly impacted by child welfare agency practices to help determine how best to address the needs of at-risk youth in Nunavik.

\section{METHODS}

\section{Residence}

Due to a lack of foster homes and specialized social and health services in the northern region of Quebec, child welfare services in Nunavik have struggled to offer stable placements to high-risk youth. Youth may be transitioned to out-of-community placements when in-community placement is not possible.

In 2010, a residence was developed with the goal of offering clinically relevant and culturally appropriate care to Inuit youth presenting high-risk behaviours, including alcohol and drug use, suicidal thoughts or attempts, and delinquency. The program was created in an urban area due to the lack of infrastructure and human resources in the more rural northern region of Quebec. The program was meant as a pilot project that would be transferred to the north once a suitable building was constructed.

The residence was developed specifically for adolescents aged 12 to 18 . Although a few placements were done on a voluntary basis, most were court-ordered (for more information, see Fraser, Vachon, Arauz, Rousseau, \& Kirmayer, 2012). Parents and family members were involved in decision-making and interactions with the residence to varying degrees, depending on the reasons for the placements.

The rehabilitative residential program was developed by non-Inuit individuals. In the initial months of the program, an Inuit Elder and an Inuit educator were invited to give feedback on program development and implementation. During the first nine months of the program, the Elder participated in activities on the boys' unit and offered weekly sessions of storytelling and discussing the Inuit way of life. The Inuit educator worked mainly on the girls' unit, offering sewing classes, a "girls' talk" activity with discussions about the experience of being an Inuit girl/woman, and traditional cooking. The educator also helped staff with translation, and youths often asked for one-on-one time with her. All other educators were non-Inuit. Educators were responsible for most of the youths' care throughout their stay, facilitating activities and accompanying them throughout the day.

The program directors adopted the Circle of Courage as the guiding philosophy for the residence (Brendtro, Brokenleg, \& Van Bockern, 1990). The authors of this philosophy describe it as a "model of youth empowerment supported by contemporary research, the heritage of early youth work pioneers and Native philosophies of child care" (Reclaiming Youth International, n.d.). It is meant to foster four core values: courage, mastery, independence, and generosity. This model was chosen by the program directors for two main reasons: 1) it incorporates elements of Aboriginal cultures, and 2) it was being piloted in other child welfare programs in the region. The residence was hosted and supported by a psychoeducational organization. In Quebec, psychoeducation is a profession and an approach that views difficult behaviours as a contextual experience. Rehabilitative services focus on helping youth in daily life routines and activities through shared experiences. The psychoeducational model encourages the use of highly structured schedules with a variety of school, clinical, cultural, leisure, and routine activities including wake-up time, meals, and getting ready for bed (Gendreau, 2001; Renou, 2005). Youth must take part in all planned activities and must abide by the residence's rules, with disciplinary measures taken when necessary.

\section{Procedure}

The primary author of this paper was hired as a research consultant to design and supervise a program quality assessment. The methods were developed and discussed with the three partners involved: the residential managers, the agency involved in program development, and the regional health administrators. The administrators made final decisions regarding the methods used. Qualitative interviewing methods were chosen to obtain in-depth information on multiple issues and to allow for flexibility of the themes discussed as a function of the interviewees' perceptions. Another benefit was that methods appealed more to the youths in residence who were uncomfortable with questionnaires that they often felt were tedious and difficult to understand.

The primary author and two assistants took part in ethnographic observations between January 2010 and August 2011. Data collection and interviews took place between May 2010 and August 2011. The primary author and her team analyzed data for internal quality assurance purposes. They presented results to the program directors, the interviewees, the regional health administrators, and the Regional Partnership Committee (comprised of Inuit representatives from Nunavik institutions and organizations).

The regional health board and the Research Ethics Committee at the Jewish General Hospital, Montreal, Quebec, gave approval to further analyze and publish the results of the study. Consent was obtained from the regional health board and the residential program. It was not possible to obtain consent retroactively from youths and for this reason no direct quotations from youths are cited in this paper.

\section{Data}

Professionals' perceptions of youths' needs: Semi-structured interviews were conducted with a) six educators; b) two therapists, 
specifically an art therapist and a psychologist; and c) the Inuit educator/cultural broker who facilitated all cultural activities. Interviews were approximately 45 minutes long and were recorded and transcribed for analysis. The interviews covered a series of questions related to youth, the program overall, how the program was developed, and how the program met or did not meet the needs of youth.

Youths' perceptions of their own needs: The Inuit educator/ cultural broker interviewed six youths using a semi-structured interview protocol. Interviews were conducted in a room outside of the units on campus with four girls and two boys; each met separately for approximately one hour. The interview covered subjects such as previous placements, boredom, suicidal ideations, aspirations, and spirituality. Interviews were conducted in both English and Inuktitut, with English being the primary language. They were recorded and transcribed.

Videos about youths' experience in placement were produced with seven girls and six boys. A single youth declined to participate. Youths made the videos in groups of two, except for one girl who was new to the residence and did the video alone with the research assistant. Facilitators asked youth volunteers to film each other talking about the residential centre and showing their experience on campus. The goal of this activity was to better understand youths' feelings about the placement, what they enjoy, and what they would like to see changed. Facilitators were present during the filming and would ask questions to help guide the activity.

\section{Ethnography}

We used an ethnographic approach for this study that involved many hours of participation in regular activities on residence floors with youths and staff. The main researcher and two research assistants took part in routine activities with the youths (e.g., sewing, girls' talk group, activity centre, smoking breaks) as well as team meetings. The research team kept detailed records of observations, decisions, and reflections about youths' experience of placement, clinical practices, and organization of care throughout the evaluation process. The main researcher also took part in various administrative activities, including weekly program development meetings and clinical discussions.

\section{Data analysis}

All data was transcribed and read by research assistants and the lead researchers. A research assistant and the primary author (S.F.) performed thematic inductive analyses (Boyatzis, 1998; Braun \& Clarke, 2006, Strauss \& Corbin, 1990). In thematic analysis, one looks for emerging patterns of themes within the gathered data. Inductive approaches are driven by the data rather than by theory, with the main focus on the perceptions or experiences of the participants.

All data was read an initial time during which all thoughts and observed patterns were highlighted, allowing for an emergence of insights and interpretations. We then used the observed patterns to generate initial codes by organizing the material according to the groups of actors (educators, therapists, cultural broker, youths, external observers). At this step, also known as open coding, multiple in-depth discussions took place to define an extensive set of codes that emerged from the data. The third phase, axial coding, involved grouping specific codes under more general themes to document youths' needs. Transcripts were reread to establish whether these broader concepts encompassed the more exhaustive codes developed in early phases. We then defined all categories and linked emerging themes with significant extracts. The sixth step consisted of relating emerging themes with the literature on the subject, which was done by making sense of the emerging data in relation to the contexts and experiences of Inuit youth and the professionals working with them. The final four codes that emerged in this final step are developed in the discussion of this paper.

Because the residence was undergoing important structural changes, it was only possible to return to the cultural broker and one therapist to validate findings. Not being able to validate the findings from other participants is a limitation to be considered.

\section{RESULTS}

\section{Educators}

During interviews, educators consistently reported that these youths required attention, respect, and being responsible or being held accountable for their decisions and actions:
They need to be self-accountable, for their day-to-day way of life and not to expect things to be given to them. Like I can work and buy my own things. I mean there is nothing like knowing that one can work, because it's ... self-worth, because it's self-esteem. (Educator, 2011)
Educator: Attention, respect. They command a lot of respect. One of their main needs is to be held accountable. Accountability.
Interviewer: In what sense?

Educator: They have this need to ... I mean, it's not just a need for them. But, if they do something, and they're not held accountable, then they'll keep on doing it. ... So there's a need for them to be held accountable, in order for them to progress. Otherwise, it's never a lesson learned. (2011)

Structure and consistency are seen as basic needs for these youths. Educators and their managers explained that ensuring structure and consistency of program and scheduling was one of the most important tasks for educators. Educators generally felt that another of their fundamental tasks was creating a rapport with the youths, i.e., making them feel comfortable in order to provide a safe space for communication. 
I think they're definitely in need to have a place to communicate what's going on, to communicate their frustrations; a safe place for them to explore ways, to recognize conflict, to know what conflict is. (Educator, 2011)

These "safe spaces" allow youth to work on certain interpersonal and psychological difficulties they may have. In these cases, safe spaces are areas of non-judgement and acceptance despite one's personal difficulties.

Educators explain that youth should have fun and positive experiences to develop self-esteem. This is done through activities that youth feel capable of finishing. Activities that are too challenging and make them question their abilities become obstacles to well-being, creating frustration, disappointment, and anger:

They like to be rewarded and they like to be told they're doing well. I think that the girls gravitate towards things that they feel safe doing and things that they know they're strong at, because they want to be able to succeed. (Educator, 2011)

Ideally, these activities should incorporate skills that are usable and valued in the environment to which they will return, to help foster a sense of independence and build self-esteem:

To me, it's more long term, something that can be useful for them in the future. Basic life skills. It meets the specific needs; it gives them a skill that they can use when they leave here. It's more like a skill development training. (Educator, 2011)

Many educators commented on the adaptation of activities to meet the specific needs of these youths, citing cultural differences. A major theme was the need for hands-on activities such as stone carving and practical outdoors activities:

These kids love hands-on activities, sports, and outdoor activities. They like the things they know. Games work exceptionally. Anything that gets them moving; anything that gets them using their hands. (Educator, 2011)

I've noticed-I've noticed in conflict resolution in particular there are a lot of role plays. I've noticed and I think it might be a cultural thing, that they're very uncomfortable doing role play. (Educator, 2011)

Reports by staff from group homes or residential programs youth have attended in the past highlight the importance of structure and discipline in intervention strategies and recommendations. Intervention plans often propose setting clear expectations, consistency, and routines. Individual or group counselling, as well as anger management and/or addiction rehabilitation programs, are recommendations that social workers and educators often formulate for these youths.

\section{Therapists}

Therapists primarily focused on the need to communicate. They discussed the importance of having a safe space for expression where youth can feel accepted and heard. Therapists noted that the youths needed to understand what is happening in their life and the reasons why:

They need to understand why. Why do they need structure? Explain it to them before you say structure, and bedtime. Why? You know, I thought it was a great question when this client, one of my girls, [chuckles] one of the girls I worked with said, "But why?" (Therapist, 2011)

The therapists described the importance of accompanying the youths in finding answers to their questions by talking to social workers, educators, or managers. Therapists noted that when youths understood how they were living and what would be taking place in the near future, there would be a reduction in anxiety and fewer associated difficult behaviours.

Having an adapted and individual plan was also discussed as being important for well-being. Therapists felt that there should be a certain consistency within a program with various options for the youths to choose from:

$[\mathrm{H}]$ aving options.... Something that is clear, so it does not create confusion. They know where they are going.

You have some kind of structure, guidelines, but then there is something individual. (Therapist, 2011)

One therapist also discussed the importance of youths taking part in activities they are familiar with and will be able to continue doing within their communities, especially activities that make sense to their worldview and experiences.

A program that takes into consideration some of the stuff that they do up north. I was going to say swimming [chuckles] but fishing, hunting. I think that it is great that they go camping. (Therapist, 2011)

Clinical reports from therapists who had met the youths before or during placement often gave very complete pictures of their lives and personal and family dynamics. They tended to explain individual difficulties as responses to complex realities including family life and past histories. Recommendations offered by therapists for these youths often included living in structured environments, having clear limits and consistency, taking part in therapy, working on past traumas, reducing alcohol use, and increasing school attendance. They also recommended drug education, support, positive reward systems, a secure environment, and help in developing trusting relationships. 


\section{Inuit educator/cultural broker}

Like the therapists, the cultural broker felt that the youths had to grasp their current reality in order to plan for the future. Within this process of understanding, the cultural broker emphasized the importance of personal time and space:

More room, more privacy, alone time, relaxing time to think about what happened yesterday or what I am going to do today. When they know what they are going to do they are pretty smooth. (Cultural broker, 2011)

So they need their alone space but they need someone they can talk to all the time. A safe place for them to be like every person in the world. (Cultural broker, 2011)

The cultural broker explains that in contexts of personal, family, and even community upheaval, youth can feel unsafe. They have often experienced physical and/or sexual abuse as well as neglect and bullying. In such situations, the residential facility can be seen and felt as a safe space far from threats to one's well-being. However, beyond the geographical space, the youths found "safety" in culturally relevant activities and contexts, which foster feelings of security and openness. Such activities included traditional sewing, traditional meals, talks about the northern reality, and any space where there was an opportunity to speak and be understood in their language. The cultural broker explains that the key is opening doors for sharing without obligating youth to talk about their feelings and experiences. The cultural broker explains that in small northern communities, talking about one's feelings takes place spontaneously during shared moments. People are never directly asked or told to open up. Sharing may be done in unstructured group activities; however, some youths may feel uncomfortable discussing certain issues in front of their peers and directly ask resource people for one-on-one time, an individual space that the cultural broker felt was very important:

[A need] is for them to talk about the problems, to share the problems, not necessarily to fix it-if they can fix, that's great-but to at least make them open up, and talk about it. (Cultural broker, 2011)

I think what is important for them is to have a comfort level; to know that someone can talk to them and answer them. Because these kids, when they ask questions, they expect a concrete answer. (Cultural broker, 2011)

The cultural broker also discussed the importance of structure, with a caution that the type of structure and discipline offered in residential care is not what Inuit youth and staff would be used to in their communities:
It is good for them to have a tight schedule with lots of activities, but at the same time when they leave here they are going to have culture shock. Because it's so different from what they live up there, so it's as if it helps them to feel better but it doesn't prepare them for reality. (Cultural broker, 2011)

The cultural broker discussed needs of youth as going far beyond the individual. Youth need to have good parents with appropriate parenting skills and they need to know about their culture and have the ability to pass it on. Youth require culture to be well and culture requires youth in order to survive:

$[\mathrm{T}]$ o carry on their culture, to not lose it.... That's how we survive. ... So they can be independent, so they can belong, and they can master something; and also develop generosity. (Cultural Broker, 2011)

I think to be connected to home, to be surrounded by Inuit staff, to talk their language, to know what it means to be Inuit, to talk about being Inuit today. Taking part in traditional activities, as if they can forget everything else for a moment. (Cultural broker, 2011)

[Youth need] for their parents to stop putting stuff like alcohol and drugs [in their bodies]. It's one of the biggest things. (Cultural Broker, 2011)

\section{Youth}

The most important theme in youths' discourse was family: family history, family relationships, and spending time with family. By far, the most difficult part of being at the residence was being away from family. Many youths felt guilt, sadness, or desperation at being far from family members. Family members were mentioned as important resources in difficult times. Many youths mentioned that thinking about family members at times when they felt suicidal helped them cope and deterred them from harmful actions. Specific family members were also identified as role models, people to look up to when trying to take a positive path. Some of the most important family members included aunts, uncles, and especially grandparents. Although youths rarely used the word "Elders" to describe influential people in their lives, they often talked of their grandparents.

Youths also verbalized the importance of cultural activities and traditional food in their daily routine. These activities connected them to home, their past, previous generations, and good memories. Taking part in activities like sewing was mentioned as a way to calm down. When these activities were not available or not allowed at a specific time because of scheduling, the youths could become very angry and aggressive.

For many youths, the natural environment was of great importance as well. This included enjoying outdoor activities like 
taking a walk by the river, camping, and playing in the snow. The youths often mentioned taking a walk outside as being the best place to relax and think when angry or upset.

Having alone time, or personal space for reflection, was seen as necessary during difficult times. Youths also acknowledged the importance of having people around when feeling upset, especially people they can talk to and trust. However, they expressed a preference for approaching these people when needed rather than being requested to talk.

The youths also expressed the need to have outings, to be off campus, to have something "different" in their week, and to feel "normal." Being identified as a client of the residence was felt as being stigmatizing and embarrassing.

The youths also spoke about the desire to be surrounded by more Inuit staff-individuals who speak Inuktitut and can share traditional activities and the Inuit way. Not being understood by non-Inuktitut speaking staff created mounting frustration among the youths.

Many youths talked of the importance of spirituality in their lives. Some have requested the possibility to practice their religion by going to church; however, when this was offered by the residential staff, they did not necessarily feel it met their needs. Many felt that church or reading the Bible had to be done in Inuktitut with family and friends, rather than being a solitary experience.

\section{DISCUSSION}

The primary objective of this study was to explore the needs of Inuit youths in the care of child welfare services from the perspective of four groups of actors: educators, therapists, a cultural broker, and the youths themselves. In this study, individuals were not requested to discuss particular types of needs, or needs as related to something specific; rather, we extrapolated the perceived needs from discussions to determine what they felt mattered most when working with youth. We also used ethnographic observations and daily logs as a source of information. A secondary objective was to explore how culture is embedded within the identification and perception of these needs.

\section{Needs}

Each group of actors discussed a variety of subthemes that seemed to be guided by their own experiences and cultures (see Table 1). Educators discussed the importance of developing skills, learning responsibilities, being accountable for one's actions, having structured environments, and living positive experiences. Interestingly, and most likely not coincidently, these perceived needs are also the crux of psychoeducational theories (Gendreau, 2001; Renou, 2005). Although educators also used words like mastery, independence, and belonging, these words were rarelyif ever-contextualized or explained in any meaningful way, suggesting difficulty using this philosophy. As described elsewhere, educators also found it hard to explain how these values were implemented within daily activities (Fraser et al., 2012). In our own observations and during program development meetings, we did not notice any greater reinforcement of psychoeducational values as compared to the Circle of Courage model. It is possible that the educators' previous personal and professional experiences influenced their perceptions of youth above and beyond any imposed residential philosophy. It may also be that the Circle of Courage model was not adequately implemented within the program at that time.

Recommendations offered by educators and mental health workers in clinical reports included living in a stable and structured environment, anger management therapy, and individual or group therapy. Although family situations were explained as reasons for the youths' difficulties, needs and recommendations focused on individual behaviours.

Therapists and the cultural broker discussed the importance for youth to have a sense of control over their current situation by understanding the context and the functioning of the residence.

The cultural broker and youths shared similar thoughts on the needs of youth and included a systemic perception. They described the importance of spirituality and connectedness, which took place in three spaces: personal space, relational spaces, and spaces of action through concrete and mostly traditional activities. They underlined connections with family and culture as elementary for well-being, as well as speaking one's language and having Inuit staff who could understand their reality.

The needs to communicate and have trusting relationships were discussed by all four groups of actors. The therapist, cultural broker, and youths also talked about the importance of having a safe place to open up. Their notions of "safe place" and "communicating," however, were conceptually different. The therapist focused on confidential spaces of non-judgement where youth could talk about their experiences. Educators and mental health workers felt that youth needed closure (e.g., processing after moments of conflict, finding solutions to problems) and communication was an avenue for this. The cultural broker viewed safe spaces as areas of sharing and potential discussions without any expectations of meeting objectives or discussing particular events. The cultural broker and youths highlighted the importance of unstructured time and space that allowed for spontaneity in sharing and developing relationships. The youths also implicitly discussed safe spaces. Those who had experienced abuse in their homes viewed the residence as a safe space, but they also found spaces of comfort with family and friends, or alone and outside. Similar differences have been noted in qualitative work done in other Aboriginal communities and in intercultural interventions with Aboriginal people. Although similar words may be used by therapists/professionals and Aboriginal people, the meanings behind "therapeutic landscapes" and "spaces of healing" may be quite different. Gone (2008) describes how therapeutic clinics will encourage verbal communication, rumination on past trauma, and self-discovery. Having to do so in a space and with people who symbolically represent the oppressor may be anti-therapeutic and perhaps even a perpetuation of colonial practices (Gone, 2008; Berger \& Epp, 2006). 
Although a variety of needs were discussed by more than one group of actors, there was variation in the way they understood and conceptualized these needs. Two main themes emerged when attempting to understand the similarities and differences observed among groups of actors: culture and structure.

\section{Culture}

All groups of actors brought up the topic of culture; however, the space given to culture and the discourse surrounding culture differed among non-Inuit (educators and therapists) and Inuit (cultural broker and youths).

The educators and therapists were aware of the importance of family and culture in the youths' lives, but gave very little space to these themes when discussing the youths' needs. They talked about the importance of adapting activities and programs to the culture and context of youths. Such adaptations included skill-enhancing activities that are usable in the youths' home communities, as well as hands-on activities. Culture seemed to be viewed as an important characteristic or factor to be taken into consideration during program development and in activities. This view is not uncommon, and has been criticized for its stigmatizing potential and its tendency to view culture as a characteristic of "the other" (Bibeau \& Corin, 1996).

On the other hand, culture is central in the discourses of the cultural broker and youths. Culture is described as a safe space that allows for exploration of feelings and sharing experiences. Culture provides possibility for connection and a sense of belonging. Speaking one's language and taking part in cultural activities allow for a certain healing process to take place. Adopting this view, culture becomes a lens through which we experience, perceive, and understand life. Culture is not foreign; it is embedded within our daily actions, thoughts, and perceptions (Bibeau \& Corin, 1996). The cultural broker suggested that being connected to culture is not only necessary for the youths' healing process but is also necessary for culture itself. This concept parallels the fundamental principles of interactionism and social psychology (Giddens, 1984). It is believed that culture can be re-enacted and transmitted through daily interactions between individuals. As discussed by the cultural broker, without these daily interactions between Inuit - and in Inuktitut-a group risks losing culture and culture risks being lost. Many have argued that is it through this precise process that the removal of Inuit, and more generally of Aboriginal children, from communities to residential schools has had such a long-lasting and devastating impact. Youth were placed in settings where they were isolated from families and from their own cultures. This led to ruptures in intergenerational teachings of culture and parenting skills. It also created intergenerational trauma, which in turn has led to generations of families being unable to offer their children the care they require. More contemporary residences for Inuit youth, or for youth from other Aboriginal communities, are attempting to incorporate cultural elements in their programs to try to reduce the impact of removal on youth well-being. However, many have argued that cultural competence goes beyond the inclusion of cultural activities within programs and extends to political and economic considerations (Gone, 2008; King, 2011; Kirmayer, Simpson, \& Cargo, 2003; Kirmayer, 2012). Do communities have the health, economic resources, and political power to maintain and transmit their cultures? Do the structures and systems in place facilitate empowerment? The cultural broker and the youths suggested that culture is about sharing with family, being in community, and transmitting cultural knowledge, all of which require one's presence within his/her community and family. Considering that the current system of care has been unable to address the structural causes of overrepresentation of Inuit people in care, some may argue that no matter what is put into place, outof-community placements cannot be culturally appropriate because they imply that youth were taken away in the first place.

Moreover, our analysis suggests that personal perceptions of youths' needs are guided by professional and personal culture and competencies. Interviews with educators, however, suggest limited awareness of this phenomenon. Educators would float between discussing "youths' needs" and the needs they felt the youths had without differentiating between the two. Culture, being a lens through which we perceive and experience the world, will naturally guide our understanding of youths' needs, an understanding that is co-constructed in our interactions with youth (Aggarwal, 2012).

\section{Structure}

In this study, educators and therapists highlighted the importance of structured programs and consistency in schedules and rules. Nearly all educators and therapists recommended structure in clinical reports. Our ethnographic observations and analyses of individual logs highlighted a relationship between personal wellbeing and this type of structured and predictable environment. The cultural broker also mentioned structure as beneficial, but cautioned that most Inuit youth and staff would not be used to this way of life.

Structure, as understood in psychoeducational and residential programs, generally takes the form of schedules with the time, space, and content of activities being clearly stated and rigorously maintained; rules and consequences are known and consistently reinforced (Gendreau, 2001; Renou, 2005). It is believed that psychological and emotional disorganization can be "worked" through structure of ones' time and space complemented by a rehabilitative or therapeutic process. It is not uncommon to view rehabilitative practices this way. The structure-oriented approach may be congruent with occidental, neoliberal cultures that value efficacy and productivity (Otero, 2005). However, a reliance on external control may lead to a shrivelled internal control and eventually to ruptures with one's own cultures. In a context where the client "belongs" to a similar culture to that of the institutions that offer structure, the rules and regulations may be compatible with the clients' worldviews. In this way, by their rules and regulations, institutions ensure cultural reproduction by transmitting and reinforcing certain behaviours. However, in a context where the client and the institution do not share 
Table 1. Youths' needs as perceived by various actors.

\begin{tabular}{|c|c|c|c|c|}
\hline Needs & Educators & Therapists & Cultural brokers & Youths \\
\hline Trusting relationships & $\sqrt{ }$ & $\sqrt{ }$ & $\sqrt{ }$ & $\sqrt{ }$ \\
\hline Space for communication/expression & $\sqrt{ }$ & $\sqrt{ }$ & $\sqrt{ }$ & $\sqrt{ }$ \\
\hline Structure & $\sqrt{ }$ & $\sqrt{ }$ & $\sqrt{ }$ & \\
\hline Skills & $\sqrt{ }$ & $\sqrt{ }$ & $\sqrt{ }$ & \\
\hline Personal space & $\sqrt{ }$ & $\sqrt{ }$ & $\sqrt{ }$ & $\sqrt{ }$ \\
\hline Attention & $\sqrt{ }$ & & & \\
\hline Respect & $\sqrt{ }$ & & & \\
\hline Responsibility/accountability & $\sqrt{ }$ & & & \\
\hline Having positive experiences & $\sqrt{ }$ & & & \\
\hline Sense of control over own life & & $\sqrt{ }$ & $\sqrt{ }$ & $\sqrt{ }$ \\
\hline Speaking one's language & & & & $\sqrt{ }$ \\
\hline Cultural activities & $\sqrt{ }$ & $\sqrt{ }$ & $\sqrt{ }$ & $\sqrt{ }$ \\
\hline Connection with family/positive relationships & & & $\sqrt{ }$ & $\sqrt{ }$ \\
\hline Ability to transmit culture & & & $\sqrt{ }$ & \\
\hline Outdoor activities and space & $\sqrt{ }$ & & & $\sqrt{ }$ \\
\hline Feeling normal & & & & $\sqrt{ }$ \\
\hline Spirituality & & & & $\sqrt{ }$ \\
\hline
\end{tabular}

fundamental values, the imposed structure may create further rifts with one's own history.

There is another fundamental issue in the use of time, space, and place in intercultural encounters: that of epistemological discrepancies in the conceptualization of these elements. Various authors have discussed this eloquently, observing important differences in how "western" and Aboriginal cultures conceptualize time, space, and place (Gone, 2008; Wilson, 2003). These differences often go unnoticed but are not without repercussions. Gombay (2009) suggests that occidental cultures tend to view time as absolute, linear, and quantitative, while Inuit tend to view time as contingent and cyclical. For Inuit, time and space are intertwined and highly dependent on ecological context. Having lived for centuries on the land, Inuit may be particularly aware of the unpredictability of life, having to develop a

heightened ability to be flexible and adaptable (Gombay, 2009). These aspects of traditional Inuit culture do not seem congruent with the mandatory adherence to rigid organization of time and space through structured schedules and routines. All informants acknowledged the difficulty the youths had adopting a rigid structure. Whether this difficulty was mostly due to their personal life experiences, "behavioural profiles," or cultural differences is difficult to determine; however, educators, mental health workers, and the cultural broker all perceived it as being related to cultural differences. The cultural broker did not see structure as necessarily being negative. She discussed how Inuit have experienced tremendous social changes that have led to what she calls "corruption of family practices"-practices that may need to be revisited. As an example, the current parenting programs being developed in Nunavik focus on parents' ability to offer nurtured guidance through a certain structure.

Structure, as discussed by the cultural broker and youths, may be more congruent with the way it is conceptualized in certain forms of ethnopsychiatry. In the field of ethnopsychiatry, rather than structuring time and space, therapists work with the client's traditional culture as an internal guide to organize or reorganize emotional and psychological space (Moro, 1997; Moro, 2004). Culture is used and viewed as a structuring agent and an internalized guide. Ethnopsychiatrists may attempt to reignite cultural values deeply entrenched within people's being, in order to support their client's internal path-one that is congruent with the client's worldview. They may revisit traditional myths or encourage the use of traditional practices to reinforce the internal structures already present within their client.

Ethnographic research suggests that when working with Inuit clients in particular, values such as connectedness with the land, traditional foods and activities, relationships, cultural belonging, and continuity may be core elements of successful 
programs (Kirmayer, Fletcher, \& Watt, 2008). Although the association between culture and structure was not explicitly discussed by the various interviewees, it was implicitly raised by the cultural broker and youths. They discussed the process by which culture aided well-being. Being together and sharing traditional activities brought calmness and a space where experiences could be explored and shared in tranquility. Moreover, when the youths discussed personal role models, they generally talked of individuals who did not engage in delinquent activities and who also took part in cultural activities such as sewing, berry picking, and hunting. The youths saw these individuals as models of "a good path." In this sense, structure can be understood as the use of culturally relevant spaces, places, relations, and actions to offer youth the possibility to find a certain tranquility and connection that allows for healing to take place.

\section{Limitations}

There are multiple limitations to this work. Data was collected for quality assurance purposes and not for research purposes, limiting the quantity and quality of data available for analysis. Sample sizes were small due to the fact that the residence receives only eight girls and eight boys at a time. The program was only in its first year of development and therefore was evolving to better suit youths' needs. Due to the fact that youths return to their communities after their stay in the residence, it was impossible to consult them after data analysis to validate the findings. Despite these important shortcomings, little research is available on this subject, a topic that warrants special attention due to the growing dissatisfaction with current child welfare services in Nunavik and in Aboriginal communities across Canada. Documenting and describing perceptions of various actors allows for an analysis of similarities and differences in views. This promotes a certain awareness of complementarity and differences in experiences and for a dialogue to take place among actors to improve the current system of care.

\section{CONCLUSIONS}

Program development and implementation should be viewed as a multicultural task, where multiple perspectives meet and interact. Individuals in charge of developing programs are guided by their own professional and personal cultures. The mere understanding of culture is culturally construed. Indeed, a major obstacle to this multicultural encounter is lack of awareness of the subjectivity of our experiences and the multiplicity of perceptions and voices. Difference in views is not necessarily problematic; on the contrary, it provides material for creativity and innovation. Koestler (1967) describes how the interaction of two conflicting phenomena or elements can lead to the development of new and more complex ideas. For this to take place, the two elements must merge or collide rather than add on to one another; a process of hybridization. Concretely, this means that developing programs based on North American values but including aspects of Aboriginal traditional culture are not necessarily examples of creative and innovative practices. Indeed, adding sewing activities or traditional food to a curriculum does not mean that educators understand the importance of these activities for youth and maximize their benefits. In our study, we witnessed situations of crisis and power struggles between youths and educators because, for example, the youths wanted to sew at a particular time when other activities were scheduled. We also participated in a discussion about the relevance of traditional meals, where educators felt frustrated that the youths were still eating cafeteria fries after preparing a traditional meal. Educators were considering reducing the frequency of traditional meals for this reason. From exchanges with the youths it became clear that seeing the Inuit educator/ cultural broker prepare and sharing the food was soothing, and eating fries did not take away from that experience of togetherness.

One must go beyond additive strategies and explore outside of the realms of the child welfare systems currently in place. Culture, as described by the Inuit youths and the Inuit cultural broker, is about being together, sharing, and transmitting knowledge. The same interviewees view culture as fundamental for well-being. History's difficult lesson has been that removal of children to out-of-community placements has led to ruptures in culture and intergenerational trauma. In order for innovative and culturally safe practices to emerge, the diverging parties must open dialogue and become aware that we are all bearers of culture, which highly influences our perceptions. Non-Inuit professionals would benefit from exploring the internal workings of such practices to better understand their own methods and teachings. One must equally acknowledge that the dialogue is circumscribed within a long history of often strenuous and unequal interactions. To develop practices that work in a context of social change and respect the culture of the client, professionals must reflect upon how their own practices can be not only "adapted" but can "evolve" in the face of diversity (Aggarwal, 2012). Rehabilitative strategies used by psychoeducational professionals may be explored and adapted by Inuit communities and workers in a context where youth remain within their own communities to share, transmit, and transform culture. Programs could look at developing spaces, techniques, and interactions that allow for the revitalization and reinforcement of internalized culture and values to offer guidance and structure, rather than give structure to youth by depending only on external mechanisms of controlling time and space. 


\section{REFERENCES}

Aggarwal, N. K. (2012). Hybridity and intersubjectivity in the clinical encounter: Impact on the cultural formulation. Transcultural Psychiatry, 49, 121-139.

Bennett, M., \& Blackstock, C. (2002). A literature revieww and annotated bibliography focusing on aspects of Aboriginal child welfare in Canada. Ottawa, ON: First Nations Child \& Family Caring Society of Canada.

Berger, P., \& Epp, J. R. (2006). Practices against culture that "work” in Nunavut schools: Problematizing two common practices. McGill Journal of Education, 41, 9-23.

Bibeau, G., \& Corin, E. (1995). Culturaliser l'épidémiologie psychiatrique. Les systèmes de signes, de sens et d'actions en santé mentale. In F. Trudel, P. Charest, \& Y. Breton (Eds), La construction de l'anthropologie québécoise (pp. 105-148). Quebec City, QC: Les Presses de l'Université Laval.

Blackstock, C., \& Trocmé, N. (2005). Community-based child welfare for Aboriginal children: Supporting resilience through structural change. Social Policy Journal of New Zealand, 24, $12-33$.

Boyatzis, R. E. (1998). Transforming Qualitative Information. Thousand Oaks, CA: Sage Publications.

Braun, V., \& Clarke, V. (2006). Using thematic analysis in psychology. Qualitative Research in Psychology, 3(2), 77-101.

Brendtro, L., Brokenleg, M., \& Van Bockern, S. (1990). Reclaiming youth at risk: Our hope for the future. Bloomington, IN: National Educational Services.

Carriere, J., \& Richardson, C. (2009). From longing to belonging: Attachment theory, connectedness, and indigenous children in Canada. In S. McKay, D. Fuchs, \& I. Brown (Eds.), Passion for action in child and family services: Voices from the prairies (pp. 49-67). Regina, Saskatchewan: Canadian Plains Research Center.

Cross, T., Earle, K., Echo-Hawk Solie, H., \& Manness, K. (2000). Cultural strengths and challenges in implementing a system of care model in American Indian communities. Systems of Care: Promising Practices in Children's Mental Health, 2000 Series, Volume I. Washington, DC: Center for Effective Collaboration and Practice, American Institutes for Research.
Fraser, S. L., Vachon, M., Arauz, M. J., Rousseau, C., \& Kirmayer, L. J. (2012). Inuit youth transitioning out of residential care: Obstacles to re-integration and challenges to wellness. First Peoples Child and Family Review, 7, 52-75.

Gendreau, G. (2001). Jeunes en difficulté et intervention psychoéducative. Montreal: Sciences et Culture.

Giddens, A. (1984). The constitution of society: Outline of the theory of structuration. Berkeley, CA: University of California Press.

Gombay, N. (2009). Today is today and tomorrow is tomorrow: Reflections on Inuit understanding of time and place. INALCO Proceedings of the 15th Inuit Studies Conference, Orality, Paris, France. Retrieved from http://www. inuitoralityconference.com/art/Gombay.pdf

Gone, J. P. (2008). “So I can be like a Whiteman”: The cultural psychology of space and place in American Indian mental health, Culture and Psychology, 14(3), 369-399.

King, M. (2011). Scaling up the knowledge to achieve Aboriginal wellness. Canadian Journal of Psychiatry, 56(2), 73-74.

Kirmayer, L. J. (2012). Rethinking cultural competence. Transcultural Psychiatry, 49, 149-164.

Kirmayer, L. J., Fletcher, C., \& Watt, R. (2008). Locating the ecocentric self: Inuit concepts of mental health and illness. In L. J. Kirmayer \& G. Valaskakis (Eds.), Healing traditions: The mental health of Aboriginal peoples in Canada (pp. 289-314). Vancouver, British Columbia: University of British Columbia Press.

Kirmayer, L. J., Simpson, C., \& Cargo, M. (2003). Healing traditions: Culture, community and mental health promotion with Canadian Aboriginal Peoples. Australasian Psychiatry, 11(s1), s15-s23.

Koestler, A. (1967). The ghost in the machine. New York, NY: Macmillan.

Lafrance, J., \& Bastien, B. (2007). Here be dragons! Breaking down the iron cage for Aboriginal children. In I. Brown, F. Chaze, D. Fuchs, J. Lafrance, S. McKay, \& S. Thomas Prokop (Eds.), Putting a human face on child welfare: Voices from the prairies (pp. 89-113). Regina, Saskatchewan: Prairie Child Welfare Consortium. 
Libesman, T. (2004). Child welfare approaches for indigenous communities: International perspectives. Child Abuse Prevention Issues, 20. Retrieved from http://www.aifs.gov.au/ nch/pubs/issues/issues20/issues20.html

Moro, M.-R. (1997). L'altérité, un point de vue philosophique. Champ psychosomatique, 11/12, 3-6.

Moro, M.-R. (2004). Psychiatrie transculturelle de l'enfant et de l'adolescent. Paris: Dunod.

Office of the Auditor General of Canada (2011). Programs for First Nations on reserves. 2011 status report of the auditor general of Canada. Ottawa, ON. Retrieved from http://www.oag-bvg. gc.ca/internet/English/parl_oag_201106_04_e_35372.html

Otero, M. (2005). Santé mentale, adaptation sociale et individualité contemporaine. Cahiers de recherche sociologique, 41-42, 65-69.

Reclaiming Youth International. (n.d.). The Circle of Courage philosophy. Retrieved from http://www.reclaiming.com/content/ about-circle-of-courage

Renou, M. (2005). Psychoeducation: une conception, une méthode. Montreal: Sciences et Culture.

Sirois, L., \& Montminy, K. (2010). Nunavik: Follow-up report on the recommendations of the investigation into youth protection services in Ungava Bay and Hudson Bay. Quebec City, QC: Commission des droits de la personne et des droits de la jeunesse.

Strauss, A. L., \& Corbin, J. M. (1990). Basics of qualitative research: Grounded theory procedures and techniques. Newbury Park, CA: SAGE Publications.

Wilson, K. (2003). Therapeutic landscapes and First Nations peoples: An exploration of culture, health and place. Health and Place, 9, 83-93. 


\section{Foodland Security: Access to Inuit Country Food in an Urban Setting As told by Barry Pottle through contemporary Inuit art photography

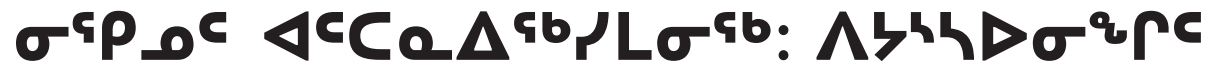

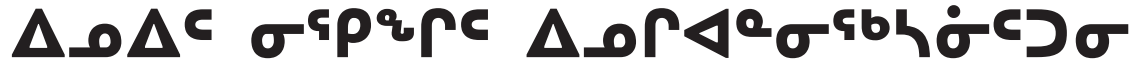

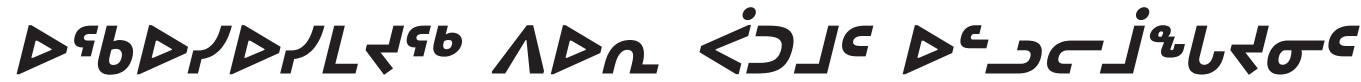

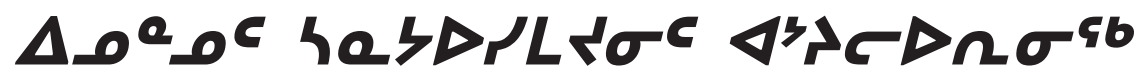

Barry Pottle, Inuk photographer (Nunatsiavut), Ottawa, Ontario, Canada

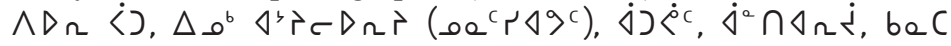

\section{INTRODUCTION}

$\mathrm{B}$ arry Pottle, an Inuk photographer originally from Nunatsiavut, presented Inuit voices, images, and issues related to food security at a conference on the Arctic at the University of Washington in Seattle, Washington in May 2012.

The symposium, entitled Canada and the U.S. in the Arctic: Past Successes, Future Challenges, was sponsored by the Canadian Studies Center of the Henry M. Jackson School of International Studies at the University of Washington; the Canadian consulates in Seattle and Anchorage, Alaska; the U.S. consulate in Vancouver, British Columbia; and the 13th District U.S. Coast Guard. Participants included university faculty and students, government and industry representatives, as well as members of the general public. The group discussed Arctic environmental challenges, economic development, and maritime issues.

Barry's keynote address on food security for urban Inuit took the form of a photojournalism presentation, giving participants a window into Inuit life and customs, specifically how urban Inuit experience dietary changes once they leave the Inuit Nunangat (Inuit Homeland). He gave an overview of Inuit in urban centres and their access to country food ${ }^{1}$ for personal and group/event consumption. Barry's photojournalism represents a new form of Inuit art depicting traditional and contemporary Inuit activities.

Barry explains: "The project Foodland Security is based on an original art project that I have been exploring over the past couple of years. Not only is the name a play on words (the land, food, and security) but it's about my knowledge and experiences of Inuit country food in an urban context. Through my art I wanted to raise awareness of this issue. This issue is relatively new and unexplored, so I had the opportunity to highlight it. The images used in this project are original pieces of art by me, the photographer. Inuit move to urban centres for many reasons: to find jobs, education, and medical services; to join family and friends; or to escape severe weather conditions or abusive situations. Associations dedicated to urban Inuit in Canada include:

- Association of Montreal Inuit

- Edmonton Inuit Cultural Society

- Tungasuvvingat Inuit, Ottawa

- Manitoba Urban Inuit Association, Winnipeg

- $\quad$ St. John's Native Friendship Centre

- Yellowknife Inuit Association

\section{FOODLAND SECURITY IS ABOUT ACCESS TO INUIT COUNTRY FOOD}

Country food is intertwined with the Inuit culture. This food comes from animals and plants that people hunt, fish, or gather. These traditional foods include caribou, seal, whale, fish, birds, and berries. Food preparation includes the skinning and butchering of animals, cleaning of plants, and further preparation for eating such as boiling, drying, and other techniques.

Once in urban centres, Inuit experience a great shift in diet from traditional or country food to store-bought, processed foods. 
Processed foods are often less healthy than country food and may have high levels of sodium, trans fats, and sugar. This, along with a sedentary lifestyle, contributes to the increase of diseases previously unknown among Inuit, such as diabetes and heart disease. Storebought foods are now commonly eaten by Inuit, but they cannot replace the nutritional and cultural value of food acquired from the land, sea, and air, and may be modified or genetically altered.

\section{WHAT DOES COUNTRY FOOD MEAN TO YOU? ${ }^{\mathrm{ii}}$}

"We need Inuit country food to feel who we are!"

"Good for my body and soul."

"[They are] not just foods we crave, but they are a part of us."

"It means ... strength, and healthiness."

"It's also good for the spirit, and eating my own country means healing."

"Eating my country food is less stressful, and I get less tired. I have lots of energy all the time."

"If you compare Inuit and the caribou or seals, both Inuit and the caribou are fast runners."

"When we eat the liver of the seal at minus 40 or 50 , it means we are hot for the rest of the day. That is how the seal survives in the cold."

"Getting country food is really important for us. For many, country food is not just part of their diet that they miss terribly; it helps them emotionally."

"We have had occasions where someone is struggling and the first thing they ask for is their country food. Country food represents a way of life, not just a diet."

"Country food means maintaining the good health that I was brought up with from birth. It means that I get to eat the freshest and purest forms of vitamins, minerals, and nutrition. If I don't eat it, I get weak and sick."

"Country food means many things to me. It provides a nutrition that I don't get from store-bought foods."

"The satisfaction of eating country foods cannot be described. There is a spiritual and cultural charge that comes from eating country food-especially caribou."

"My children and I are smiling before, during, and after a meal of quaq (raw frozen meat or fish) or tiqtitaq (fried caribou). It means we are Inuit, and can continue to be Inuit, even if we are not living in the Arctic. It also takes me to the time and place where my grandparents survived on these foods."
"Appreciation is always expressed to the hunter who harvested the catch and to God when receiving country food, while eating, and after."

\section{HOW OFTEN DO YOU GET COUNTRY FOOD?}

"I can get country from home because my son lives in Iqaluit and he sends me fish, seal meat, or maktaaq (whale skin with blubber)."

"I also have trips up north to Nunavut and whenever I am up there, I can get country food. So, I get it once every few months."

"It is sent by relatives, and I bring it down when I travel anywhere north."

"I get country food from my dad in Labrador. I get it a couple times a year when I go home or when my family comes here."

"I get enough so that I can eat it a couple times a month."

"If I was in Labrador with my family, I would be eating country food every day."

"Occasionally country food is brought to our office (an Inuit organization), but not often enough lately.”

"Many times I get my own fish and caribou during my travels to Nunavut. Sometimes I order my caribou from my relatives in Arviat during winter."

"I try to stock up and fill up my freezer at all times because I share my fish and caribou with my students and friends on a monthly basis here in Ottawa."

Barry writes, "Although I was aware of some of the answers to the questions I posed to my fellow Inuit, I was not aware nor did I realize how powerful or meaningful the responses would be. Country food is everything to Inuit and not having access to it has an impact on families, communities, and individuals. It's never easy to acquire country food in urban areas and issues such as cost, distance, availability, and government processes make it even more challenging at times. But as I learned, Inuit are resourceful and have found means to overcome those challenges to get the food that means so much to them."

"My plan in setting out to do this project was- first and foremost - an art project as I strive to bring awareness and justice to what I call Contemporary Urban Inuit Photography. But as the project progressed, it at times seemed to take on a life of its own. I'm very proud of how it turned out in the end!"

Dedicated to Ottawamiut (the Inuit in Ottawa). Nakummek! (Thank you!) 


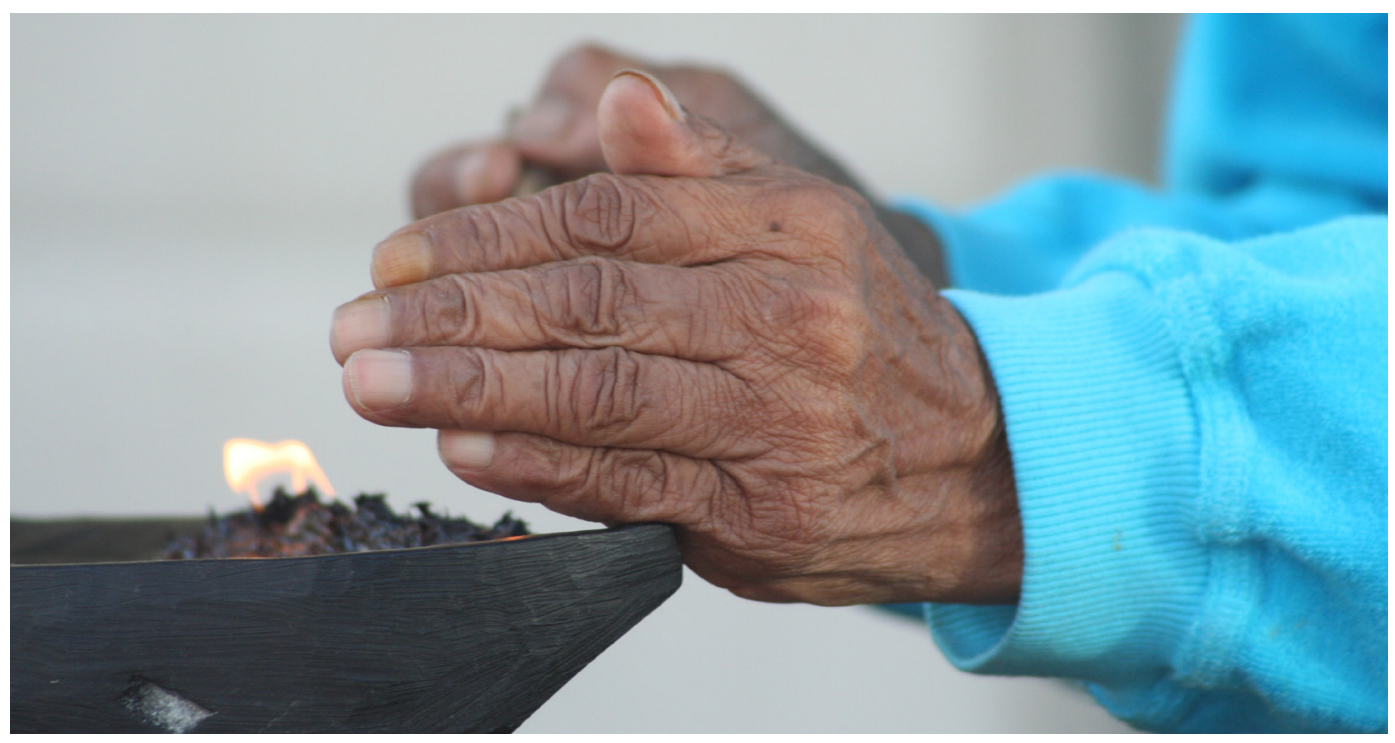

Image 1. The qulliq (lamp) traditionally was used for cooking and warmth. Here, it is used ceremonially at the beginning of conferences, events, and meetings. (Photo credit: B. Pottle)

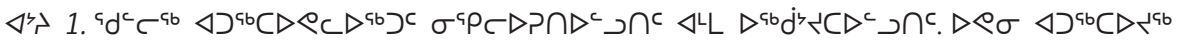

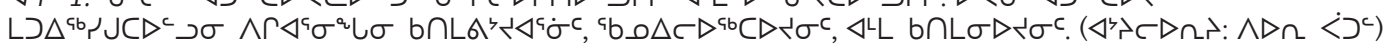

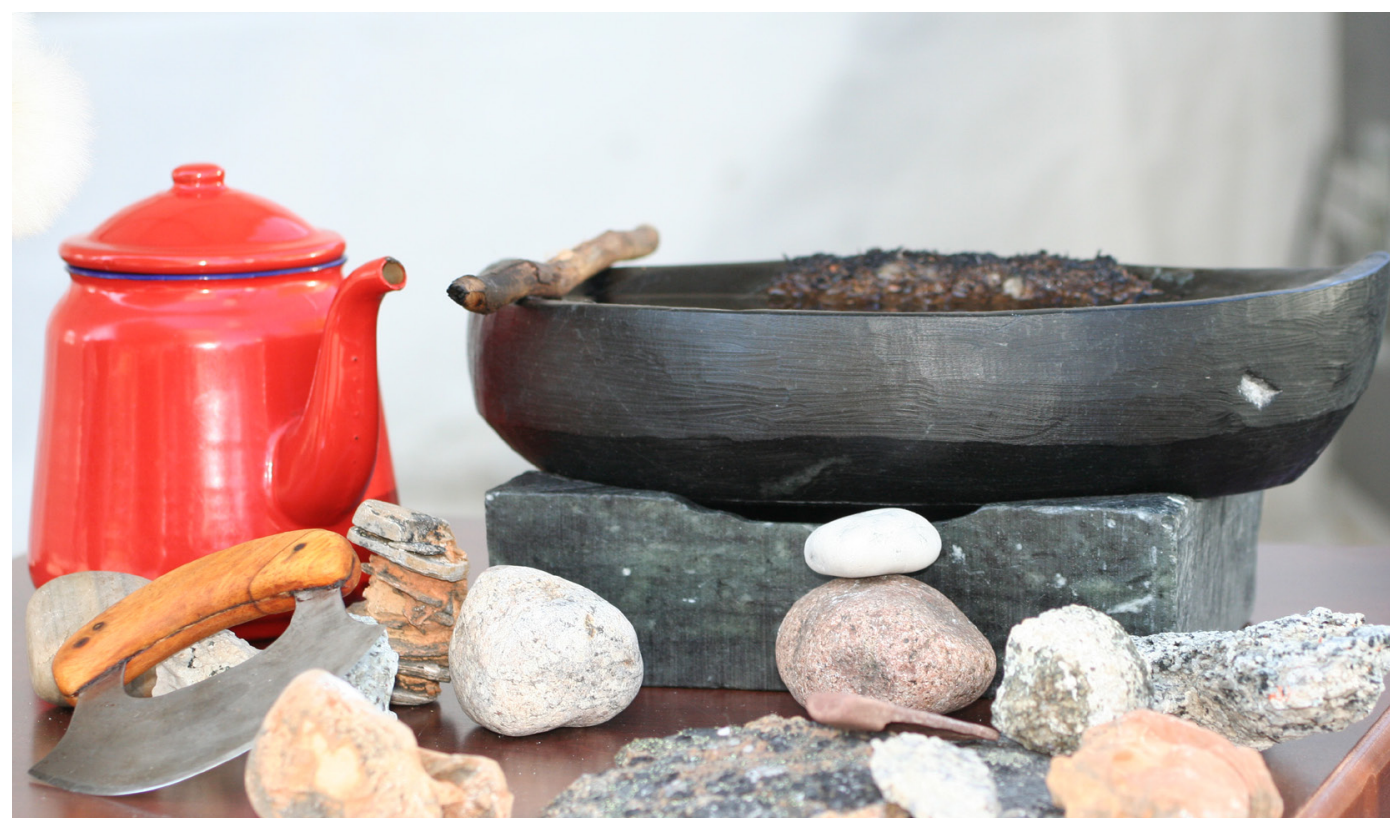

Image 2. Inuit still life. (Photo credit: B. Pottle)

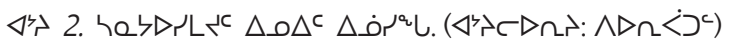




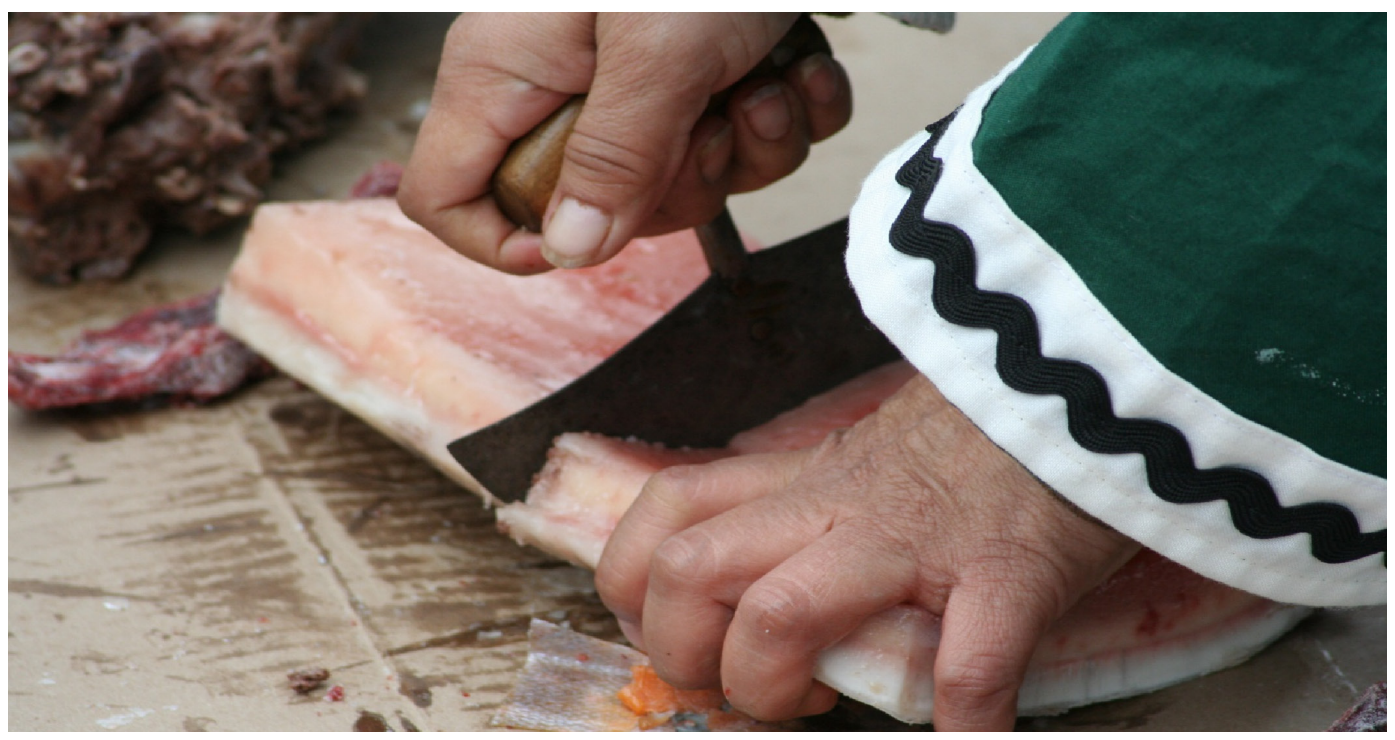

Image 3. Starting the feast: cutting maktaaq (whale skin with blubber) with an ulu (traditional Inuit woman's knife). (Photo credit: B. Pottle)

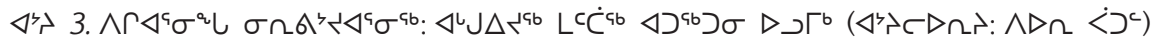

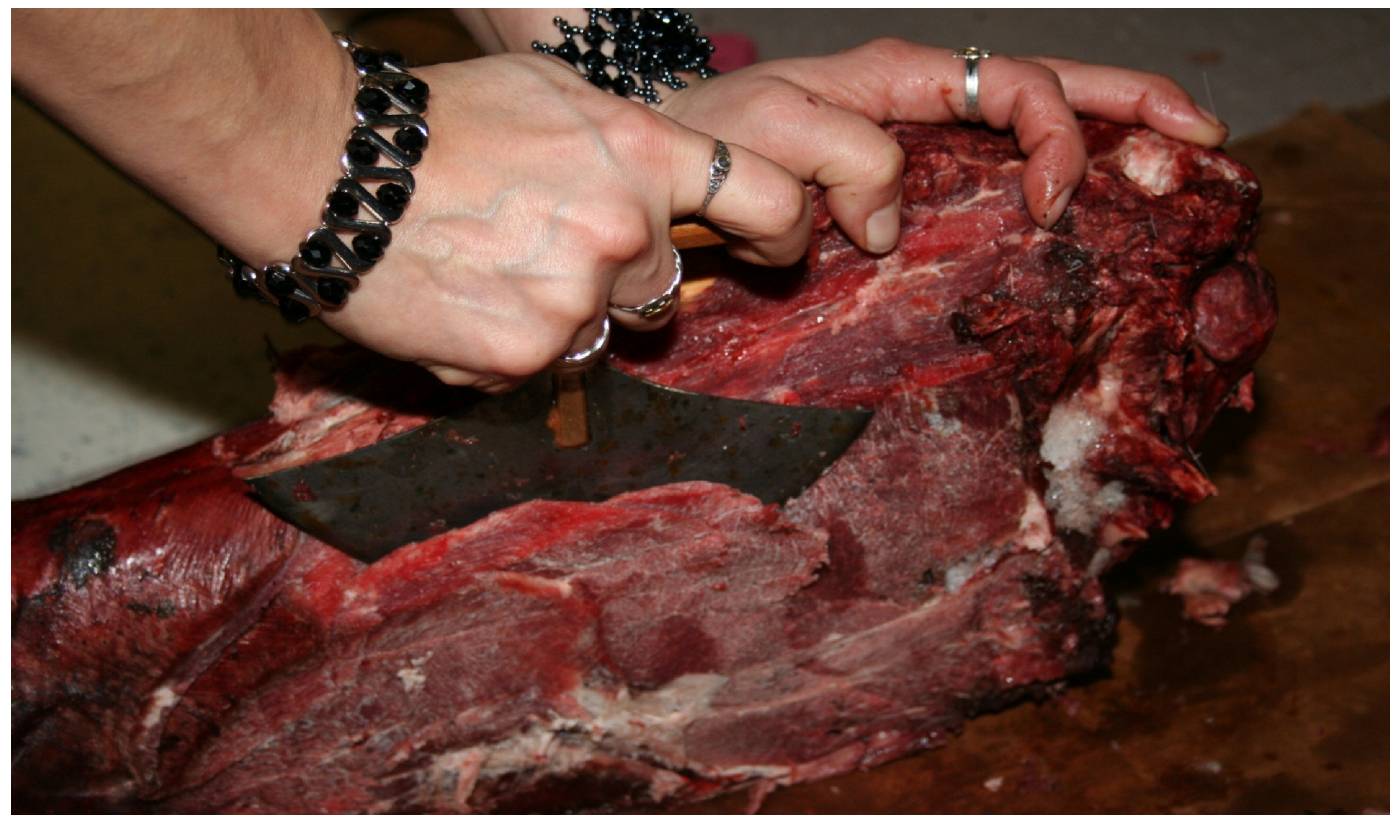

Image 4. Cutting tuktu (caribou) with an ulu (traditional Inuit woman's knife). (Photo credit: B. Pottle)

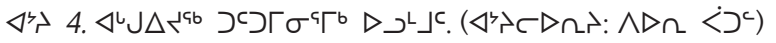




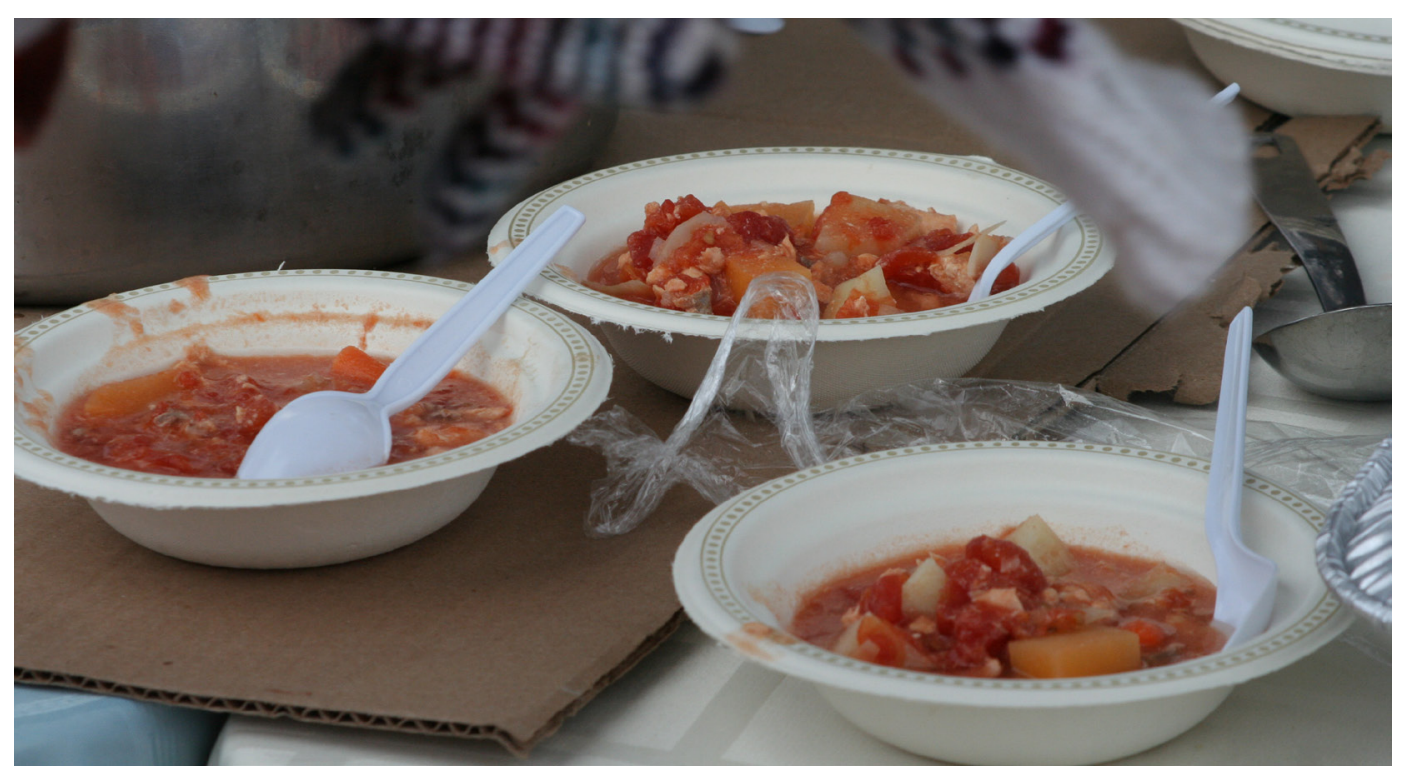

Image 5. Contemporary implements used with traditional foods. (Photo credit: B. Pottle)

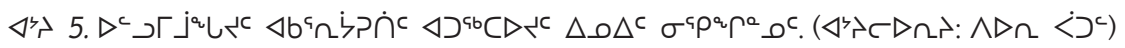

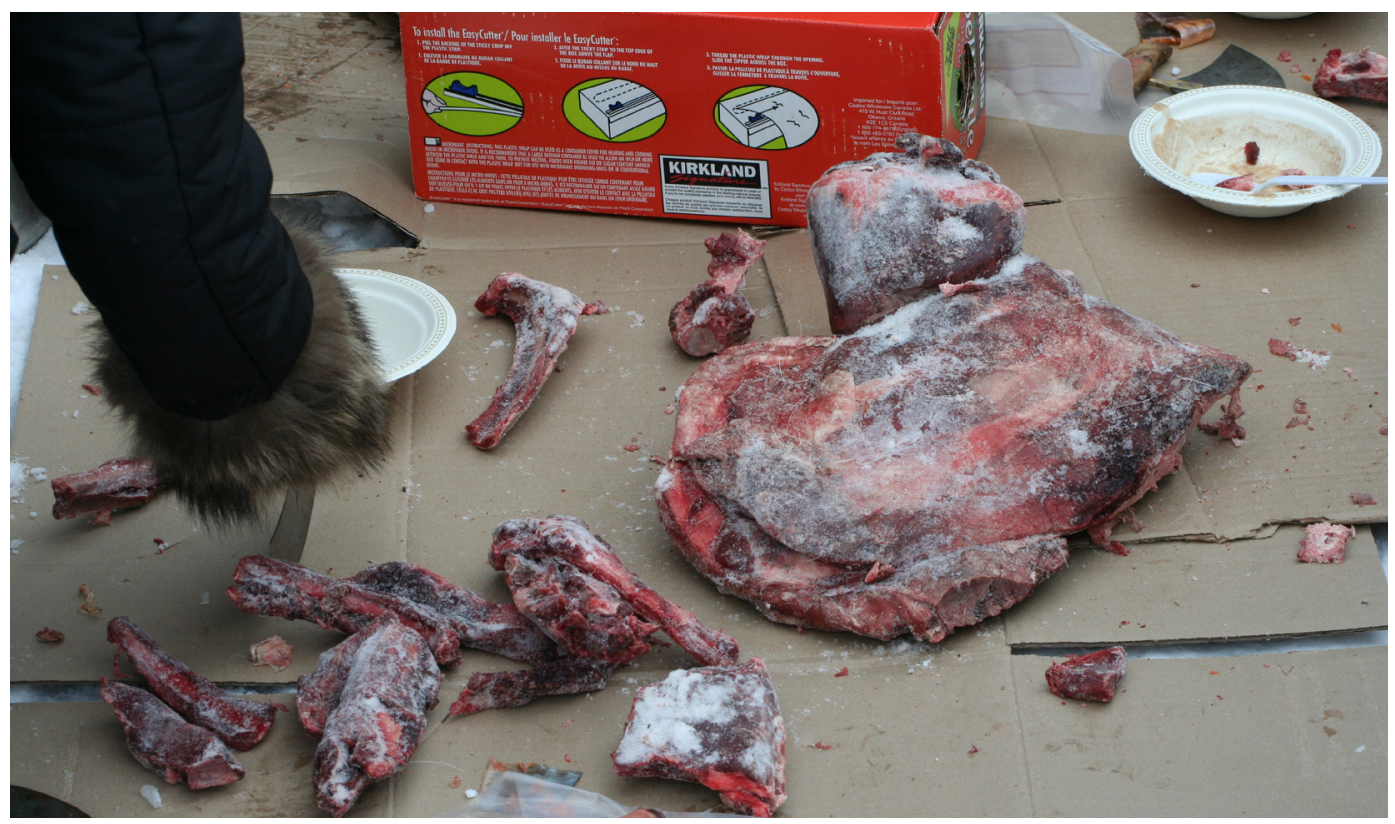

Image 6. Setting the table: a contemporary twist on traditional ways. (Photo credit: B. Pottle)

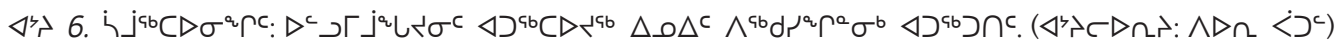




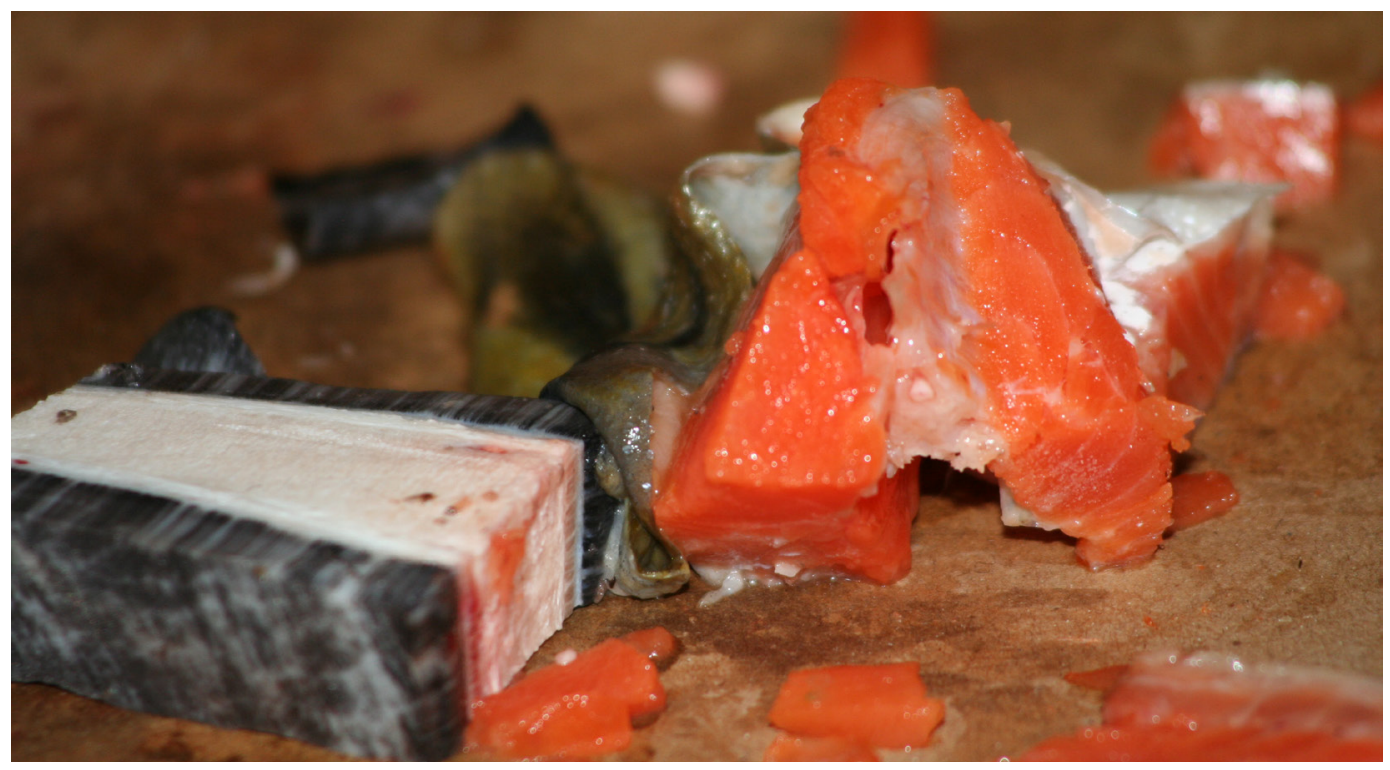

Image 7. Maktaaq and iqaluk (char). (Photo credit: B. Pottle)

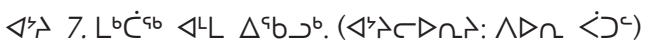

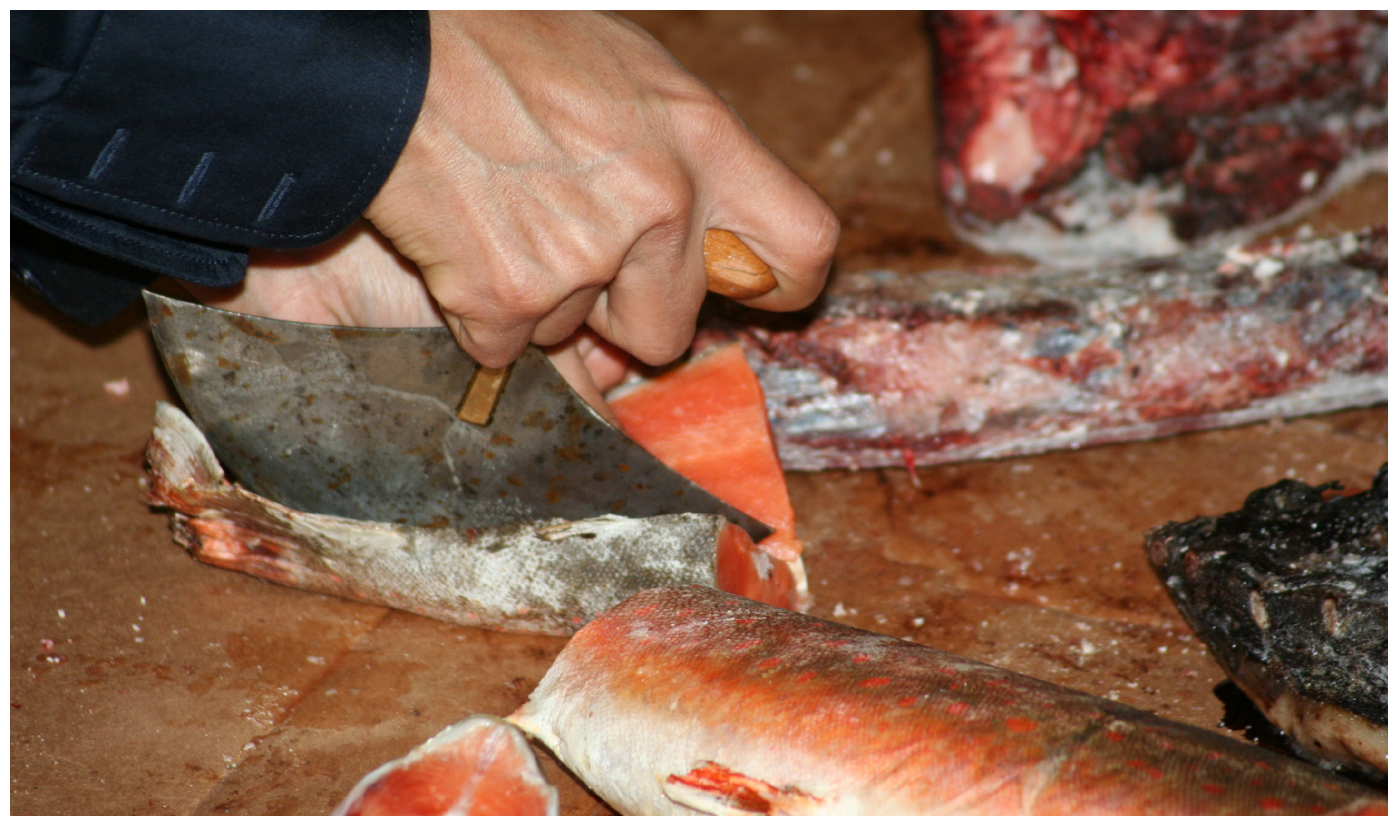

Image 8. Cutting iqaluk (char). (Photo credit: B. Pottle)

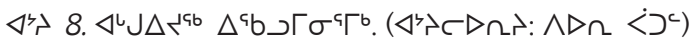




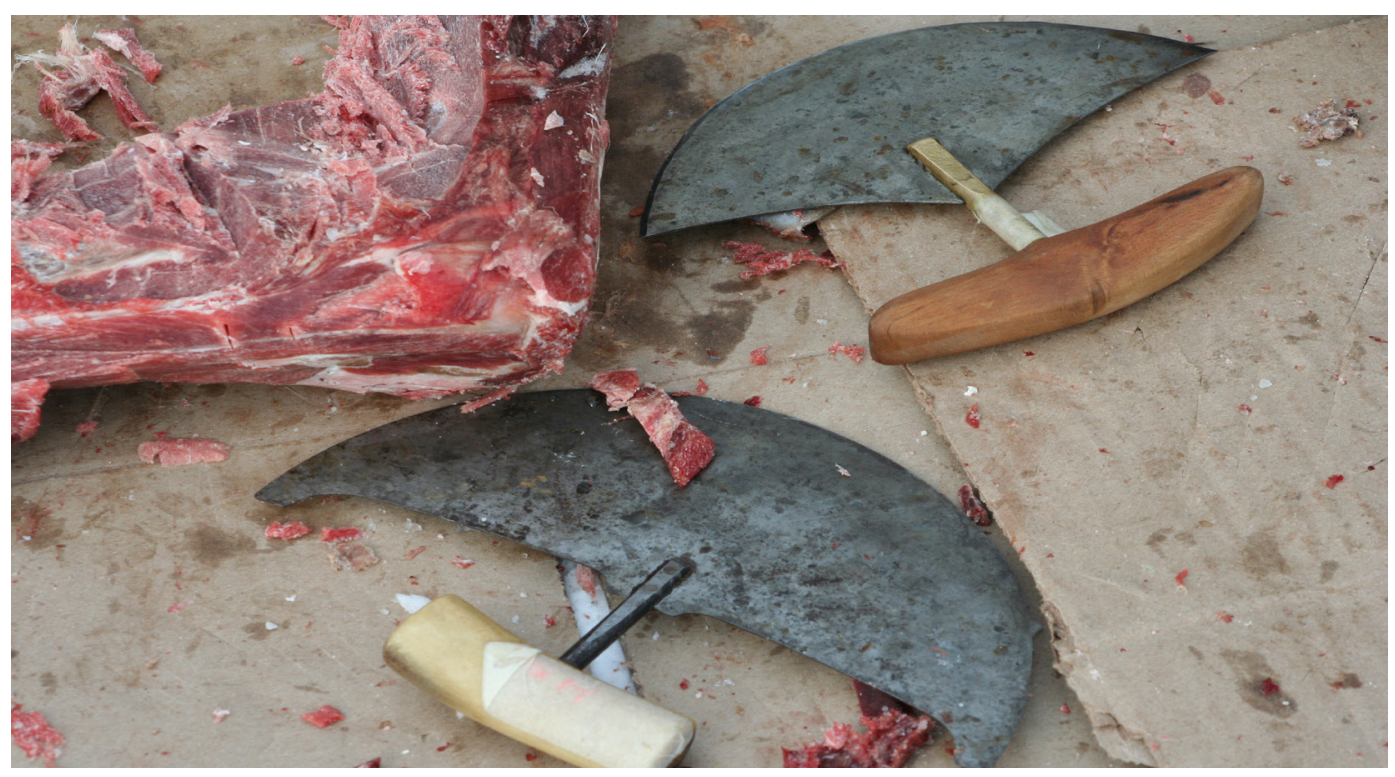

Image 9. After the cut: leftover tuktu (caribou) and ulus (traditional Inuit women's knives). (Photo credit: B. Pottle)

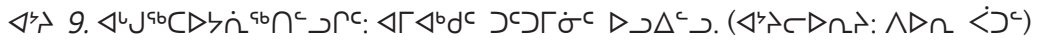

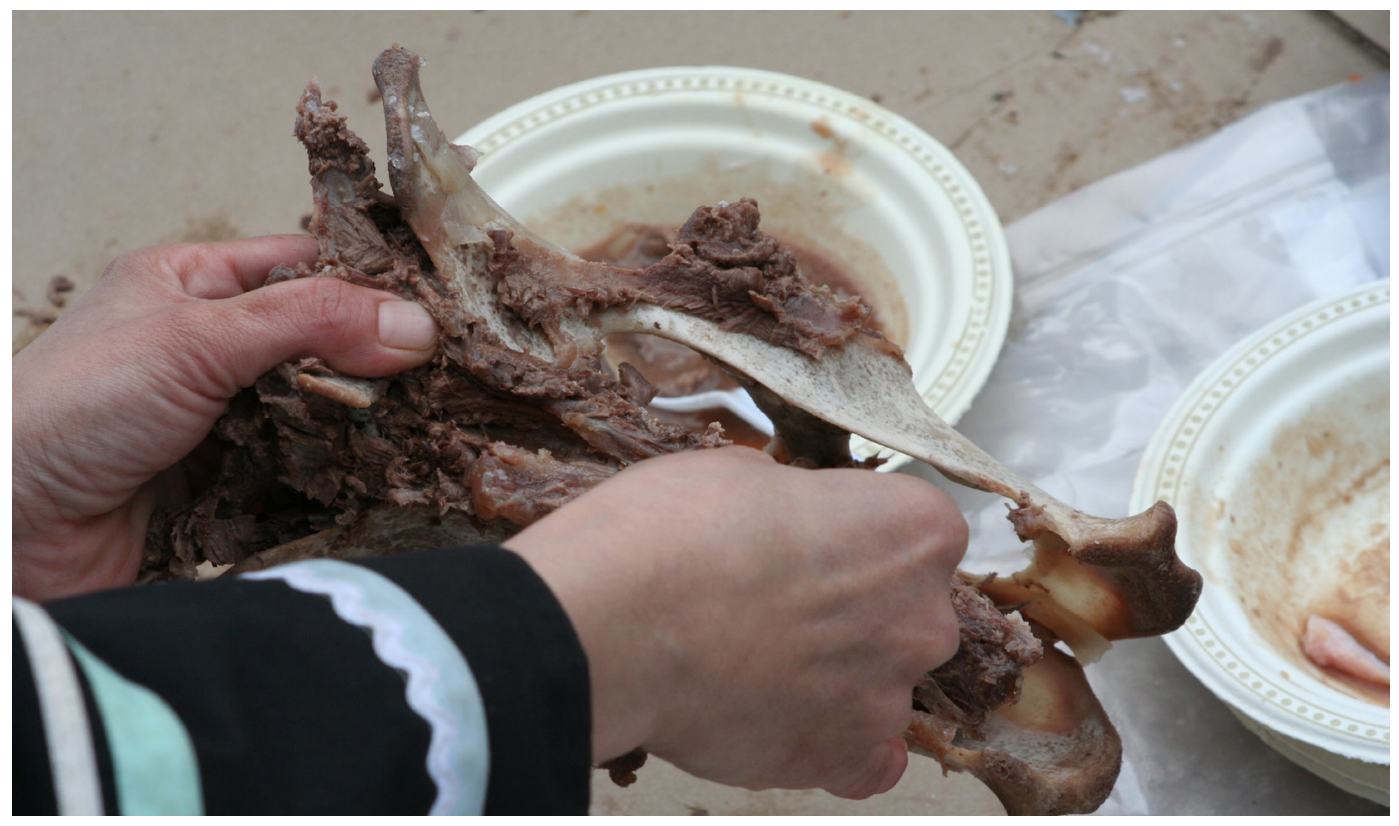

Image 10. Eating a piece of tuktu (caribou). (Photo credit: B. Pottle)

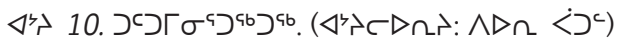




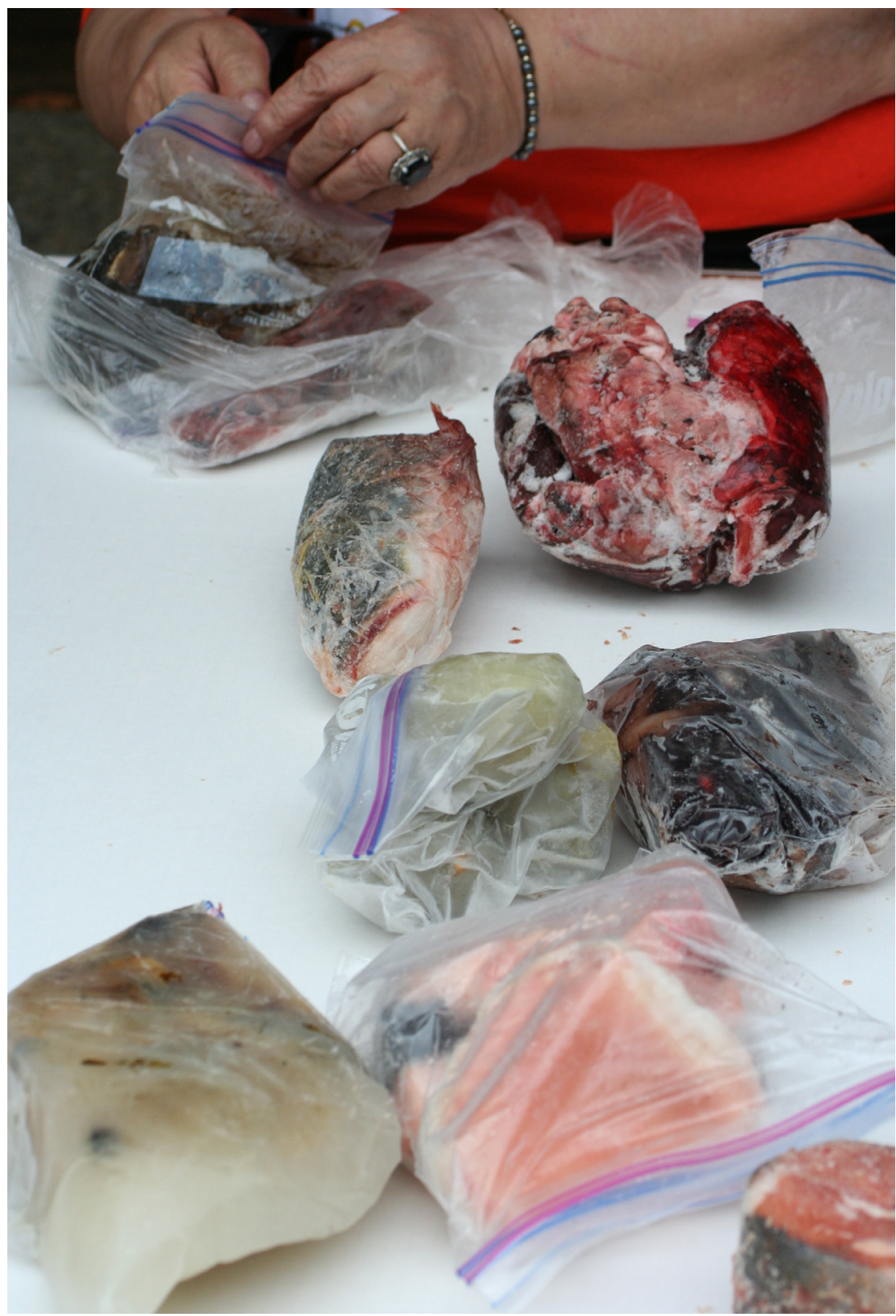

Image 11. Country food from the community freezer (fish, seal, tuktu), ready for sharing at events and social gatherings. (Photo credit: B. Pottle)

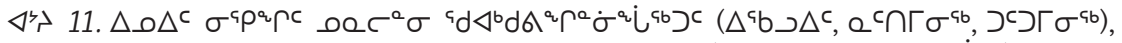

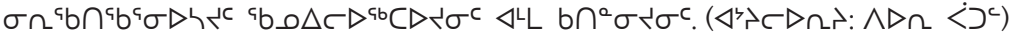




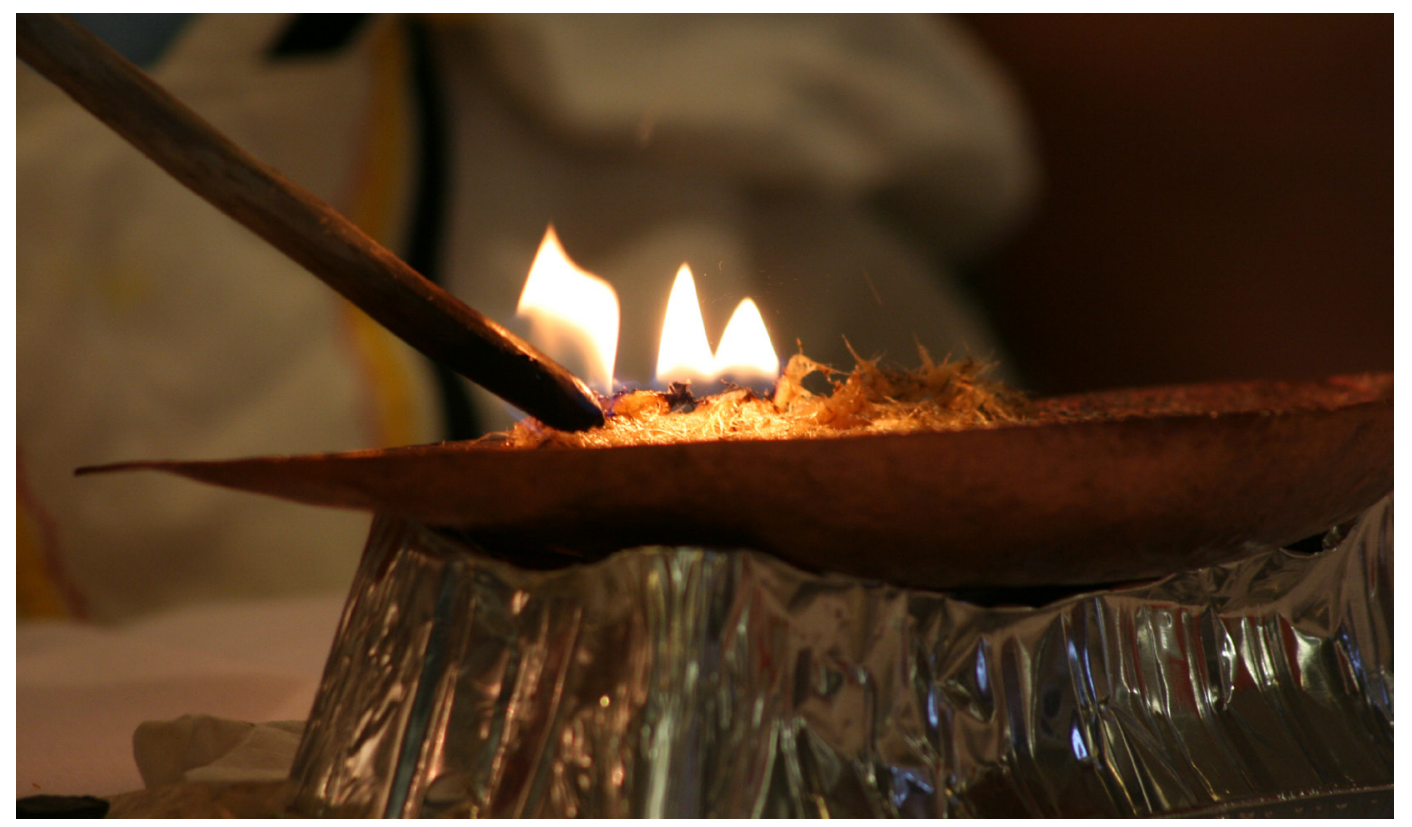

Image 12. Lighting the qulliq, a traditional Inuit oil-lamp. (Photo credit: B. Pottle)

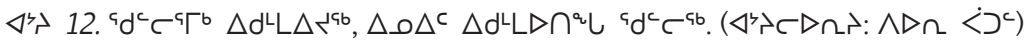




\section{ENDNOTES}

i While some Inuit use the term "Inuit food," Barry prefers "country food."

ii Quotations in this article are from an informal survey of Barry's friends and acquaintances in different urban centres. "Although I know what country food means to me," says Barry, "I decided to ask what it meant to other Inuit, as well as how often they eat country food and how they acquire it." 


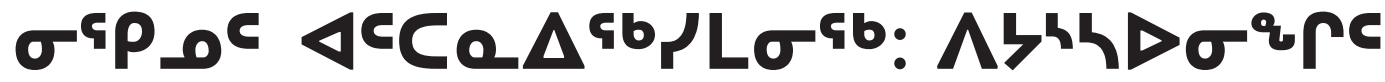

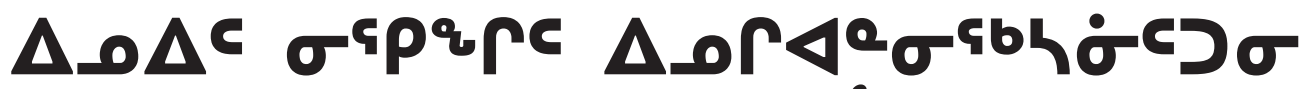

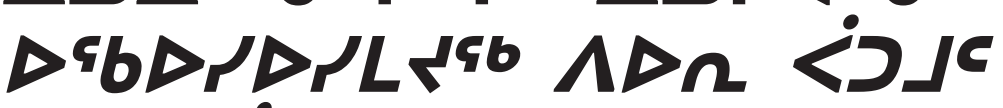

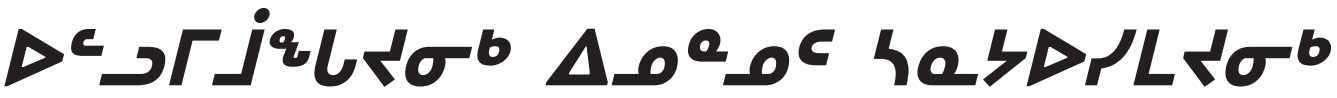

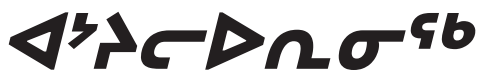

\section{Foodland Security: Access to Inuit Country Food in an Urban Setting As told by Barry Pottle through contemporary Inuit Art Photography}

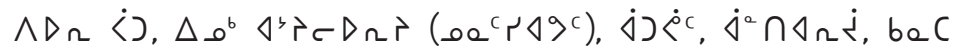
Barry Pottle, Inuk photographer (Nunatsiavut), Ottawa, Ontario

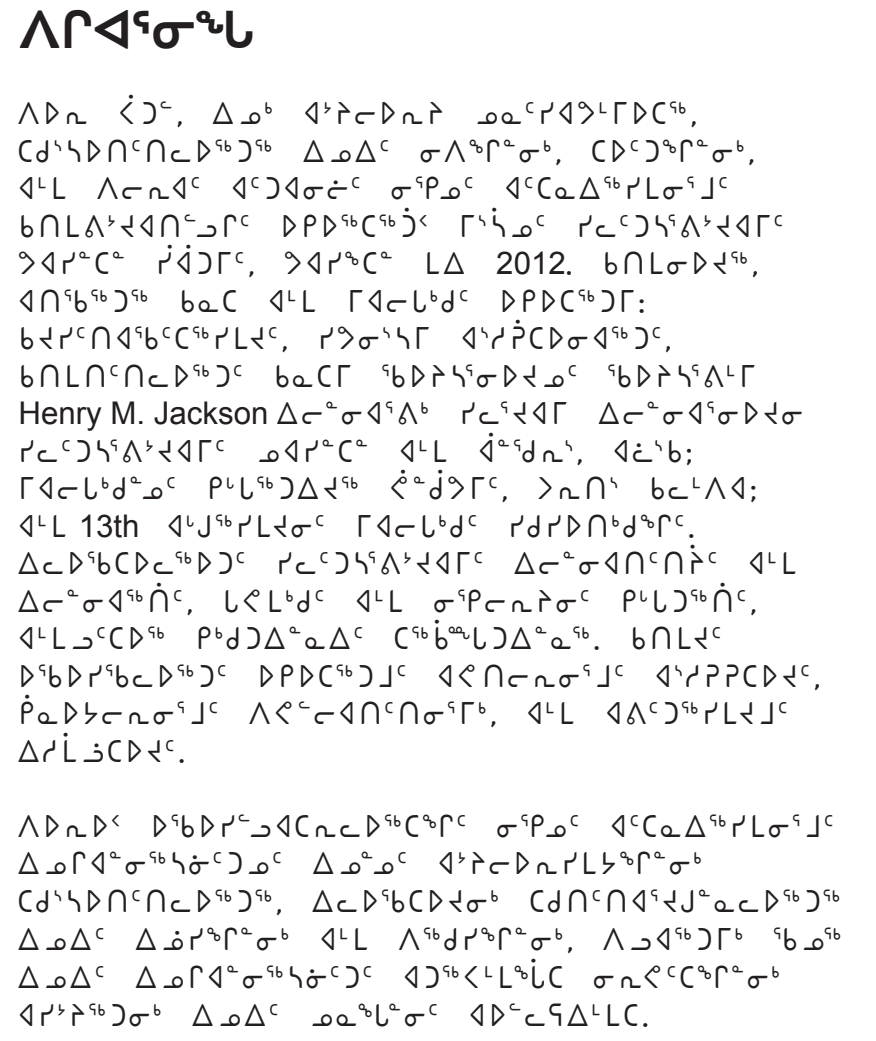

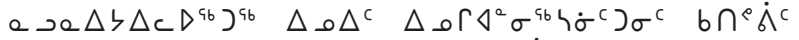

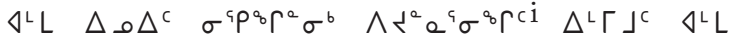

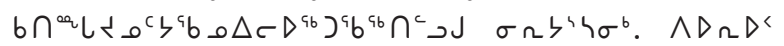

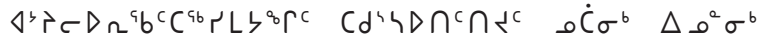

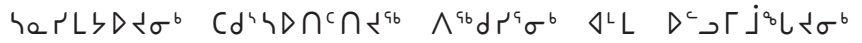
$\Delta \rho^{a} \sigma^{c}$ b $\left.b\right\lrcorner \Delta C D^{\mathrm{bb}} C D \backslash \sigma^{b}$.

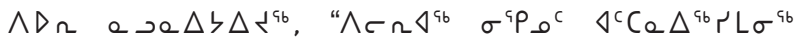

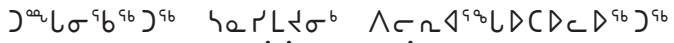

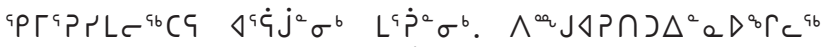

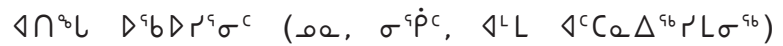

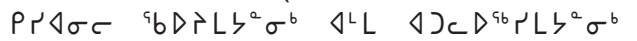

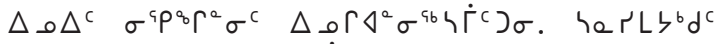

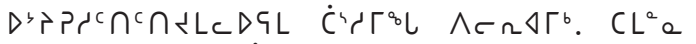

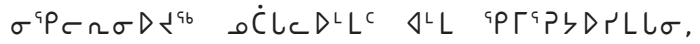

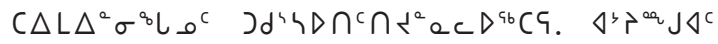

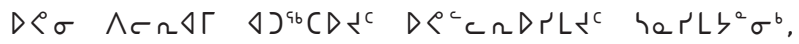

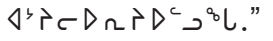

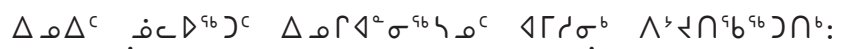

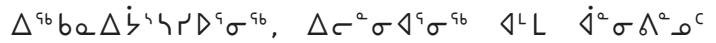

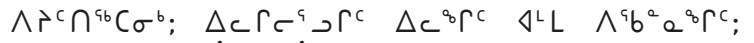

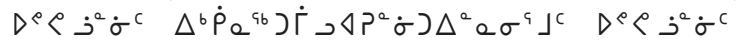

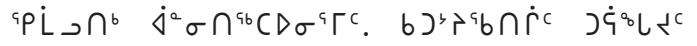

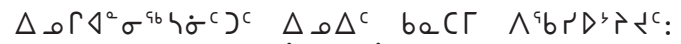

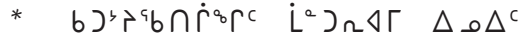

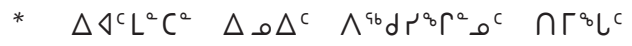




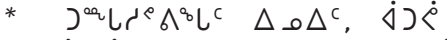

* $\quad \dot{L} \sigma j<\Gamma \quad \Delta \Delta_{0} \Delta^{c} b J^{s} r^{a} b \cap \dot{\Gamma}^{b} \Gamma^{c} ; \quad \Delta \sigma<\Delta^{b}$

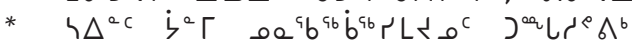

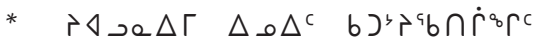

\section{$\sigma^{a} p^{c} c n^{b} \Gamma^{a} \sigma^{b} \quad \Delta^{c} \mathrm{Ca} \Delta^{a b} r L^{a b}$

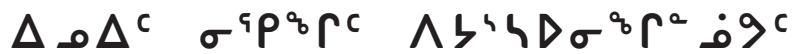

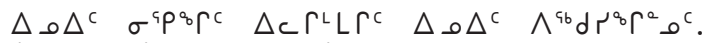

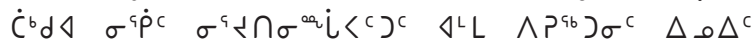

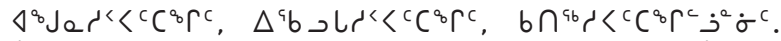

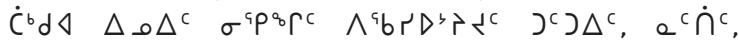

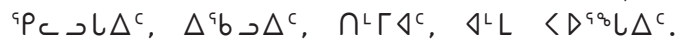

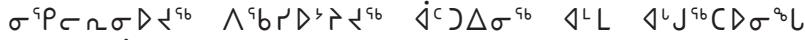

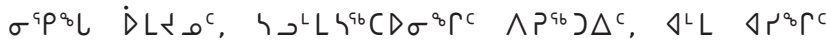

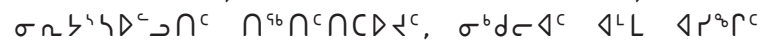
$\triangle)^{a b} C D \triangleleft c$

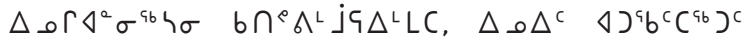

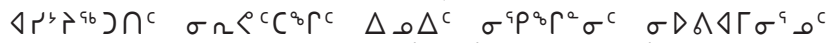

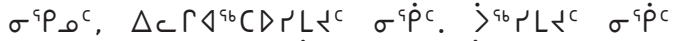

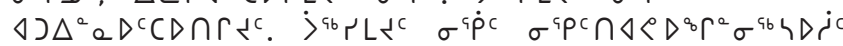

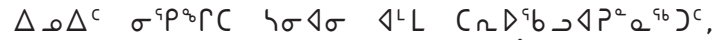

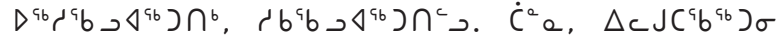

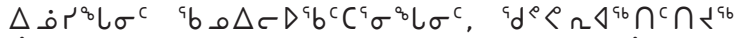

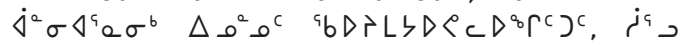

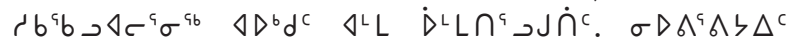

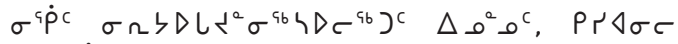

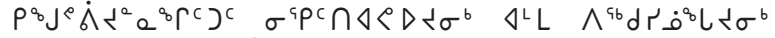

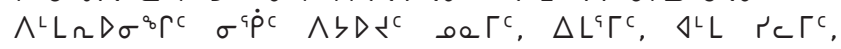

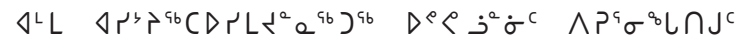
$A r_{s} r_{a b} C D r L r_{c b}$.

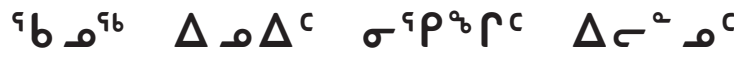 $\supset p^{9} b^{9 b}<{ }^{c}{ }^{\text {ii }}$}

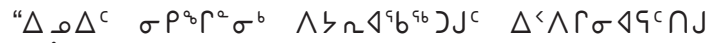
$\rho \circ \dot{j} \sigma \mathrm{\gamma} ! "$

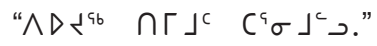

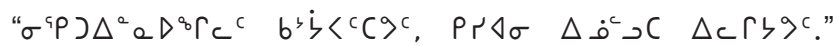

"JPa $\left.P^{a b}\right)^{a b} \quad \ldots \quad L^{a q} \Gamma \sigma^{a b}, \triangleleft^{L} L \quad{ }^{a} b \_\Delta^{a q} \Gamma \cap \Delta^{a} \sigma^{a b} . "$

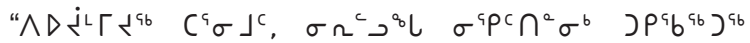

$L \Gamma \zeta^{9} \sigma^{96}$."

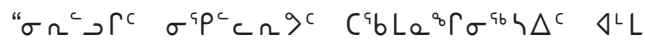

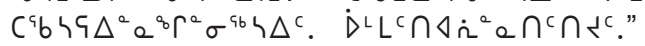

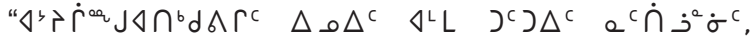
$\left(L^{b} p^{b} \quad \Delta_{0} \Delta^{c} \quad \Delta^{L} L \quad J^{c}\right) \Delta^{c} \quad D^{c} c b \Delta^{a} a \Delta^{c}$."

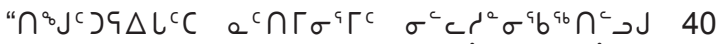
$D^{e}<\dot{j}^{a} \dot{\sigma}^{c}$ 50, $\left.\supset P b^{a b} J^{a b} \quad D^{c}\right\lrcorner c^{c} \dot{L} J^{c} \quad D^{a b} \dot{d} \sigma \Delta c^{a b} J J^{c}$. $\left.\left(\Delta L^{a} a e^{c} \dot{\cap}^{c} \dot{D} L e^{c}\right)^{c} \quad \Delta^{b} \dot{P}_{a^{a b}}\right)^{c} \Gamma^{c}$."

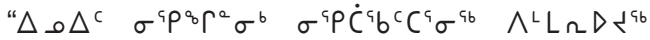

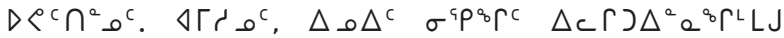

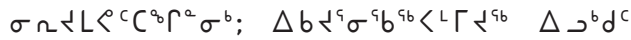

$\Delta^{<} \wedge^{a} \sigma \Delta \sigma^{b} d^{c} . "$

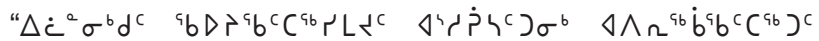

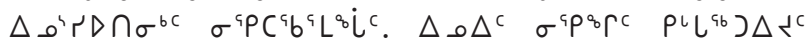

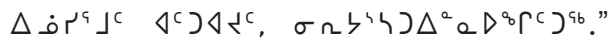

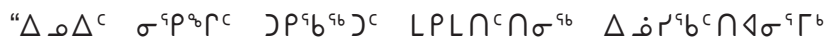

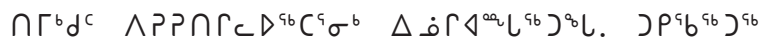

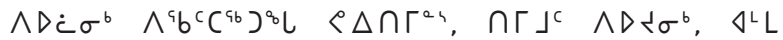

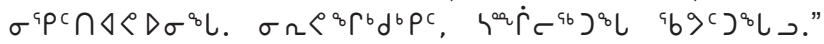

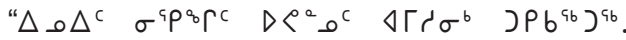

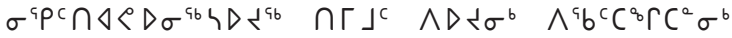
$\sigma \triangleright \Delta \triangleleft \Gamma \sigma^{\mathrm{c}} \sigma^{\mathrm{b}} \quad \sigma^{\mathrm{q}} P \sigma^{\mathrm{c}} . "$

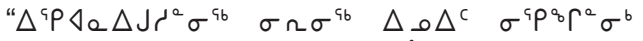

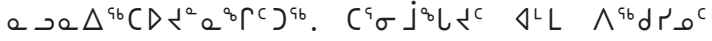

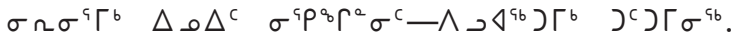

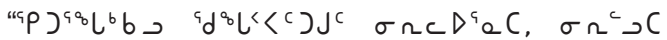
$\left.\triangleleft^{L} L \quad \sigma \Omega b \dot{n}^{a b}\right){ }^{a} d \Delta^{a} \Gamma^{b} \quad D^{e}<\dot{j}^{a} \dot{\sigma}^{c} \bigcap^{\text {ab }} \cap C^{a b}$. $\left.\left.\left.J^{a} b^{a b}\right)^{a b} \triangle \dot{a}^{c} C, \Delta^{L} L \Delta 0^{a b} \Gamma^{a} a^{a b}\right) C, \quad D P D C^{a b}\right) \Gamma$

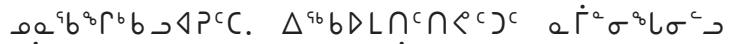

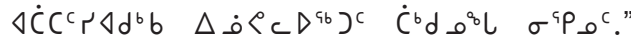

"d $\left.d \triangle \triangle \Gamma \zeta D \sigma^{\circ} b \quad C d^{h} \zeta D \cap C D^{\circ} \Gamma^{a} a^{a b}\right)^{a b} \quad \Delta^{8} b a d^{c} \cap J^{c}$

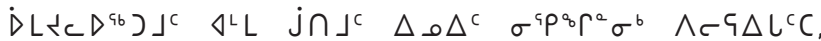
$\left.\sigma \Omega^{c}\right\lrcorner C, \quad \triangleleft^{L} L \quad \sigma n ל \dot{n} \uparrow \Delta L^{c} C . "$

\section{${ }^{\mathrm{a} b} \mathrm{o}^{\mathrm{ab}} \quad \Delta \Delta^{\mathrm{c}} \quad \sigma^{\mathrm{b}} \Gamma^{\mathrm{a}} \sigma^{\mathrm{b}}$

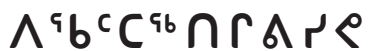

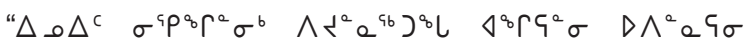

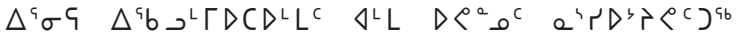
$\left.\Delta^{c} b\right\lrcorner^{a} \sigma^{b}, \quad a^{c} \cap \Gamma \dot{\sigma}^{c} D^{e}<\dot{\partial}^{a} \dot{\sigma}^{c} L^{c} \dot{C} \Gamma^{b}$."

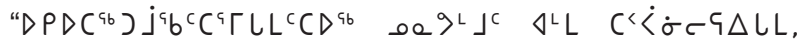

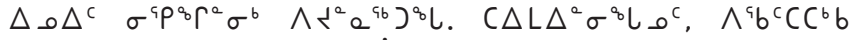
$\left.\triangle C D \Delta^{a b}\right)^{b} b \quad C^{a b} P L C \Delta^{c}$ aborcal $L C$."

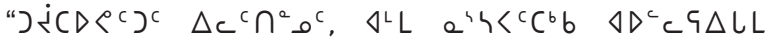
$\left.\left.D P D C^{9 b}\right)\right\lrcorner^{c} . "$ 


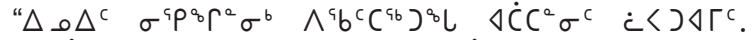

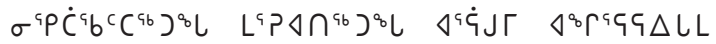

$D^{e}<\dot{j}^{a} \dot{\sigma}^{c} \Delta c^{b} b \quad L D^{a q} L G \Delta^{L} L C$."

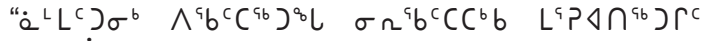

Cab PCL'."

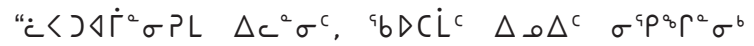
$\sigma \Omega^{9} b^{c}\left(\zeta^{9 b}\right)^{\circ} b . "$

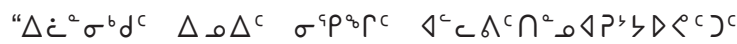

$\left.\left.\left(\Delta \Delta^{\circ} \Delta^{c} \quad b\right)^{b} \Gamma^{q} b \cap \dot{\Gamma}^{b} \Gamma^{c}\right), \quad p r \Delta \sigma \quad \dot{L}^{a} a \quad \Delta \Gamma L^{c} b^{c} C^{c b}\right)^{c} . "$

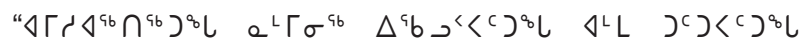

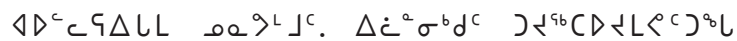

$\left.\mathcal{X}^{c} \supset \Gamma \sigma^{c} \Gamma^{b} \quad \Delta c^{a} \sigma^{c} \quad \triangleleft^{c} \Delta \Delta \sigma^{c} \quad \Delta P D^{b} J \cap^{c}\right\lrcorner J . "$

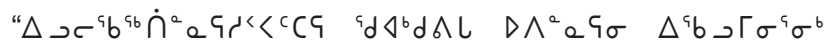

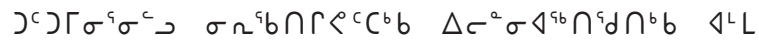

$\left.\wedge^{a} b^{a} a^{b} b \quad C^{9 b} P C L^{c} \quad C \dot{L} \sigma \quad \dot{\jmath}\right) \dot{e} \Gamma . "$

$\left.\Lambda D_{\Omega} \cap \cap q^{a b}\right)^{a b}, \quad \dot{\sigma}^{a} b D+L c D C_{\Delta} \Delta^{a b} C^{b} b \quad \Delta c^{b} \Gamma^{c}$

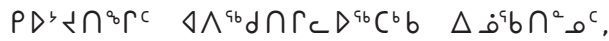

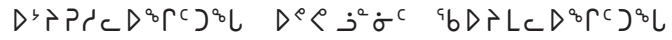

$L^{a c} \Gamma \sigma^{8} \Gamma^{a} \sigma^{b} \Delta^{L} L \quad J P^{a} b^{a} \sigma^{8} \Gamma^{a} \sigma^{b} P D^{b} L \cap D D^{c} . \Delta \sigma^{c} \Delta^{c}$

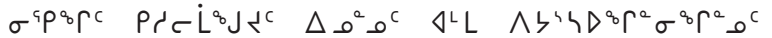

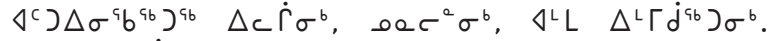

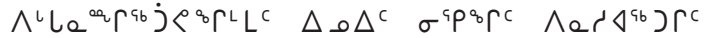

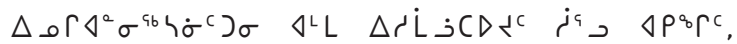

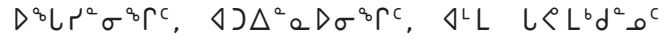

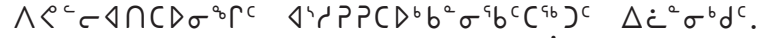

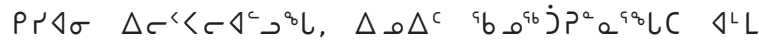

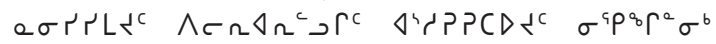

$\wedge \sigma \triangleleft^{a} L C \quad \Lambda^{L} \operatorname{Ln} D \Gamma \zeta^{\circ} \Gamma^{e} \sigma^{b}$.

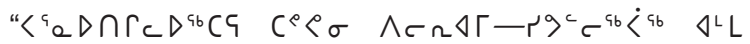

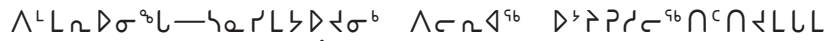

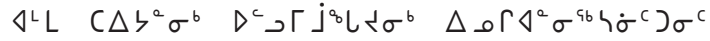

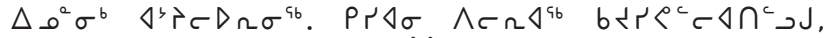
$\left.\left.\Delta \dot{c}^{a} \sigma^{b} d^{c} \Delta^{\mathrm{L}} \Gamma \sigma^{b} \Delta \dot{a} r^{a} b^{a b} j \dot{j} c D^{a b}\right)^{a b}, \nabla \wedge J r^{c} \cap \Delta^{a b}\right)^{a b}$

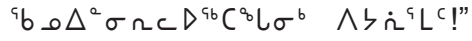

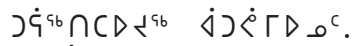

ad $d^{\mathrm{\Gamma}} \dot{\mathrm{r}}$ !

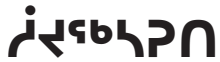

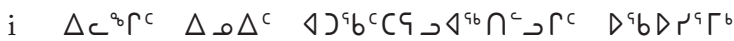

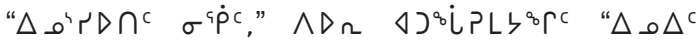

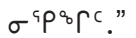

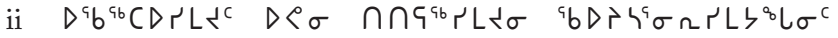

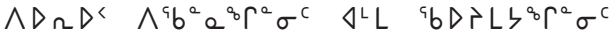

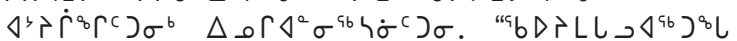

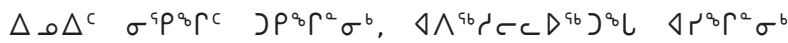

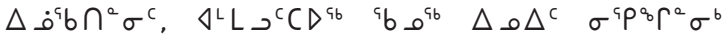

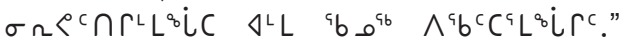




\title{
Socioeconomic and Psychosocial
} Adversity in Inuit Mothers from Nunavik during the First Postpartum Year

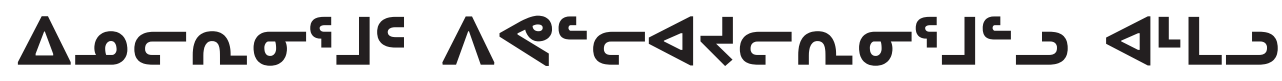

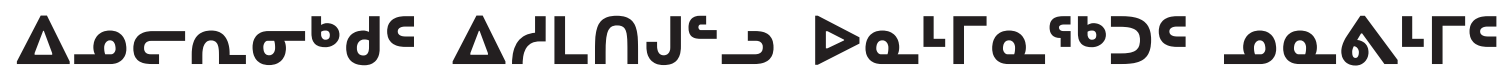

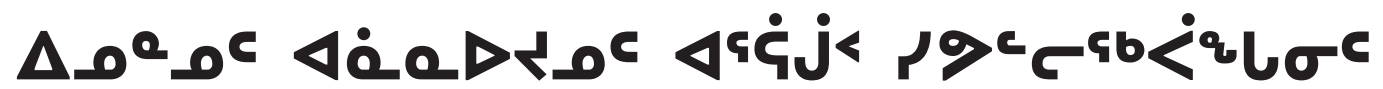

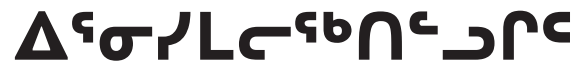

Stéphanie Fortin, Centre de recherche du CHU de Québec, Québec, Québec; and School of Psychology, Laval University, Québec, Québec, Canada

Sandra W. Jacobson, PhD, Department of Psychiatry and Behavioral Neurosciences, Wayne State University School of Medicine, Detroit, Michigan, USA

Jocelyne Gagnon, PhD, Centre de recherche du CHU de Québec, Québec, Québec, Canada

Nadine Forget-Dubois, PhD, Centre de recherche du CHU de Québec, Québec, Québec, Canada

Ginette Dionne, PhD, School of Psychology, Laval University, Québec, Québec, Canada

Joseph L. Jacobson, PhD, Department of Psychiatry and Behavioral Neurosciences, Wayne State University School of Medicine, Detroit, Michigan, USA

Gina Muckle, PhD, Centre de recherche du CHU de Québec, Québec, Québec; and School of Psychology, Laval University, Québec, Québec, Canada

\begin{abstract}
The postpartum year is a crucial period for child development and mother-child attachment. In a young and prolific population such as the Inuit from Nunavik (northern Quebec, Canada), postpartum maternal well-being is even more concerning. This study aims to document the prevalence and co-occurrence of socioeconomic and psychosocial risk factors in this population, and to use these factors to identify specific profiles of women. Data collection involved 176 mothers recruited during pregnancy and interviewed 12 months after delivery. Socioeconomic (age, education, single parenting, unemployment, welfare) and psychosocial (psychological distress, suicidal thoughts and attempts, spousal abuse, drug and alcohol use) risk factors were documented. Four high-risk conditions (socioeconomic precariousness, distress, domestic abuse, and substance use) were computed and considered in the analysis. Adversity was salient because most of the women (58\%) simultaneously experience many high-risk conditions, with socioeconomic difficulties, distress, and spousal abuse being the most prevalent. Distinct profiles were identified: those without
\end{abstract}


socioeconomic and psychosocial risk factors (30.8\%) and those experiencing distress (69.2\%). From the latter category, two specific profiles of distressed mothers emerged: single women coping with socioeconomic stressors (40.1\%), and women with fewer financial difficulties but in an abusive relationship and more likely to use drugs or binge drink (29.1\%). Our results support the need for preventive and public health programs in this population to improve maternal as well as infant wellbeing.

\section{KEYWORDS}

Adversity, poverty, distress, domestic violence, substance use, postpartum year, Inuit, Aboriginal peoples

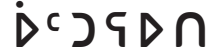

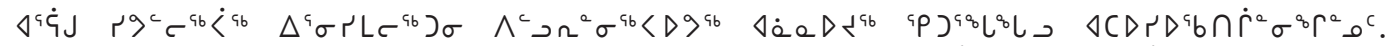

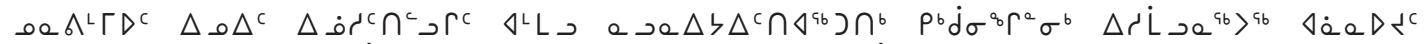

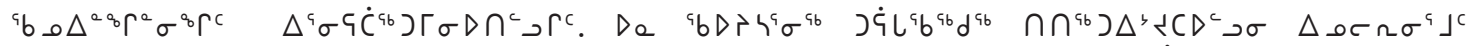

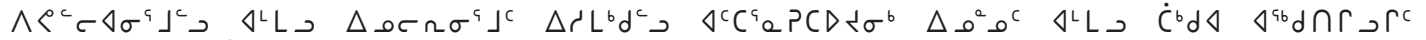

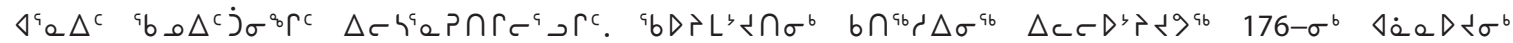

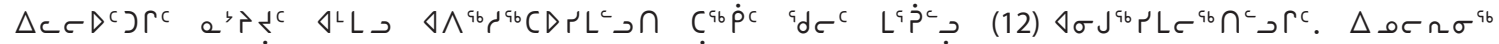

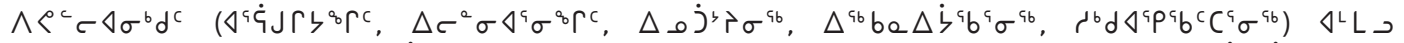

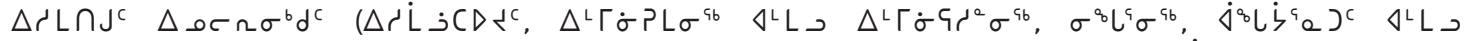

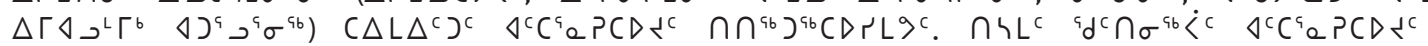

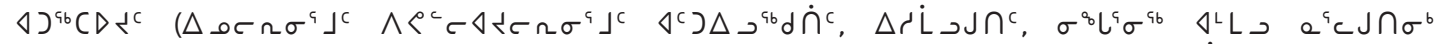

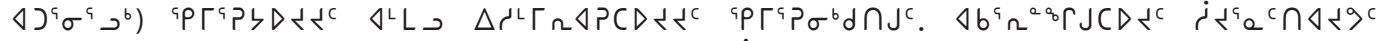

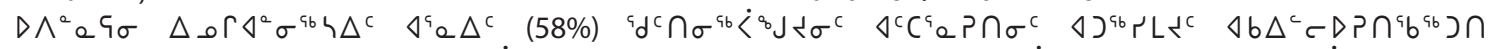

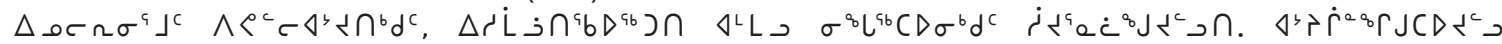

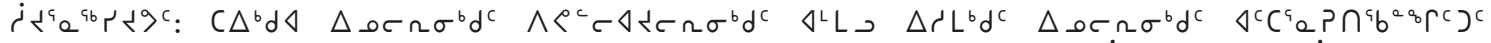

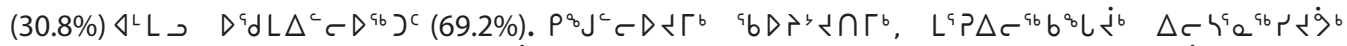

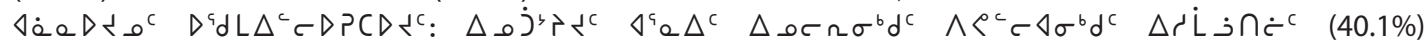

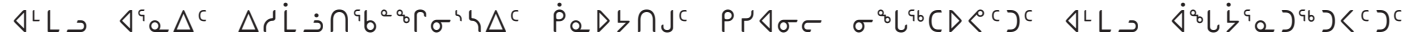

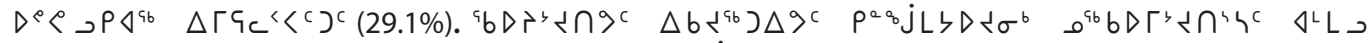

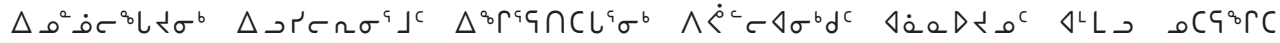
$\Delta \dot{\omega}^{c} \cap \Delta^{\mathrm{c}} \sigma^{\mathrm{b}} \Gamma^{\mathrm{a}} \rho^{\mathrm{c}}$.

\section{$D^{a} b D r^{a b} C^{c}$}

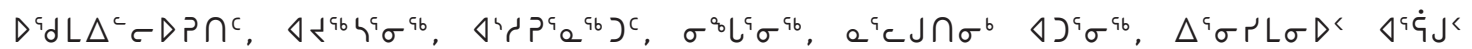

\section{INTRODUCTION}

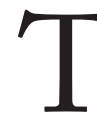
he postpartum year, starting after childbirth, is a critical period for early child development and for the establishment of a mother-child relationship (Stein et al., 2010). Mothers - the principal caregivers for most children during the first year of life-play a decisive role in the optimal development of their children. Difficulties that interfere with mothers' parenting ability are therefore of public health concern (Logsdon, Wisner, \& Pinto-Foltz, 2006). Normative population studies show that many mothers experience personal and marital distress during this transitional period (Elek, Brage Hudson, \& Bouffard, 2003; McConachie et al., 2008; Sakala, Declercq, \& Corry, 2002). Among Canadian Aboriginal Peoples, where 50\% of the population is under 24-years of age (Statistics Canada, 2008), adverse socioeconomic conditions and a high rate of psychosocial problems further add concern about optimal parenting among mothers (Commission des droits de la personne et des droits de la jeunesse, 2007).

Socioeconomic and psychosocial stressors - such as poverty, psychological distress, substance use, and domestic abuse-can significantly impair maternal functioning and therefore parenting 
practices (MacKenzie, Kotch, \& Lee, 2011; Whitaker, Orzol, \& Kahn, 2006). Family stress theory proposes that socioeconomic stressors indirectly affect the development of young children through the stress and distress experienced by their mother (Ewart \& Suchday, 2002; Kotchick, Dorsey, \& Heller, 2005; Westbrook \& Jones Harden, 2010). Stress and depressive symptoms in mothers are linked to parenting that is less warm, supportive, and involved (Jackson, Brooks-Gunn, Huang, \& Glassman, 2000; Jackson \& Scheines, 2005), is more restrictive (Gutman, Friedek, \& Hitt, 2003), and shows fewer child-centred behaviours (Bluestone \& Tamis-LeMonda, 1999). Similarly, reflective functioning theory suggests that psychosocial difficulties-such as depression, domestic abuse, and substance use-impact mothers' understanding of their child's needs, emotions, and intents (Schechter et al., 2008; Sharp \& Fonagy, 2008; Wohlgemuth Levy, 2003). These difficulties are also significantly related to negative maternal behaviours, such as intrusiveness, anxiety, and rejection/ hostility (Grienenberger, Kelly, \& Slade, 2005; Rosenblum, McDonough, Sameroff, \& Muzik, 2008).

The study of individual risk factors, i.e., any situation or environmental characteristic that raises the likelihood of developing adverse outcomes, does not well represent personal experience because people tend to experience multiple risk factors at the same time (Chmura Kraemer, Stice, Kazdin, Offord, \& Kupfer, 2001; Kelley et al., 2010; MacKenzie et al., 2011). A cumulative approach to the study of risks assumes that child outcomes are affected by the increased stress caused by additional risk factors, regardless of the specific nature of these risks (DeaterDeckard, Dodge, Bates, \& Petit, 1998). Studies supporting this approach have generally concluded that developmental difficulties tend to increase with the number of risk factors (Hooper, Burchinal, Roberts, Zeisel, \& Neebe, 1998; Jaffe, Capsi, Moffitt, Polo-Tomás, \& Taylor, 2007; MacKenzie et al., 2011). Pioneers in this approach, Sameroff et al. (1987) found that each additional risk factor resulted in an average decrease of four verbal intelligence quotient (IQ) points in the Rochester Longitudinal Study, which evaluated 215 four-year-old children from socially heterogeneous environments. This result has been replicated in three independent studies examining different child outcomes (Atzaba-Poria, Pike, \& Deater-Deckard, 2004; Biederman, Faraone, \& Monuteaux, 2002; Raviv, Taussig, Culhane, \& Garrido, 2010; Yumoto, Jacobson, \& Jacobson, 2008). To our knowledge, only one epidemiological study (Whitaker et al., 2006) has focused on cumulative psychosocial risk factors in the postpartum year. This study found that behavioural problems at three years of age went up significantly as the number of postpartum risk factors (i.e., mental health problems, domestic violence, and substance use) increased.

Throughout the last two decades, health surveys conducted by governmental agencies (Jetté, 1992; Pageau, Ferland, \& Déry, 2003; Santé Canada, 1998) have highlighted the persistence of socioeconomic and psychosocial disparities between Aboriginal Peoples and the general Canadian population. However, Aboriginal Peoples were considered as a homogenous group, even though Inuit, Métis, and First Nations groups have each their own historical, cultural, and social characteristics. Of all the health concerns among the Inuit, the so-called social pathologies—such as suicide, violence, and substance abuse - are the most prevalent and destructive. Although there have been improvements in the last decades, socioeconomic issues such as unemployment, low income, poor education, and decreased housing quality remain major problems for the Inuit (Bjerregaard, Young, Dewailly, \& Ebbesson, 2004).

In 2004, one major health survey (the Nunavik Inuit Health Survey, also known as Qanuippitaa) was conducted in the 14 Nunavik (northern Quebec) communities. Qanuippitaa surveyed Inuit men and women from 521 households, which was about $27 \%$ of the population. This representative sample of the Nunavik adult population provided prevalence rates of demographic, socioeconomic, and psychosocial risk factors (Rochette, StLaurent, \& Plaziac, 2007). The survey highlighted that a large portion of the population experienced socioeconomic stressors $\mathrm{i}$ : $78 \%$ of respondents did not graduate from high school, and 58\% had an income of less than $\$ 20,000$ and a precarious employment status (Anctil, 2007), compared to $34 \%$ and $11 \%$, respectively, in the general population of Canada (Statistics Canada, 2009; Statistics Canada, 2011). Rates of psychological distress, a broad state of emotional suffering, were $15.1 \%$ and $13.9 \%$ in the groups of Inuit women aged 15-29 and 30-49 years old, respectively (Kirmayer \& Kenneth, 2007). In contrast, the Canadian Community Health Survey (CCHS) reported distress rates from $6.8 \%$ to $8.3 \%$ in women of similar ages (Gravel \& Béland, 2005). A history of suicidal thoughts was reported by $18.4 \%$ of Inuit women for the 12 months preceding the survey, while $25.7 \%$ reported at least one lifetime suicide attempt (Kirmayer \& Kenneth, 2007). Women in the CCHS reported a similar proportion of suicidal thoughts (16\%), but the rate of lifetime attempts was 6 times lower (4.2\%) (Government of Canada, 2006). About six in 10 Inuit women experienced at least one incident of physical abuse during adulthood, with $70 \%$ of these abuses from a spouse or partner (Lavoie, Muckle, Fraser, \& Boucher, 2007). In the 1999 General Social Survey, the rate of physical and sexual spousal violence against Canadian women overall was $8 \%$ (Canadian Centre for Justice Statistics (CCJS), 2006). Marijuana and abusive alcohol use were also more prevalent among Inuit women than in the general Canadian population. Half of the Inuit surveyed used marijuana in the year preceding Qanuippitaa, and $47.1 \%$ were at risk of alcohol-related problems (Muckle, Boucher, Laflamme, \& Chevalier, 2007), compared with $7.8 \%$ and less than $5 \%$, respectively, in women in the general Canadian population (Government of Canada, 2006). Our team (Muckle et al., 2011) recently reported a high prevalence of alcohol use, smoking, and drug use during pregnancy in a sample of 248 Nunavik women from the Hudson Bay region who participated in the Environmental Contaminants and Child Development (ECCD) study. Rates of smoking, alcohol use, binge drinking, and marijuana use were $92 \%, 60 \%, 38 \%$, and $36 \%$, respectively.

This study, part of the ECCD study, aims to describe the adversity faced by Inuit mothers from Nunavik during the first postpartum year, a positive but stressful period of transition 
that is important for early child development and mother-child bonding. Here, adversity is defined as a condition in which the mother faces multiple risk factors or negative events that were likely to jeopardize the development of their child during the year following childbirth. First, we document the prevalence, i.e., number of cases for a given time period (postpartum year), and the co-occurrence of socioeconomic and psychosocial risk factors. Second, we identify association patterns among the factors. We computed binary (i.e., yes/no) high-risk conditions and used an innovative analysis to identify specific profiles of women. Outcomes of this study are significant to the Inuit population of Nunavik, where fertility rates are higher than the rest of Quebec (Rochette et al., 2007). Our findings may lead to specific prevention and public health programs for Inuit mothers in the prenatal and postpartum periods.

\section{METHODS}

\section{Participants}

The sample consisted of 176 women who participated in the ECCD study (Jacobson et al., 2008; Muckle, Ayotte, Dewailly, Jacobson, \& Jacobson, 2011), which was conducted in the three largest communities (Puvirnituq, Inukjuaq, and Kuujjuaraapik) of Nunavik between November 1995 and March 2002. The Nunavik region is located north of the 55 th parallel in the province of Quebec. About 11,300 Inuit live in 14 villages scattered along a 2000-km shoreline of the Hudson Bay, Hudson Strait, and Ungava Bay. Midwives and nurses provided us with the names of pregnant women shortly after their first prenatal visit. A research assistant contacted each potential participant by telephone and invited her to meet at the village nursing station to learn about the objectives and procedures of the study, which focused on infant health and development. Women without telephones were notified through the radio station. The study received approval from ethical review boards at Laval University and Wayne State University. It received the support of the Nunavik Nutrition and Health Committee, the relevant municipal councils, the Pauktuutit Inuit Women's Association, and the Nunalituqait Ikaluqatigiitut Association. Each participant gave a detailed consent, and participation was voluntary. Women could refuse to answer any question or end the interview at any time during a visit. Participants received a financial compensation of $\$ 20$ per visit.

During the study period, participants reported 417 pregnancies. Fifty-nine potential participants were excluded for the following reasons: previous participation in the study $(n=47)$, miscarriage during the first trimester of pregnancy $(n=3)$, or inability to contact $(n=9)$. An additional 110 women declined to participate $(26.4 \%)$. Women who volunteered to participate were interviewed at the nursing station during pregnancy $(N=248)$, and at 1 month $(N=215)$ and 12 months after delivery $(N=176)$. Interviews were conducted in English, French, or Inuktitut with the help of an Inuit interpreter. Research staff working as interviewers held a master's or a doctoral degree in psychology and were trained to support participants during the interviews as needed. Staff referred participants to the local health or social services when appropriate. The main reasons for the loss of participants after enrolment were: infant adopted by a family living outside of the three communities participating in the study $(28 \%)$, mother moving to a community not participating in the study (22\%), miscarriage or infant mortality (22\%), and inability to contact (18\%). Refusal rates after enrolment were $3.6 \%$ and $6.7 \%$ at the 1- and 12-month follow-up visits, respectively.

\section{Instruments and variables}

We assessed the following demographic and socioeconomic characteristics through the interviews: mother's age at delivery, years of education, welfare status, employment status, single parent status, village of residency, language used in interviews (Inuktitut vs. French or English), and the adoption status of the child.

We measured psychological distress using a short version of the Indice de détresse psychologique de Santé Québec (14 items), also known as the IDPESQ-14 (Préville, Boyer, Potvin, Perrault, \& Légaré, 1992). This instrument, developed from the Psychiatric Symptoms Index (Ilfeld, 1976), assesses the frequency (never, once in a while, or often) of symptoms of depression (e.g., sadness, lost interest in activities), anxiety (e.g., feeling tense, restlessness), irritability and cognitive problems (e.g., attention difficulties) experienced during the previous week. The weighted sum of all items, which ranges from 14 to 42, provides a summary score for psychological distress. A clinical cut-off score $\geq 26$ is used to identify possible cases of depression (Audet, Lemieux, \& Cardin, 2001). The IDPESQ-14 has good internal consistency and reliability among the Inuit (Cronbach's alpha $=.88$ ) and a stable factorial structure (Jetté, 1992). We used two specific yes/no questions (Tousignant, Hanigan, \& Bergeron, 1984) previously used in Inuit health surveys in Nunavik to document the prevalence of postpartum and lifetime suicidal thoughts and attempts.

We assessed domestic abuse with the Conflict Tactics Scales (CTS) (Strauss, 1984). This instrument examines the frequency of abusive responses (i.e., verbal and physical) that each partner has reportedly used during spousal disagreements over the previous 12 months. In this study, the women were asked about their own behaviours and those of their spouse or partner. In the original instrument, three standardized scores were calculated: reasoning, verbal abuse, and physical abuse. In this study, we omitted the reasoning subscale because women found it difficult to understand during a pilot phase. We selected specific items to come up with scores for verbal abuse (items 2, 6, 7; e.g., to shout or yell at my partner) and physical abuse (items 11 to 16; e.g., to slap my partner, to punch or hit my partner with something that could hurt) that better reflect the items generally used in epidemiological studies of domestic violence (Chang, Theodore, Martin, \& Runyan, 2008; Connelly, Newton, Landsverk, \& Aarons, 2000; Taylor, Lee, Guterman, \& Rice, 2010).

We used the following indicators of alcohol consumption during the postpartum year: alcohol use, binge drinking (at least 
Table 1. High-risk conditions during the postpartum year.

\begin{tabular}{lll}
\hline High-risk conditions & Definitions & \%es \\
\hline Socioeconomic precariousness & Either receiving welfare or being a single parent & 51.1 \\
Distress & $\begin{array}{l}\text { Psychological distress score over the clinical } \\
\text { cut-off }(\geq 26) \text { or history of suicidal thoughts or } \\
\text { attempt(s) in the year following childbirth }\end{array}$ & 37.5 \\
Verbal or physical abuse by the mother or her \\
spouse at least once a month during the year \\
following childbirth
\end{tabular}

five standard drinks in one session), number of binge drinking episodes, and average number of standard drinks per binge episode. Two trained research assistants independently coded the reports of alcohol use. Disagreements were discussed until a consensus was reached. We also recorded illicit drug use during the postpartum year for marijuana, cocaine (including crack cocaine), solvent sniffing, heroin, psilocybin mushrooms, phencyclidine (PCP), sedatives, and amphetamines (see Muckle et al., 2011, for detailed descriptions of the interviews about alcohol and drug use). Smoking during the postpartum year (including number of cigarettes per day) was documented with questions from the Santé-Québec Health Survey Among the Inuit of Nunavik (Jetté, 1992).

\section{Statistical analysis}

Descriptive statistics were obtained for the risk factors. We used Spearman correlations and Cramer's Phi to examine the associations among continuous and binary (yes/no) risk factors. Four binary (yes/no) high-risk conditions were constructed (Table 1). Exploratory latent class analysis models were tested statistically to identify the different participant profiles (latent classes) in regard to socioeconomic and psychosocial high-risk conditions. Latent class analysis is a statistical method based on the assumption that distinct subgroups sharing common characteristics exist within the sample. The best-fitting model is the most parsimonious, i.e., the one that explains the observed data with the smallest number of classes. Class membership is estimated for each participant. Finally, we used independent samples $t$-tests and chi-square tests to compare the risk profiles on high-risk conditions, demographic factors (village of residency, language used at the interview, adoption status of the child, mother's age), and socioeconomic variables (education, welfare status, employment status).

A relatively large portion of the data (31.7\%) was missing for the CTS variables. Reasons for the missing data were: failure to administer the CTS to two participants (1.1\%), loss of two questionnaires $(1.1 \%)$, participant not in a relationship for at least 6 months or not living with her spouse during the postpartum year (26.1\%), and partial or complete refusal to complete the CTS $(4.5 \%)$. Due to the sensitive nature of this measure, it is possible that the women who refused to complete the CTS were more likely to be those who were in an abusive relationship, suggesting a pattern of data not missing at random (MNAR)ii. We used pattern mixture models followed by sensitivity tests to look at the influence of the possible MNAR pattern on parameter estimations in preliminary regression models testing the association between the CTS and the main outcomes of the study (Allison, 2001). The results showed that the missing data did not significantly affect parameter estimates. Consequently, we performed further statistical analyses - including CTS variables - with all available data from mothers living in a couple (married or not) or who had a boyfriend during the 6-month period preceding the interview (69\% of the sample) without the concern for an eventual MNAR bias. Data were analyzed using SPSS 12 (SPSS Inc., Chicago, IL) and Mplus 5.21 software (Muthén \& Muthén, 2009).

\section{RESULTS}

Participant characteristics and the prevalence of risk factors are shown in Table 2 . About $10 \%$ of mothers were less than 18 years of age and one-third were unmarried at the time of delivery. Only $21 \%$ had graduated from high school. One year after delivery, six out of 10 women were unemployed ${ }^{\mathrm{iii}}$, and almost four out of 10 received welfare. Inuktitut is the first language among Nunavik Inuit, but since most participants were fluent in French or English, interviews were mainly conducted in one of these two languages. When the child was adopted, the 12-month postpartum interview was conducted with the adoptive mother (13\%).

During the postpartum year, one out of four women experienced psychological distress above the clinical cut-off, i.e., the 
Table 2. Demographic and psychosocial characteristics of the Inuit mothers in the postpartum year.

\begin{tabular}{|c|c|c|c|c|c|c|}
\hline & $N$ & $n(\%)$ & Mean & Median & $S D$ & Range \\
\hline Marital status (\% single) & 176 & $53(29.0)$ & & & & \\
\hline Age & 176 & & 27.0 & 26.1 & 7.5 & $14.6-55.1$ \\
\hline Education (years) & 176 & & 8.7 & 9.0 & 2.0 & $0-14.3$ \\
\hline Employed & 175 & $68(38.9)$ & & & & \\
\hline Receiving welfare & 176 & $66(37.5)$ & & & & \\
\hline Interviewed in Inuktitut & 176 & $26(14.8)$ & & & & \\
\hline Adoptive mothers & 176 & $23(13.1)$ & & & & \\
\hline Psychological distress ${ }^{\mathrm{a}}$ & 172 & & 22.2 & 20.0 & 6.3 & $14.0-41.0$ \\
\hline Suicidal thoughts ever & 176 & $113(64.2)$ & & & & \\
\hline Suicidal thoughts postpatrum & 168 & $34(19.3)$ & & & & \\
\hline Suicidal attempts ever & 176 & $69(39.2)$ & & & & \\
\hline Suicidal attempts postpartum & 170 & $12(6.8)$ & & & & \\
\hline \multicolumn{7}{|l|}{ Domestic abuse ${ }^{b}$} \\
\hline Verbal & 122 & $(86.1)$ & & & & \\
\hline Physical & 120 & $(48.3)$ & & & & \\
\hline Substance Use & 122 & $(86.1)$ & & & & \\
\hline Alcohol use & 173 & $105(60.7)$ & & & & \\
\hline Binge drinking $(\% \text { yes })^{c}$ & 105 & $67(63.8)$ & & & & \\
\hline No. of episodes ${ }^{\mathrm{d}}$ & 67 & & 22.8 & 8.0 & 32.2 & $0.8-193.0$ \\
\hline No. of standard drinks/binge ${ }^{\mathrm{d}}$ & 67 & & 8.6 & 8.0 & 3.4 & $4.8-25.6$ \\
\hline Illicit drug use & 176 & $53(30.1)$ & & & & \\
\hline Marijuana use ${ }^{\mathrm{e}}$ & 53 & $50(94.3)$ & & & & \\
\hline Others drug use $\mathrm{e}^{\mathrm{e}}$ & 53 & $9(17.0)$ & & & & \\
\hline Tobacco use & 176 & $157(89.2)$ & & & & \\
\hline No. of cigarettes/day ${ }^{f}$ & 157 & & 10.2 & 10.0 & 5.3 & $1.0-35.0$ \\
\hline
\end{tabular}

\section{aDPESQ-14}

${ }^{\mathrm{b}} \mathrm{By}$ partner and mother only for women in a relationship

cAbstainers excluded

dOnly for binge drinkers

${ }^{\mathrm{e}}$ Only for drug users

fNon-smokers excluded 
Table 3. Correlations among psychosocial risk factors.

\begin{tabular}{|c|c|c|c|c|c|c|c|c|c|}
\hline Risk factors & 1 & 2 & 3 & 4 & 5 & 6 & 7 & 8 & 9 \\
\hline \multicolumn{10}{|l|}{ Distress } \\
\hline 1.Psychological distress & - & & & & & & & & \\
\hline 2. Suicidal thoughts ever ${ }^{a}$ & $.26^{* *}$ & - & & & & & & & \\
\hline 3. Suicidal thoughts ${ }^{\mathrm{a}}$ & $.23^{* *}$ & $.38^{* *}$ & - & & & & & & \\
\hline 4. Suicidal attempts ever ${ }^{\mathrm{a}}$ & .14 & $.60^{* *}$ & $.18^{*}$ & - & & & & & \\
\hline 5. Suicidal attempts ${ }^{\mathrm{a}}$ & $.22^{* *}$ & $.20^{* *}$ & $.44^{* *}$ & $.35^{* *}$ & - & & & & \\
\hline \multicolumn{10}{|l|}{ Substance use } \\
\hline 6. Binge drinking ${ }^{\mathrm{a}}$ & .08 & .05 & .11 & .07 & .11 & - & & & \\
\hline 7. Drug use $\mathrm{e}^{\mathrm{a}}$ & .15 & $.23^{* *}$ & $.18^{*}$ & $.34^{* *}$ & $.17^{*}$ & $.29^{* *}$ & - & & \\
\hline 8. No. cigarettes/day & .05 & $.25^{* *}$ & $.15^{*}$ & .15 & .08 & .08 & -.02 & - & \\
\hline \multicolumn{10}{|l|}{ Domestic abuse } \\
\hline 9. Verbal abuse ${ }^{\mathrm{b}}$ & $.44^{* *}$ & $.19^{*}$ & $.21^{*}$ & .13 & .11 & $.20^{*}$ & $.24^{* *}$ & .08 & - \\
\hline 10. Physical abuse $\mathrm{e}^{\mathrm{b}}$ & $.24^{* *}$ & $.20^{*}$ & $.45^{*}$ & .16 & $.24^{* *}$ & $.22^{* *}$ & $.19^{*}$ & .09 & $.53 * *$ \\
\hline
\end{tabular}

Note. $N$ ranges from 166 to 176 . Phi coefficients are presented when two binary risk factors were simultaneously analyzed; Spearman's rho values are presented for the remaining analyses. ${ }^{\circledR}$ Binary variables: $0=$ no and $1=$ yes.

bonly for women in a relationship ( $N$ ranges from 120 to 122$)$.

${ }^{*} p<.05$

$* * * 01$

level likely to require professional help. A large majority of women reported at least one episode of verbal domestic abuse during the postpartum year. About half of the women reported physical abuse during the same time period. Women in the study committed spousal abuse as frequently as their partner. We observed moderate Spearman correlations between the frequency of being the victim and the perpetrator of violence in the couple for both verbal $\left(r_{s}=.62, p<.001\right)$ and physical abuse $\left(r_{s}=.55, p<.001\right)$. During the postpartum period, 6 women out of 10 consumed alcohol, with a majority binge drinking ( $n=67 / 105$ alcohol consumers). About one-third of the participants reported using illicit drugs. Most of the drug users consumed only marijuana $(n=44 / 53)$. Cocaine, solvent sniffing, psilocybin mushroom, and sedative use were rarely reported. Almost all participants smoked cigarettes, with 50\% of the smokers smoking more than half of a pack daily. The prevalence of composite high-risk conditions was $51.1 \%$ for socioeconomic precariousness, $37.5 \%$ for distress, $35.8 \%$ for domestic violence, and $46.3 \%$ for substance use.

With regard to the relationship between demographic and socioeconomic variables: welfare was related to unemployment $(\Phi=.57, p<.01)$, number of years of education $\left(r_{s}=-.29, p<.01\right)$, and single parenting $(\Phi=.23, p<.01)$; unemployment was related to number of years of education $\left(r_{s}=-.25, p<.01\right)$ and age $\left(r_{s}=-.17, p<.05\right)$. As shown in Table 3, among the psychosocial risk variables, we observed the strongest associations between distress and domestic abuse variables. Psychological distress was as strongly associated with violence from the participant's partner as from the participant (data not shown: partner $r_{s}=.44, p<.01$; mother $\left.r_{s}=.45, p<.01\right)$. Verbal and physical abuse were associated for both partner $\left(r_{s}=.41, p<.01\right)$ and participant $\left(r_{s}=.39, p<.01\right)$. Illicit drug use was related to all suicide variables and both types of domestic abuse. Additionally, weak to moderate relationships were seen between socioeconomic and psychosocial risk factors: single parenting was associated with greater psychological distress $\left(r_{s}=.16, p<.5\right)$, postpartum suicidal thoughts $(\Phi=.17, p<.5)$, and physical abuse $\left(r_{s}=.29, p<.01\right)$; unemployment was associated with verbal abuse $\left(r_{s}=.25, p<.01\right)$; welfare status was associated with postpartum suicidal thoughts $(\Phi=.21, p<.01)$, and drug use $(\Phi=.18, p<.05)$; and poorer education was associated with postpartum suicidal thoughts $\left(r_{s}=.17, p<.05\right)$ and binge drinking $\left(r_{s}=.22, p<.01\right)$. The age of the mother was unrelated to distress, substance use, or domestic abuse variables. Examination of the coexistence of high-risk conditions revealed that $80.1 \%$ of women met criteria for at least one of these risks, $57.9 \%$ for at least two, $24.9 \%$ for at least three, and $5.7 \%$ for all high-risk conditions.

Exploratory latent class analyses of the computed high-risk conditions revealed that a three-class solution (Figure 1) provides the best fit for the data set, which showed three subgroups of mothers with distinct profiles in our sample (lowest AIC =927.19). First, $30.8 \%$ of the mothers were at low risk, since they did not 


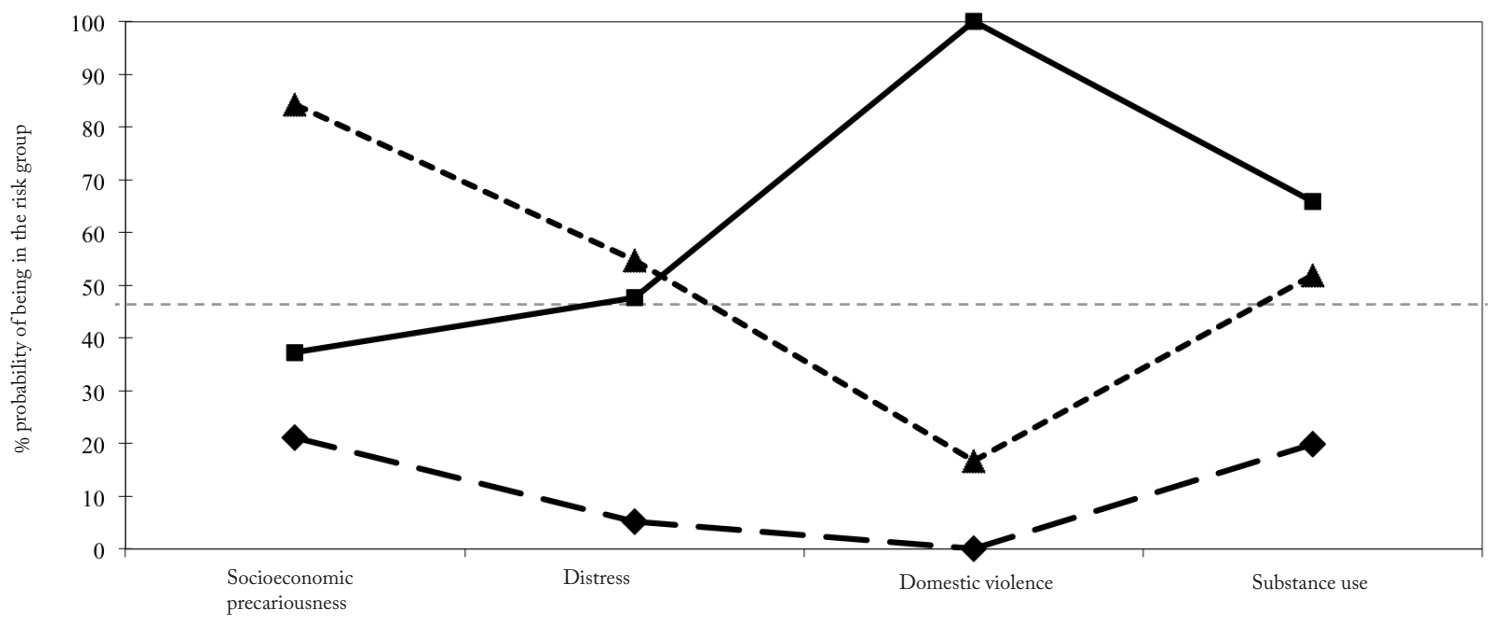

Risk conditions

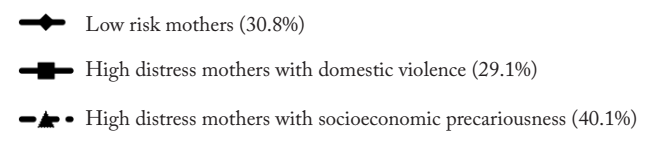

Figure 1. Risk profiles in Inuit mothers $(N=176)$. The proportions reported are for the latent classes based on the estimated model. They represent the probability of being in the risk group for each risk condition.

encounter socioeconomic precariousness, distress, or domestic violence, and most of them did not report substance use (77.3\%). Second, $69.2 \%$ of mothers were experiencing higher levels of distress $\left(\chi^{2}[1, n=176]=34.68, p=.001\right)$. Third, there were two subgroups or profiles within the group of distressed mothers: 1) mostly single mothers characterized by their higher likelihood of having socioeconomic issues, and 2) women with fewer financial difficulties, but all experiencing domestic abuse. Mothers from those two profiles did not significantly differ on distress $\left(\chi^{2}[1, n=125]=0.72, p=.79\right)$, but those experiencing domestic violence were more likely to report substance use than women with an economically at-risk profile $\left(\chi^{2}[1, n=131]=4.22, p=.04\right)$. Therefore, women in the domestic violence group

$(M=2.59, S D=0.84)$ faced significantly more high-risk conditions than those in the economically at-risk group: $(M=1.82, S D=0.73)$; $t(129)=5.58, p=.00)$.

Mean comparisons analysis between the low- and the two high-risk groups combined did not show significant differences on most demographic (language of the interview, adoption status of the child) and socioeconomic variables (age, education, employment). This is in spite of none of the mothers of the lowrisk group receiving welfare compared to half of those in the highrisk groups $\left(\chi^{2}[1, n=176]=36.27, p=.00\right)$.

\section{DISCUSSION}

The primary aim of this study was to examine the prevalence and the coexistence of socioeconomic and psychosocial risk factors among Inuit mothers in the postpartum year, a critical period for child development. Our results show many mothers struggled with socioeconomic and psychosocial difficulties during this period. We found the prevalence rates of these difficulties in our study to be similar to those reported by women of childbearing age in the 2004 Nunavik Inuit Health Survey (Qanuippitaa). Rates of psychological distress, lifetime history of suicide attempts, and substance use, however, were higher in our study. The higher rate of distress might be due to being interviewed during the postpartum months, a period well-recognized to be high-risk for maternal depression. Differences in prevalence rates between Qanuippitaa and our study may also be due to sample differences between studies: the Qanuippitaa sample included $27 \%$ of the entire adult population of the region, with households selected to be representative of the population. We conducted our study in the three largest communities of the Hudson Bay region. As a consequence, it is possible that outcomes in this study may not be relevant to the entire Inuit population. 
In addition, prevalence rates reported in this study corroborate the established disparities between Aboriginal Peoples and the general Canadian population (Pageau et al., 2003; Santé Canada, 1998). One year after delivery, $38.9 \%$ of Inuit women are employed compared to $64.3 \%$ of Canadian women with a child younger than three years old (Statistics Canada, 2007); the high school graduation rate is 4 times lower in Inuit women compared to Canadian women overall (Statistics Canada, 2009); the proportions of binge drinkers and marijuana users in the last 12 months are 2 and 4 times higher, respectively; the rate of suicide attempts in the postpartum year exceeds the rate of lifetime attempts among Canadian women of childbearing age (Government of Canada, 2006); and 7 times as many women in this study reported physical abuse than in the 1999 General Social Survey of Canada (CCJS, 2006).

In our study, the adversity during the postpartum year is obvious, since 6 women out of 10 simultaneously encounter at least two high-risk conditions. In addition to the personal and marital adjustment related to the birth of a child, many Inuit mothers have to deal with stressful psychosocial and socioeconomic difficulties likely to challenge their adaptation and well-being. Furthermore, this adversity may jeopardize optimal parental abilities in this fast growing population during a critical period of child and attachment development. Additional studies following infants through childhood are needed to examine the effect of socioeconomic and psychosocial adversity during the postpartum year, not only on child development but also on mother-child bonding.

The cross-cultural nature of this study raises issues about the validity of some psychosocial measures. From our experience with interviewing Inuit women, it appears that social desirability does not influence responses as much as in Caucasian populations. It is possible that studies in Caucasian populations underestimate the rates of social pathologies compared to those reported in this study. Furthermore, the fact that our participants had been interviewed several times before the postpartum interviews may have led to a more complete disclosure of sensitive personal information. Assessing constructs with a psychosocial meaning-especially violence and distress-across cultures poses methodological challenges (Kirmayer \& Jarvis, 2005). For example, yelling at one's spouse may be considered psychological abuse in some populations, but this behaviour may be socially acceptable in others (Levendosky, Bogart, \& von Eye, 2007), and likely easier to disclose. A questionnaire developed for a specific population therefore may not be reliable for another cultural group, because cultural groups define experience and express the underlying constructs in different ways (Kirmayer \& Kenneth, 2007). It is possible that our measures over- and under-identified specific forms of distress and violence, while others may not be prevalent among the Inuit.

A second aim of the study was the identification of patterns and specific profiles of women based on risk factors. We did this to better understand postpartum adversity in Inuit mothers from Nunavik, and consequently to suggest an appropriate target of intervention. Our results showed moderate relationships among psychosocial risk factors, especially between domestic abuse and distress indicators. Due to the research design, it is not possible to determine the causal relationship between these variables: experiencing domestic abuse may create or exacerbate distress, but distress may also trigger domestic violence. Nevertheless, our results emphasize the importance of supporting women in an abusive relationship, since the frequency of verbal and physical abuse is the risk factor most associated with maternal distress.

We also found consistent associations between drug use and suicide and domestic abuse, which corroborate findings from previous studies in female Inuit youth (Kirmayer, Boothroyd, \& Hodgins, 1998; Tester \& McNicoll, 2004) and data from mental health services in Nunavik (Lessard, Bergeron, Fournier, \& Bruneau, 2008). These studies have identified recent alcohol abuse and drug use as risk factors and triggers of suicide attempts among the Inuit. In this study, alcohol abuse or binge drinking was not related to suicide variables, but was related to both types of violence and associated with higher education level. These outcomes linking substance use with some desperate, impulsive, and aggressive behaviors against self and others have clinical implications. For example, substance use intervention programs should have a wider focus to encompass affect and impulse management with culturally respectful strategies. The surprising association between alcohol abuse and higher education was also found in the Qanuippitaa survey (Muckle et al., 2007) and in the present cohort during the pregnancy period (Muckle et al., 2011). It may be explained by the fact that the more educated women have larger incomes, providing them easier access to alcoholic beverages that are very expensive in the North.

Our results suggest that socioeconomic difficulties are likely to jeopardize maternal well-being during the postpartum period. According to the Maslow's Universal Hierarchy of Needs theory, it is very difficult to reach a sense of well-being when the most fundamental human needs are not fulfilled (Harsenne, 2003). This finding shows the need for more effective governmental programs to improve employment opportunities and make food more affordable.

Using the data on high-risk conditions, we identified three distinct profiles of Inuit mothers. The first profile was a low-risk one, representing the third of our sample in which most of the women do not encounter any of the defined risk conditions. The second and third profiles referred to two subgroups of mothers susceptible to postpartum distress, but who have distinct experiences: domestic violence or socioeconomic precariousness. We failed to depict the resilient profile of mothers because our study did not include protective factors. The only variable that could be conceptualized in this way was education level and it did not significantly differ among the resilient and the risk groups. Moreover, the low-risk profile does not have any specific demographic characteristics when compared to others except welfare status, which was absent in this group. Welfare is the most severe socioeconomic risk factor included in this study, likely to reflect longer periods of unemployment and greater difficulties meeting family financial needs. 


\section{CONCLUSIONS}

The results of this study support that Inuit mothers are at greater risk of distress in the postpartum period. In addition to adapting to the birth of a child, most of them have to deal with multiple psychosocial and socioeconomic adverse events. This study identified three risk profiles of Inuit mothers: one low-risk group, and two high-risk groups with different patterns of distress. This information has implications for prevention and public health programs to improve well-being in this population. To be most effective, programs should target both distinct subgroups: mothers experiencing financial difficulties and women in an abusive relationship, who are more likely to use substances. The fact that the economically precarious profile is the most prevalent reinforces the need to prioritize public programs addressing economic conditions in Nunavik. Further qualitative studies on the resilient low-risk group would also be beneficial to better understand the key factors of a positive postpartum transition among Inuit women.

\section{ACKNOWLEDGEMENTS}

We are very grateful to the Nunavik population for their participation and especially to the women who generously agreed to share personal information about their pregnancy and postpartum experiences. We thank the professionals from the local health centres and nursing stations for their assistance in recruiting the cohort. We also wish to thank the Nunavik Nutrition and Health Committee, the municipal councils, and community groups for supporting this study. Special thanks to Brenda Tuttle, Rene Sun, Edna Lachance, Christine Bouffard, Karine Poitras, Carole Vézina, Germain Lebel, Danie Laverdière, Lisa Chiodo, and Neil Dodge, who all significantly contributed to data collection and analysis. Special thanks to Dominic Barrieau, France Fortin, and Olivier Boucher, who helped us in the revision to the text. Finally, we want to acknowledge all the granting agencies supporting the ECCD study: National Institute of Environmental Health and Sciences/ National Institutes of Health (R01-ES07902); Indian and Northern Affairs Canada (Northern Contaminants Program); Health Canada; Hydro-Québec (Environmental Child Health Initiative), the Department of Public Health of the Nunavik Regional Board of Health and Social Services; the Joseph Young Sr. Fund from the State of Michigan; the Canadian Institutes of Health Research; and the Fonds de la recherche en santé du Québec.

\section{REFERENCES}

Allison, P. D. (2001). Missing data: Quantitative applications in the social sciences. Thousand Oaks, CA: Sage Publications.

Anctil, M. (2008). Nunavik Inuit Health Survey 2004: Qanuippitaa? How are we? Survey highlights. (Report No.: 978-2-550-52862-3). Quebec City, QC: Institut national de santé publique du Québec.

Audet, N., Lemieux, M., \& Cardin, J. (2001). Enquête sociale et de santé 1998 - Cahier technique et méthodologique: Définition et composition des indices, vol. 2. Montreal, QC: Institut de la statistique du Québec.

Atzaba-Poria, N., Pike, A., \& Deater-Deckard, K. (2004). Do risk factors for problem behaviour act in a cumulative manner? An examination of ethnic minority and majority children through an ecological perspective. Journal of Child Psychology and Psychiatry, 45, 707-718.

Biederman, J., Faraone, S. V., \& Monuteaux, M. C. (2002). Differential effect of environmental adversity by gender: Rutter's index of adversity in a group of boys and girls with and without ADHD. American Journal of Psychiatry, 158, 1556-1562.

Bjerregaard, P., Young, T. K., Dewailly, E., \& Ebbesson, S. O. (2004). Indigenous health in the Arctic: An overview of the circumpolar Inuit population. Scandinavian Journal of Public Health, 32, 390-395.

Bluestone, C., \& Tamis-LeMonda, C. S. (1999). Correlates of parenting styles in predominantly working- and middle-class African American mothers. Journal of Marriage and Family, 61, 881-893.

Canadian Centre for Justice Statistics, Statistics Canada. (2006). Family Violence in Canada: A Statistical Profile (Report No. 85-224-XIE). Ottawa, ON.

Chang, J. J., Theodore, A. D., Martin, S. L., \& Runyan, D. K. (2008). Psychological abuse between parents: Associations with child maltreatment from a population-based sample. Child Abuse and Neglect, 32, 819-829.

Chmura Kraemer, H., Stice, E., Kazdin, A., Offord, D., \& Kupfer, D. (2001). How do risk factors work together? Mediators, moderators, and independent, overlapping, and proxy risk factors. The American Journal of Psychiatry, 158, 848-856. 
Commission des droits de la personne et des droits de la jeunesse. (2007). Investigation into child and youth protection services in Ungava Bay and Hudson Bay - Nunavik - Report, conclusions of the investigation and recommendations. Retrieved from http:// www2.cdpdj.qc.ca/en/publications/Documents/rapport_ Nunavik_anglais.pdf

Connelly, C. D., Newton, R. R., Landsverk, J., \& Aarons, G. A. (2000). Assessment of intimate partner violence among highrisk postpartum mothers: Concordance of clinical measures. Women E' Health, 31, 21-37.

Curtis, T., Larsen, F. B., Helweg-Larsen, K., \& Bjerregaard, P. (2002). Violence, sexual abuse and health in Greenland. International Journal of Circumpolar Health, 61, 110-122.

Deater-Deckard, K., Dodge, K. A., Bates, J. E., \& Petit, G. S. (1998). Multiple-risk factors in the development of externalizing behavior problems: Group and individual differences. Development and Psychopathology, 10, 469-493.

Elek, S. M., Brage Hudson, D., \& Bouffard, C. (2003). Marital and parenting satisfaction and infant care self-efficacy during the transition to parenthood: The effect of infant sex. Issues in Comprehensive Pediatric Nursing, 26, 45-57.

Ewart, C. K., \& Suchday, S. (2002). Discovering how urban poverty and violence affect health: Development and validation of a neighborhood stress index. Health Psychology, $21,254-262$.

Government of Canada. (2006). The human face of mental health and mental illness in Canada (Report No.: 0-662-72356-2). Ottawa, ON.

Graham, J. W. (2009). Missing data analysis: Making it work in the real world. Annual Review of Psychology, 60, 549-576.

Gravel, R., \& Béland, Y. (2005). The Canadian Community Health Survey: Mental health and well-being. Canadian Journal of Psychiatry, 50, 573-579.

Grienenberger, J. F., Kelly, K., \& Slade, A. (2005). Maternal reflective functioning, mother-infant affective communication, and infant attachment: Exploring the link between mental states and observed caregiving behaviour in the intergenerational transmission of attachment. Attachment E Human Development, 7, 299-311.

Gutman, L. M., Friedel, J. N., \& Hitt, R. (2003). Keeping adolescents safe from harm: Management strategies of African American families in high-risk communities. Journal of School Psychology, 41, 167-184.
Harsenne, M. (2003). Psychologie de la personnalité. Brussels: De Boeck.

Hooper, S. R., Burchinal, M. R., Roberts, J. E., Zeisel, S., \& Neebe, E. C. (1998). Social and family risk factors for infant development at one year: An application of the cumulative risk model. Journal of Applied Developmental Psychology, 19, $85-96$.

Ilfeld, F. W. (1976). Further validation of a psychiatric symptom index in a normal population. Psychological Reports, 39, $1215-1228$.

Jackson, A., Brooks-Gunn, J., Huang, C. C., \& Glassman, M. (2000). Single mothers in low-wage jobs: Financial strain, parenting, and preschoolers' outcomes. Child Development, 71, 1409-1423.

Jackson, A. P., \& Scheines, R. (2005). Single mothers' selfefficacy, parenting in the home environment, and children's development in a two-wave study. Social Work Research, 29, $7-20$.

Jacobson, J. L., Jacobson, S. W., Muckle, G., Kaplan-Estrin, M., Ayotte, P., \& Dewailly, E. (2008). Beneficial effects of a polyunsaturated fatty acid on infant development: Evidence from the Inuit of Arctic Quebec. Pediatrics, 152, 356-364.

Jaffe, S. R., Capsi, A., Moffitt, T. E., Polo-Tomás, M., \& Taylor, A. (2007). Individual, family, and neighborhood factors distinguish resilient from non-resilient maltreated children: A cumulative stressors model. Child Abuse and Neglect, 31, 231-253.

Jetté, M. (1992). Et la santé des Inuits, ça va? Rapport de l'enquête Santé Québec auprès des Inuits du Nunavik 1992. Quebec City, QC: Santé Québec.

Kelley, M. L., Klostermann, K., Doane, A. N., Mignone, T., Lam, W. K., Fals-Stewart, W., \& Padilla, M. A. (2010). The case for examining and treating the combined effects of parental drug use and interparental violence on children in their homes. Aggression and Violent Behavior, 15, 76-82.

Kirmayer, L. J., Boothroyd, L. J., \& Hodgins, S. (1998). Attempted suicide among Inuit youth: Psychosocial correlates and implications for prevention. Canadian Journal of Psychiatry, 43, 816-822.

Kirmayer, L. J., \& Jarvis, G. E. (2005). Depression across cultures. In D. Stein, A. Schatzberg, \& D. Kupfer (Eds.), Textbook of mood disorders (pp. 611-629). Washington, DC: Psychiatric Press. 
Kirmayer, L. J., \& Kenneth, P. W. (2007). Nunavik Inuit Health Survey 2004: Qanuippitaa? How are we? Mental health, social support and community wellness (Report No.: 978-2550-50631-7). Quebec City, QC: Institut national de santé publique du Québec.

Kotchick, B. A., Dorsey, S., \& Heller, L. (2005). Predictors of parenting among African American single mothers: Personal and contextual factors. Journal of Marriage and Family, 67, 448-460.

Lavoie, F., Muckle, G., Fraser, S., \& Boucher, O. (2007). Nunavik Inuit Health Survey 2004: Qanuippitaa? How are we? Epidemiological portrait of physical violence and property offences in Nunavik (Report No. 978-2-550-50730-7). Quebec City, QC: Institut national de santé publique du Québec.

Lessard, L., Bergeron, O., Fournier, L., \& Bruneau, S. (2008). Étude contextuelle sur les services de santé mentale au Nunavik (Report No. 978-2-550-54680-1). Quebec City, QC: Institut national de santé publique du Québec.

Levendosky, A. A., Bogart, G. A., \& von Eye, A. (2007). New directions for research on intimate partner violence and children. European Psychologist, 12, 1-5.

Logsdon, C., Wisner, K. L., \& Pinto-Foltz, M. D. (2006). The impact of postpartum depression on mothering. Journal of Obstetric, Gynecologic, E Neonatal Nursing, 35, 652-658.

MacKenzie, M. J., Kotch, J. B., \& Lee, L. (2011). Toward a cumulative ecological risk model for the etiology of child maltreatment. Children and Youth Services Review, 33, 1638-1647.

McConachie, H., Hammal, D., Welsh, B., Keane. B., Waterston, T., Parker, L., \& Cook, M. (2008). Wellbeing of new mothers. Community Practitioner, 81, 19-22.

Mirowsky, J., \& Ross, C. E. (2002). Measurement for a Human Science. Journal of Health and Social Behavior, 43, 152-170.

Muckle, G., Ayotte, P., Dewailly, E. E., Jacobson, S. W., \& Jacobson, J. L. (2001). Prenatal exposure of the northern Québec Inuit infants to environmental contaminants. Environmental Health Perspectives, 109, 1291-1299.

Muckle, G., Boucher, O., Laflamme, D., \& Chevalier, S. (2007). Nunavik Inuit Health Survey 2004: Qanuippitaa? How are we? Alcohol, drug use and gambling among the Inuit of Nunavik: epidemiological profile (Report No. 978-2-550-50441-2). Quebec City, Quebec: Institut national de santé publique du Québec.
Muckle, G., Laflamme, D., Gagnon, J., Boucher, O., Jacobson, S. W., \& Jacobson, J. L. (2011). Alcohol, smoking, and drug use among Inuit women of childbearing age during pregnancy and estimated prevalence of children at risk for alcohol effects. Alcoholism: Clinical and Experimental Research, 35, 1081-1091.

Muthén, L. K., \& Muthén B. O. (2009). Mplus: Statistical analysis with latent variables (Version 5.21) [Computer software]. Los Angeles, CA: Muthén \& Muthén.

Pageau, M., Ferland, M., \& Déry, S. (2003). Our children: Health status of children aged $0-5$ years in Nunavik. Kuujjuaq, QC: Régie régionale de la santé et des services sociaux Nunavik.

Préville, M., Boyer, R., Potvin, L., Perrault, C., \& Légaré, G. (1992). La détresse psychologique: détermination de la frabilité et de la validité de la mesure utilisée dans l'Enquête Santé Québec. Quebec City, QC: Ministère de la Santé et des Services sociaux.

Raviv, T., Taussig, H. N., Culhane, S. E., \& Garrido, E. F. (2010). Cumulative risk exposure and mental health symptoms among maltreated youth placed in out-of-home care. Child Abuse and Neglect, 34, 742-751.

Rochette, L., St-Laurent, D., \& Plaziac, C. (2007). Nunavik Inuit Health Survey 2004: Qanuippitaa? How are we? Sociodemographic portrait (Report No.: 978-2-550-50443-6). Quebec City, QC: Institut national de santé publique du Québec.

Rosenblum, K. L., McDonough, S. C., Sameroff, A. J., \& Muzik, M. (2008). Reflection in thought and action: Maternal parenting reflectivity predicts mind-minded comments and interactive behavior. Infant Mental Health Journal, 29, 362-376.

Roth, P. L. (1994). Missing data: A conceptual review for applied psychologists. Personnel Psychology, 47, 537-560.

Sakala, C., Declercq, E. R., \& Corry, M. P. (2002). Listening to mothers: The first national U.S. survey of women's childbearing experiences. Journal of Obstetric, Gynecologic, छ Neonatal Nursing, 31, 633-634.

Sameroff, A., Seifer, R., Zax, M., \& Barocas, R. (1987). Early indicators of developmental risk: Rochester Longitudinal Study. Schizophrenia Bulletin, 13, 383-394.

Santé Canada (n.d.). Stratégies relatives à l'évaluation des programmes de lutte contre l'abus des substances chez les autochtones: examen de la question. Retrieved January 10, 2013 from http://www.hc-sc. gc.ca/fniah-spnia/alt_formats/fnihb-dgspni/pdf/pubs/ads/ literary_examen_review-fra.pdf 
Schechter, D. S., Coates, S. W., Kaminer, T., Coots, T., Zeanah, C. H., Davies, C., .. . Myers, M. M. (2008). Distorted maternal mental representations and atypical behavior in a clinical sample of violence-exposed mothers and their toddlers. Journal of Trauma Eं Dissociation, 9, 123-149.

Sharp, C., \& Fonagy, P. (2008). The parent's capacity to treat the child as a psychological agent: Constructs, measures and implications for developmental psychopathology. Social Development, 17, 737-754.

Statistics Canada. (2007). Femmes au Canada: une mise à jour du chapitre sur le travail 2006 (Report No. 89F0133XIF). Retrieved from http://publications.gc.ca/collections/ Collection/Statcan/89F0133X/89F0133XIF2006000.pdf

Statistics Canada. (2008). Population reporting an Aboriginal identity, by age group, by province and territory (2006 Census). Retrieved from http://www40.statcan.gc.ca/101/cst01/demo40a-eng. htm.

Statistics Canada. (2009). Population 15 years and over by bighest degree, certificate or diploma (1986 to 2006 Census). Retrieved from http://www.statcan.gc.ca/tables-tableaux/sum-som/101/ cst01/educ42-eng.htm

Statistics Canada. (2011). Persons in low income after tax (2001 to 2005). Retrieved from http://www.statcan.gc.ca/tablestableaux/sum-som/101/cst01/famil19b-eng.htm

Stein, A., Arteche, A., Lehtonen, A., Craske, M., Harvey, A., Counsell, N., \& Murray, L. (2010). Interpretation of infant facial expression in the context of maternal depression. Infant Behavior and Development, 33, 273-278.

Strauss, M. A. (1979). Measuring intrafamily conflict and violence: The Conflict Tactics (CT) Scales. Journal of Marriage and Family, 41, 75-88.

Tabachnick, B. G., \& Fidell, L. S. (2007). Using multivariate statistics (5th ed.). Boston, MA: Pearson Education.

Taylor, C. A., Lee, S. J., Guterman, N. B., \& Rice, J. C. (2010). Use of spanking for 3-year old children and associated intimate partner aggression or violence. Pediatrics, 126, 415-424.

Tester, F. J., \& McNicoll, P. (2004). Isumagijaksaq: Mindful of the state: social constructions of Inuit suicide. Social Science E Medicine, 58, 2625-2636.

Tousignant, M., Hanigan, D., \& Bergeron, L. (1984). Le mal de vivre: comportements et idéations suicidaires chez les cégepiens de Montréal. Santé Mentale au Québec, 9, 122-133.
Westbrook, T. R., \& Jones Harden, B. (2010). Pathways among exposure to violence, maternal depression, family structure and child outcomes through parenting: A multigroup analysis. American Journal of Orthopsychiatry, 80, 386-400.

Whitaker, R. C., Orzol, S. M., \& Kahn, R. S. (2006). Maternal mental health, substance use, and domestic violence in the year after delivery and subsequent behavior problems in children at age 3 years. Archives of General Psychiatry, 63, 551-560.

Wohlgemuth Levy, D. (2003). The impact of prenatal cocaine use on maternal reflective functioning (Doctoral dissertation). Available from ProQuest Dissertations and Theses database. (UMI No. 3083680).

Yumoto, C., Jacobson, S. W., \& Jacobson, J. L. (2008). Fetal substance exposure and cumulative environmental risk in an African American cohort. Child Development, 79, 1761-1776.

\section{ENDNOTES}

i Since no specific statement by gender was made, we reported the results regardless of the gender.

ii In the MNAR pattern, missing data relate to the variable itself and cannot be ignored regardless of their proportion (Graham, 2009; Roth, 1994).

iii The governmental maternity leave program at time of the study allowed up to six months of leave after delivery. 


\section{Co-op Healthy Foods Corner and}

Meal Packages: A Partnership among

Community Members, a Grocery Store,

and Community Radio in Pangnirtung,

Nunavut

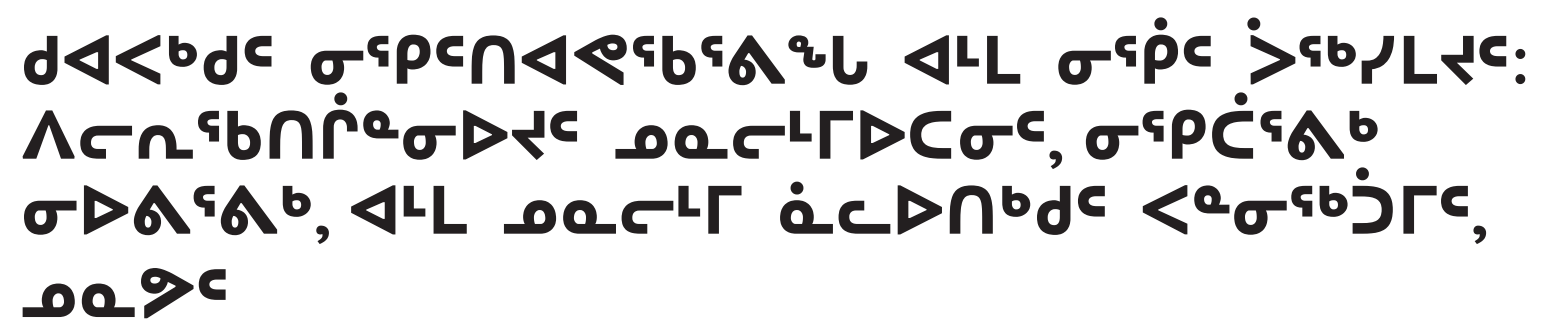

Cassandra Racicot-Matta, MSc, School of Dietetics and Human Nutrition, McGill University, Montréal, Québec, Canada

Markus Wilcke, RN, Director, Population Health - Qikiktaaluq Region, Government of Nunavut, Pangnirtung, Nunavut, Canada

Oleepika Nashalik, Member, Community Steering Committee, Pangnirtung, Nunavut, Canada

Grace Egeland, PhD, Associate Professor, School of Dietetics and Human Nutrition, McGill University, Montreal, Quebec; and Faculty, Centre for Indigenous Peoples' Nutrition and Enviroment (CINE), McGill University, Montréal, Québec, Canada

$\mathrm{P}$ angnirtung, Nunavut is a fly-in community of 1,500 people located 50 kilometers south of the Arctic Circle at the north end of Cumberland Sound. The majority of residents (95\%) are Inuit and most speak Inuktitut. In 2007, Pangnirtung participated in a comprehensive, multi-community survey of Inuit health and wellness (the Inuit Health Survey), under the direction of a community steering committee created specifically for the task. Committee members were therefore familiar with research on health and nutrition in Canada's Arctic regions. Survey results from Pangnirtung encouraged the committee to create activities to raise health knowledge in the community, following the principles of Inuit Qaujimajatuqangit (Inuit traditional knowledge). One of the resulting activities was to increase the availability of healthy food options in the community by linking local radio programming with grocery store initiatives. What follows is the story of the progress and success of this particular pilot program, which took place in March 2009.

At the time of the project, food costs in the Canadian North were almost two times higher than in southern Canadian provinces, particularly for whole grain pastas, milk products, and fruits and vegetables (Indian and Northern Affairs Canada, 2008). This increased expense is due to high transportation costs and lack of storage space in stores, and is often a deterrent to purchasing healthy foods. The community steering committee proposed that the Pujualussait Centre, a community-run non-governmental organization dedicated to health promotion in Pangnirtung, partner with the Centre for Indigenous Peoples' Nutrition and Environment (CINE) at McGill University to promote healthy food consumption at point of sale, in this case the local cooperative (co-op) grocery store. 
This intervention was named the Co-op Healthy Foods Corner and offered packaged, ready-to-make dinners, lunches, and snacks for two to four people. As an alternative to commercially frozen ready-to-eat foods, the meals were comprised of uncooked country foods, whole grain pastas and rice, and fruits and vegetables. These healthy food packages used products available at the local co-op but divided the regularly large consumer packaging amounts into smaller sizes to fit budget and meal requirements. The rationale for creating packages to feed two to four people was for ease of sales and co-op freezer size. The foods were chosen with the guidance of a local nurse, a graduate student in human nutrition sciences, and community members who proposed culturally and locally appropriate recipes. The co-op made no further profit on the foods, but instead divided the cost of the large regular consumer containers among the smaller meal packages to come up with the final healthy meal package price. Program workers were able to create healthy meal packages for two to four people at the same price point, and often lower, than that of commercially prepared frozen dinners. Samples of these meals were available to try at the Healthy Foods Corner kiosk located in the store. Customers were also given takehome placemats printed with nutrition information, including the Nunavut Food Guide, recipes, appropriate portion sizes, explanations for understanding food packaging and Nutrition Facts tables, as well as the benefits of eating country foods over market foods. Some examples of the packaged meals were Arctic char with a vegetable stir fry, and whole grain spaghetti pasta with a tomato, seaweed, and mushroom sauce. Daily local radio announcements gave information about the healthy food packages at the co-op and the program. Radio is a central avenue for spreading information in Pangnirtung, as in many northern and remote communities, and largely contributed to the success of this program.

In total, six individuals worked on the Co-op Healthy Foods Corner program: a program coordinator with a strong educational background in nutrition and project coordination; a local nurse with close community ties who advised the program coordinator on direction; two Inuktitut-speaking community members with an interest in health who acted as the face of the program and were trained in basic nutrition, cooking, and kitchen hygiene techniques; a local radio announcer who spoke Inuktitut and could broadcast ads and information about the program; and the manager of the local co-op store.

The program took place over the period of one month with a different type of food package offered at the beginning of each week (Monday). The program evaluation process was basic, looking only at the time for program-prepared food packages to sell and the movement of perishable items out of the grocery store. Program staff found that all food packages were sold by Day 3 (Wednesday) of being on the store shelves and sales of perishable food items increased. The increase in the sales of perishable food items was most likely due to their inclusion in the food packages; this is still a beneficial outcome, however, as it shows more perishable foods were sold to community households.

Future research in this area would benefit from a more rigorous evaluation to understand the underlying characteristics that led to the program's success. Additionally, the sustainability of this kind of project needs to be addressed. The most promising avenue for sustainability would be a partnership with northern grocery retailers at a corporate rather than simply local level. It is important to note that this program implemented as above requires no additional cost to the grocery retailers themselves, only an allowance for programming to be run in partnership with the store. Potential benefits to the grocery store include increased movement of perishable goods and therefore decreased product spoilage, given the emphasis on fresh fruits and vegetables in food packages; increased traffic into the store; and promotion of the store via radio messaging about the program.

The Co-op Healthy Foods Corner program is an example of what community-driven passion can achieve. This program not only provided valuable information about health and nutrition, but also built community capacity by training members to develop and implement a health program that addressed local needs. This project would not have been possible without partnership with the local co-op. Their assistance and willingness to be involved is greatly appreciated. We hope this small but successful project may inspire other communities to respond to a local need through involvement of community members.

\section{REFERENCES}

Indian and Northern Affairs Canada. (2008). Revised Northern food basket-highlights of price survey results for 2006, 2007 and 2008. Retrieved December 21, 2009, from http://www.aincinac.gc.ca/nth/fon/fc/hpsr-eng.asp 


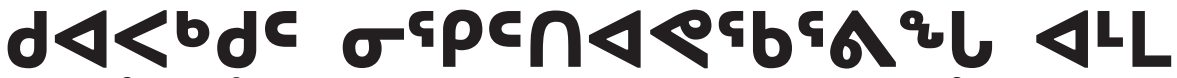

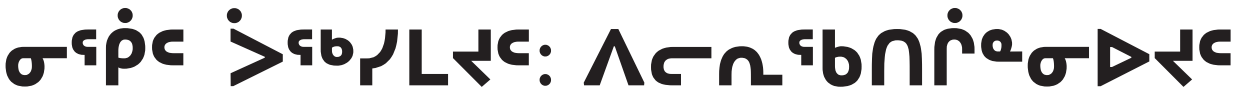

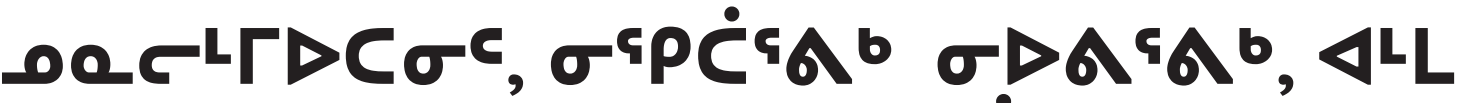

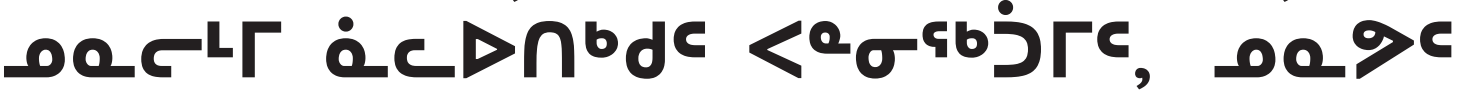
Co-op Healthy Foods Corner and Meal Packages: A Partnership among Community Members, a Grocery Store, and Community Radio in Pangnirtung, Nunavut

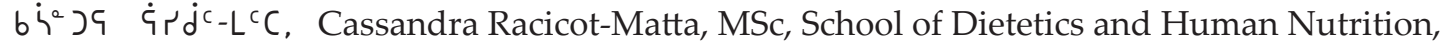
McGill University Montréal, Québec, Canada

L b` $\quad \Delta^{c} P$, Markus Wilcke, RN, Director, Population Health - Qikiktaaluq Region, Government of Nunavut, Pangnirtung, Nunavut, Canada

$D \dot{c} \wedge b \quad a c^{b}$. Oleepika Nashalik, Member, Community Steering Committee, Pangnirtung, Nunavut, Canada

J५ $\Delta^{4} \dot{\Delta} \Gamma c^{\circ}$. Grace Egeland, PhD, Associate Professor, School of Dietetics and Human Nutrition, McGill University, Montréal, Québec; and Faculty, Centre for Indigenous Peoples' Nutrition and Enviroment (CINE), McGill University, Montréal, Québec, Canada

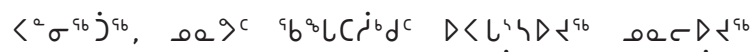

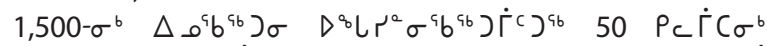
$\sigma \Gamma^{b} L \sigma \quad D P D C^{a b} j^{<} \quad P^{c} \sigma^{a a} J \Delta^{a} b \sigma^{c} \quad D \Delta^{a} a^{b} b \sigma<\sigma^{a} \sigma^{a b} j$

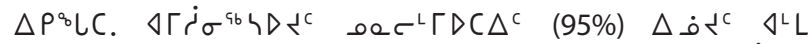
$\left.\left.\triangle \sigma^{c} \cap\right)^{c} D^{a} b P^{a} a^{a b}\right) \Delta^{a} a<\dot{j}^{c} \Omega^{c} . \quad 2007-\Gamma^{c},<\sigma^{a b} j^{a b}$

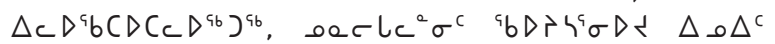

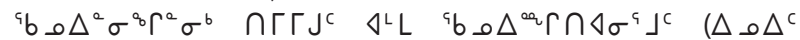

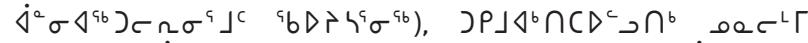

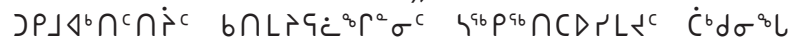

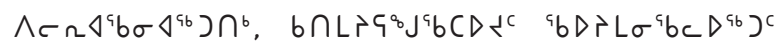

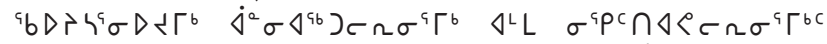
bec厂 $\left.D P D C^{a b}\right) \Gamma^{c}$. ${ }^{a} b D i\left\langle 3 \cap \Gamma \sigma D L^{c}<\sigma^{a b} \Gamma^{c}\right.$ $\left.\left.\triangle ל D^{a b} \Gamma \Gamma \Delta c D^{a b}\right)^{c} b \cap L>c \dot{c} \sigma^{b}{ }^{a b} b \Delta C D^{a b} \bigcap^{c} \cap\right\lrcorner \bigcap^{c}$

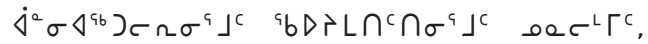

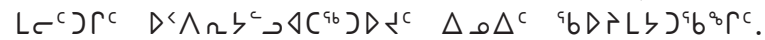

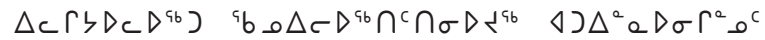

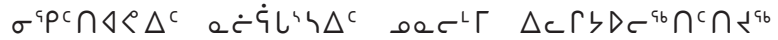
$\dot{a} c \Delta \cap^{b} d^{c} \wedge c \Omega \Delta \Gamma^{b} \sigma D \Delta^{a} \Delta^{L} \Gamma \quad \sigma \Delta \Delta \Delta^{b} J L^{a} a^{a b} J \sigma^{b}$. $\Delta d \triangleleft$

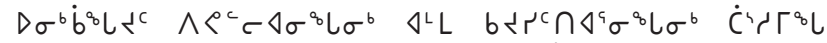
$\left.\Lambda \subset \cap \Delta^{a b} L D C D L \Gamma^{b}, \Lambda \subset n \Delta^{b} J c D^{a b}\right)^{a b} \dot{L}^{c} r$ 2009-Г.

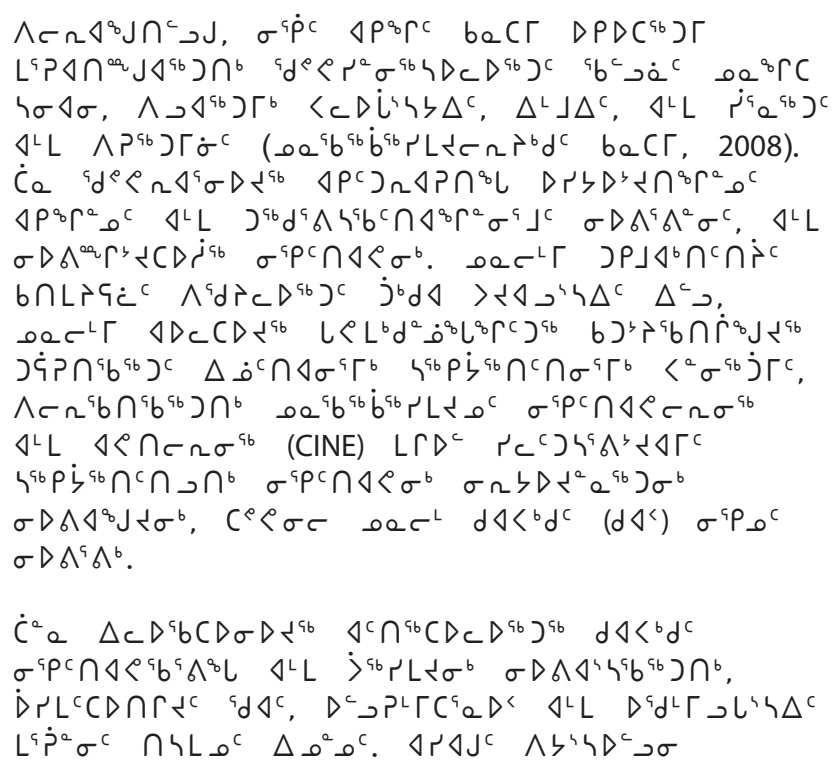




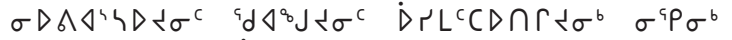

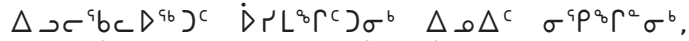

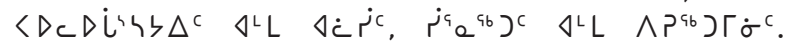

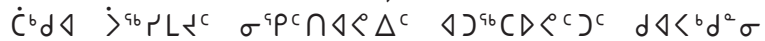

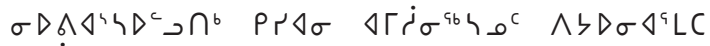

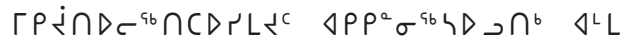

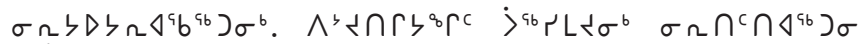
$L^{a} \dot{P}^{a} \sigma^{b} \quad \cap \zeta L \rho^{c} \quad \sigma D \Delta \Delta^{b} J L^{a} a \sigma \triangleleft^{c} L C \quad \triangleleft^{L} L \quad d \triangleleft\left\langle^{b} d^{c}\right.$

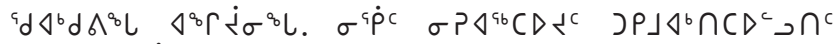

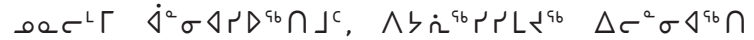

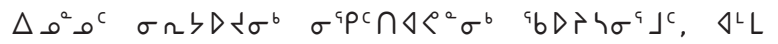

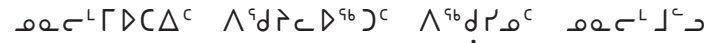
$\sigma^{a} P \subset D^{a b}\left(D d^{a} a^{a b}\right) \sigma^{b} . \quad d \Delta\left\langle^{b} d^{c} \quad \dot{P}_{a} D b \subset D^{a} \sigma^{a} b^{b} b^{a} \sigma c D^{b} \Gamma^{c}\right)^{c}$

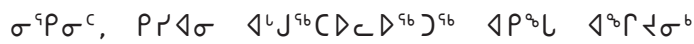

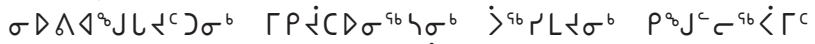
$\left.\left.L^{a b} P \cap^{c} \cap^{c}\right\lrcorner \cap^{b} \quad \sigma^{a c} \cap \Delta<\sigma^{b}\right\rangle^{a b}{ }^{a} L L^{b} \sigma^{b} \quad \Delta P^{b} \Gamma^{a} \sigma^{b}$.

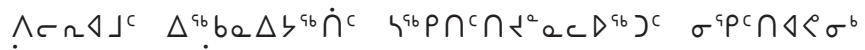

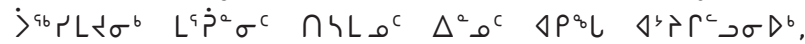

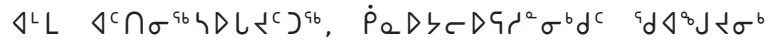

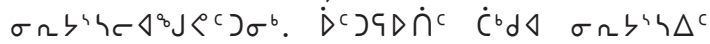
$\left.\left.\Delta \supset \Delta^{a} a D_{c} D^{a b}\right)^{c} \quad \sigma^{a} P^{c} \cap \Delta \Delta^{a} b^{a} \Delta^{L} \Gamma \quad \sigma D \Delta^{a} \Delta \dot{\Gamma}^{c}\right)^{c}$.

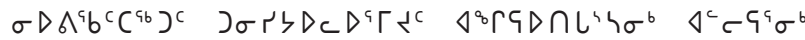

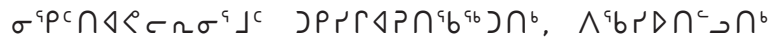
ـ ـ

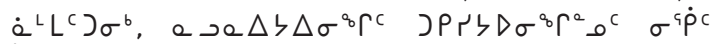

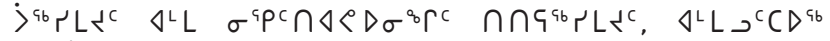

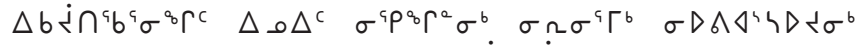
$\sigma^{c} P \sigma^{b} h \sigma \Delta \sigma . \Delta c^{8} \Gamma^{c}{ }^{a} b D P h D \dot{\Pi}^{c} j^{a b} \Gamma^{2} L^{c} \sigma \Omega b^{4} h \Delta^{c}$

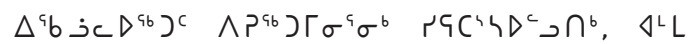

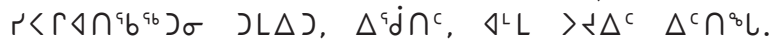

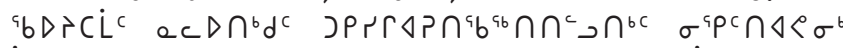

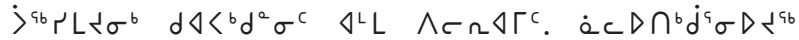

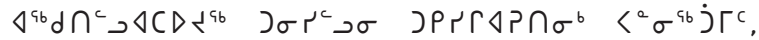

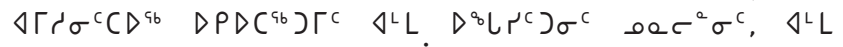

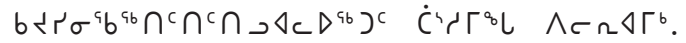

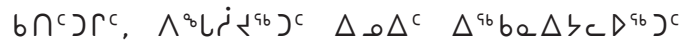

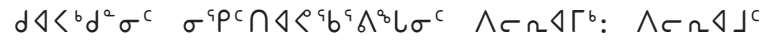
$\triangle D c^{c} \cap r \quad \Delta c^{a} \sigma \Delta^{a b} r L \sigma^{a} b^{a b} J \sigma \quad \sigma^{a} p c \cap \Delta<c n \sigma^{a} \Gamma^{b} \quad \triangleleft^{L} L$

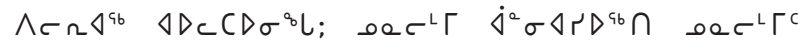
${ }^{a} b D+L^{c} \cap \Delta^{a b} J^{a b} \quad D^{a} b D^{b} r \Gamma \Delta c \Delta^{a b} J^{a b} \quad \Lambda c \Omega \Delta \Gamma^{b} \quad \Delta D_{c}{ }^{c} \cap r \Gamma^{b}$

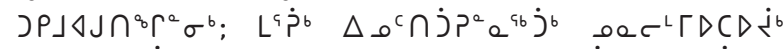
$\Lambda\left\{L \sigma^{a} b^{a b} j^{b} \quad \cap \Gamma D^{<}{ }^{a b} b \Delta^{a} \sigma^{b} L \sigma^{b} \quad D<{ }^{a b} b L D_{C} D^{a b} j^{b}\right.$

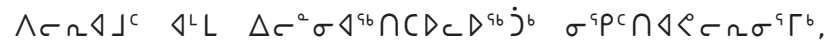

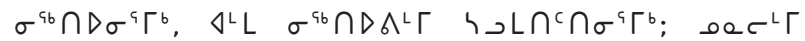
ac $\left.D \cap^{c} \cap r \quad \triangle 0^{c} \cap j p^{a} a c D^{a b} J^{a b} \quad D^{a} b D^{a} r^{a b}<c D^{a b}\right)^{a b}$

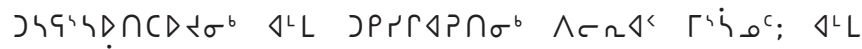

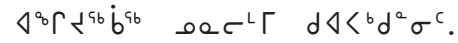

$\left.\Lambda c \Omega \Delta^{a b} \quad \Delta d \sigma D \sigma^{a} b c D^{a b}\right)^{a b} \quad \Delta C D r^{a} \Gamma^{b} \quad C^{a b} P \Gamma^{b} \quad \Delta^{b} P \Gamma^{b} b \Gamma^{c} J^{b}$

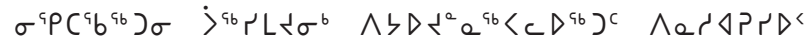

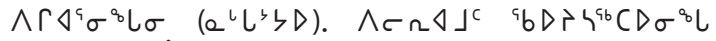

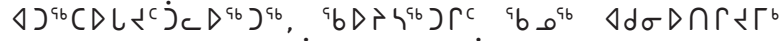

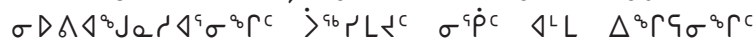
$\left.\triangle D L^{a} \dot{\sigma}^{q b} 4 \Delta^{c}\right)^{c} \quad \sigma^{q} P \dot{C}^{c} \triangle^{L} \Gamma^{c} \quad \sigma D \Delta^{c} \Delta^{L} \Gamma \quad \triangle \sigma C D L^{c}$.

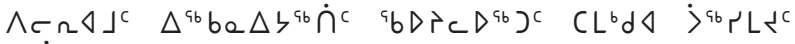
$\left.\sigma^{a} \dot{p} c \quad \sigma D \Delta \Delta^{b} b<c D^{a b}\right)^{c} \quad D^{c} J^{i b} \sigma \quad \Lambda^{i b} L \Delta^{a} \sigma \quad\left(\Lambda^{b} L^{c} \cap^{a b}\right)$

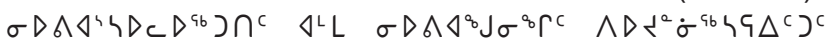

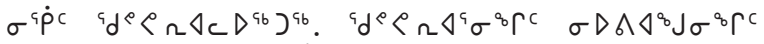

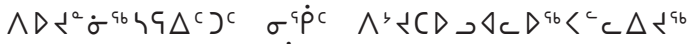

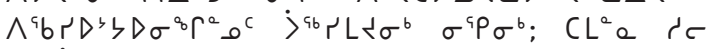

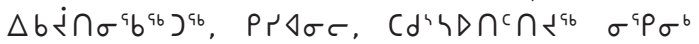

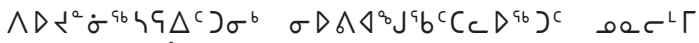
$\left.\Delta^{c}\right\lrcorner \Gamma D^{q} b \cap \dot{\Gamma} \circ^{c}$.

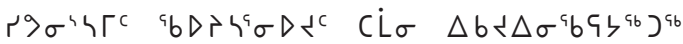

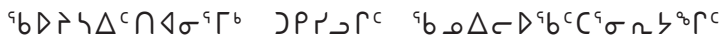

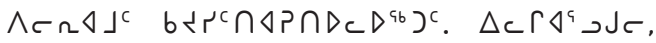
$L P C L^{a} a^{a} \sigma^{b} L \quad\left(\Delta L^{a} a \Delta^{c}\right) \sigma^{b} \wedge c \Omega \Delta \sigma^{b} \quad b L \Gamma S D b \Omega \Delta c^{b}$.

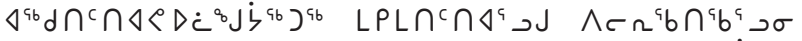

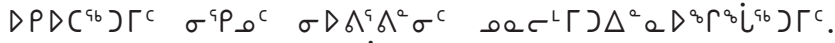

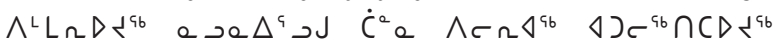
$\left.{ }^{a} d \dot{c} \dot{\sigma}^{c}\right) \cap x^{c} \quad \Delta P^{a} b^{a b} \cap \cap^{b} b \sigma^{b} \Gamma^{c} J^{a b} \quad \sigma^{c} p \sigma^{b} \sigma D \Delta \Delta^{4} h c^{a} \sigma^{b}$ $\left.a^{L} \Gamma \sigma^{a b}, \Delta b i \cap\right) \Delta^{a} a^{a} \Gamma^{b} \wedge c n \Delta^{a b} \quad \Delta D c\left(D \sigma^{b} L \sigma^{c}\right.$

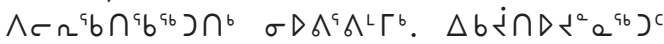

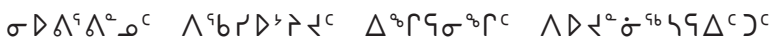

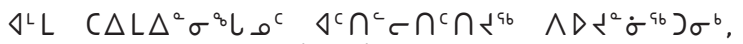

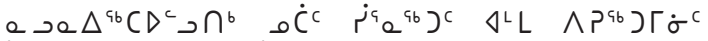
$\left.\left.j^{a b} b^{a b} r L^{c}\right\lrcorner \cap^{b} \quad \sigma^{a} \dot{P} ; \quad \sigma D \Delta^{a} \triangle D^{c} b^{c} C \sigma^{a b} h D c^{a}\right\lrcorner \sigma$

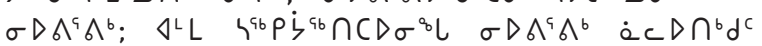

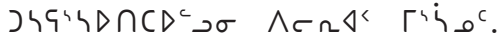

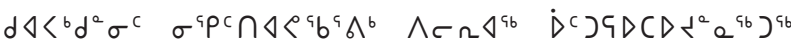

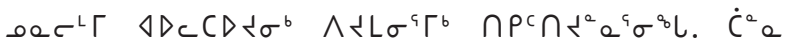

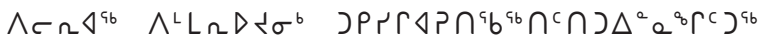

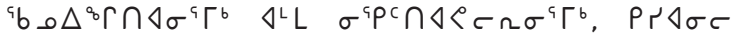

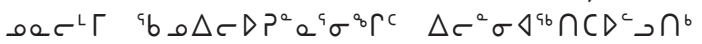

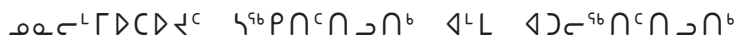

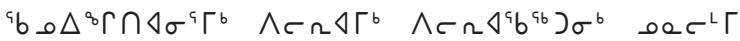

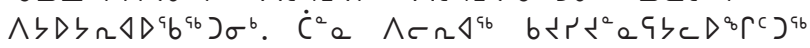

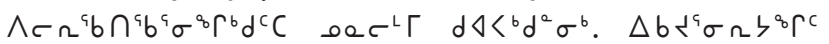

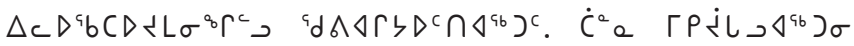

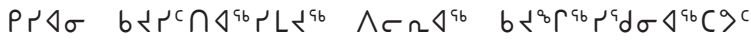

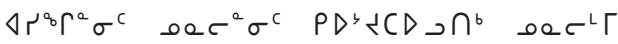

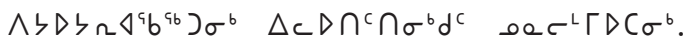

\section{כ prrspíc}

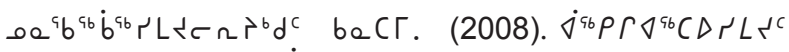

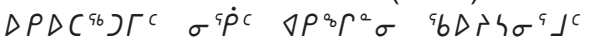

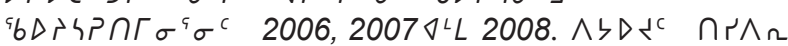
21, 2009, $\triangleright \rho^{c}$ http://www.ainc-inac.gc.ca/nth/fon/fc/ hpsr-eng.asp 


\title{
Medevac and Beyond: The Impact of Medical Travel on Nunavut Residents

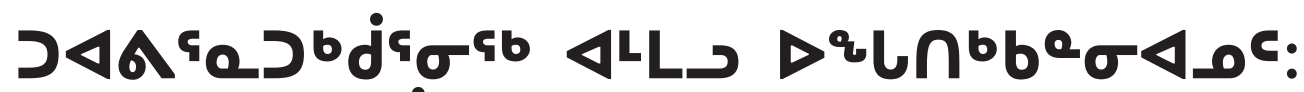

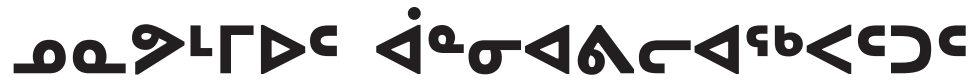

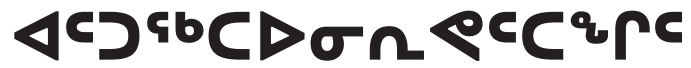

Cameron McKenzie, MSW, RSW, PhD Student in Health Policy \& Equity, York University, Toronto, Ontario, Canada

\begin{abstract}
This qualitative study identifies key factors that contribute to negative psychosocial outcomes for Inuit patients using the lqaluit, Nunavut, medevac (used for emergency transfers) and medical transfer (for non-emergency cases) programs. The study also reports on the existence and appropriateness of social and cultural supports in hospitals and communities for medically transferred patients and their families. I analyzed results from a literature review, document analysis, and 20 in-depth, semi-structured interviews with health care professionals and policy and decision makers in lqaluit and Ottawa, Ontario. Respondents were either directly involved in medevac and medical transfer programs or were health professionals who work with those using the services. In addition, variables impacting patient speed of recovery and overall mental health were considered, including isolation, social support, and emotional stress. Findings revealed that Inuit patients do experience a lack of social supports such as escorts and translators on medical trips south. They also often encounter a lack of cultural sensitivity once in the south, and suffer from homesickness and isolation. This study demonstrates that the current medical transfer system in Nunavut does not fully meet the psychosocial needs of Inuit patients and their families, which has direct effects on patients' mental health and on medical outcomes of treatment in the south.
\end{abstract}

\section{KEYWORDS}

Inuit, medevac, medical transfer, isolation, psychosocial, Nunavut

\section{DC) $\supset \cap$}

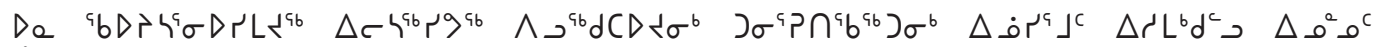

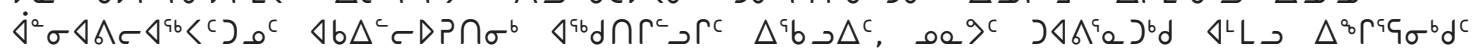

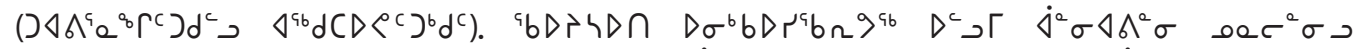

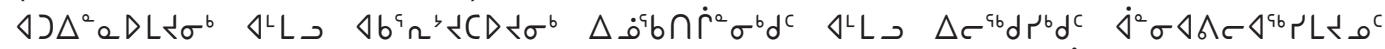

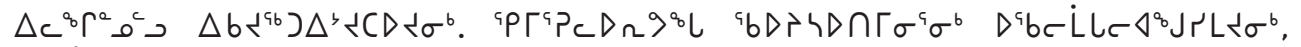

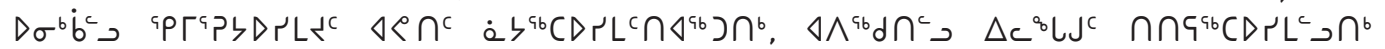

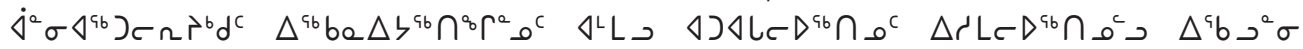




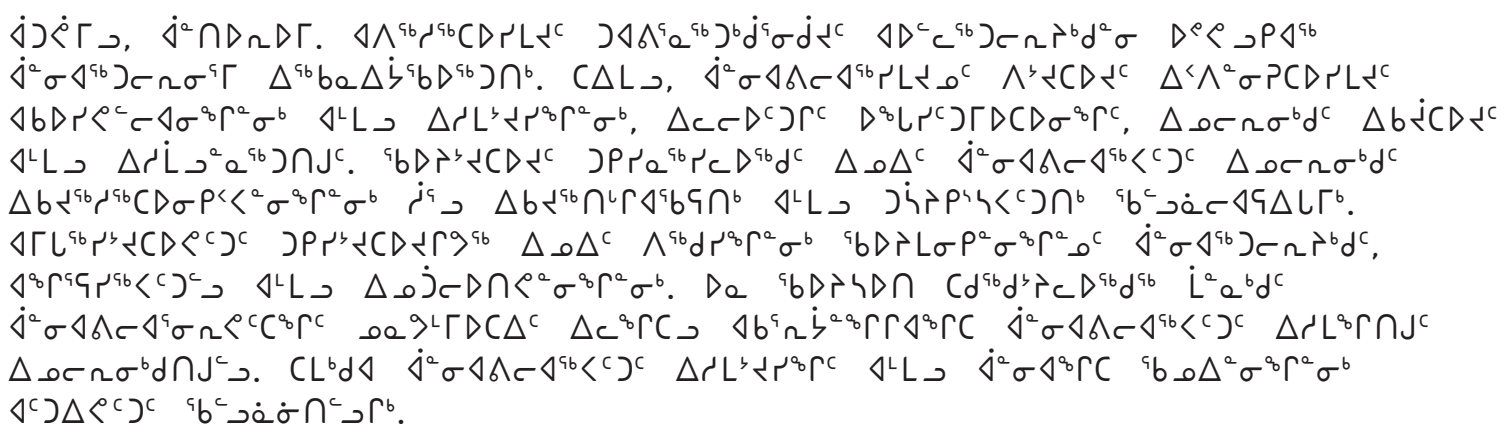

\title{
$D^{9} b D r^{9 b} C^{c}$
}

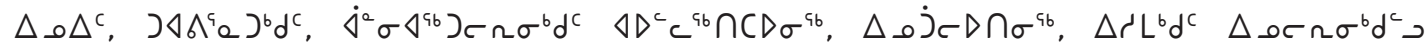

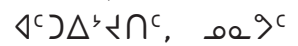

\section{INTRODUCTION}

$\mathrm{I}$ n Nunavut, $58 \%$ of patients needing inpatient and outpatient hospital care are transported outside of the territory (Canadian Institute for Health Information, 2010) through medical travel in the form of "medevac" or "medical transfer." Medevac and medical transfer refer to transferring patients by air for medical treatment. While medevac refers to emergency evacuations, medical transfer denotes the practice of transporting patients on a commercial airline. In this study, I use both terms when data is specific to one program while in some cases I use the collective term "medical transfer" to characterize both programs. The medevac program is essential to the medical model of health care for very ill or high-risk Nunavut residents, or those who need complex care. Medical transfers provide patients with non-emergency transportation, such as for CT or MRI scans, to southern hospitals (Nunavut Department of Health and Social Services, 2010b).

In Iqaluit, Nunavut, patients needing critical medical treatment-such as major surgeries, complex obstetrical care, and treatment for kidney failure-are transferred to Ottawa, Ontario. In other cases, patients must extend their stay in the south for rehabilitative care after critical health incidents, such as strokes or heart attacks. Generally, patients are required to stay in Ottawa for periods ranging from a week to three months, though they may be transferred to a southern Canadian hospital for ongoing procedures such as cancer treatment or dialysis. This costly medical travel program for patients and escorts consumes 40\% of Nunavut's health budget (Nunatsiaq News, 2011). However, to date there has been no evaluation of the impact of medical transfer on Inuit psychosocial health or medical outcomes in Nunavut.

This qualitative study asked for input from health care professionals and policy and decision-makers (20 participants in total) in Ottawa and Iqaluit about the various levels of social and emotional impact that a medevac or medical transfer has on patients, including their medical recovery rates. A secondary goal was to determine the existence and appropriateness of social and cultural supports in hospitals and communities for medically transferred patients and their families. For the purpose of confidentiality, all study participants have been given pseudonyms.

\section{METHODS}

Research for this study moved through four phases. It began with a review of scholarly and grey literature on the topics of medical transfer and patient isolation in Nunavut. The Nunavut Research Institute (NRI) provided a scientific research license, allowing access to grey literature through the Arctic College Library. The next step was a review of Nunavut government policies on health care, looking at whether these policies address the issues of isolation, social support, and emotional stress and, if so, to what extent and by which governmental jurisdictions. The Nunavut governmental library was the source for official documents regarding the health care system, including the financial records for medevacs. Information given to Nunavut residents travelling south for medical care also was reviewed. I then began field research in the northern community of Iqaluit. It included consulting with local social service agencies, researching local media accounts, and completing archival research. I also reviewed newspaper records and governmental pamphlets regarding health care policy and prevention programs and applied them to this research. Finally, I conducted in-depth, semi-structured interviews with 20 key informants/respondents in the health care field, including medical and administrative staff at the Qikiqtani General Hospital in Iqaluit and the Ottawa Hospital, other health care workers in Iqaluit, an employee of the Government of Nunavut, and representatives from Inuit organizations in Ottawa. Participants were recruited via word-of-mouth at relevant organizations. 
Of the 25 individuals approached, 20 consented to an interview. The remaining five either declined participation or did not respond to the invitation, despite follow-up. Eleven interviews were conducted in Iqaluit and nine were held in Ottawa. There were two sets of interview questions: the first specifically for individuals involved in the logistics of the medical transfer program, and the second for health care professionals who deal with issues of social isolation. The latter were chosen because of their work with patients who have used the system. The interviews took an average of one hour to complete, with some taking as little as 30 minutes and others up to an hour and a half. In order to accommodate respondents' availability, interviews were spread over a two-month period. Of the 20 interviews, 17 were conducted face-to-face, two via telephone, and one via e-mail. To ensure confidentiality, each respondent was assigned a coded number replaced by a pseudonym in this report. Some respondents expressed an interest in receiving a copy of the study, which I provided once the study was finalized. Based on the NRI licensing agreement, respondents also received a copy of the final draft and an executive summary that was translated into Inuktitut. Lastly, the findings were brought back to the community through an interview on CBC North radio in August of 2011.

Data from the interviews led to a universal "composite description" (Creswell, 2007) of what patients experienced and how they experienced it (Moustakas, 1994). Semi-structured interviews have the dual advantage of allowing for conversational fluidity while simultaneously establishing consistency across several interviews. They involve a fixed set of questions, but the researcher may also pose new questions as issues arise during the interview (Guion, Diehl, \& McDonald, 2011). I sought to clarify participant comments as needed to gain the most comprehensive understanding of the intended meaning (Glesne, 2010).

A third party transcribed all interviews and coded them for common themes or patterns based on the participants' perceptions and responses. The Coding Manual for Qualitative Researchers (Saldaña, 2009) was used to aggregate, sort, and interpret data. Three primary thematic categories emerged: challenges surrounding medical escort policies, a lack of cultural competency in primary treatment facilities, and a lack of social supports and resources for Inuit patients. These categories were then used to explain possible reasons for negative psychosocial outcomes among Inuit transported south for medical treatment.

\section{RESULTS}

The following summarizes the answers to specific questions posed to health care professionals and other respondents during interviews. Not all respondents provided full answers to all questions as some questions fell outside their area of expertise. Some data have not been collected, including information about the nature of injuries (e.g., motor vehicle accidents, slips and falls, etc.) and whether there were external factors such as drug or alcohol abuse. Because of this, there is no quantitative data provided in the results. Future research is needed to correlate these external factors with the use of medevac and medical transfers.

Respondents confirmed there were 247 medevac transfers in the 12-month period from April 2009 to March 2010. The total percentage of Qikiqtani patients requiring medevac services was unknown. Twenty-six percent of all cases (64 transfers) involved pediatric patients, and 6\% (15 transfers) were obstetrical in nature.

The proportion of surgical, palliative, and other medical specialties was unknown to the respondents. Patients stayed an average of 12 days in Ottawa, with an average inpatient stay of 7.17 days, as indicated by one respondent. In most cases, patients do not require hospitalization upon their return to Nunavut, with the exception of those needing in-hospital palliative care. When asked whether some patients required repeat visits, participants responded that this depended on the type of care received. For example, three respondents noted that follow-up care could be required for cardiac and cancer patients. Respondents knew of no available data pertaining to the psychosocial impact of medical transfer on patients and their families, or responded that none existed. "Stella" added: "The government is more interested in their physical condition [than psychosocial] and not interested in the rest, and this is a real gap in the system."

It should be noted that all of the respondents felt that the medevac/medical transfer service itself was highly respected for the quality of care provided-for speed, efficiency and reliability, and the professionalism of the health care staff. Stella noted, "[The Government of] Nunavut is better than other territories in bringing more escorts down for support. NTI [Nunavut Tunngavik Incorporated] may help transfer people, but they do not pay for housing or food, leaving family members struggling for lack of resources. [The Government of] Nunavut does a better job, but it's still tough." As expected, the service is subject to adverse weather conditions and other delays.

When asked whether they had concerns associated with the medical transfer program, almost all (19 of 20) participants brought up issues related to non-medical escort policies, flight logistics, or patients' and/or escorts' social-emotional issues. The analysis of the interviews revealed three broad categories of concerns: 1) personal support for medically transferred patients, 2) cultural competency of medical staff, and 3) availability of community supports for medically transferred Inuit patients.

In terms of personal supports, the two that participants repeatedly mentioned were escorts and interpreters. In certain cases, patients can have a family member accompany them, provided they meet the escort criteria that fall under Nunavut's Health and Social Services Extended Health Benefits Policy. The medical escort (such as a doctor or nurse) or a non-medical escort (an adult accompanying a patient requiring assistance) must be deemed necessary by the referring medical practitioner (Nunavut Department of Health and Social Services, 2010a). The medical escort's duties are limited to providing care while the patient is travelling. 
Questions regarding escort policies seemed to frustrate and even anger participants. One interviewee expressed irritation with the inconsistencies regarding the provision of escorts, sharing that some elderly and unilingual individuals go alone, while others who could easily manage without escorts are given one. Other respondents pointed out the difficulty of finding a last-minute escort in cases of sudden illnesses, adding to patient stress. Some interviewees talked about the financial or emotional burden placed on non-medical escorts. "Pam" stated: "For the family/ escort there is the added stress of leaving home and the problems that may occur when they are away. For example, who will look after the needs of their children/own family? How will they manage financially if they are not working?" These concerns point to the problematic interruption of social assistance benefits for individuals needing to leave Nunavut. In addition, when the escort is a family provider, time away means having to budget in advance for this possibility, adding further stress. "Julie" elaborated, "For the social worker [working with these individuals] there is no way to get [social assistance funding] for them while they are staying here." Other stresses for the escort may be emotional: worrying about family members and, in particular, children. A number of respondents pointed out that the escorts were worried about the risk of physical and sexual abuse, risk of violence, and food insecurity while they are gone.

Just as escorts are important to the well-being of patients, interviewees also pointed to the necessity and value of interpreters to the program. Respondents identified the Ottawa Health Services Network Inc. (OHSNI) as an organization that helps facilitate patients' transfer and stay in southern hospitals. However, even with this resource, interpreters are often spread too thin and may only be available at the time of admission for the initial assessment and then at the time of discharge. There is no day-today translation for patients unless a family member with a better understanding of English is present, as was indicated by three respondents. As a result, patients feel marginalized. Without enough English knowledge, patients are unlikely to be accepted for rehabilitation programs, resulting in either their placement in longterm care-where isolation and lack of language support are again major problems — or their transfer back north, without receiving much needed rehabilitation.

The second primary area of concern was related to cultural competency or sensitivity. Respondents uniformly confirmed that traditional healing methods went unrecognized in southern patient care and pointed to the cultural gap between Inuit and the hospital medical culture in Ottawa. Some patients find it difficult or are upset to hear criticism about the medical care they received in Nunavut prior to medical transfer. Cultural differences have led to problems of adherence both in Iqaluit and in Ottawa. "Grace" pointed out that these patients are poor, come from small communities, and have little formal education, making it exceedingly difficult for them to understand and follow medical care information and directions once back home: "[Given the] poverty, abuse - lots of issues - what we are seeing is non- [adherence] or caregivers that have no clue of how to take care of [these individuals]. Patients maybe not being able to verbalize their needs. . embarrassed or afraid of what consequences might be." Even patients with some Englishspeaking ability may be unable to understand what medical personnel say, and patients are often shy and do not want to ask questions, leaving them uninformed about their medical condition and unable to provide informed consent.

According to a few respondents, lack of cultural sensitivity demonstrated by staff can also be a barrier. "Meaghan" said, "In my experience [the south] is a scary place to be in, and [patients] suffer a big cultural shock. Using terms like 'social work' can cause feelings of guilt and embarrassment. For my Inuk mom at the Ottawa Hospital, everyone was talking too loudly and it was not culturally appropriate." In the hospital setting, this can lead to awkward misunderstandings. "Dina" said, "Very often the doctor will say, "go home; we will see you next week." The patient thinks that home is in the north, when the doctor means go back to Larga Home [a boarding house for patients and families], and not north." Grace observed that Inuit attach a different meaning to some common English phrases. For example, "I'm sorry," in the context of giving bad news in the hospital, is understood by Inuit as, "I'm responsible or it's my fault." Therefore, telling family about the death of a loved one can be seen as accepting blame rather than offering simple condolences. Cultural sensitivity also extends to the choice of interpreters. It is not culturally appropriate, for example, to match an elderly male Inuk with a young female interpreter.

Cultural divides not only affect Inuit patients' understanding of the medical staff, but medical staff may also find Inuit forms of communication confusing. For example, lack of facial expression or emotion is normal among Inuit, but this may be misunderstood as the patient being "not all there," said Stella, resulting in a very literal and task-oriented approach to the patient. Medical staff may express frustration with Inuit, e.g., using statements such as "Here we go again" to mean an unwelcome challenge or nuisance, said Julie. Inuit preference for "country food" (e.g., caribou, seal, and arctic char) - particularly among Elders-is also ignored. Cultural insensitivity is evident even at the level of cognitive and psychometric tests. One section of the Montreal Cognitive Assessment, also known as MoCA, shows animal pictures that patients need to identify, including a lion, a camel, and a rhinoceros (Nasreddine et al., 2005). Patient scores on such tests may be affected by cultural unfamiliarity with these animals and not represent true ability. Most important, perhaps, cultural concerns are tied to ethical decision-making regarding very ill patients. As Grace pointed out, sending very sick patients south for medical care is sometimes not recommended because of the cultural importance of being able to die at home, surrounded by family and loved ones in a familiar environment.

Several respondents described how the lack of cultural competency and demonstrated cultural sensitivity highlights the disempowerment experienced by Inuit using the system. They described how the medical transfer system itself takes away Inuit patients' control, which worsens anxieties about their illnesses. As one respondent observed, patients have no control over the 
decisions about the organization and timing of flights. He added, "When individuals are sick, it is important that they feel that they have some control over things affecting them [given that they are already losing a lot of control of their illness]. Right now the system does not even give you a little control: you have to do it 'our' way." During their stay at the hospital, patients are further disempowered because of language and cultural barriers. "Chris" commented, "People need to know that they can choose the care they receive. We do not give them that option. We control the means of getting the service. Where is the individual's responsibility to take care of themselves?" Finally, unlike most patients who have the freedom to sign themselves out of a hospital (even when doctors recommend otherwise), individuals using medical transfers must receive an "okay" before being allowed to fly home.

The last area of concern that study participants unanimously observed was the lack of social supports and resulting social isolation and "homesickness" while on medical travel. "Sarah" said that it is even difficult for the patients to hear news from home because "most of them do not have a long distance [telephone plan] to call their family." Four respondents pointed out that for Inuit, homesickness is not just about missing home, but rather it means that a person feels very lost and out of place. Several respondents reported that homesick Inuit may feel so lost and depressed that they will sometimes plan to leave Ottawa before completing their treatments. Inuit patients may purposefully break rules, such as drinking alcohol, said Pam. The sense of despair resulting from homesickness can also lead to feelings of anger and hopelessness, making healing more challenging. "Heather" gave a personal example: "My mom would get depressed. She was in [the hospital] for eight months straight. It was hard on her children and it was hard on her. I also have a nephew who was getting cancer treatments and is now not working, yet it was hunting season at home. He wants to be there-on the land-and not here." According to "Jane," the psychological separation from the north, family, and friends leads to such despair that some patients may give up on getting better, dying suddenly from strokes or heart attacks. Inuit patients may feel further isolated by their condition, being unable to move around due to illness, or from the isolation units they are placed in when carrying infectious illnesses such as tuberculosis (TB) and methicillin-resistant Staphylococcus aureus (MRSA). Feelings of despair in this state can make a patient refuse treatment in the hope that this means they can return home. This happens because "people will not understand what they are sometimes told and not know they have to be here for six weeks," said "Debbi." Meaghan tied resistant patient behaviour not only to homesickness, but also to the Inuit historical relationship to western health care: "Historically, trauma has been associated with going into an institution and experiences in the system [of residential schools]. TB patients in the past were picked up in a ship and would not return.”

As mentioned, homesickness among Inuit correlates to incidences of depressive symptoms; however, respondents seemed to disagree about its prevalence. On one hand, Grace felt that homesickness cannot be understood as true clinical depression, yet Jane reported that more than $90 \%$ of Inuit admitted to hospital in the south experienced depressive symptoms. For "Melissa," factors such as the warmer hospital temperatures, which are very uncomfortable for Inuit patients, contribute to feeling unwell and therefore to a risk of developing depression or other mental health issues.

There are no formal programs for addressing the psychosocial needs of Inuit patients in Ottawa hospitals. Jane remarked that social workers are trained to carry out psychosocial assessments, and the results could be passed along to other hospital staff, allowing them to find ways to meet the cultural needs of Inuit patients. However, Stella commented on the dilemma of addressing any preexisting mental health issues among some of the patients arriving for care, saying, "[I]f they are here for three weeks, do you open that wound and do you help them through it and talk about it? But when there is no service up north [to continue supporting them], then what do you do? Are you causing more harm than good?"

There is limited support for patients and families in Ottawa. For example, the boarding house Larga Home is only available to Inuit from Baffin Island. Its mandate is the provision of transportation, food, and lodging (Davidson, n.d.). OHSNI offers Inuktitut/English interpreters, assists with communication among medical staff and families, and offers administrative support for appointments (Ottawa Health Services Network Inc., 2010). It gives access to nurses and social workers, as well as medical equipment and medications, and helps facilitate transfers between Nunavut and Ottawa. Once OHSNI professional staff gives clearance, Larga Home arranges air transport home.

Aside from the initial escort and a translator (if available) there are no Inuit caregiver provisions in Ottawa hospitals. Jane did, however, point out a new program at the University of Alberta Hospital (in Edmonton) where Inuit are hired to provide culturally appropriate healing practices, as well as to help educate staff about cultural norms.

To the final interview question about government agency awareness of social support problems, respondents agreed that governments have not prioritized the psychosocial needs of Inuit transferred to the south. Pam used a personal example:

When I went back home to Pond Inlet in 2007, I approached the MLA [Member of the Legislative Assembly] about my own experience while south for cancer treatment, and [expressed] the issues that exist concerning [the lack of psychosocial support for] cancer patients and longer term care - and nothing happened. Those long-term care and cancer patients are the ones most lacking support. Inuit patients and parents of younger patients are not really comfortable about the feelings that arise from either their illness or being away for so long. It may be too much for them, and when they are in Ottawa, some do not talk at all about what is going through their minds [because there is no one there to talk to].

Highlighting similar issues, Jane stated:

The lack of visibility of Inuit, and non-existence of political pressure has left Inuit as an invisible people. Rarely do I meet anyone outside of the hospital that even realizes that Inuit 
are sent by medevac to Ottawa for health care. I believe Inuit, like the [other] Aboriginal people of Canada, are a lost people.

\section{DISCUSSION}

The current state of health care delivery in Nunavut is built on a long history of cultural and political decisions, primarily taken outside of the territory and without input from Inuit. The present health care system in Nunavut and the poor overall health of the population is rooted in the colonial history of Inuit and the erosion of the traditional holistic understanding of health. Forced clustering, residential schools, and other threats to Inuit language and culture have led to increased psychological and social problems in the local population (Smylie, 2009). Anxiety, depression, and suicide are all serious problems, particularly among the Inuit youth of Nunavut (NTI, 2008). Additionally, social determinants of health, such as poverty, unemployment, and poor and overcrowded housing contribute to negative psychosocial outcomes including an extremely high incidence of violence in the Inuit community (NTI, 2008). Specifically, pregnant women are subject to high levels of abuse and trauma, but the risk of violence is high for all Inuit women, regardless of reproductive age (New Economy Development Group, 2006; Nunavut Department of Health and Social Services, 2007). Women and children are also vulnerable to sexual abuse (National Collaborating Centre for Aboriginal Health, 2010; Richmond \& Ross, 2008). In a larger sense, health inequities, such as lower life expectancies, higher rates of infectious illnesses, and higher rates of suicide can be directly linked to these social and economic determinants of health (Creswell, 2007). Emotional and family problems have also increased due to daily hardships: food insecurity, inadequate housing, higher incidences of medical illnesses, and lower life expectancy (Smylie, 2009).

In the early years, the responsibility for Inuit health care belonged to provincial governments, religious organizations, and even the Hudson Bay Company (NTI, 2008). Since 1945, however, the Canadian federal government has been involved in the delivery of health care services to First Nations, Métis, and Inuit communities, of which medical transfer is now a key part (Aboriginal Affairs and Northern Development Canada, 2011; Health Canada, 2007). Care for Inuit was transferred wholly to the Department of Indian Affairs in 1939, but it was not until the late 1970s that there was any discussion about involving Inuit themselves in the decision-making process for their own health care (Health Canada, 2007). Currently, while Inuit are beginning to be more involved at the policy level, health care outcomes remain poor and government support for Inuit health care programs is increasingly threatened.

At the time that this study was originally conducted (2010), Health Canada was making concerted efforts to address diabetes and TB in First Nations and Inuit populations-as well as the consequences of residential schooling - through the Aboriginal Healing Foundation (Health Canada, 2007). However, due to the influence of the federal government, several Inuit-focused organizations, such as Pauktuutit Inuit Women of Canada, have had funding reduced, or eliminated entirely as in the case of the National Aboriginal Health Organization (CBC News, 2012; Fitzpatrick, 2012). The health budget for Inuit Tapiriit Kanatami (ITK), formerly Inuit Tapirisat of Canada, has also been cut by $40 \%$. The decrease in funding, which amounts to $\$ 3$ million over two years, has a significant negative impact on ITK's ability to effectively respond to health challenges facing Inuit (Inuit Tapiriit Kanatami, 2012).

These funding cuts are especially alarming in light of the gap in the health status of First Nation and Inuit communities as compared to Canadians overall, which for Inuit is largely influenced by impoverished living conditions, including food insecurity, crowded living conditions, and housing in need of major repair (Huet, Rosol, \& Egeland, 2012). For example, most Canadians can expect to live 79 years on average whereas the average life expectancy for Inuit is between 64 and 67 years (Peters, 2011; Wilkins, Uppal, Finès, Senécal, \& Guimond, 2008). In Nunavut, suicide rates are 11 times higher and TB incidence is 62 times greater than the Canadian average, with 100 new active cases of TB documented in 2010 (Health Canada, 2006; MacDonald, Hébert, \& Stanbrook, 2011). Lower respiratory tract infections have been found to be the leading cause for the medical evacuation and hospitalization of Inuit children: rates are as high as $48.4 \%$ among infants under the age of 6 months (Banerji, 2009). Poor ventilation in overcrowded housing is a primary cause of these illnesses, with about four in 10 Inuit living in overcrowded housing - 13 times more than the Canadian average (Tester, 2006).

An important finding of the present study is that most respondents perceived a negative psychosocial impact on Inuit who travel south for medical care. The interviews revealed that no official programs have yet been developed to adequately meet the psychosocial needs of Inuit patients who require medical transfer to the south and their families. Furthermore, there is little sensitivity shown for Inuit cultural practices within hospitals, which has a negative impact on the rate of recovery and points to a governmental failure to meet current Nunavut Inuit health care needs.

The respondents identified a number of shortcomings related to the medevac system and medical transfers. Organization and logistics could be improved with respect to handling of the escorts and family members that need to accompany patients. Financial supports for escorts and family are inadequate. The organization of the transport program is under the control of the medical system, which leaves patients with little to no say in the process. Overall, the biggest problem with transferring Inuit patients south-whether through medevac or medical transfers-is social isolation, which has a negative impact on both physical and mental health. On a positive note, the support and care provided by the staff at OHSNI is seen as excellent and staff is devoted to Inuit clients. One such helpful OHSNI program is the Petty Cash Fund, which allows cash supplements to a maximum of $\$ 200$ per patient per visit. Additionally, Larga Home is an important source of contact with other Inuit in addition to its boarding and transportation services. 
Still, the obvious systemic problems that lead to social isolation-cultural insensitivity, inadequate interpretation services, and lack of Inuit staff and cultural supports such as "country food" or visiting Inuktitut-speaking support workers-all have yet to be addressed.

\section{LIMITATIONS}

The primary shortcoming of this study is that patients and their families were not interviewed. Much more precise data with respect to psychosocial issues could be obtained by talking directly to the people affected.

Some concerns were raised about the wording of the interview questions. For example, one respondent observed that the question "In your experience do Inuit patients in southern hospitals encounter a higher incidence of depression?" was somewhat limiting. He noted that any patient who goes to a hospital with an illness would be unhappy to be there. While this question could have been worded more carefully, most respondents felt depression was a distinct and common issue for Inuit, based on cultural and language barriers.

Finally, this study may have benefited from an analysis of relevant quantitative statistical data. This could be the focus of a subsequent study.

\section{CONCLUSIONS}

This study demonstrates that the current medical transfer system in Nunavut does not fully meet the psychosocial needs of Inuit patients and their families, which has direct effects on patient mental health and on medical outcomes of treatment in the south. While this study mostly focuses on patients from Nunavut, the findings could parallel the reality of other northern Inuit regions or remote native communities internationally. Furthermore, it is hoped that this study will serve as a basis for further inquiry into the inequalities experienced by Aboriginal individuals in remote communities, and the policies surrounding health care of Inuit.

In truth, there will always be a need for medical transfer in Nunavut: the region's sparse population will hardly justify the extent of medical personnel or technology needed to meet all the demands that arise in acute care medical settings. Despite this reality, this study demonstrates several psychosocial factors that have an impact on patients and their families when they travel south for medical care. Addressing these factors with culturally sensitive and specific solutions may lessen the negative effects they have on mental health and medical outcomes.

Based on this study's findings, I propose the following recommendations to address the needs of Inuit patients who travel south for medical care. As suggested by Jane, language differences can be lessened through labelling medications and medical instructions in Inuktitut. Escort roles, and the process for getting an escort, should be better explained in a written, translated form. The government needs to provide greater moral and financial support to patients and escorts arriving in Ottawa. As one respondent noted, social assistance payments should not be interrupted for patients and escorts when they are required to leave Nunavut for medical care.

The Government of Nunavut needs to be more financially accountable to Nunavut residents in funding health care initiatives. This point refers directly to comments found in the NTI Annual Report for 2008, which notes that "NTI informed both [territorial and federal] governments that Inuit did not agree with the conversion of an Aboriginal-specific program into general funding of the public government, and instead, NTI said that Inuit have the right to review and sign off on government health funding intended for them" (NTI, 2008). Their assessment of the dispute concludes "there is no mention made of accountability to Inuit" (NTI, 2008).

Communication between northern and southern medical facilities with regard to patient transfers needs to be more reliable and consistent. As noted by several respondents, electronic medical records could improve this situation through creating a secure and dependable link among the various health care facilities.

The largest group of patients sent south for routine evaluation consists of those sent for diagnostic imaging with CT and MRI scans (Qikiqtani Hospital Medevac, 2010). Several respondents supported investing in CT and MRI scanners in Iqaluit with trained technicians on staff, and establishing a better satellite network for rapid transmission of images for interpretation by radiologists in the south. This could dramatically reduce medical transport costs for Nunavut.

Cultural sensitivity training for medical staff in southern hospitals would help health care professionals better understand Inuit norms and values, and in turn, improve medical outcomes. Many respondents said that training should include attention to verbal and non-verbal communication, awareness of Inuit connection to the land, recognition of the importance of "country food," and awareness of and sensitivity to Inuit spirituality.

Support for Inuit patients in Ottawa could be improved by hiring more interpreters and social support staff such as social workers. Ottawa does have some dedicated support services for Inuit clients, but many are underfunded and staff is overworked. Expanding these services, and collaborating with other organizations that provide patient care to Inuit in additional Canadian cities, may provide some new solutions.

One potentially cost-effective solution to the problem of isolation would be to hire Inuit visitors to attend patients in the hospitals and engage them in culturally relevant and appropriate activities. Visitors can help preserve cultural and linguistic contact, said Jane, and give much needed moral support during the hospital stay. Isolation can also be reduced by giving patients prepaid long distance phone cards to call home, perhaps funded by the Government of Nunavut or through a grant from Health Canada, as proposed by three respondents.

Findings confirm a general failure to implement a holistic approach to care for Inuit patients who are sent south. In addition, social isolation has an obvious and serious negative impact on 
mental health and medical outcomes for Inuit. Homesickness and removal of cultural support contribute to a profound sense of loss, disempowerment, and depression experienced by Inuit, leading to non-adherence, early cessation of therapy, and a reduced sense of well-being. Ultimately, problems stem from the social, economic, and political determinants of health that all conspire to perpetuate conditions of poverty for Inuit of Nunavut. The larger social issues of education, housing, unemployment, substance abuse, and accidental injury still need to be addressed with greater vigour. These conditions ultimately tax the health budget and drain the medevac and medical transfer programs. Government agencies need to set priorities to address these inequalities in a timely manner. It is hoped that the conditions leading to social isolation and depression for Inuit can be lessened or eliminated with further research, and the implementation of the recommendations I have outlined in this study.

\section{REFERENCES}

Aboriginal Affairs and Northern Development Canada. (2011). A bistory of Indian and Northern Affairs Canada. Retrieved December 15, 2012, from http://www.aadnc-aandc.gc.ca/ eng/1314977281262/1314977321448

Banerji, A., Greenberg, D., White, L. F., Macdonald, W. A., Saxton, A., Thomas, E., ... Roberts, A. (2009). Risk factors and viruses associated with hospitalization due to lower respiratory tract infections in Canadian Inuit children: A case-control study. The Pediatric Infectious Disease Journal, 28(8), 697-701.

Canadian Institute for Health Information. (2010). Have health card, will travel: Out-of-province/-territory patients. Retrieved April 25, 2012 from: http://secure.cihi.ca/cihiweb/products/ out_of_province_aib_201003_e.pdf

CBC News. (2012, April 9). National Aboriginal Health Organization's funding cut: Organization to close at end of June. CBC Nerws. Retrieved April 22, 2012, from http://www. cbc.ca/news/politics/story/2012/04/09/north-naho-fundingcut.html

Creswell, J. W. (2007). Qualitative inquiry and research design: Choosing among five approaches. Thousand Oaks, CA: Sage Publications.

Davidson, B. (n.d.). Welcome to Larga Home. Larga Homes Ltd. Retrieved April 29, 2012, from http://www.largaweb.com/ about_us.htm

Fitzpatrick, M. (2012, April 16). Inuit women's group upset over Health Canada grant cut. CBC Nerws. Retrieved April 22, 2012, from http://www.cbc.ca/m/touch/canada/story/2012/04/16/ pol-health-cuts.html
Glesne, C. (2010). Becoming qualitative researchers: An introduction. Boston, MA: Pearson.

Guion, L. A., Diehl, D. C., \& McDonald, D. (2011). Conducting an in-depth interview (Document No. FCS6012). Retrieved April 17, 2012 from Department of Family, Youth and Community Services, Florida Cooperative Extension Service, Institute of Food and Agricultural Sciences, University of Florida website: http://edis.ifas.ufl.edu/pdffiles/FY/FY39300.pdf

Health Canada. (2006). First Nations, Inuit and Aboriginal health: Suicide prevention. Retrieved April 29, 2012, from http://www. hc-sc.gc.ca/fniah-spnia/promotion/suicide/index-eng.php

Health Canada. (2007). History of providing health services to First Nations people and Inuit. Retrieved April 27, 2012, from http://www.hc-sc.gc.ca/ahc-asc/branch-dirgen/fnihb-dgspni/ services-eng.php

Huet, C., Rosol, R., \& Egeland, G. M. (2012). The prevalence of food insecurity is high and the diet quality poor in Inuit communities. The Journal of Nutrition, 142(3), 541-547.

Inuit Tapiriit Kanatami. (2012). Inuit describe Health Canada cuts as unconscionable. Retrieved April 29, 2012 from https://www.itk. $\mathrm{ca} / \mathrm{media} /$ media-release/inuit-describe-health-canada-cutsunconscionable

MacDonald, N., Hébert, P. C., \& Stanbrook, M. B. (2011). Tuberculosis in Nunavut: A century of failure. Canadian Medical Association Journal, 183(7), 741-741.

Moustakas, C. E. (1994). Phenomenological research methods. Thousand Oaks, CA: Sage Publications.

Nasreddine, Z. S., Phillips, N. A., Bédirian, V., Charbonneau, S., Whitehead, V., Collin, I., .. . Chertkow, H. (2005). The Montreal Cognitive Assessment, MoCA: A brief screening tool for mild cognitive impairment. Journal of the American Geriatrics Society, 53(4), 695-699.

National Collaborating Centre for Aboriginal Health. (2010). Family violence as a social determinant of First Nations, Inuit and Métis health. Prince George, British Columbia: University of Northern British Columbia.

New Economy Development Group. (2006). Piliriqatigiinngniqworking together for the common good: Health integration initiative project in Nunavut. Iqaluit, Nunavut: Nunavut Tunngavik Incorporated. 
Nunatsiaq News. (2011, March 1). Health department must trim medical travel, Nunavut MLAs complain. Nunatsiaq Online. Retrieved April 29, 2012, from http://www.nunatsiaqonline. ca/stories/article/98789_health_department_must_trim_ medical_travel_mlas_say/

Nunavut Department of Health and Social Services. (2007). Proposal for a coordinated expansion of maternal/newborn health services in Nunavut 2007-2017, draft 5. Iqaluit, Nunavut: Government of Nunavut.

Nunavut Department of Health and Social Services. (2010a). Medical travel-Extended health benefits. Government of Nunavut. Retrieved April 29, 2012, from http://www.hss.gov.nu.ca/en/ Medical\%20Travel\%20EHB.aspx

Nunavut Department of Health and Social Services. (2010b). Medical travel-Medevac. Government of Nunavut. Retrieved April 29, 2012, from http://www.hss.gov.nu.ca/en/ Medical\%20Travel\%20Medevac.aspx

Nunavut Tunngavik Incorporated (2008). Nunavut's health system: A report delivered as part of Inuit obligations under Article 32 of the Nunavut Land Claims Agreement, 1993. Iqaluit, Nunavut: Author.

Ottawa Health Services Network Inc. (2010). Mandate. Retrieved April 28, 2012, from http://www.ohsni.com/en/page/Mandate

Peters, P. A. (2011). Shifting transitions: Health inequalities of Inuit Nunangat in perspective. Journal of Rural and Community Development, 7, 35-58.

Qikiqtani Hospital Medevac. (2010). Service statistics for the year ended March 31, 2010. Iqaluit, Nunavut.

Richmond, C. A., \& Ross, N. A. (2009). The determinants of First Nation and Inuit health: A critical population health approach. Health and Place, 15(2), 403-411.

Saldaña, J. (2009). The coding manual for qualitative researchers. Thousand Oaks, CA: Sage Publications.

Smylie, J. (2009). The health of Aboriginal peoples. In D. Raphael (Ed.), Social determinants of health: Canadian perspectives, 2 nd edition (2nd ed., pp. 280-301). Canadian Scholars' Press.

Tester, F. J. (2006). IGLUTAQ (in my room): The implications of homelessness for Inuit: A case study of housing and homelessness in Kinngait, Nunavut Territory. Vancouver, British Columbia: University of British Columbia.
Wilkins, R., Uppal, S., Finès, P., Senécal, S., Guimond, E., \& Dion, R. (2008). Life expectancy in the Inuit-inhabited areas of Canada, 1989 to 2003 (Catalogue No. 82003 X). Health Reports, 19, 7-19. Retrieved April 17, 2012 from Statistics Canada website: http://www.statcan.gc.ca/pub/82003-x/2008001/article/10463-eng.htm 


\section{Journal of Aboriginal Health}

The Journal of Aboriginal Health (JAH) was established by the National Aboriginal Health Organization (NAHO) with the intention of fostering a dynamic community of people concerned with issues of Aboriginal health. Launched in 2004, the peer-reviewed journal includes articles from leading health scholars, academics and Aboriginal community members. This special edition is the very first of its kind, solely devoted to exploring themes critical to Inuit health and well-being. It is being published through collaboration between Inuit Tuttarvingat of NAHO and the Nasivvik Centre for Inuit Health and Changing Environments.
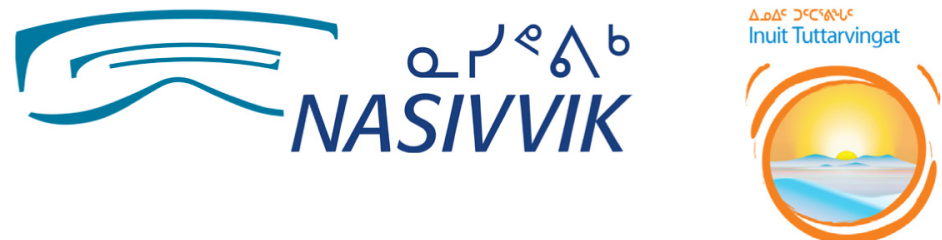

\section{Arrets

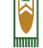

